\title{
FIFTEENTH MEETING OF THE UJNR PANEL ON FIRE RESEARCH AND SAFETY MARCH 1-7, 2000
}

VOLUME 2

Sheilda L. Bryner, Editor

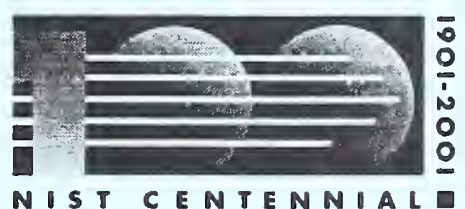

NGT

ac

100

.056

NO. 6588

2000

V.2

National Institute of Standards and Technology Technology Administration, U.S. Department of Commerce 

NISTIR 6588

\section{FIFTEENTH MEETING OF THE UJNR PANEL ON FIRE RESEARCH AND SAFETY MARCH 1-7, 2000}

VOLUME 2

Sheilda L. Bryner, Editor

November 2000

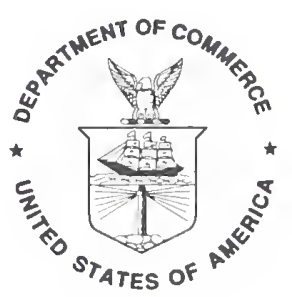

U. S. Department of Commerce Norman Y. Mineta, Secretary

Technology Administration Dr. Cheryl L. Shavers, Under Secretary of Commerce for Technology National Institute of Standards and Technology Raymond G. Kammer, Director 



\section{OPEN TECHNICAL PAPERS}





\section{A PRELIMINARY MODEL FOR URBAN FIRE SPREAD}

- Building Fire Behavior Under the Influence of External Heat and Wind -

by

Keisuke HIMOTO and Takeyoshi TANAKA

DPRI, Kyoto University

Gokasho, Uji, Kyoto 611-0011, JAPAN

\section{INTRODUCTION}

Post-earthquake fires are considered to be one of the important factors that enlarge the damage when a densely inhabited urban area is hit by a severe earthquake. It will be necessary to have a means for predicting the behavior of urban fires in order to explore the measures to effectively mitigate the damage caused by such post-earthquake fires.

Several models are already available in Japan for the purpose of predicting the fire spread in urban areas. It can be said that these models were developed based on the model so-called "Hamada formula", which was introduced by Hamada, Emeritus of University of Tokyo more than 50 years ago ${ }^{[1]}$. The Hamada model was constructed mainly based on the statistical data on the spread of the urban fires in the past, which frequently burned Japanese cities into ashes, as a function of wind velocity. However, now that the conditions of the cites, including building materials and constructions, have extremely changed, it is doubtful that the validity of the statistically-based model still remains.

It is considered to be necessary to develop a physically-based model for the better assessment of the post-earthquake fire loss in modern cities. In this study, a model for predicting fire spread from a building to another was explored in a simple configuration as the first step. The ultimate goal of this study is to construct a model which is capable of predicting the fire spread in the cities in which a number of houses are arbitrarily located.

\section{THE URBAN FIRE SPREAD MODEL}

\section{2-1. Concept of the Model}

A city consists of buildings having different conditions and being arrayed in a complex geometrical relationship. The behavior of an urban fire will be affected by such man-made conditions as well as weather conditions such as general wind velocity. Here, it is regarded that an urban fire is the cluster of burnings of many individual buildings simultaneously involved in the fire. In other words, predicting an urban fire is nothing but predicting each of these buildings involved. A significant difference of this prediction from conventional predictions of building fires is that a building is ignited and burns under the thermal environment induced by the fires of the other buildings.

The urban fire model considered in this study consists of two parts as follows:

(a) Prediction of individual building fire:

The model is, as illustrated in FIGURE 1, similar to one of the conventional one layer compartment fire models to a certain degree ${ }^{|2||3|}$. The predictions of the heat transfer to the 
boundary, the vent flow, the heat conduction in walls containing moisture and the mass burning rate as a function of the room temperature are incorporated. The compartment gases are assumed to be black from the beginning. This fire compartment exchange heat with the external environment at elevated temperature and radiation source. The heat ejects from the fire to the outside of the building, which constitutes the heat with source of temperature environment, is also an indispensable output of the prediction.

\section{(b) Thermal environment of the building:}

It is assumed that a building is exposed to the elevated temperature due to wind blown plumes as well as the thermal radiation from other buildings on fire as illustrated in FIGURE 2. Although fire brands are another important mechanism of fire spread, this is not taken into account in the model at this moment.

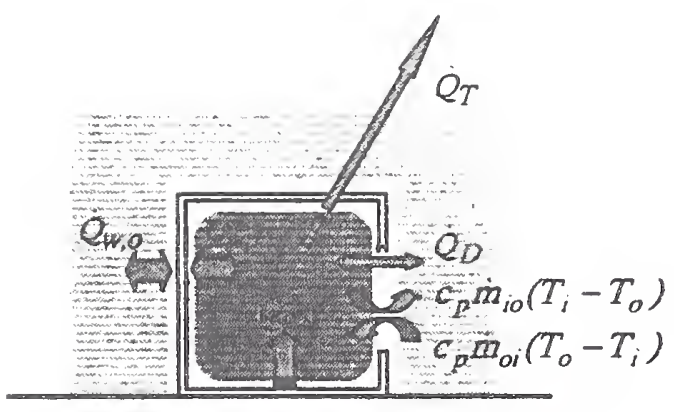

FIGURE 1. Heat transfer between gases inside the building and the atmosphere

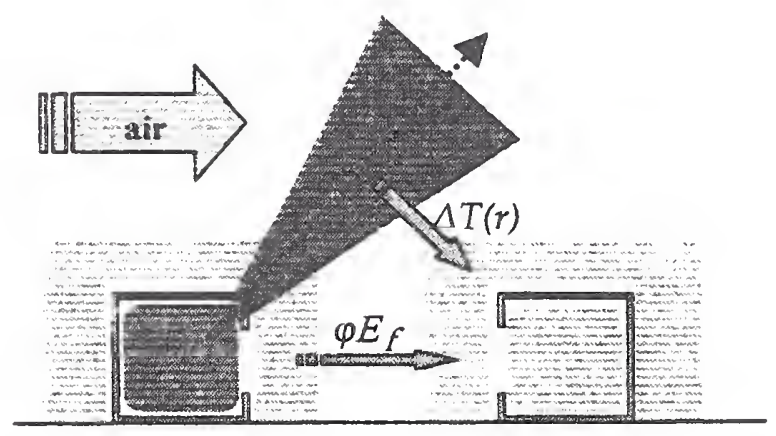

FIGURE 2. Heat transfer between different buildings

\section{2-2. Modeling of the Building Fire}

Basically just like one of the existing compartment fire models, the part of the building fire can be formulated as follows:

\section{2-2-1. Zone relationship}

In this model, the relationships which hold for physical properties in the compartment gases, considered as a zone, are described as follows:

(1) Conservation of mass

$$
\frac{d}{d t}\left(p_{i} V_{i}\right)=\sum \dot{m}_{o i}-\sum \dot{m}_{i o}+\dot{m}_{b, i}
$$

(2) Conservation of energy

$$
\frac{d}{d t}\left(c_{p} p_{i} T_{i} V_{i}\right)=\dot{Q}_{c, i}-\sum \dot{Q}_{W, i}-\sum \dot{Q}_{D}+\sum c_{p} \dot{m}_{o i} T_{o}-\sum c_{p} \dot{m}_{10} T_{i}-\left(q L_{f}-c_{p} T_{f}\right) \dot{m}_{b, i}
$$

(3) Conservation of oxygen

$$
\frac{d}{d t}\left(p_{i} V_{i} Y_{O 2, i}\right)=\sum \dot{m}_{O I} Y_{O 2, o}-\sum \dot{m}_{i o} Y_{O 2,1}-\Gamma_{O 2, i}
$$

(4) Conservation of combustible gases

$$
\frac{d}{d t}\left(p_{t} V, Y_{f, i}\right)=\sum \dot{m}_{o t} Y_{f, o}-\sum \dot{m}_{i o} Y_{f, t}+m_{b, t}-\Gamma_{f, i}
$$


(5) Equation of gas state

$\rho_{i} T_{i}=\rho_{o} T_{o}$

Eqns.(1)-(5) hold for an arbitrary space in a building having multiple spaces and openings, and $\sum$ devotes to take sum of the concerning walls or openings.

\section{2-2-2. Zone Equations}

From Eqns.(1) - (5), the following formulas, useful for computations of the model, can be derived:

(1) Compartment gas temperature

$$
\frac{d T_{i}}{d t}=\frac{T_{i}}{c_{p} \rho_{o} T_{o} V_{i}}\left[\dot{e}_{c, i}-\sum \dot{Q}_{W, i}-\sum \dot{e}_{D}+c_{p} \sum \dot{m}_{o l}\left(T_{o}-T_{l}\right)+\left\{-q L_{f}+c_{p}\left(T_{f}-T_{i}\right)\right\} \dot{m}_{b, i}\right]
$$

(2) Concentration of oxygen

$$
\frac{d Y_{O 2, i}}{d t}=\frac{T_{i}}{\rho_{O} T_{o} V_{i}}\left\{\sum \dot{m}_{O l}\left(Y_{O 2, O}-Y_{O 2, I}\right)-\left(\Gamma_{O 2, i}+\dot{m}_{b, I} Y_{O 2, i}\right)\right\}
$$

(3) Concentration of combustible gas

$$
\frac{d Y_{f, i}}{d t}=\frac{T_{i}}{\rho_{o} T_{o} V_{i}}\left\{\sum \dot{m}_{o i}\left(Y_{f, o}-Y_{f, i}\right)+\dot{m}_{b, l}\left(1-Y_{f, i}\right)-\Gamma_{f, i}\right\}
$$

(4) Pressure equation

$$
\frac{\dot{Q}_{c, i}-\sum \dot{Q}_{W, i}-\sum \dot{Q}_{D}}{c_{p} \rho_{o} T_{o} \sqrt{g} \sum(A \sqrt{H})}+\frac{\sum \dot{m}_{o i} T_{o}-\sum \dot{m}_{i o} T_{i}}{\rho_{o} T_{o} \sqrt{g} \sum(A \sqrt{H})}-\frac{\left({ }_{q} L_{f}-c_{p} T_{f}\right) \dot{m}_{b, i}}{c_{p} \rho_{o} T_{o} \sqrt{g} \sum(A \sqrt{H})}=0
$$

\section{2-2-3. Modeling of elements}

Eqns. (6) - (9) are supplemented with the component processes such as burning rates, heat release rate, openings flow rate, etc. as follows to form a closed system of the equations to actually solve this model.

\section{(1) Mass burning rate}

It is considered that the fuels to feed the compartment fire consist of live fire load and built-in combustible such as interior lining and timber structural members. It is assumed here that the mass burning rates of the two kinds of fire loads are given as

$$
\dot{m}_{b, i}=\frac{1}{4} \frac{\sigma\left(T_{i}^{4}-T_{f}^{4}\right)+h_{f u e l}\left(T_{i}-T_{f}\right)}{q L_{f}} A_{\text {fuel }}
$$

where the coefficient $1 / 4$ is the empirical constant from the experiments by Ohmiya et. al to take into account the insulation effect of char layer on the surface of combustibles ${ }^{[4]}$.

In case of the live fire load, the surface area of the fuel $A_{\text {fur }}$ is estimated by following

$$
A_{\text {fuel }}=\phi w A_{\text {floor }}
$$

where $\phi$ is the fuel surface area coefficient first introduced by Harmathy ${ }^{[s]}$. According to the live load survey by Aburano et. al survey of actual combustibles, $\phi$ is correlated with live fire load density $w$ as ${ }^{[6]}$

$$
\phi=0.61 w^{-2 / 3}
$$


(2) Heat generation rate

Obviously, the heat release rate within the compartment is supposed to be controlled whichever the smaller of the heat releases due to the supply rates of the fuel and oxygen. Hence,

$$
\dot{Q}_{c, i}=\min \left\{\Delta H_{f}\left(\dot{m}_{b, i}+\sum \dot{m}_{o i} Y_{f, o}\right) \Delta H_{O 2} \sum \dot{m}_{o i} Y_{O 2, o}\right\}
$$

\section{(3) Consumption rate of chemical species}

Using the heat generation rate is determined like (13), the consumption rates of oxygen and combustible fuel are respectively given by

$$
\begin{aligned}
& \Gamma_{O 2, i}=\frac{\dot{Q}_{c, i}}{\Delta H_{O 2}} \\
& \Gamma_{f, i}=\frac{\dot{Q}_{c, i}}{\Delta H_{f}}
\end{aligned}
$$

\section{(4) Heat loss to the wall}

The heat losses to inside and outside of the compartment wall surfaces, in other words the negative heat gain of the wall are respectively calculated as follows:

$$
\begin{aligned}
& \dot{Q}_{W, i}=\dot{q}_{0}^{*} A_{W}=\left\{\varepsilon_{W, i} \sigma\left(T_{i}^{4}-T_{W, i}^{4}\right)+h_{i}\left(T_{i}-T_{W, i}\right)\right\} A_{W} \\
& Q_{W, o}=\dot{q}_{1}^{*} A_{W}=\left\{\varepsilon_{W, o}\left(1-\varphi_{W}\right) \sigma T_{o}^{4}-\varepsilon_{W, o} \sigma T_{W, o}^{4}+h_{o}\left(T_{o}-T_{W, o}\right)+\varphi_{W} E_{f}\right\} A_{W}
\end{aligned}
$$

The surface temperature of the compartment wall in Eqn.(16) and (17), $T_{w, i}$ and $T_{w, o}$, can be obtained numerically solving the one dimensional heat conduction equation with moisture content as

$$
\frac{\partial T}{\partial t}=\left(\frac{k}{\Phi}\right) \frac{\partial^{2} T}{\partial t^{2}}-\frac{\dot{q}_{v}}{\Phi}
$$

with the boundary conditions as

$$
\begin{aligned}
& -\left.k \frac{\partial T}{\partial x}\right|_{x=0}=\dot{q}_{0}^{\prime}(t) \\
& -\left.k \frac{\partial T}{\partial x}\right|_{x=1}=-\dot{q}_{i}^{\prime}(t)
\end{aligned}
$$

In this model, the evaporation of water begins at the boiling point and the temperature stays until all the water in the wall be evaporated.

(5) Heat loss from the opening by radiation

The compartment receives radiation from the external sources, i.e., houses on fire, through the opening, and in return emit heat back to the outside due to the elevation of the compartment temperature. The net radiation heat loss through the opening can be written as.

$$
\dot{Q}_{D}=\left\{\sigma T_{i}^{4}-\left(I-\varphi_{d}\right) \sigma T_{o}^{4}-\varphi_{d} E_{f}\right\} A_{D}
$$

Note that the net heat loss can be negative depending on the intensity of the external source and the compartment temperature.

\section{(6) Opening flow rate}

The rates of flows through the openings can be formulated as a function of the temperatures and the pressures of the compartment and the outdoor. And then the compartment pressure is solved to satisfy Eqn.(9). 


\section{(7) Heat emission to outside of the compartment}

It is necessary to estimate the heat ejected out through the opening, because this turns into the driving force of the fire-induced hot air flow to which other buildings are exposed. The heat consists of the heat of combustion of excess fuel and the enthalpy of the opening flow at elevated temperature. Hence,

$$
\dot{Q}_{T}=\left(\Delta H_{f} \dot{m}_{b, 1}-\dot{Q}_{c, 1}\right)+c_{p} \sum \dot{m}_{i o}\left(T_{t}-T_{o}\right)
$$

\section{2-3.Modeling of External Conditions}

As was already mentioned, it is indispensable for an urban fire spread model to take into account the external wind and the thermal environments of buildings, i.e. thermal radiation and atmospheric temperature elevation due to blown down fire plume induced by the burning of the other buildings. The issue of fire brands are not dealt with in this model although it should be incorporated in the future.

\section{2-3-1. Wind pressure coefficient}

Winds blow down the fire plumes from burning buildings and also enhance the ventilation of burning building, thereby affecting the behavior of the fires of the buildings. In order to assess the wind pressures on building surfaces, the angle between the direction of wind and a building surface, as illustrated in FIGURE 3, has to be known. Hence, a rectangular coordinate system ( $x, y, z)$ is considered on the urban terrain where $\mathrm{x}$-axis and $\mathrm{y}$-axis are set for east-west and north-south directions, respectively, and $\mathrm{z}$-axis for vertical direction.

Although the distribution of the wind pressure coefficient $C_{N}$ acting on actual building surfaces are rather complicated, the coefficient is approximated in this model as follows:

$$
C_{N}= \begin{cases}-0.8+0.3 \cos \eta & (\cos \eta \geq 0) \\ -0.8-1.6 \cos \eta & (\cos \eta<0)\end{cases}
$$

where $\cos \eta$ is the cosine of the angle between the directional vector $\mathbf{v}=\left(v_{v}, v_{y}\right)$ of the wind and the normal vector $\mathbf{n}$ of the surface, which can be given as $\cos \eta=(\mathbf{v}, \mathbf{n})$.

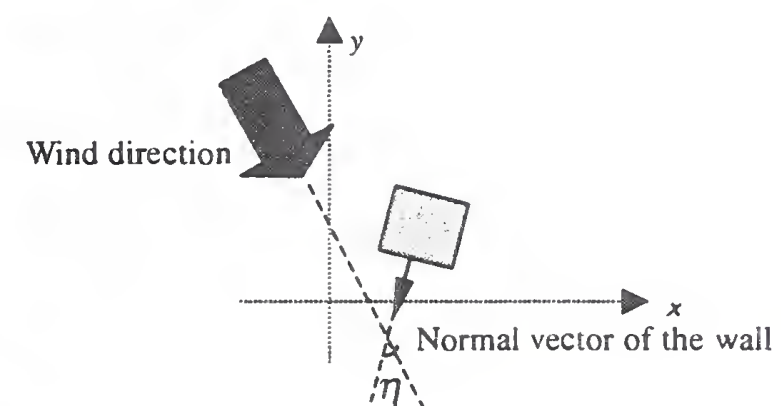

FIGURE 3. Wind direction and normal

\section{2-3-2. Fire-induced plume}

\section{(1) Temperature along wind blown plume axis}

Although the behaviors of usual vertical plumes have been well studied ${ }^{[2]}$, there is not ample data on the fire plumes that are blown down by external winds. From what little existing wind tunnel experiment, it is not clear if the wind enhance or reduce the plume entrainment ${ }^{[8]}$. Here, the results from vertical plumes are used to assess the temperature in the down stream of a burning building, until new findings have been obtained on this topic, i.e. the temperature rise along the axis of the plume is given as: 


$$
\Delta T_{0}= \begin{cases}900 & \left(\frac{z}{\dot{Q}_{T}^{2 / s}}<0.08\right) \\ 60\left(\frac{z}{\dot{Q}_{T}^{2 / s}}\right)^{-1} & \left(0.08 \leq \frac{z}{\dot{Q}_{r}^{2 / s}} \leq 0.2\right) \\ 24\left(\frac{z}{\dot{Q}_{T}^{2 / s}}\right)^{-5 / 3} & \left(0.2<\frac{z}{\dot{Q}_{r}^{2 / s}}\right)\end{cases}
$$

(2) Rise angle of a plume axis

The results on rise angle of the axis of a plume blown down cannot be said ample either. Here we temporarily employ the result from the wind tunnel experiments for the line-heat source by Yokoi ${ }^{[8]}$, which is given by

$$
\tan \theta=0.1 \Omega^{-1 / 4}
$$

where $\Omega$ is the non-dimensional parameter defined as

$$
\Omega \equiv \frac{U_{\infty}}{\left(\frac{Q^{\prime} g}{c_{\rho} \rho_{0} T_{0}}\right)^{1 / 3}}=\frac{U_{\infty}}{\left(\frac{\dot{e}_{r} g}{c_{p} \rho_{o} T_{0} \sqrt{A_{\text {floor }}}}\right)^{1 / 3}}
$$

\section{(3) Off axis temperature}

Buildings are located on the terrain surface, so usually more or less at a remote position from the plume axis. Letting $r$ be the distance to the point of interest, i.e., position of a building, the temperature rise at the point is calculated as (FIGURE 4):

$$
\Delta T(r)=\Delta T_{0} \exp \left\{-\left(\frac{r}{b}\right)^{2}\right\}
$$

where the distance $r$ is calculated as (FIGURE 5):

$$
r=\left|G_{0}-P_{0}\right|=\sqrt{\left|G_{0}\right|^{2}-\left(G_{0}, a\right)^{2}}
$$

with

$$
a=\frac{\left(v_{x}, v_{y}, \tan \theta\right)}{1+\tan ^{2} \theta}
$$

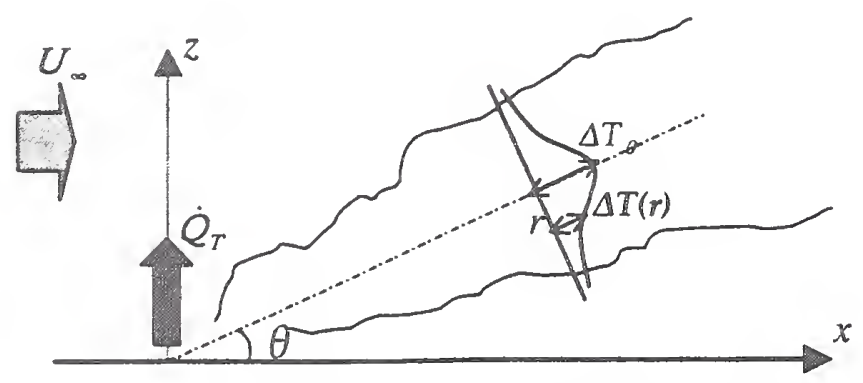

FIGURE 4. Plume axis and distance $r$

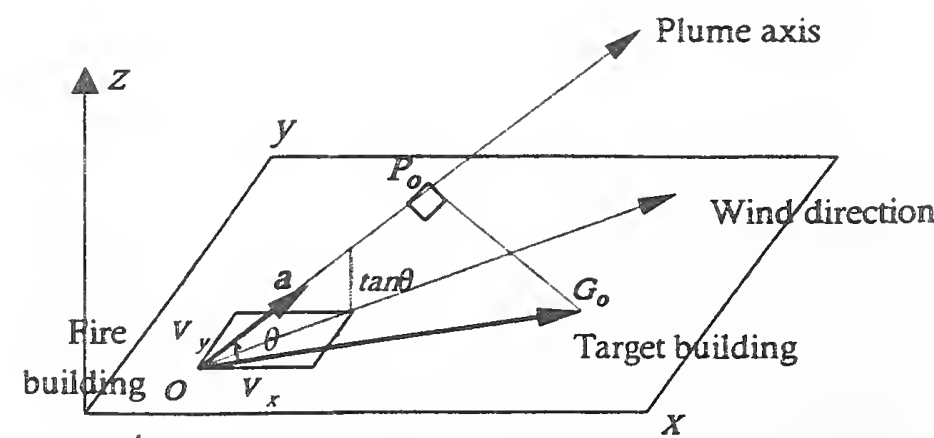

FIGURE 5. Plume axis and target building 


\section{2-3-3. Thermal radiation from building fire}

A building receive the radiant heat from multiple surfaces of multiple buildings on fire, so the total radiant heat flux incident upon a target building is given as

$$
\dot{q}_{R}^{*}=\sum_{j=1}^{N}\left(E_{j} F_{i j}\right)
$$

However, the actual calculation of the view factors included in Eqn.(29) is quite complicated in real city configuration so an attempt is now being made to develop a practical means of the calculation.

\section{PRELIMINARY SAMPLE CALCULATIONS}

Although the model has not been completed yet that the fire spread predictions in a actual urban configuration is not possible, some preliminary calculations in simple geometric conditions were carried out. The buildings of the same sizes are arrayed in parallel in a row so that the configuration factors involved can be calculated by a well-known formula as follows:

$$
\begin{aligned}
& X=\frac{s}{u}, Y=\frac{t}{u} \\
& F_{d l-2}=\frac{1}{2 \pi}\left(\frac{X}{\sqrt{1+X^{2}}} \tan ^{-1} \frac{Y}{\sqrt{1+X^{2}}}+\frac{Y}{\sqrt{1+Y^{2}}} \tan ^{-1} \frac{X}{\sqrt{1+Y^{2}}}\right)
\end{aligned}
$$

\section{3-1. Conditions in common}

\section{(1) Building geometry}

Small-scale rectangular parallelepiped compartment of $4.0[\mathrm{~m}]$ by $4.0[\mathrm{~m}]$ square floor with $2.5[\mathrm{~m}]$ of height is considered in the calculation.

\section{(2) Opening size}

The opening with the dimensions of $2.0[\mathrm{~m}]$ by $2.0[\mathrm{~m}]$ is considered.

\section{(3) Wall property}

The wall is assumed to be normal-weight concrete having physical properties as follows as shown in TABLE 1 . The thickness is uniformly $0.1[\mathrm{~m}]$ in all walls.

\section{(4) Fuel property}

The physical properties of wood are used as those of the fuel. The fire load density is $30.0\left[\mathrm{~kg} / \mathrm{m}^{2}\right]$.

\section{(5) Weather condition}

The wind direction is made to be west wind and on the wind velocity, it is supposed to be made to change from windless $0.0[\mathrm{~m} / \mathrm{s}], 4.0[\mathrm{~m} / \mathrm{s}]$ and $8.0[\mathrm{~m} / \mathrm{s}]$.

TABLE 1. Wall properties

\begin{tabular}{|c|c|c|c|c|c|}
\hline & $\begin{array}{c}\text { Thermal } \\
\text { conductivity } \\
{[\mathrm{kW} / \mathrm{m} \cdot \mathrm{K}]}\end{array}$ & $\begin{array}{c}\text { Density } \\
{\left[\mathrm{kg} / \mathrm{m}^{3}\right]}\end{array}$ & $\begin{array}{c}\text { Specific heat } \\
{[\mathrm{kJ} / \mathrm{kg} \cdot \mathrm{K}]}\end{array}$ & $\begin{array}{c}\text { Thickness } \\
{[\mathrm{m}]}\end{array}$ & $\begin{array}{c}\text { Water content } \\
{\left[\mathrm{kg} / \mathrm{m}^{3}\right]}\end{array}$ \\
\hline Properties & 0.0163 & 2250 & 0.895 & 0.1 & 5.0 \\
\hline
\end{tabular}

\section{3-2. Calculation-A}

A rectangular radiation source with $150\left[\mathrm{~kW} / \mathrm{m}^{2}\right]$ of emissive power is assumed in front of the building as shown in FIGURE 6. The only opening of the building faces to the heat source. The air temperature to which the building exposed is specified at $500[\mathrm{~K}]$ in this case. This calculation is to exhibit how the 

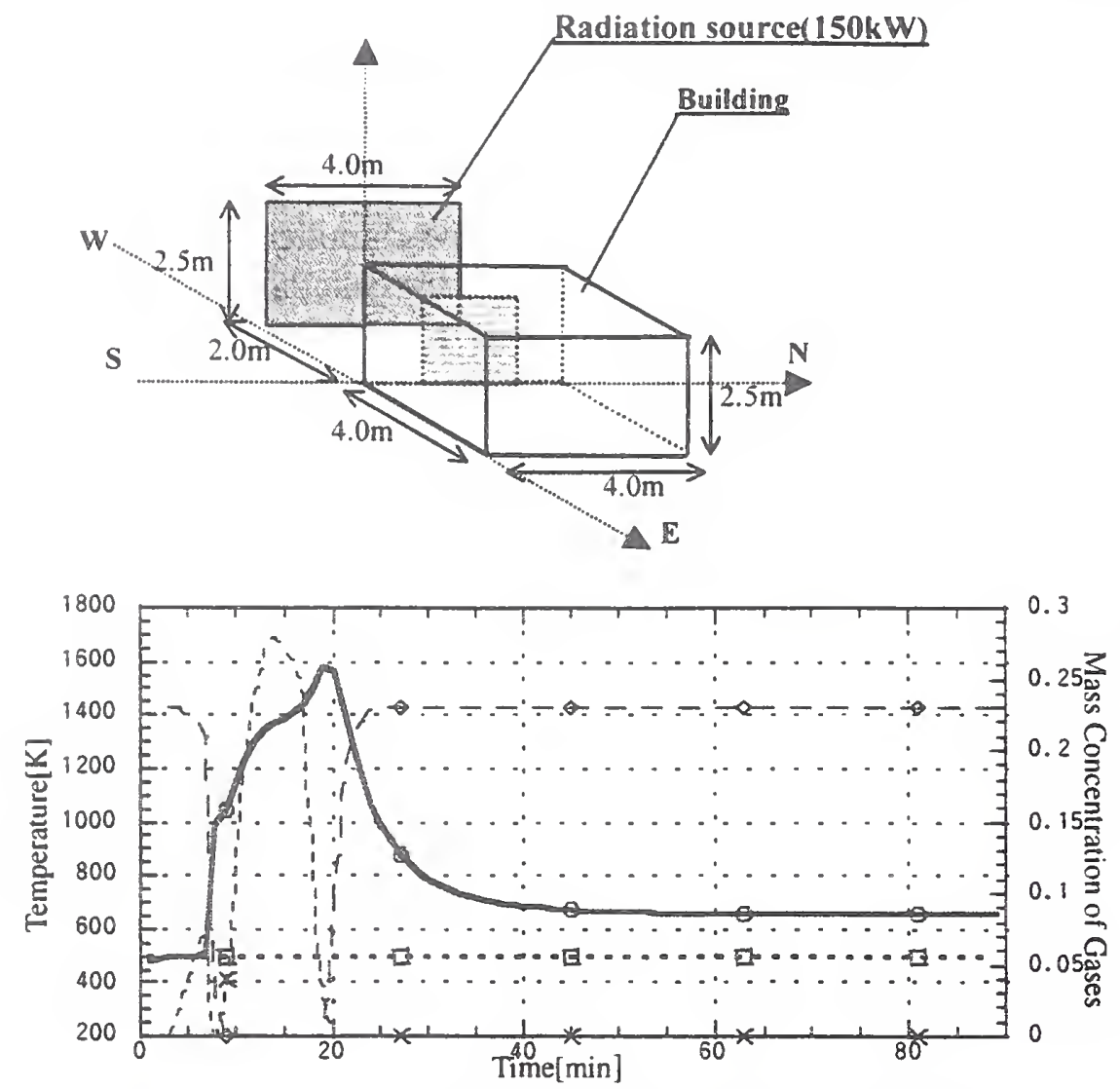

FIGURE 6. Calculation-A condition

The combustibles in the building was ignited by receiving heat from the outside and the temperature rises fairly quickly to around $1400[\mathrm{~K}]$, and the temperature started to go down due to the burnt out when $20[\mathrm{~min}]$ has passed. The reason why the temperature does not come down to the ambient temperature after the burnt out is attributed to the fact that the building is always exposed to the radiation.

\section{3-3. Calculation-B}

In this calculation, 3 buildings, which is mentioned earlier in condition (1), are placed in parallel in a row as shown in FIGURE 8. A fire is artificially initiated at the west end building. The calculations are carried out for the wind velocity from $0.0,4.0$ and $8.0[\mathrm{~m} / \mathrm{s}]$. This time, the opening of the first building is set on the east wall and the others in the west. The initial ambient temperature is $300.0[\mathrm{~K}]$. The results are shown at FIGURE 9-11.

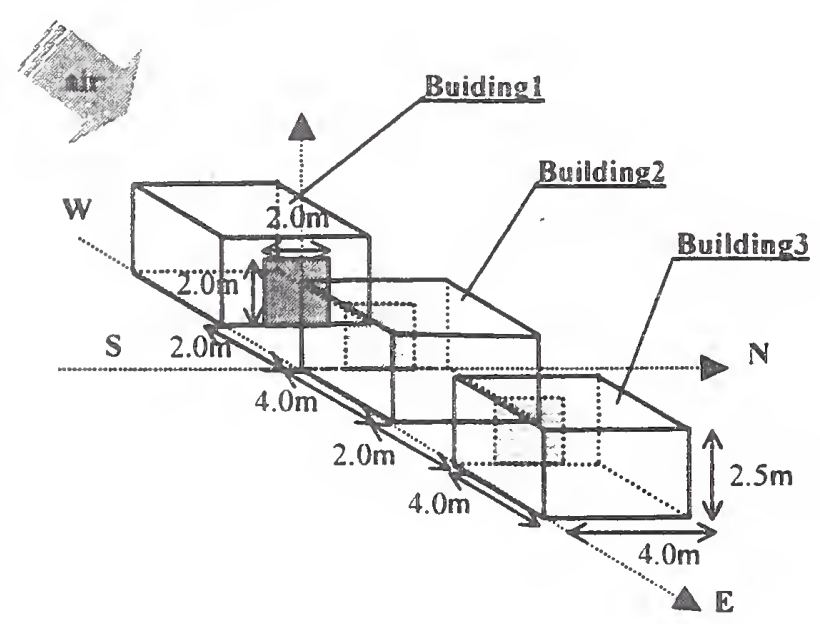

FIGURE 8. Calculation-B condition 

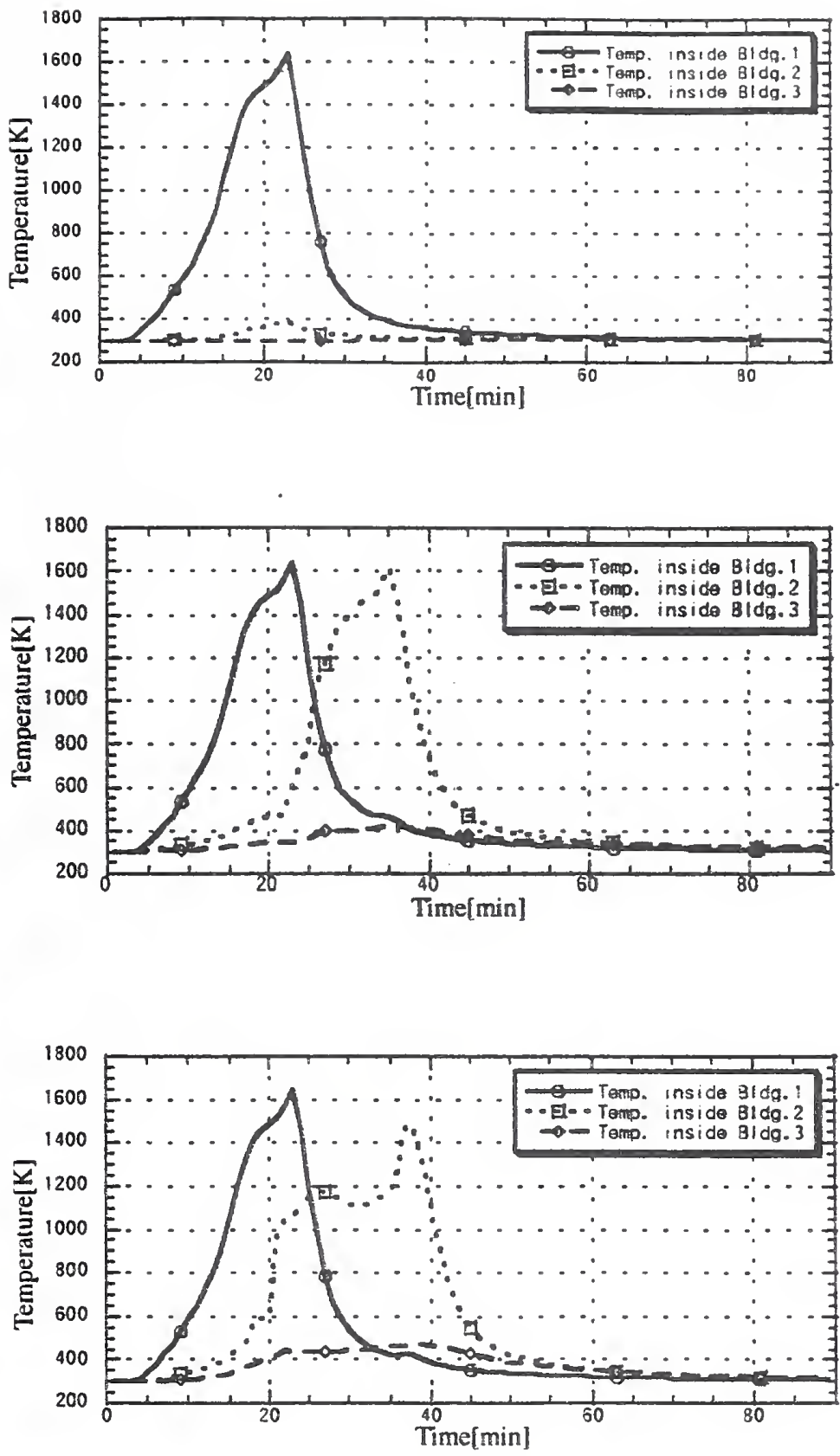

FIGURE 9 . Temperature change-a $(0.0 \mathrm{~m} / \mathrm{s})$

According to the calculation, the possibility of fire spread to the building of the lee side rose and the time for fire spread was shortened as the wind velocity get faster. That seems to be because the higher the wind velocity, the more the fire plume blown down so that the buildings were exposed to the higher temperature. The reason why the remotest buildings did not burn even if the wind velocity strengthens is that there was no direct radiation from the building of origin and the temperature due to fire plume did not rise to the critical ignition temperature of combustibles.

\section{CONCLUDING REMARKS}

The burning behavior of the fire spread model was examined for different wind velocities. The result shows that the wind velocity may become a factor affecting the spreading speed of fire. 
Of course there is a lot to be done before a practically useful urban fire model can be obtained. The current model is nothing but the first step for such model.

\section{NOMENCLATURE}

\section{Alphabets}

\begin{tabular}{|c|c|}
\hline$A_{D}$ & area of doorway $\left[\mathrm{m}^{2}\right]$ \\
\hline$A_{\text {floor }}$ & area of floor $\left[\mathrm{m}^{2}\right]$ \\
\hline $\begin{array}{l}A_{\text {fuel }} \\
A \sqrt{H}\end{array}$ & $\begin{array}{l}\text { surface area of the fue }\left[\mathrm{m}^{2}\right] \\
\text { opening factor }\left[\mathrm{m}^{5 / 2}\right]\end{array}$ \\
\hline$A_{w}$ & opening factor $\left[\mathrm{m}^{2}\right]$ \\
\hline$b$ & balf width of plume $[\mathrm{m}]$ \\
\hline & $\begin{array}{l}\text { specific heat of wall } \mathrm{kJ} / \mathrm{kg} \cdot \mathrm{K}] \\
\text { wind pressure coefficient }[\mathrm{Pa} / \mathrm{kJ}]\end{array}$ \\
\hline$C_{N}$ & $\begin{array}{l}\text { wind pressure coefficient }[\mathrm{Pa} / \mathrm{kJ}] \\
\text { specific heat of gas }[\mathrm{kJ} / \mathrm{kg} \cdot \mathrm{K}]\end{array}$ \\
\hline$E_{f}$ & $\begin{array}{l}\text { specific heat of gas }[\mathrm{kJ} / \mathrm{kg} \cdot \mathrm{K}] \\
\text { emissive power of fire }\left[\mathrm{kW} / \mathrm{m}^{2}\right]\end{array}$ \\
\hline$E_{j}$ & $\begin{array}{l}\text { emissive power of fire }\left[k W / \mathrm{m}^{2}\right] \\
\text { emissive power of wall }-j\left[\mathrm{~kW} / \mathrm{m}^{2}\right]\end{array}$ \\
\hline$F_{i j}$ & $\begin{array}{l}\text { emissive power of wall }-j\left[k W / \mathrm{m}^{2}\right] \\
\text { configuration factor from wall }-i \text { to wall }-j\end{array}$ \\
\hline$G_{0}$ & $\begin{array}{l}\text { configuration factor from wall }-i \text { to wall }-j \\
\text { acceleration of gravity }\left[\mathrm{kg} / \mathrm{m}^{2}\right]\end{array}$ \\
\hline $\begin{array}{l}G_{o} \\
h_{\text {fuel }}\end{array}$ & positional vector of heat receiving building \\
\hline $\begin{array}{l}h_{\text {fuel }} \\
h_{i}, h_{o}\end{array}$ & convection heat transfer coefficient of fuel[ $\left[\mathrm{W} / \mathrm{m}^{2} K\right]$ \\
\hline $\begin{array}{l}h_{i}, h_{o} \\
\Delta H_{f}, \Delta H_{O 2}\end{array}$ & $\begin{array}{l}\text { convection heat transfer coefficient of wal }\left[\mathrm{kW} / \mathrm{m}^{2}\right] \\
\text { heating value of combustibles and oxygen }[\mathrm{kJ} / \mathrm{kg}]\end{array}$ \\
\hline & heat transfer coefficient of wail $[\mathrm{kW} / \mathrm{m} \cdot \mathrm{K}]$ \\
\hline $\begin{array}{l}\dot{m}_{b, i} \\
\dot{m}_{i o}, \dot{m}_{o i}\end{array}$ & mass burning rate $[\mathrm{kg} / \mathrm{s}]$ \\
\hline $\begin{array}{l}\dot{m}_{i o}, \dot{m}_{o i} \\
P_{o}\end{array}$ & $\begin{array}{l}\text { mass flow rate }[\mathrm{kg} / \mathrm{s}] \\
\text { positional vector on plume axis }\end{array}$ \\
\hline 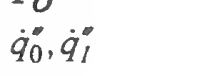 & $\begin{array}{l}\text { positional vector on plume axis } \\
\text { incident heat flux to the wall per unit area }\left[\mathrm{kW} / \mathrm{m}^{2}\right]\end{array}$ \\
\hline$\dot{q}_{R}^{*}$ & $\begin{array}{l}\text { incident heat flux to the wall per unit area }\left[\mathrm{kW} / \mathrm{m}^{2}\right] \\
\text { incident radiation flux per unit area }\left[\mathrm{kW} / \mathrm{m}^{2}\right]\end{array}$ \\
\hline$\dot{q}_{v}$ & $\begin{array}{l}\text { incident radiation flux per unit areal }\left[\mathrm{kW} / \mathrm{m}^{2}\right] \\
\text { heat absorption rate per unit wall volume }\left[\mathrm{kW} / \mathrm{m}^{3}\right]\end{array}$ \\
\hline$q L_{f}$ & $\begin{array}{l}\text { heat absorption rate per unit wall volume }\left[\mathrm{kW} / \mathrm{m}^{3}\right] \\
\text { heat of decomposition of combustibles }[\mathrm{kJ} / \mathrm{kg}]\end{array}$ \\
\hline$Q^{\prime}$ & heat release rate per unit length $\left[\mathrm{kW} / \mathrm{m}^{2}\right]$ \\
\hline$\dot{Q}_{c, 1}$ & heat generation rate $[k W]$ \\
\hline$\dot{Q}_{D}$ & heat loss rate through doorway $\left[\mathrm{k} W / \mathrm{m}^{2}\right]$ \\
\hline$\dot{Q}_{T}$ & heat emission rate to outside $[k W]$ \\
\hline$\dot{Q}_{w, i}, \dot{Q}_{w, o}$ & incident heat rate to the $w a l[k W]$ \\
\hline $\begin{array}{l}s, t \\
T_{f}\end{array}$ & width and height of the target wall[m] \\
\hline $\begin{array}{l}T_{f} \\
T_{1}, T_{0}\end{array}$ & decomposition temperature of fuef $[K]$ \\
\hline $\begin{array}{l}T_{1}, T_{o} \\
T_{w, i}, T_{w, o}\end{array}$ & $\begin{array}{l}\text { temperature inside and outside compartment }[K] \\
\text { wall surface temperature }[K]\end{array}$ \\
\hline & $\begin{array}{l}\text { wall surface temperature }[K] \\
\text { temperature rise above plume axis temperature }[K]\end{array}$ \\
\hline$\Delta T(r)$ & $\begin{array}{l}\text { temperarure rise above plume axis temperature }[K] \\
\text { temperature rise above ambient temperature }[K]\end{array}$ \\
\hline & distance to the targed $m]$ \\
\hline$U_{\infty}$ & wind velocity $[\mathrm{m} / \mathrm{s}]$ \\
\hline$v_{x}, v_{y}$ & $x, y$-coodinate of wind direction $[m]$ \\
\hline$V_{t}$ & volume of the compartment $\left[\mathrm{m}^{3}\right]$ \\
\hline & fire load density $\left[\mathrm{kg} / \mathrm{m}^{2}\right]$ \\
\hline
\end{tabular}


$\begin{array}{ll}Y_{f, i}, Y_{f, o} & \text { concentration of combustible gas } \\ Y_{O 2, i}, Y_{O 2,0} & \text { concentration of oxygen }\end{array}$

\section{Greeks}

$\begin{array}{ll}\Gamma_{f, i}, \Gamma_{O 2, l} & \text { consumption rate of fuel and oxygen }[\mathrm{kg} / \mathrm{s}] \\ \varepsilon_{w, i}, \varepsilon_{w, 0} & \text { emissivity of wall } \\ \eta & \text { angle between wind direction and normal vector }\left[\mathrm{rad}^{\prime}\right] \\ \theta & \text { inclination of plume axis }[\mathrm{rad}] \\ \Omega & \text { dimensionless wind velocity } \\ \rho_{i}, \rho_{o} & \text { occupant gas density }\left[\mathrm{kg} / \mathrm{m}^{3}\right] \\ \phi & \text { fuel surface area coefficient }\left[\mathrm{m}^{2} / \mathrm{kg}\right] \\ \varphi_{d}, \varphi_{w} & \text { configuration factor of doorway and wall }\end{array}$

(The case in which there is especially no notice on additional number, ' $i$ ' stands for inside the compartment and ' $o$ ' for outside.)

\section{REFERENCES}

[1] Fire Hand Book, $3^{\text {rd }}$ ed. Japan Association for Fire Science and Engineering

[2] Matsuyama, K. et al: Simple Predictive Method for Room Fire Behavior, Fire Science and technology, Vol. 18, No. 1, pp23-32 (1998)

[3] Ohmiya Y. ,Tanaka T. Wakamatsu T. : A Room Fire Model for Predicting Fire Spread by External Flames, Fire Science and Technology, Vol.18, No.1, pp11-21 (1998)

[4] Ohmiya Y. ,Tanaka T. ,Wakamatsu T. : Burning Rate of Fuels and Generation Limit of the External Flames in Compartment Fire, Fire Science and Technology, Vol.16, No.1-2, pp 1-12 (1996)

[5] Harmathy T. Z. : A New Look at Compartment Fires, part 1-2, Fire Technology, Vol.8, (1972)

[6] Aburano, K. et al: Survey and Analysis on Surface Area of Fire Load, Fire Science and technology, Vol. 19, No. 1, ppl1-25 (1999)

[7] Beyler C. L. : Fire Plumes and Ceiling Jet, Fire Safety Journal, Vol.11, pp53-76 (1986)

[8] Yokoi S. : Temperature Distribution in the Down Stream of a Line Heat Source, Study of Disaster, Vol.8 (1970) 


\title{
Systematic Experiments of Room and Corridor Smoke Filling for use in Calibration of Zone and CFD Fire Models
}

\author{
Ken MATSUYAMA and Takao WAKAMATSU \\ Dept. of Architecture, Faculty of Science and Technology, Science University of Tokyo \\ 2641, Yamasaki, Noda-shi, Chiba 278-8510, Japan \\ Kazunori HARADA \\ Dept. of Architecture and Environmental Design, Kyoto University \\ Yoshida-honmachi, Sakyo-ku, Kyoto 606-8501, Japan
}

\section{INTRODUCTION}

In the smoke control designs, smoke layer height and temperatures are calculated for safety checking. Quite often, the design Heat Release Rate (HRR) is described by $t^{2}$-fires $[1,2]$,

$$
Q_{f}=\alpha t^{2}
$$

where $Q_{f}[\mathrm{~kW}]$ is design HRR, $\alpha\left[\mathrm{kW} / \mathrm{s}^{2}\right]$ is the fire growth rate, and $t$ [sec.] is the time from ignition. Putting the design fires in the building to be designed, the smoke propagation is calculated typically by zone models [3-6] such as BRI2 and CFAST. To be certain with the calculated results, the models will have to be validated against design fire scenarios.

Both BRI2 and CFAST has been verified against many experimental data. However most of the experiments were carried out using steady HRR, mainly because of the simplicity of experimental procedures. Thus question may arise if those models are still valid for $\mathrm{t}^{2}$-fires.

In this study, a series of full scale experiments were carried out using $t^{2}$-fires. Fire room and corridor smoke filling process was measured. The size of the corridors and arrangement of smoke curtains were varied in several patterns. Comparisons were made between experimental results and the results by two zone models, BRI2 and CFAST.

\section{EXPERIMENTAL PROCEDURE}

\subsection{Fire Source}

Figure 1 shows the schematics of the fire source. A triangular shaped polyurethane mattress was used as a fire source. Base width is 600 [mm], while the height of the triangle is 900 [mm]. The thickness was 160 [mm]. Using three load cells, the mass loss rate was measured continuously. The HRR was calculated by multiplying its heat of combustion $36[\mathrm{~kJ} / \mathrm{g}]$.

\subsection{Room and Corridor Arrangement}

The experiments were carried out on third floor of Full-Scale Fire Laboratory at the Building Research Institute. Figure 2 shows the arrangement of room and corridors. The dimension of the room of fire origin is $\mathrm{W} 7,900 \times \mathrm{D} 3,300 \times \mathrm{H} \mathrm{2,700}[\mathrm{mm}]$. Doorway size between fire room and corridor was $\mathrm{W} 1,000 \times \mathrm{H} 2,000$ [mm]. Corridor ceiling height was 2,700 [mm]. 


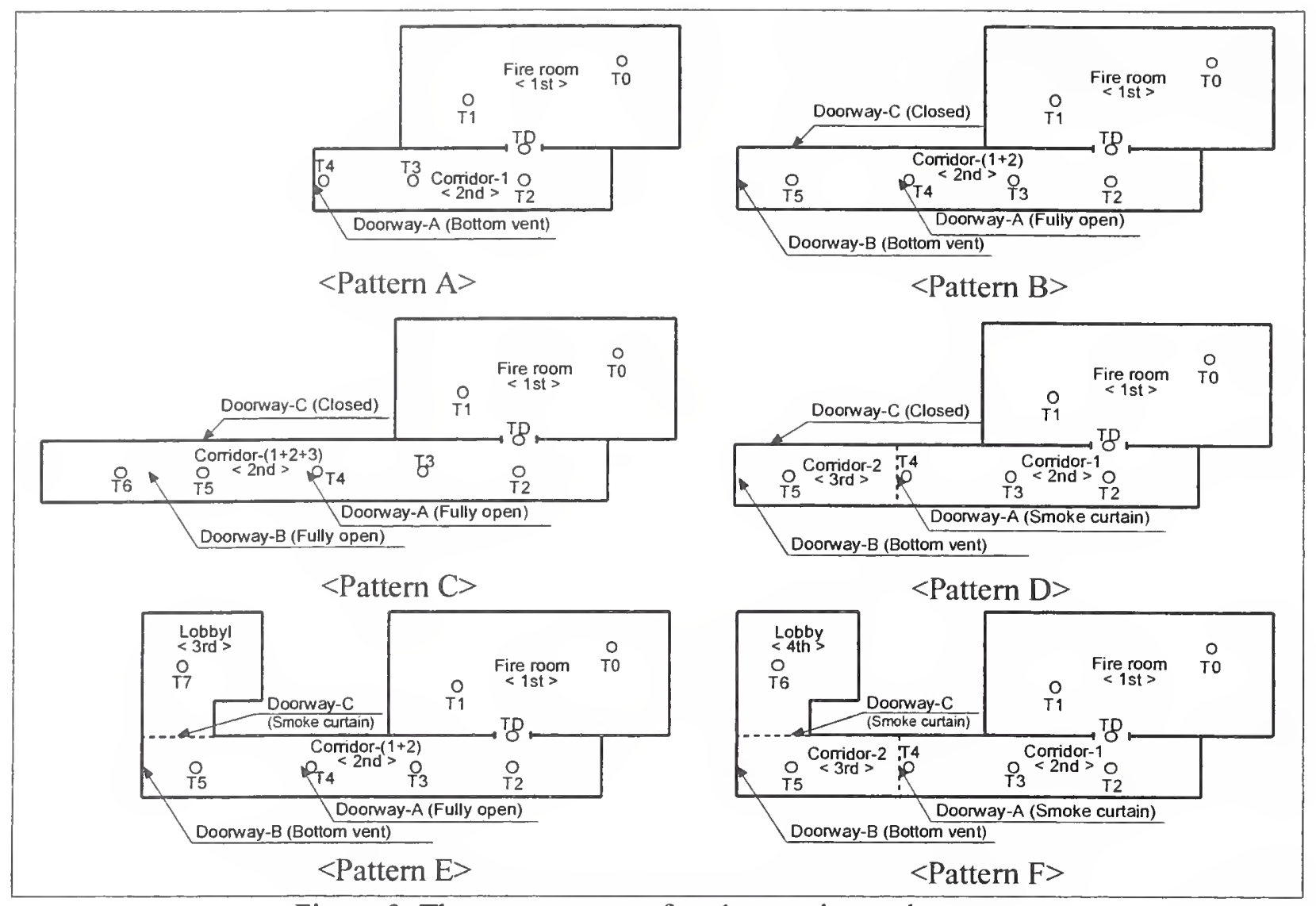

Figure 3 The arrangement of each experimental pattern

Table 3 summarizes the opening condition of the doorways between corridor spaces. As shown in Figure 4, doorway height was changed in three ways. It was either fully open, smoke curtain at the top, or small vent at the bottom.

Table 3 The opening condition of the doorway

\begin{tabular}{c||c|c|c|c|c|c}
\hline & Pattern A & Pattern B & Pattern C & Pattern D & Pattern E & Pattern F \\
\hline \hline Doorway-A & Bottom vent & Fully open & Fully open & Smoke curtain & Fully open & Smoke curtain \\
\hline Doorway-B & $\cdots$ & Bottom vent & Fully open & Bottom vent & Bottom vent & Bottom vent \\
\hline Doorway-C & $-\cdots$ & $-\cdots$ & Closed & Closed & Smoke curtain & Smoke curtain \\
\hline
\end{tabular}

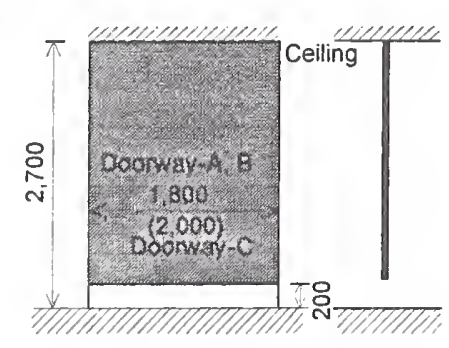

$<$ Bottom vent >

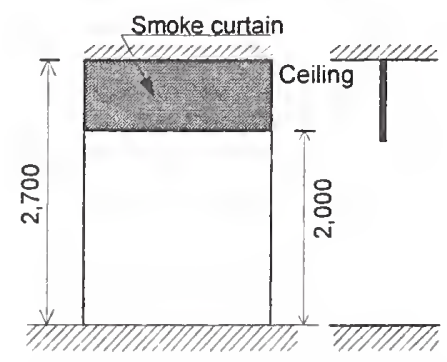

$<$ Smoke curtain >

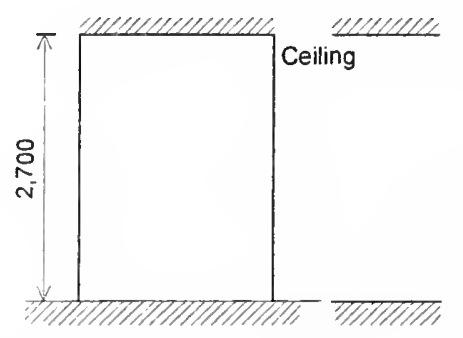

$<$ Fully open >

Figure 4 The schematic of doorway condition (unit: $\mathrm{mm}$ ) 


\subsection{Smoke Temperature Measurements}

To measure the smoke layer height and temperature, thermocouple trees were put in the locations shown in Figure 2. The tree has type- $\mathrm{K}$ thermocouples $(0.3[\mathrm{~mm}]$-diam.). As shoen in Figure 5 vertical temperature distribution was measured at by installing 14 thermocouples on earch tree. Doorway smoke temperature profile was measured by 15 thermocouples (tree TD). The total number of thermocouples was 127.

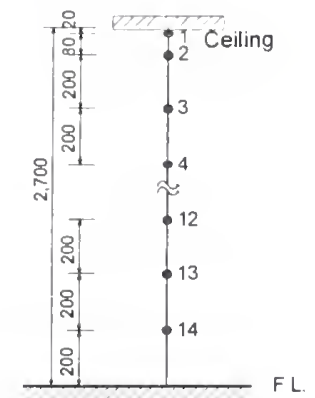

a) trees $\mathrm{T} 0-\mathrm{T} 7$

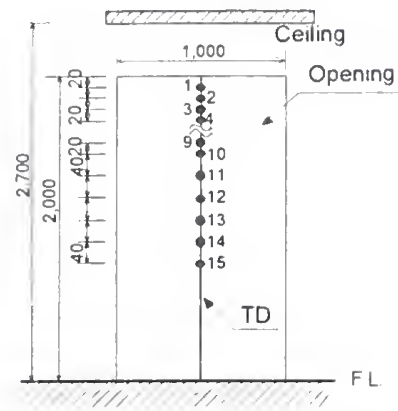

b) tree TD

Figure 5 The schematic of the thermocouple trees (unit: $\mathrm{mm}$ )

\section{RESULTS}

\subsection{Fire Growth Rate}

As an example, measured HRR curve for exp. pattern A is shown in Figure 6. The HRR could be well approximated by $t^{2}$-growth. The fire growth rate for this experiment was $0.0065\left[\mathrm{~kW} / \mathrm{s}^{2}\right]$. Also in the other experiments, the HRR is almost t-squared. The fire growth rates are summarized in Table 4. The range of scatter was 0.0079 to $0.0045\left[\mathrm{~kW} / \mathrm{s}^{2}\right]$.

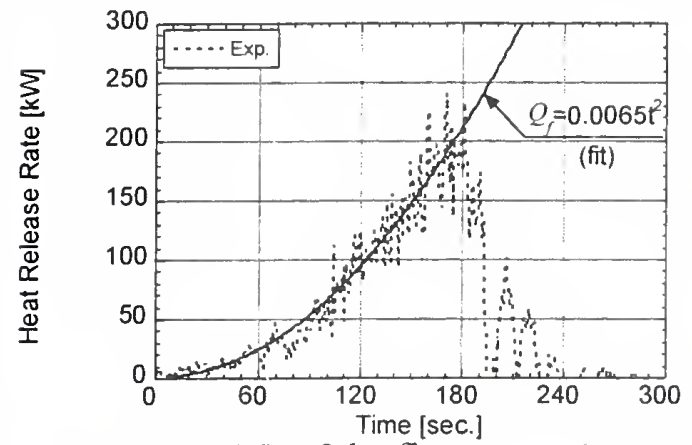

Table 4 Results of fire growth rate

\begin{tabular}{c|c|c|c}
\hline Experimental pattern & $\mathrm{A}$ & $\mathrm{B}$ & $\mathrm{C}$ \\
\hline \hline $\begin{array}{c}\text { Fire Growth Rate } \\
\cdot \cdot\left[\mathrm{kW} / \mathrm{s}^{2}\right]\end{array}$ & 0.0065 & 0.0071 & 0.0056 \\
\hline \begin{tabular}{c} 
Experimental pattern \\
\hline \hline $\begin{array}{c}\text { Fire Growth Rate } \\
\cdot\left[\mathrm{kW} / \mathrm{s}^{2}\right]\end{array}$
\end{tabular} & $\mathrm{D}$ & $\mathrm{E}$ & $\mathrm{F}$ \\
\hline
\end{tabular}

Figure 6 HRR of the fire source (pattern A)

\subsection{Smoke Layer Height and Average Smoke Temperature}

Using the $\mathrm{N}$-percent method [7] $(\mathrm{N}=10 \%)$ smoke layer height and average temperature were calculated for all the experimental results. Figures 7 to 12 shows the results. In each set of figures, series (a) denotes the smoke layer height, (b) denotes the average temperatures.

\section{(1) Fire Room}

The smoke layer development in the room of fire origin is about 60 seconds after ignition (T0 and T1). After that the layer descends almost uniformly. After 120 seconds, the layer height close to the doorway (T1) is kept higher than that close to fire source (T0). This is because of the air 
inflow from corridor. After decay (180 seconds), smoke layer descends almost close to the floor (about $200 \mathrm{~mm}$ above floor at T0,600 $\mathrm{mm}$ at T1). The above tendency is common to all the experimental patterns, which means that it is almost independent on the corridor size and arrangement.

\section{(2) Corridor}

Corridor smoke layer begins to develop at about 120 seconds. The rate of smoke layer development differs slightly depending on the size of corridor. In case of small corridor (pattern A), smoke layer decended quickly after 120 seconds. While, in case of large corridor (ty pically in patterns C and D) the development is relatively slow. It should be noted that there is a special distribution difference in smoke layer height in the corridor, especially in cases of large corridor. In case of pattern $\mathrm{E}$, the difference in smoke layer development is about 30 seconds between the locations (T2 and T5).

The effect of smoke curtain is observed to delay the smoke propagate time to downstream corridors. This is obvious through the comparison between patterns $E$ and $F$. In the pattern $E$, the lobby smoke developed at 150 seconds. While in the pattern F, the lobby smoke developed at 220 seconds. The difference is attributed to the smoke curtain at the doorway-A.

As a general tendency, the smoke layer decends right after the fire source has decayed. In all of the experiments, corridor smoke layer has declined to lower than 1 meter above floor. It means that the corridor is unsafe after combustion of three minutes unless some smoke management system is provided.

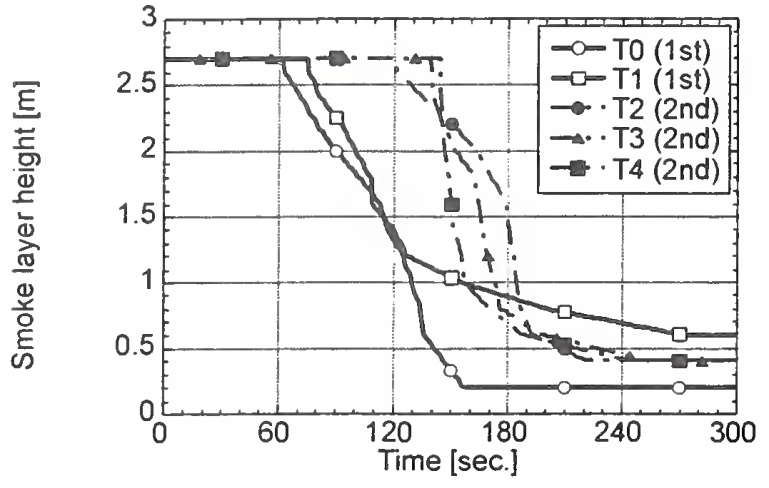

Figure 7(a) Smoke layer height (pattern A)

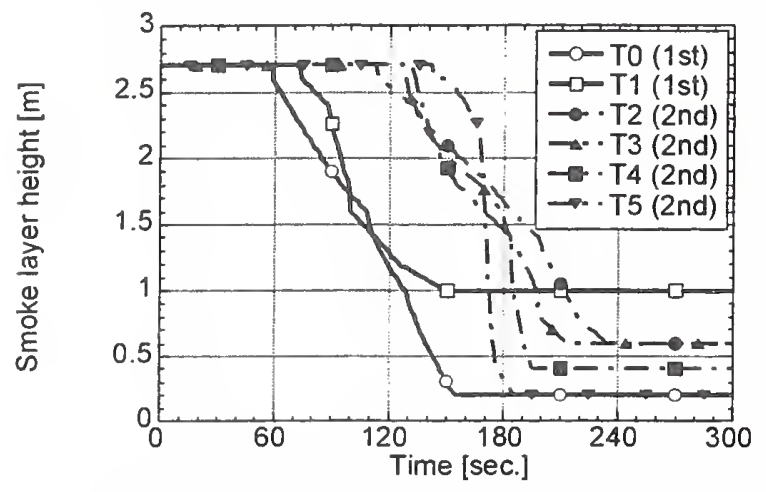

Figure 8(a) Smoke layer height (pattern B)

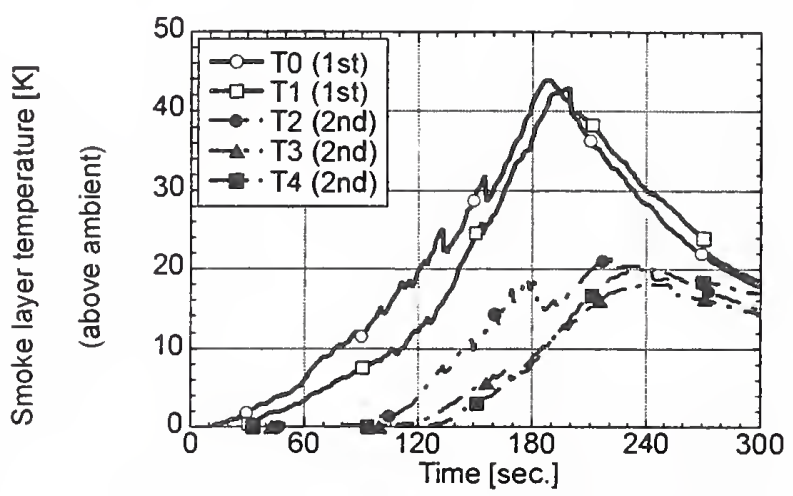

Figure 7(b) Smoke layer temp. (pattern A)

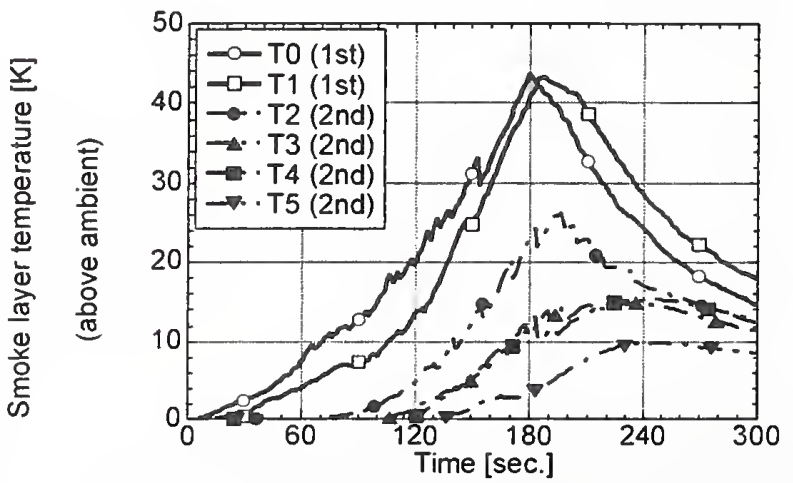

Figure 8(b) Smoke layer temp. (pattern B) 


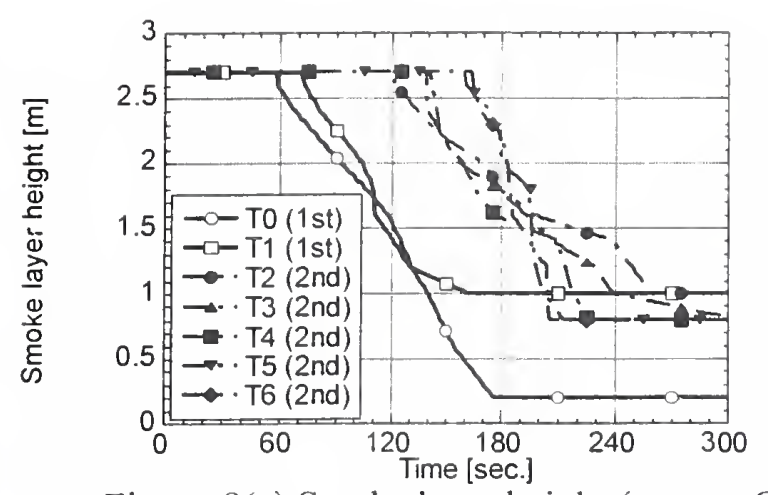

Figure 9(a) Smoke layer height (pattern C)

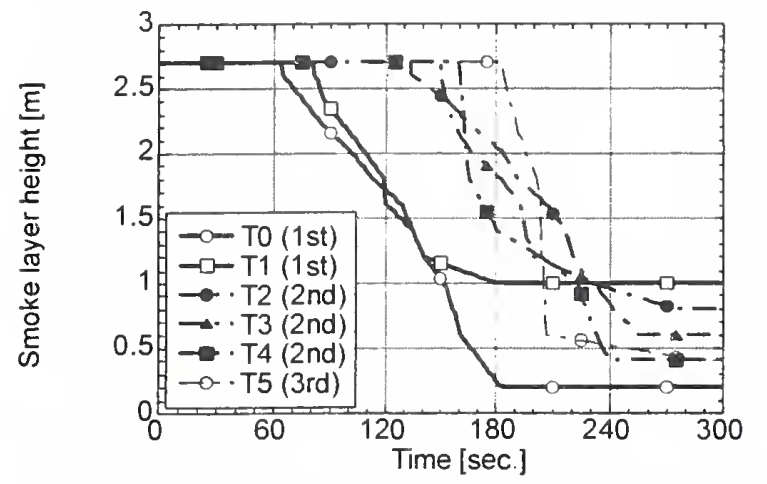

Figure 10(a) Smoke layer height (pattern D)

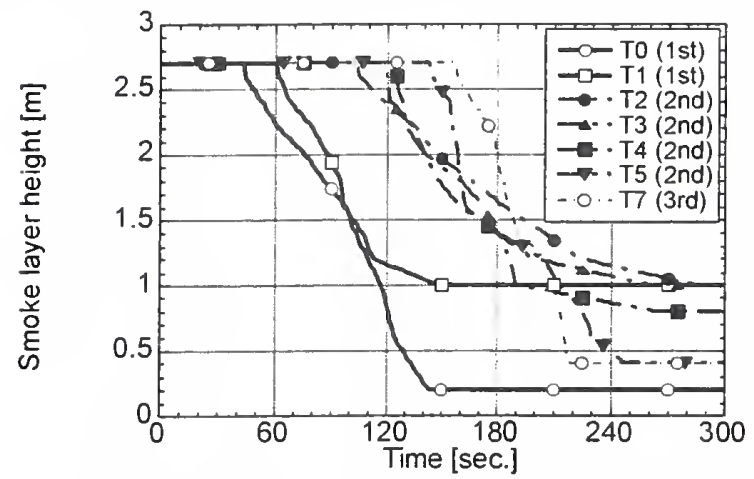

Figure 11(a) Smoke layer height (pattern E)

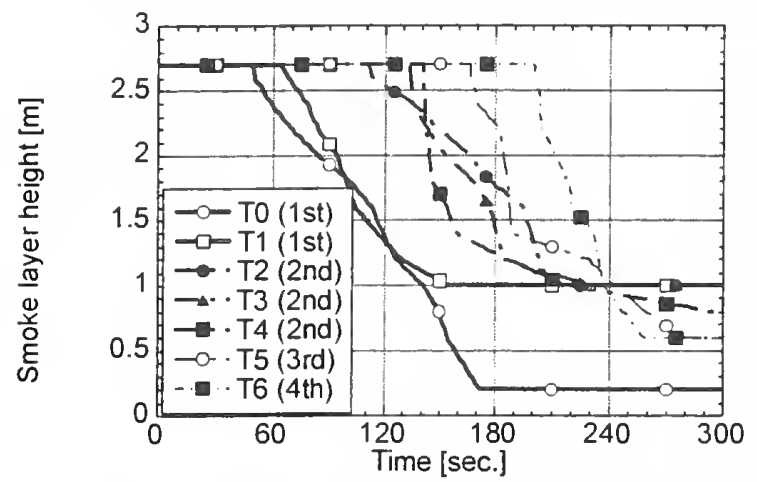

Figure 12(a) Smoke layer height (pattern F)

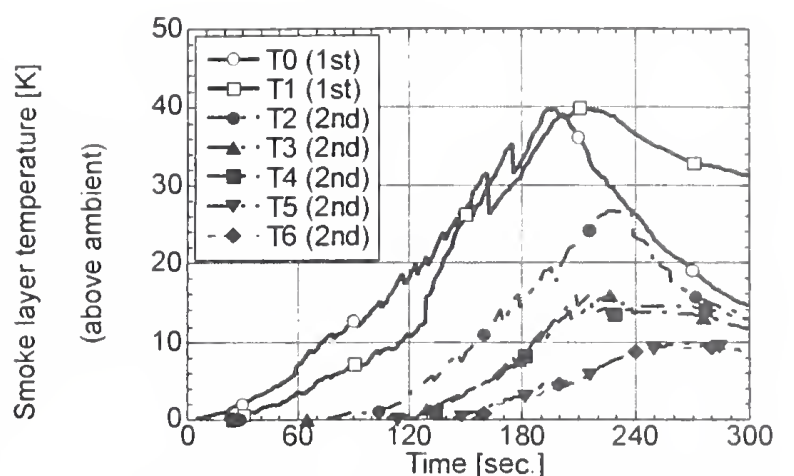

Figure 9(b) Smoke layer temp. (pattern C)

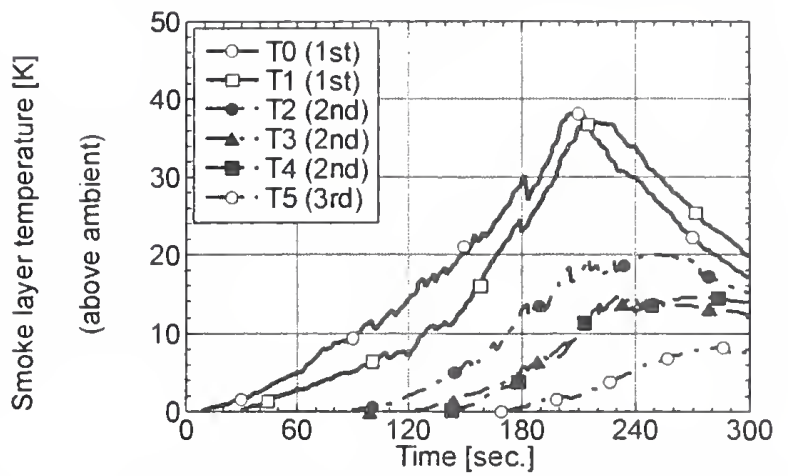

Figure 10(b) Smoke layer temp. (pattern D)

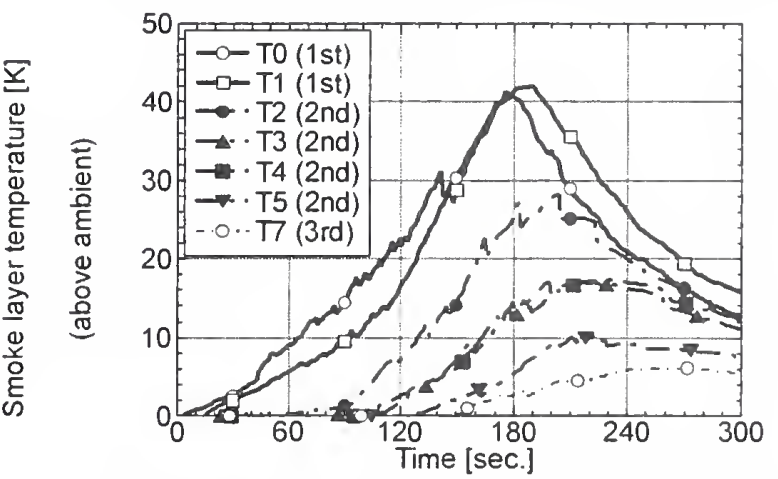

Figure 11(b) Smoke layer temp. (pattern E)

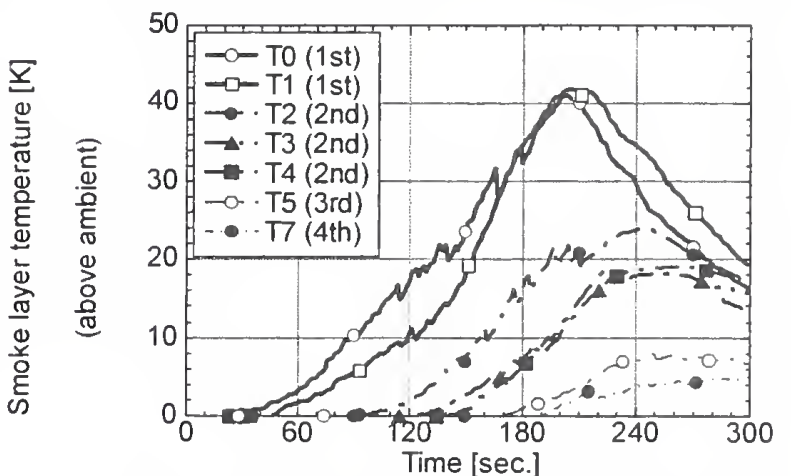

Figure 12(b) Smoke layer temp. (pattern F) 


\section{VALIDATION OF ZONE MODELS (BRI2 and CFAST) FOR t²-FIRES}

\subsection{Calculation}

Two zone models, BRI2 and CFAST was selected to simulate the experimental realization. Among the experimental data, the condition for patterns A was selected and simulated by BRI2 and CFAST, respectively. The input HRR curve is shown in Figure 13.

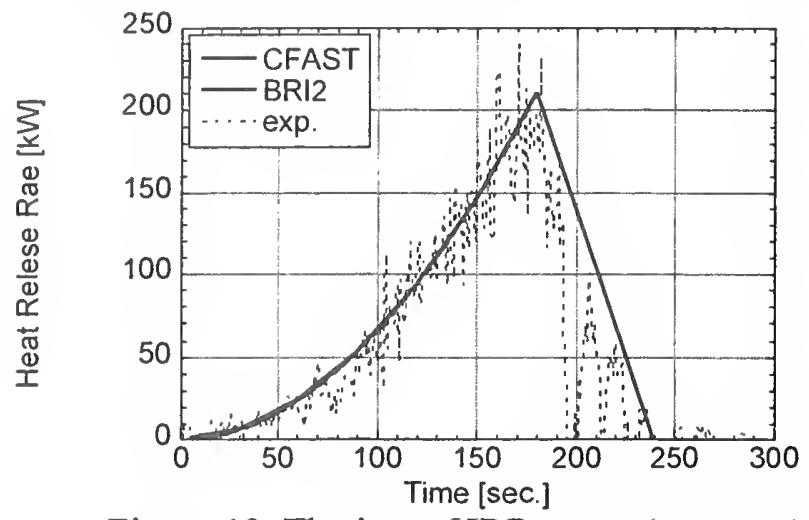

Figure 13 The input HRR curve (pattern A)

\subsection{Comparison Results}

The calculated results are shown in Figures 14, 15 (pattern A) in comparison with experimental data. Both of the two models predict faster smoke development in case of pattern A. As to the temperature, model predictions are slightly higher than the maximum temperature of the smoke layer. In this sense, the models are valid to use in engineering design purpose.

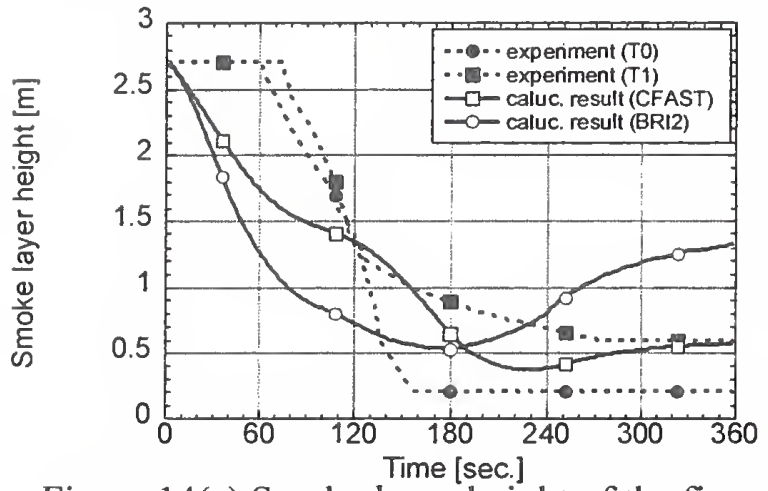

Figure 14(a) Smoke layer height of the fire room

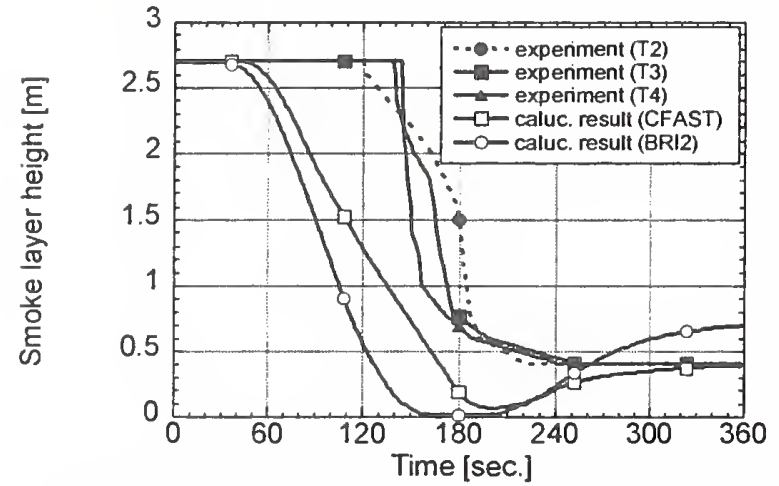

Figure 15(a) Smoke layer height of the corridor-1

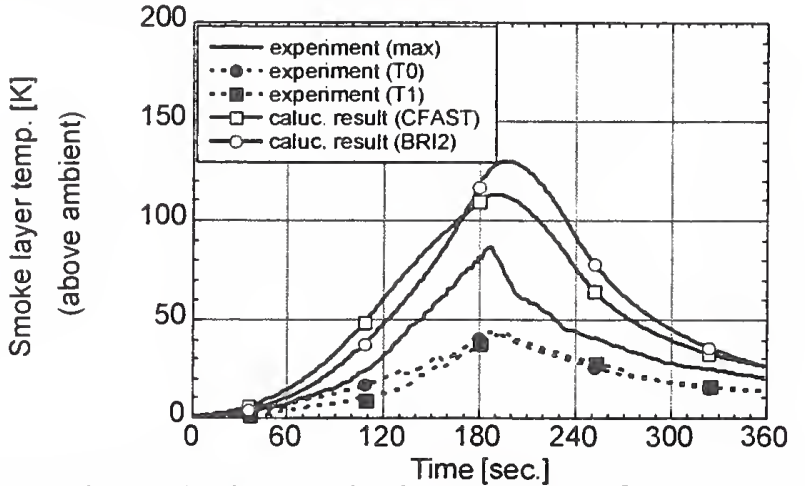

Figure 14(b) Smoke layer temp. of the fire room

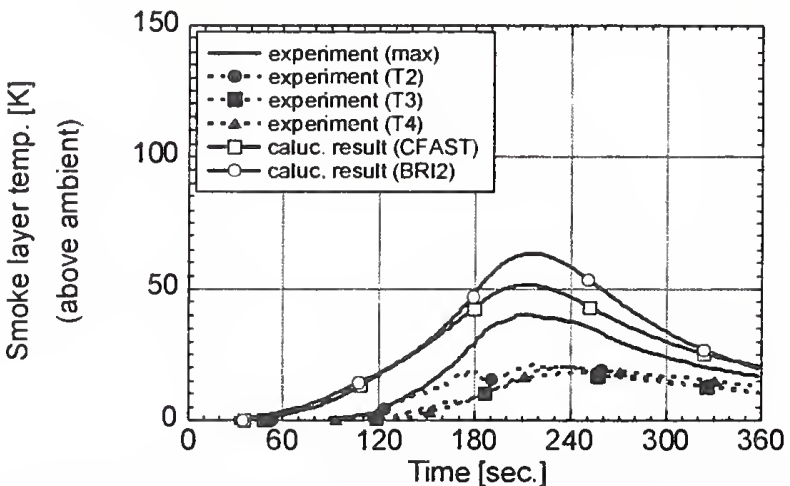

Figure 15(b) Smoke layer temp. of the corridor-1 
However, the post decay behavior is not well predicted by zone models. After decay, the model prediction gives the decrease of smoke layer temperature. At the same time, the thermal shrinkage of smoke layer seems to be predicted. As a result, smoke layer height is increased after decay. This difference is clear in case of BRI2 predictions. In experiment, there is a considerable "mixture" between smoke layer and air layer during decay period. Thus the smoke layer quickly descend to floor level. In an engineering viewpoint, this difference might mislead fire engineers. Thus there is a need to revise zone model codes to include mixing of less buoyant smoke with lower air layer.

\section{CONCLUSION}

A series of full scale experiments were carried out to investigate the smoke propagation behavior for $t^{2}$-fires. The effect of corridor arrangement (size and smoke curtains) were analyzed. The corridor size and smoke curtains have beneficial effect to delay the smoke propagation to downstream corridors. In the experiments, quick mixing of smoke after the decay of fire was observed. In the prediction of smoke layer by using zone models, this effect is not taken into account. Thus there is a need to revise zone type equations to include smoke-air mixing during post decay period.

\section{ACKNOWLEDGMENTS}

The authors would like to thank Mr. M., Mizuno, Mr. N., Nakamura and Mr. Y., Misawa (Graduate students, Science Univ. of Tokyo) for support of this experiment.

\section{NOMENCLATURE}

$Q_{f}$ : design Heat Release Rate [kW]

$t$ : time from ignition [sec.]

$\alpha$ : fire growth rate $\left[\mathrm{kW} / \mathrm{s}^{2}\right]$

\section{REFERENCES}

1. Annual report of MOC project, "Development of Fire Testing and Evaluation System of Materials and Construction (Fire Safety Design Sub Committee)", 1998 (in Japanese)

2. Society of Fire Protection Engineers and National Fire Protection Association, "The SFPE Handbook of FIRE PROTECTION ENGINEERING", 1988

3. Bodart, X. and Curtat, M., CSTB Report, 1987

4. Tanaka, T. and Nakamura, N., "A Model for Predicting Smoke Transport in Building - Based on Two Layers Zone Concept -", Report of Building Research Institute, Occasional Report No. 123, 1989 (in Japanese)

5. Jones, W. W. and Forney, G. P., "A Programmer's Reference Manual for CFAST", the Unified Model of Fire Growth and Smoke Transport, NIST Technical Note 1283, 1990

6. Rockett, J. A., "Using the Harvard/National Institute of Standards and Technology Mark Five Fire Simulation", NISTIR 4464, 1990

7. Cooper, L. Y., Harkeroad, M., Quintiere, J. and Rinkinen, W., "An Experimental Study of Upper Hot Layer Stratifivcation in Full-Scale Multiroom Fire Scenarios", Journal of Heart Transfer, Vol. 104, pp.741-749, 1982 


\title{
Research Project on Disaster Prevention in Town Planning
}

\author{
Koji Kagiya, Yoshihiko Hayashi \\ Building Research Institute \\ Ministry of Construction \\ Tachihara 1, Tsukuba-shi, Ibaraki, 305-0802, Japan
}

\begin{abstract}
It is introduced that outline of research and development program on the disaster prevention planning in urban area, especially of current research on post-earthquake fires with BRI Fire Research Wind Tunnel (BRI FRWT) within this project.
\end{abstract}

\section{Research Project on Disaster Prevention in Town Planning}

As many countries in the world suffer from forest and wildland fires, Japan has experienced frequent city fires as seen at the Great Hanshin Earthquake (1995). And much effort has been made to redevelop wooden built-up areas in many cities as well as in Kobe. It has been very difficult, however, to realize redevelopment of such areas because of many problems regarding the complicated rights of ownership or impact to existing life conditions.

To take measures to meet this situation, a research and development program on the safety in urban area was initiated with BRI as the core organization in 1998(for five years). The aim of this project is to develop the method to estimate regional safety performance against earthquake fires. With this estimation, residents, landowners, etc. are thought to be easier to discuss on regional safety planning in wooden built-up areas.

In this research program, physically based model of post-earthquake fire is required, that is modeling of the physical growth process of earthquake fire, from single building fire to city fire. And for this modeling, it is essential to quantify the effect of various facilities in earthquake fire: building, road, tree open space and river in wind.

\section{BRI Fire Research Wind Tunnel (BRI FRWT)}

Although the importance of wind effects in such fires is often pointed out, there are few quantitative studies on wind-blown fires and firebrands probably because of the lack of appropriate facilities. To meet this circumstance, Building Research Institute constructed in 1998 a large Eiffel-type wind tunnel [1]. It is designed with maximum $10 \mathrm{~m} / \mathrm{s}$ uniform wind velocity from a $5.0 \mathrm{~m}$ wide and $4.0 \mathrm{~m}$ tall outlet. Fluctuation of wind velocity is within $1.0 \%$. And it has a $5.0 \mathrm{~m}$ wide and $15.0 \mathrm{~m}$ long testing area, which can be fed maximum $15 \mathrm{MW}$ propane as the fuel. These features were determined to cover wide range of $\mathrm{Q}^{*}$ : from so-called low $\mathrm{Q}^{*}$ turbulent fires $\left(Q^{* \bullet 0.05)}\right.$ which is typical in mass fires, to buoyancy controlled flames typical in structural and furnishing fires, under reasonably strong wind and reduced-to nearly full-scale test conditions. According to the Froude modeling, the capability of this facility is equivalent to approx. $30 \mathrm{~m} / \mathrm{s}$ wind velocity and $5 \mathrm{GW}$ heat release rate in a $1 / 10$ scale test, and $250 \mathrm{GW}$ heat release rate in a $1 / 50$ scale test, which is almost the limit to achieve the similarity in fire experiments. Also the size of the testing area is believed to allow a full scale or nearly full-scale test on wind effects on fire. 


\section{Current Research on City Fire}

Current research in progress on city fire are introduced below:

\section{Thermal Plume Behavior in Wind}

City fire has caused serious damage particularly under strong winds. The growth and spread of post-earthquake fire is remarkable in this condition. The heat and brands convected by the thermal flow have serious influence even on distant areas from the burning areas. The fire behavior in the gale should be acquired to take effective measures against suffering lots of loss of properties.

A series of outdoor model tests on city fire were carried out with wood cribs as the fuel from late 1960 's to early 1970 's[2]. These tests and dimensional analysis delivered relations on the trajectory and axial temperature along the plume. However there was considerable limitation in the outdoor tests such as the lack of burning rate measurement and relatively unstable weather during making tests.

With conventional test facilities restricted on scale, repetition of test conditions, etc., general conclusions have not be drawn yet. Therefore in this research, BRI FRWT was used. To reproduce the boundary flow in urban area, roughness blocks and spires were arranged in the test section to control the spatial distribution of wind velocity. A series of tests were conducted under the condition that the fire affecting the windward houses followed a burning house: burning house was modeled with $30 \mathrm{~cm}$ square propane diffusion burner and the windward buildings were modeled with bricks arranged regularly (Figure 1,2). In the tests the theory of similarity was taken into consideration on heat release rate and wind velocity. Test conditions are shown in Table 1 .

The flame shape is different according to a dimensionless number of a Froude number. The axis temperature along the flame and thermal flow was indicated on the basis of a series of experiments lead by Saga (1997)[3]. Although our test scale (1/30) and fire source (propane burner) are different from previous study (1/200,1/140; Methanol) but the same result obtained that the axial temperature is proportional to the negative $4 / 3$ power of the Froude number (Figure 3).

The fire behavior near the flame has not been mentioned before. The result of our tests show the axial temperature is in proportion to the negative 1.0 power of the Froude number. Assuming that the thermal flow comes from a line heat source rather than a square heat source in the adjoining area of the flame as in Yokoi's study [4], the said result can be theoretically proved. Temperature distribution in the leeward was observed (Figure 4). The equation predicting the temperature was proposed using the relation between the Froude number and another dominant dimensionless number. These results on the temperature distribution in the leeward were also similar to Saga's smaller scale test [3].

The effect of a fireproof building blocking the fire spread was also tested. It depends on the length and height of the building models. In some cases, the heat was unexpectedly convected by the downward flow behind the building model, and consequently the temperature at the ground level increased in comparison with the one of the area consisted of low building models.

\section{Critical Conditions for Merging and Disintegration of Low Q* Fires}

The principal aim of this test is to generate quantitative information on mass fires as a basis for the sound technical countermeasures against mass fires. Mass fires whether in urban areas, in wildland or in forests are characterized by the low heat release rate per unit area, namely by low 
$\mathrm{Q}^{*}$ values. The $\mathrm{Q}^{*}$ value of city fire is said to be below $0.1[1]$.

Flame heating due to a city fire is controlled essentially by the length and inclination of the flame from the burning area. There are considerable experimental and modeling works on the flame behavior affected by wind. However, most of which deal with large or medium $Q^{*}$ flames or far field from the flame [5]. And it should be noteworthy that there are relatively few experimental works on low $Q^{*}$ fires compared with ones on large or medium $Q^{*}$ fires [6-8] even in quiescent environment.

However, the near field of windblown diffusion flames from low $Q^{*}$ fires are of the primary importance for the engineering treatment of fire spread in mass fires. Few laboratory studies deal with such flames [9]; it is probably because near field of windblown fire is generally much more difficult to model than a diffusion flame in quiescent unconfined environment, and turbulent low $Q^{*}$ fires are generally difficult to reproduce in laboratory. But it is very important to decide to critical conditions for merging and disintegration of low $\mathrm{Q}^{*}$ fires for fire prevention town planning, especially for density control of buildings.

The test that we are carrying out used $15 \mathrm{~cm} \times 15 \mathrm{~cm}$ square and $24 \mathrm{~cm}$ tall porous propane diffusion burners as heat sources. In this testing apparatus, we can set number of burners (1-25), distance between heat sources and mass flow of propane gas, that is, we can control heat release rate in order to reproduce various $\mathrm{Q}^{*}$ fires. In this test, we are measuring flame height and temperature distribution above heat sources in order to define "merging" or "disintegration" of fires quantitatively. This quantitative definition is thought to be necessary for windblown test conditions (Figure 5).

Some tentative test results are shown in Figure 6. This test condition is planned to reproduces $Q^{*} \approx 1$ fire. Now we are tuning this testing apparatus so that we can exactly control heat release rate in order to make various test conditions.

\section{Research Plans on City Fire}

Results of current research presented are tentative, and further consideration and additional tests are required. This research and development program started in 1998 has been carried out for five years. And within this program, following subjects are studied in progress:

Modeling of flame behaviors in wind

- Properties of fire brands: drag coefficient, burning behavior, etc.,

- Effectiveness of fire resistive buildings and greens as barriers against spread of city fires

- CFD modeling of spread of city fire

\section{REFERENCES}

1) Hasemi, Y., Kagiya, K., Hayashi, Y. and Yamana, T.: STATE-OF-THE-ART REVIEW AND THE NEEDS FOR RESEARCH WIND EFFECTS IN FIRES AND SMOKE MOVEMENT, Proceedings of UJNR, 1998

2) Sekine, T.: Behavior of Wind Blown Crib Fires, Fire Science and Technology, Vol.17, Special Issue, 1997(Originally delivered at the Kawagoe Memorial Symposium held during the $13^{\text {th }}$ UJNR Meeting on Fire Research and Safety, Gaithersburg, Md., 1996)

3) Saga, T.: Study on flame of big fires in urban area under strong wind, a theoretical study of temperature distribution downward from a plane heat source, Bulletin of Japan Association for 
Fire Science and Engineering, Vol.46, No.1, 2, 1997 (in Japanese)

4) Yokoi, S.: Study on the Prevention of Fire Spread Caused by Hot Upward Current, Report of BRI, No.34, 1960

5) Putnam, A. A.: A Model Study of Wind-blown Free-burning Fires, Proceedings of the Tenth Symposium (International) on Combustion, 1965

6) Yamashita, K. and Inagaki, M.: Study on Merging of Fires, NRIFD Research Report, Vol. 34, 1971(in Japanese)

7) Sugawa, O.: Merging Flame Height from Multi Fire Sources, Proceedings of Japan Association for Fire Science and Engineering, 1992(in Japanese)

8) Putnam, A. A. and Speich, C. F.: A MODEL STUDY OF THE INTERACTION OF MULTIPLE TURBULENT DIFFUSION FLAMES, Proceedings of Ninth Symposium of Combustion, 1963

9) Hasemi, Y. and Nishihata, M.: DETERMINISTIC PROPERTIES OF TURBULENT DIFFUSION FLAMES FROM LOW Q* FIRES, Fire Science and Technology, Vol.7 No.2 (27$34)$, 


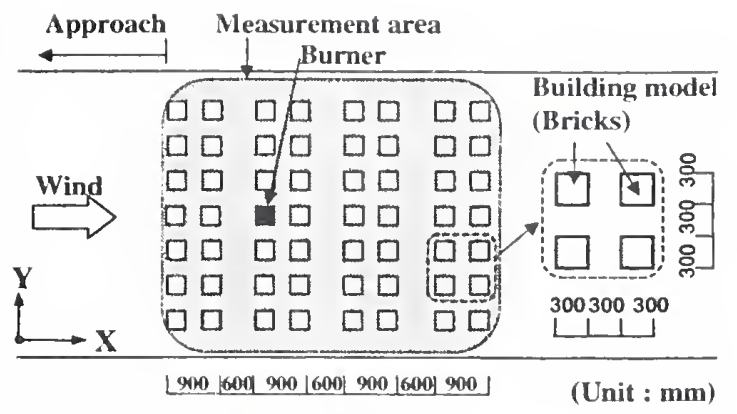

Figure 1 Test area (plan)

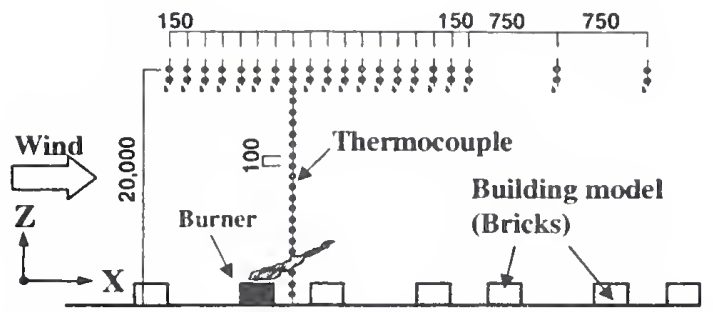

(Unit : mm)

Figure 2 Test area (cross section)

Table 1 Test conditions

\begin{tabular}{|l|c|c|c|c|c|c|}
\hline Test Number & 1 & 2 & 3 & 4 & 5 & 6 \\
\hline $\begin{array}{l}\text { Wind velocity* } \\
\text { (m/s) }\end{array}$ & 0.63 & $t .26$ & 2.52 & 0.63 & 1.26 & 2.52 \\
\hline $\begin{array}{l}\text { Heat Release } \\
\text { Rate (kW) }\end{array}$ & \multicolumn{3}{|c|}{15.0} & \multicolumn{3}{|c|}{25.0} \\
\hline
\end{tabular}

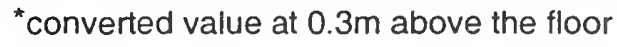

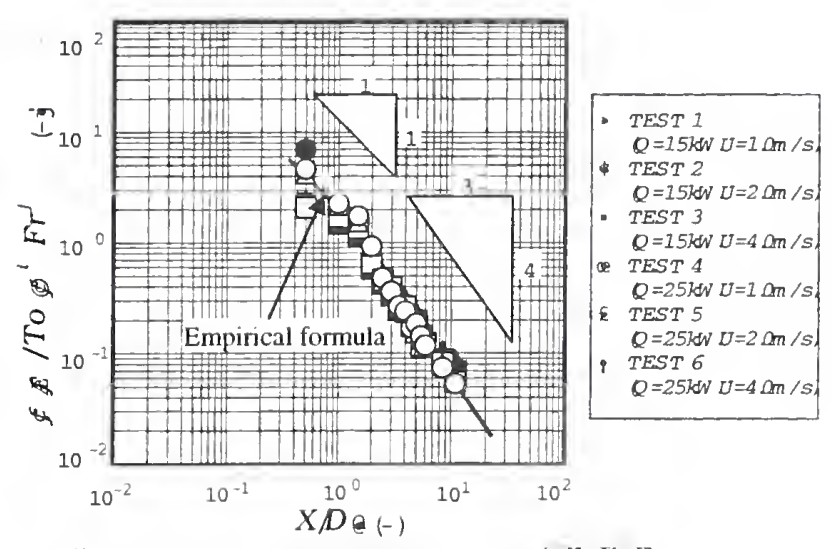

Irajectory axis Ex

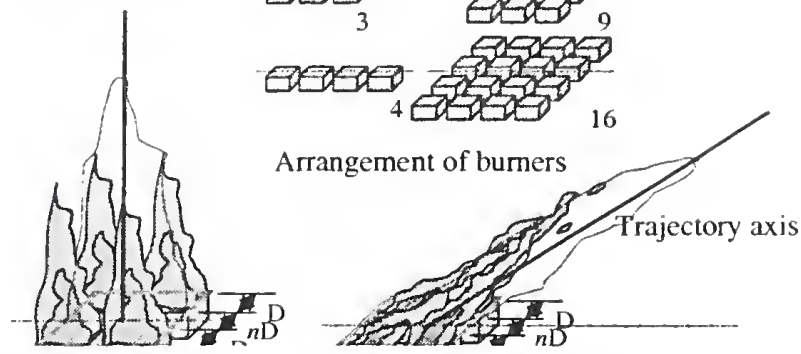

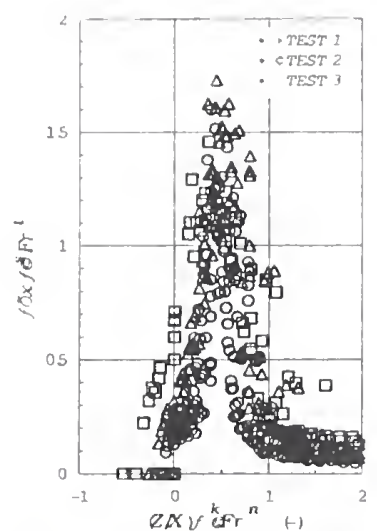

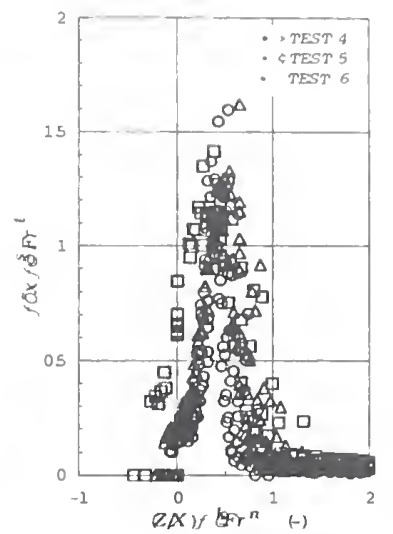

Figure 3 Axial Temperature along the flame

Figure 4 Temperature distribution in the leeward

Figure 5 Arrangement of burners

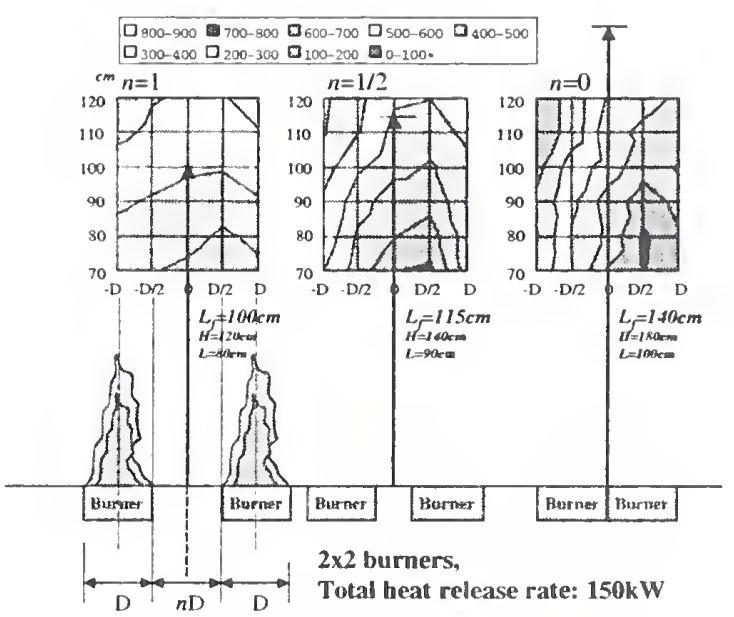

Figure 6 Tentative test results of merging of fires $\left(Q^{*} \approx 1\right)$ 


\title{
A RESEARCH AGENDA FOR FIRE PROTECTION ENGINEERING*
}

\author{
Morgan J. Hurley, P.E. \\ Technical Director \\ Society of Fire Protection Engineers \\ 7315 Wisconsin Ave., \#1225W \\ Bethesda, MD 20814
}

\section{EXECUTIVE SUMMARY}

On October 21 \& 22, 1999 the Society of Fire Protection Engineers conducted a workshop to develop a research agenda for the fire protection engineering profession. The 70 attendees came from around the world and from all segments of fire protection engineering practice: consulting, insurance, education, research, manufacturing, enforcement and facilities management (a listing of attendees is included at the end of this paper). The workshop attendees identified research priorities in the four areas: increased utility of risk concepts, increased understanding of fire phenomena, human behavior and data.

\section{WORKSHOP PROCESS}

The workshop was held for 1-1/2 days, beginning on the morning of October 21. Following welcoming remarks and a summary of workshop goals, keynote presentations were given by Joseph Moakley (a champion in the U.S. Congress of fire safety), James Quiter (senior vice president of the RJA Group, a fire protection engineering firm) and John Nutt (former chairman of Ove Arup \& Partners, an international engineering firm). These presentations were intended to help participants focus their thoughts on research needs and the benefits of fire research. Participants were then divided into five breakout groups. Each breakout group was comprised of a cross section of the workshop attendance. Each breakout group met three times, and each meeting had a different goal.

The first time that breakout groups met, participants were asked to identify fire protection problems that they had encountered in the course of their work. In the second meeting of the breakout groups, research needs were identified that would help overcome the problems identified.

Following the second meeting of the breakout groups, the plenary session was reconvened. A keynote presentation was given by Paul Fitzgerald (executive vice president of FM Global) on the benefits of fire research to business and on how those benefits are often long in coming and difficult for businesses to recognize. The breakout groups then met for a third and final time on the morning of the second day to prioritize the needs that they identified and give their perspectives on implementation of the research agenda.

\footnotetext{
"The full research agenda report can be found in "A Research Agenda for Fire Protection Engineering," Society of Fire Protection Engineers, Bethesda, MD, 2000. This paper is a summary of the full research agenda report.
} 
The workshop concluded with a plenary session where each of the breakout groups presented the research needs that their group identified as the highest priority. The results of the breakout group discussions were summarized and agreement reached on the highest needs. Forms were given to workshop participants for them to evaluate the impact, cost, feasibility and timeframe for the research needs identified at the workshop. These forms were completed after the workshop and returned to the workshop host.

The workshop attendees identified four primary areas where research is most urgently needed: fire phenomena, human behavior, risk and data.

\section{FIRE PHENOMENA}

A common issue in the breakout groups was that "gaps in current design methods result in excessive conservatism."

An understanding of fire phenomena forms the foundation upon which engineered fire protection is based. Consideration of the effects of fire on people, buildings, property or the environment first begins with consideration of the types of fires that might be expected and how those fires would behave (fire growth, heat release rate, smoke production, etc.). While there are significant opportunities for improvement in design that would result from research in other areas, strengthening the knowledge base in fire phenomena would lead to improvements in all designs.

Current predictions of fire phenomena are too often based on rules of thumb, extrapolation from small scale testing or expensive large scale testing. While these methods are based on a significant body of experience, the margin between predictions and actual behavior is often unknown, and the applicability of these methods to new fire hazards, new technologies, and any changes in the future, cannot be assumed.

Research is needed to better predict fire growth and to predict heat release rates from fully developed fires in large or elongated enclosures. Other areas where research is needed include thermal detector response in installations other than under horizontal, unobstructed ceilings, smoke detector response and suppression system efficacy.

However, a greater understanding of fire phenomena in itself is not sufficient. It is necessary to transfer knowledge gained through research into fire protection engineering practice through the development of models and other tools. A greater understanding of fire phenomena which is readily applicable through models will lead to better and more cost effective fire protection.

\section{HUMAN BEHAVIOR}

A participant in one of the breakout groups noted that "fire protection system designs assume that people will leave buildings in the event of fires. However, this often does not happen; ... we need to design for these actions." Similar remarks were made in each of the other breakout groups.

Designs that are based solely on fire behavior, equipment performance, and materials response overlook a significant factor that can often by the key to the outcome of a fire: human behavior, 
human performance, and human response. To provide better life safety, it is necessary to better understand the actions that people will take in response to a fire.

Workshop participants identified a need for research into the decisions people make in response to fire cues and pre-movement delays. Research is also needed into the impact of the fire environment on human behavior, particularly sub-lethal health effects, effects on behavior and animal to human conversions for data based on animal studies. Research into the variability of human behavior is also needed.

As with fire phenomena, increased understanding of human behavior in fire must be quantitative and predictive. Readily available models will be needed to facilitate the consideration of human behavior in engineered fire protection system design. An increased understanding of human behavior in fire will lead to more efficient life safety systems, thus providing necessary protection at acceptable cost.

\section{RISK MANAGEMENT}

The engineering community generally recognizes risk as a product of probability and consequence. However, risk is much broader than this simple equation suggests, for example, addressing issues of uncertainty.

As one workshop participant noted, "it is not possible to incorporate society's perception of acceptable risk into design, particularly as perception of 'acceptable risk' varies." Similar sentiments were expressed by others.

Fire protection engineering has typically focused only on the consequence (or hazard) part of risk. To bring about significant cost-benefit improvements in fire protection engineering design, and to better focus fire protection resources where they are needed most, research is needed into the application of risk management. Using risk management in fire protection engineering practice requires definition of the level of risk that society is willing to accept and a risk management framework.

Definition of what constitutes an acceptable risk will require the input and concurrence of public policy makers. Since definition of risk involves deciding how much loss is acceptable, this can be a politically challenging task. However, lessons can be learned from other industries, such as the automobile and aircraft industries.

Once an acceptable level of risk is established, it will become necessary to design to meet this level of risk. This will require the development of a risk analysis framework that considers risk exposure and the costs, both initial and lifecycle, of any protection methods used.

As risk analysis has been applied in other engineering disciplines, one can look to these disciplines as a starting point. The risk analysis tools used in other engineering disciplines can be evaluated for their applicability to fire protection engineering, and possibly modified accordingly. 


\section{DATA}

Each of the breakout groups expressed concern with the paucity of data that is available to fire protection engineers. Statements made included: "A significant amount of fire testing is conducted; however, the results from these tests are not readily available," and "forensic research is needed to capture performance data of real fires."

Data forms the input to engineering tools and calculations. However, data must be readily available and have known confidence. Data is needed to assess how products and materials would behave in fires. Reliability data is needed for fire protection systems. Forensic data is needed to learn more about how fires are started and for feedback regarding failures and successes. Human behavior data is needed to learn more about what types of people can be expected in different occupancies, and what types of actions they might take that could lead to fires or alter the course of fires.

It is paramount that data be widely available. Data is often difficult to obtain. A central contact point is needed for fire data. Also, data must be maintained in such a manner that it can be used with confidence.

\section{SUMMARY}

Realization of the research needs identified in this agenda will allow fire protection engineers to achieve a number of societal benefits: improved life safety, reduction of fire related costs and improved environmental protection. Additionally, others stand to benefit from an increased understanding of the physical world - product manufacturers, building owners, insurers, the fire service and the public at large.

Implementing the research agenda will not be easy. It will require a significant financial investment and several years to achieve it. Presently, there are a number of organizations involved in research, including both private companies and governmental agencies around the world. Each of these organizations will have a role to play in implementing the research agenda.

Many stand to benefit from the results of the research identified in this agenda. Therefore, it is not reasonable to depend only on the organizations now involved in fire research to conduct the necessary research with the resources they currently have available. Collaboration and partnerships will be crucial to the success of implementing this agenda.

Additionally, a champion will be needed to coalesce the diverse interests that will need to come together to ensure successful implementation of the agenda. This champion will need to advocate the agenda, break down inter-organizational barriers, and oversee and monitor completion of agenda topics.

Realization of the research agenda will be no small undertaking. However, the benefits far outweigh the costs. Implementation of the research agenda will bring about significant improvements that will improve safety and reduce fire related costs. 


\section{WORKSHOP ATTENDEES}

\begin{tabular}{|c|c|}
\hline Name & Organization \\
\hline Vytenis Babrauskas & Fire Science \& Technology, Inc. \\
\hline Mike Balch & Australian Building Codes Board \\
\hline Carl Baldassarra & Schrimer Engineering Corp. \\
\hline John Bender & National Association of State Fire Marshals \\
\hline Craig Beyler & Hughes Associates \\
\hline Jim Beyre is & Underwriters Laboratories, Inc \\
\hline Jason Boren & Bechtel \\
\hline Robert Boyer & Edwards Systems Technology \\
\hline Doug Brandes & Duke Power \\
\hline Murray Cappers & J\&H Marsh and McLennan \\
\hline Larry Maruskan & US Fire Administration \\
\hline Geoff Cox & Building Research Establishment \\
\hline Dick Crouse & American Petroleum Institute \\
\hline Richard Custer & Custer-Powell, Inc. \\
\hline Tom Daly & Hilton Hotels \\
\hline Robert D'Angelo & U.S. Army \\
\hline Mr. Ron de Veer & Queensland Department of Communication \& Information \\
\hline Dougal Drysdale & University of Edinburgh \\
\hline Ken Dungan & Risk Technologies, LLC \\
\hline Fred Emerson & Nuclear Energy Institute \\
\hline William Erny & American Petroleum Institute \\
\hline Lenny Farelo & Intel Corporation \\
\hline Paul Fitzgerald & FM Research Corp. \\
\hline Jay Fleming & Boston Fire Department \\
\hline Arnold Garson & Cerberus Pyrotronics \\
\hline Casey Grant & National Fire Protection Association \\
\hline LT Andy Grenier & U.S. Coast Guard \\
\hline John Hall & National Fire Protection Association \\
\hline Rich Hansen & U.S. Coast Guard \\
\hline Paul Heilstedt & Building Officials and Code Administrators, International \\
\hline Wayne Holmes & Hartford Steam Boiler Professional Loss Control \\
\hline Tom Jaeger & Gage-Babcock \& Associates \\
\hline Marc Janssens & Southwest Research Institute \\
\hline Robert Jonsson & Lund University \\
\hline John Klote & American Society of Heating, Refrigeration and Air Conditioning Engineers \\
\hline Bill Koffel & Koffel Associates \\
\hline Matti Kokkala & VTT Building Technology \\
\hline
\end{tabular}




\begin{tabular}{|c|c|}
\hline Bruce Larcomb & Building Officials and Code Administrators International \\
\hline Larry Little & Commonwealth Scientific and Industrial Research Organization. \\
\hline Dave Lucht & Worcester Polytechnic Institute \\
\hline John MacGreggor & Building Industry Authority \\
\hline Robert Malanga & Union Camp Corporation \\
\hline Chris Marrion & Arup Fire \\
\hline John McFassel & U.S. Army Aberdeen Test Center \\
\hline Joseph Messersmith & Portland Cement Association \\
\hline Fred Mowrer & University of Maryland \\
\hline Frederick Mulhaupt & Fire Protection Research Foundation \\
\hline Bijan Najafi & SAIC \\
\hline Harold Nelson & Hughes Associates \\
\hline David Notley & SAIC \\
\hline John Nutt & Ove Arup \& Partners \\
\hline Michael O'Hara & MountainStar Enterprises \\
\hline Jim Quintiere & University of Maryland \\
\hline Jim Quiter & The RJA Group, Inc. \\
\hline Ken Richardson & Ken Richardson Fire Technologies, Inc \\
\hline Mickey Reiss & The RJA Group, Inc. \\
\hline Robert Schifiliti & RP Schifiliti Associates, Inc. \\
\hline Jim Shields & University of Ulster Fire SERT Centre \\
\hline Paul Shipp & USG Corporation \\
\hline Nathan Siu & Nuclear Regulatory Commission \\
\hline Warren Stocker & Safeway Inc. \\
\hline Kuma Sumathipala & American Forest \& Paper Association \\
\hline Harry Taback & J\&H Marsh \& McLennan \\
\hline William Tangye & Southern Building Code Congress, International \\
\hline Ian Thomas & Centre for Environmental Safety and Risk Engineering \\
\hline Jon Traw & International Conference of Building Officials \\
\hline Beth Tubbs & International Conference of Building Officials \\
\hline Bob Weber & Clark County Nevada \\
\hline Dave Wechsler & Union Carbide \\
\hline Jack Woycheese & Gage-Babcock \& Associates \\
\hline
\end{tabular}

\section{ACKNOWLEDGEMENTS}

The research agenda is the product of all of the participants in the SFPE Research Agenda Workshop. Financial support from the National Institute of Standards \& Technology is also greatly appreciated (Grant No. 60NANB8D0047). 


\title{
Flow Behavior under Sloped Ceiling
}

\section{Osami Sugawa*, Takashi Hosozawa** Naoto Nakamura*, Ayako Itoh* and Yoshiyuki Matsubara**»,}

"Science Univ. of Tokyo, ${ }^{\star \star}$ Takenaka Co.,Ltd., ${ }^{\star \star \star}$ Fire and Disaster Management Agency

\begin{abstract}
Experimental study was carried out on the flow behavior which flows under the sloped ceiling. Temperature and flow velocity were measured to characterize the ceiling jet along the sloped ceiling surface. A diffusion gas burner was used as a model fire source giving $15-100 \mathrm{~kW}$, changing the slope angle of the ceiling adopting of $0,30,45$, and 60 deg. Based on the experimental data, excess temperature and velocity along the sloped ceiling were modeled and which are usefully applicable to estimate the activation time of heat detector and spnnkler head mounted on the sloped ceiling. Excess temperature and flow velocity along the trajectory covering the flame to ceiling-jet regions were also modeled based on the Fr model.
\end{abstract}

Key Words: sloped ceiling, ceiling jet, temperature, velocity, Froude modeling

1. Introduction

Fire detectors and sprinkler system are important measures against a fire, especially in its early stage. Hot gas in the fire plume rise up and impinge on the ceiling. Heat detectors and sprinkler systems operate based on hot flow (excess temperature and flow velocity are main physical parameters which give the operating time based on RTI model) at the points where these system are monted. It is important and necessary to know the flow behavior under the ceiling to simulate the detecting and/or operating time for a fire protecting assessment. Alpert[1] had developed the modeling on gas temperature and velocity of the ceiling jet, and also Heskestad and Delichatsios[2][3] have proceeded the correlations between excess temperature and velocity. Alpert, Heskestad and Delichatsios, the leading researchers, have developed easy-to-use quantitative model on the gas temperature and velocity along a horizontal ceiling as the flow is produced from a steady burning of fire. These correlations are widely used in hazard analysis calculation. However, there is no easy-to-use model on the ceiling jet under the sloped ceiling such as a ceiling of stairway (part of underpass) and of a semicylindrical roof (quonset hut).

In this study, we carried out experimental study on the sloped ceiling jet using a semi-full scale equipment. Based on the experimental data, the model was established which describes the excess temperature and flow velocity under the sloped ceiling. The model established here is applicable to predict the operation time of the heat detectors installed on the sloped ceiling.

\section{Experimental Procedures}

2.1 Unconfined Sloped Ceiling and Fire Source

We set up the sloped ceiling in an experiment room of $10 \mathrm{~m}(\mathrm{~W}) \times 8 \mathrm{~m}(\mathrm{D}) \times 4 \mathrm{~m}(\mathrm{H})$ which connects to the upper room having a ventilating system. The sloped ceiling is an unconfined square shape of $3.6 \mathrm{~m} \times 3.6 \mathrm{~m}$, as shown in Figure 1, and is composed of calcium silicate boards of $12 \mathrm{~mm}$

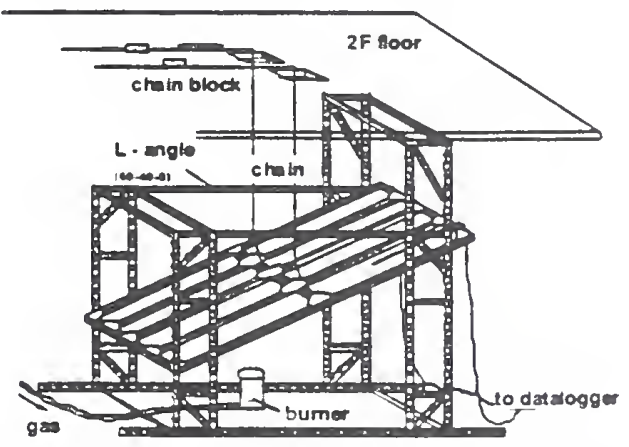

Figure 1. Expenmental set-up of sloped ceiling

thick. A round sand gas burner, having $30 \mathrm{~cm}$ high from the floor and diameter of $20 \mathrm{~cm} \phi$, was set as a fire source under the cenetr line of the ceiling. Propane gas was supplied as a fuel. 
Table1. Experimental Condition

\begin{tabular}{|c|c|c|c|c|c|c|c|c|c|c|c|c|}
\hline \multirow{2}{*}{\multicolumn{2}{|c|}{$\frac{\text { angle (degree) }}{\text { HRR }(\mathrm{kW})}$}} & \multicolumn{5}{|c|}{0} & \multicolumn{6}{|c|}{30} \\
\hline & & 15 & 20 & 30 & 45180 & 100 & 15 & 20 & 30 & 45 & 80 & 100 \\
\hline \multirow{6}{*}{$\begin{array}{c}\text { cerling } \\
\text { height }(\mathrm{m})\end{array}$} & 1.25 & 0 & 0 & 0 & 010 & & 0 & 0 & - & 0 & 0 & 0 \\
\hline & 1.5 & 0 & 0 & 0 & 010 & 0 & 0 & 0 & 0 & 0 & 0 & 0 \\
\hline & 1.75 & 0 & 0 & 0 & 010 & 0 & 0 & 0 & 0 & 0 & (2) & 0 \\
\hline & 2 & 0 & & 9 & 01 & & 0 & e & 8 & 0 & 0 & \\
\hline & 2.25 & 0 & & 0 & 010 & & 8 & 8 & 0 & 0 & & \\
\hline & 2.5 & 0 & & & 01 & & & & & & & \\
\hline \multicolumn{2}{|c|}{ angle (degree) } & \multicolumn{5}{|c|}{45} & \multicolumn{6}{|c|}{60} \\
\hline \multicolumn{2}{|c|}{ HRR (kW) } & 15 & 20 & 30 & $45 \mid 80$ & 100 & 15 & 20 & 30 & 45 & 80 & 100 \\
\hline \multirow{6}{*}{$\begin{array}{c}\text { ceiling } \\
\text { height }(\mathrm{m})\end{array}$} & 1.25 & 0 & 0 & & 010 & 0 & 8 & 8 & P & 0 & 0 & 0 \\
\hline & 1.5 & 0 & e & & 010 & 0 & 0 & 0 & 9 & 0 & 0 & 0 \\
\hline & 1.75 & 0 & 을 & & 010 & 0 & & & & & & \\
\hline & 2 & & & & & & & & & & & \\
\hline & 2.25 & & & & & & & & & & & \\
\hline & 2.5 & & & & & & & & & & & \\
\hline
\end{tabular}

\subsection{Experimental Condition}

Table1 shows the experimental conditions adopted in this study. The angle of sloped ceiling was adjusted to $0,30,45$, and 60 degree, respectively. Heat release rate varied from $10 \mathrm{~kW}$ to $100 \mathrm{~kW}$, and ceiling heights, $1.25 \mathrm{~m}$ to $2.5 \mathrm{~m}$, were adopted systematically as Table1. The solid marks in Table 1 show the cases that the flame

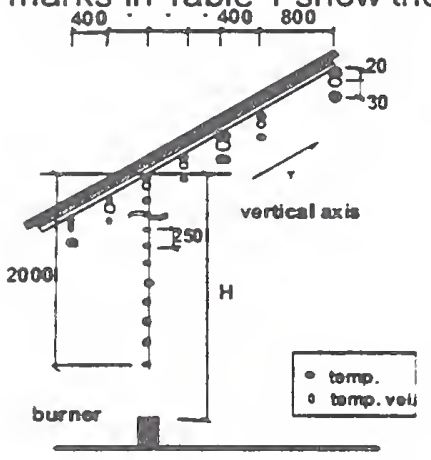

Figure 2. Measurement Points

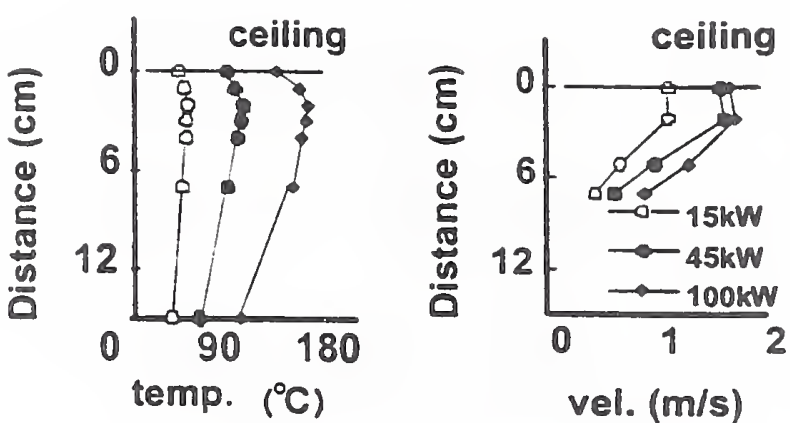

Figure 3.a Slope angle $=30 \mathrm{deg}$
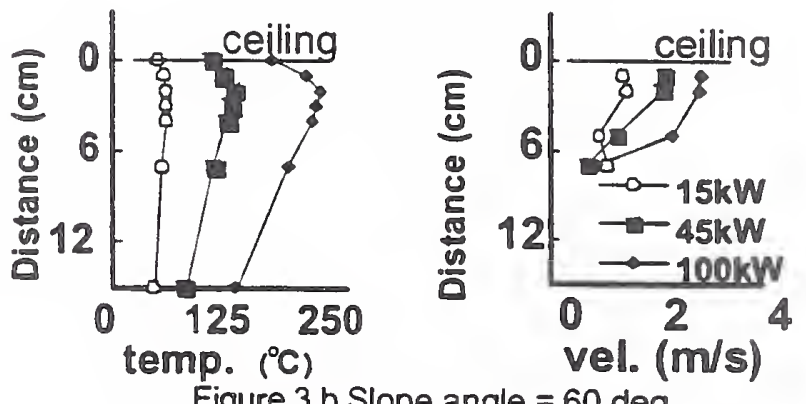

Figure 3.b Slope angle $=60 \mathrm{deg}$

Figure 3 Vertical distributions of excess temperature andflow velocity

were measured with K-type thermocouples, and the flow velocities were estimated based on the pressure difference obtained by bidirectional tubes. These data were recorded every 2 seconds during the steady condition.

\section{Results and Discussion}

3.1 Excess temperature and Velocity Distributions along Vertical Direction

Figure 3 shows the representative did not cling to the ceiling, and the open marks vertical distributions of the gas temperature and show the ones that the flame or flame tip touched velocity at a distance of $1.2 \mathrm{~m}$ apart from the cenand extend along to the ceiling depending on heat release rate.

\subsection{Measurements}

The measurement were carried out on gas tempera- $\frac{\mathscr{L}}{\partial}$ ture and velocity under the sloped ceiling. Figure 2 shows the measurement points of the temperature and velocity. The temperatures

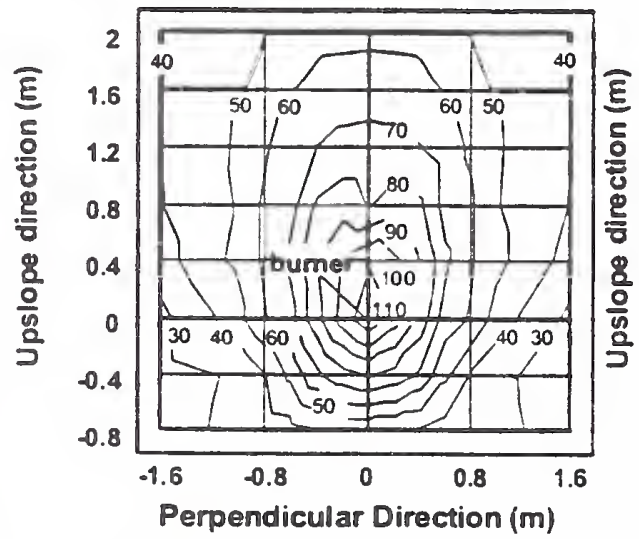

Figure 4.a Slope angle $=30 \mathrm{deg}$

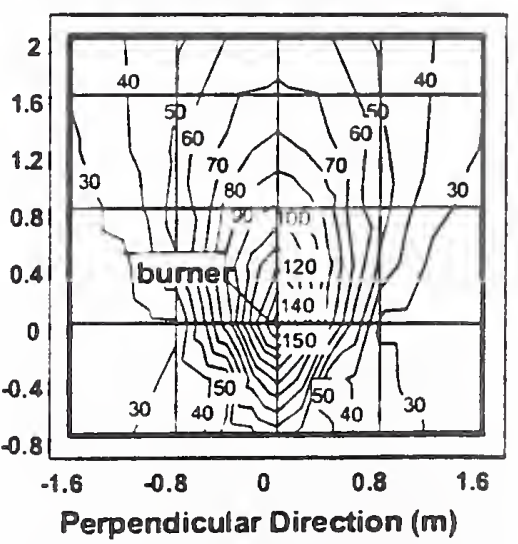

Figure 4.b Slope angle $=60 \mathrm{deg}$
Figure 4 Representative excess temperature maps. 


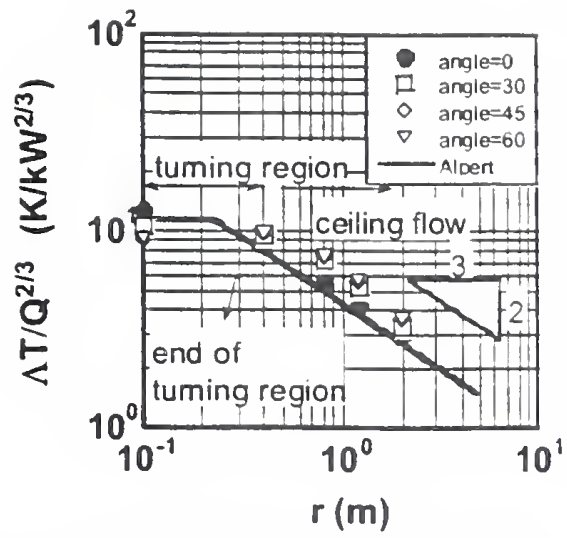

Figure 5.a Excess temperature

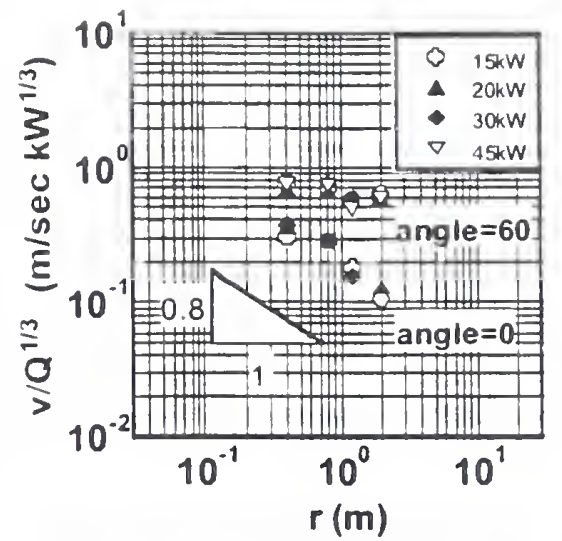

Figure 5.b Velocityalong the ceiling surface
Figure 5 Temperature and velocity along the ceiling surface. ter where the upward hot flow impinges on the ceiling and which show that the maximum temperature and velocity appeared about $2 \mathrm{~cm}$ beneath the ceiling surface. In this study, therefore, the gas temperatures and velocities observed $2 \mathrm{~cm}$ beneath the ceiling were adopted as representative values for description and analysis.

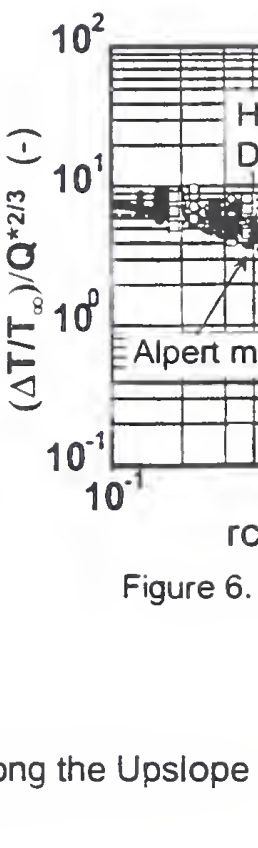

Figure $4 . a$ and $4 . b$ shows the representative temperature maps under the sloped ceiling surface. The temperature distribution of radial or elliptic-shape was observed for low sloped ceiling, and the distribution changed and expanded to round egg-shape as the ceiling angle is set steep. For downslope direction, radiation from flame tip gave apparent temperature rise resulting open end shape as Figure 4.

\subsection{Characteristic Temperature and Flow Veloc- ity along Upslope Direction}

Figure 5.a shows the correlation between the excess temperature and the upslope pass distance, $r$, from the center. The turning region is formed around the center as was estimated based on $\Delta T$ and shown in Figure 5.a. However, it was very hard to distinguish clearly the boundary between impinging region and ceiling jet region based on the observation. In the turning region, the temperature decreasing rate is small, as shown in Figure 5.a, and then in the successive ceiling jet region the temperature decreased as $\Delta \mathrm{T} \propto \mathrm{r}^{-2 / 3}$ along the upslope trajectory.

As shown in Figure 5.b, the decreasing rate of velocity along the upslope ceiling showed remarkable change depending on the slope angle. Rough estimation on the decreasing rate for horizontal ceiling gave $\mathbf{v} \propto \mathbf{r}^{-1}$. and for steep sloped ceiling. As the slope angle set steeper and approached to the vertical situation, the decreasing mode of the flow velocity for upslope direction showed the same mode, $v \propto \mathbf{r}^{0}$ as that observed from a line fire source.

3.4 Excess Temperature along Upslope Direction Figure 6 shows the relation between dimensionless temperature rise and dimensionless path 


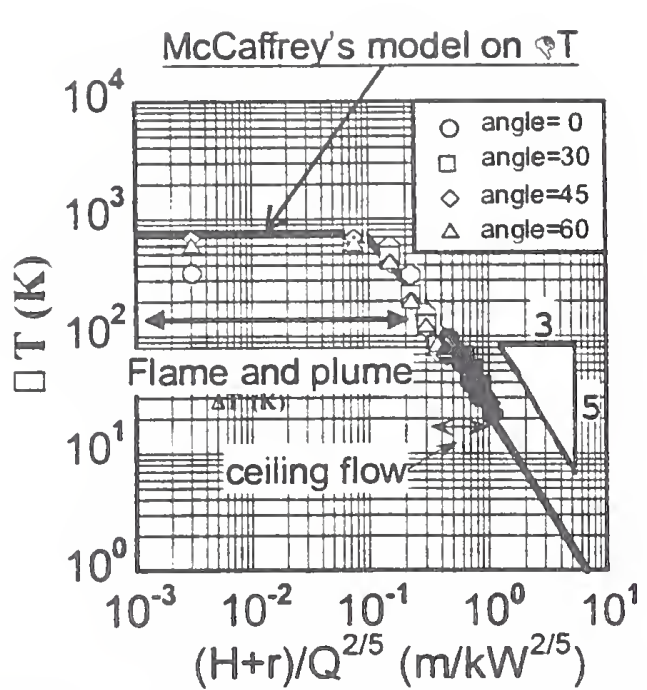

Figure 7.a Excess temperature distribution along the flow pass including flame, plume and ceiling jet reions. Thick line is given based on McCaffrey's model on flame and plume. $H=1.5 \mathrm{~m}$ and $\mathrm{Q}=20 \mathrm{~kW}$

along the upslope trajectory. This figure is illustrated taking the same model with the HeskestadDelicatsios' model. The established model on excess temperature model for upslope direction ( $Y$-axis) are represented as followings:

$$
\begin{aligned}
& \Delta \mathrm{T}_{\mathrm{ver}}^{*}=(0.41+0.2 \mathrm{y} / \mathrm{H})^{-4 / 3} \quad(\theta=0) \\
& \Delta \mathrm{T}_{\text {ver }}^{*}=(0.41+0.4 \mathrm{y} \cos \theta / \mathrm{H})^{-4 / 3} \quad(0<\theta \leq 90)
\end{aligned}
$$

where $\Delta T^{*}=\left(\frac{\Delta T}{T_{\infty}}\right) / Q^{\cdot 2 / 3}$ and $Q^{\circ}=Q / p_{\infty} c_{\mathbf{p}} T_{\infty} \sqrt{g} H^{5 / 2}$

The coefficients of these formula are different

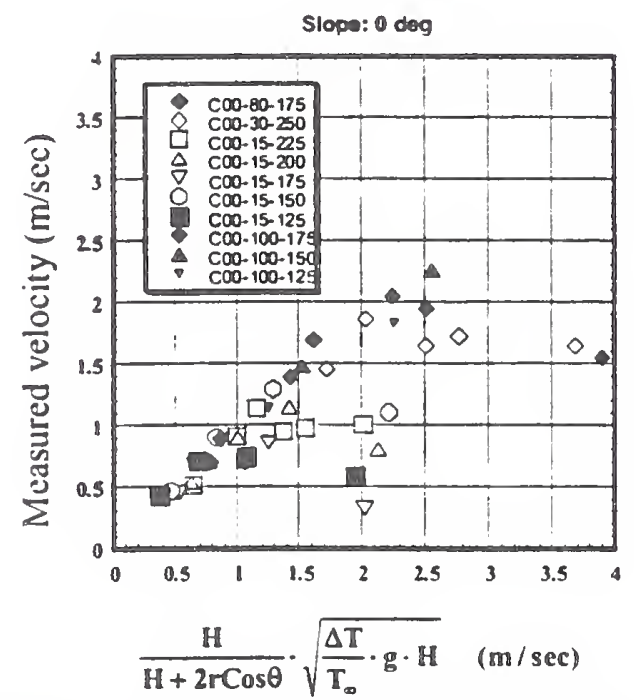

Figure 8 Correlation between measured velocity and temperature based velocity with location modification for slope angle of 0 deg.

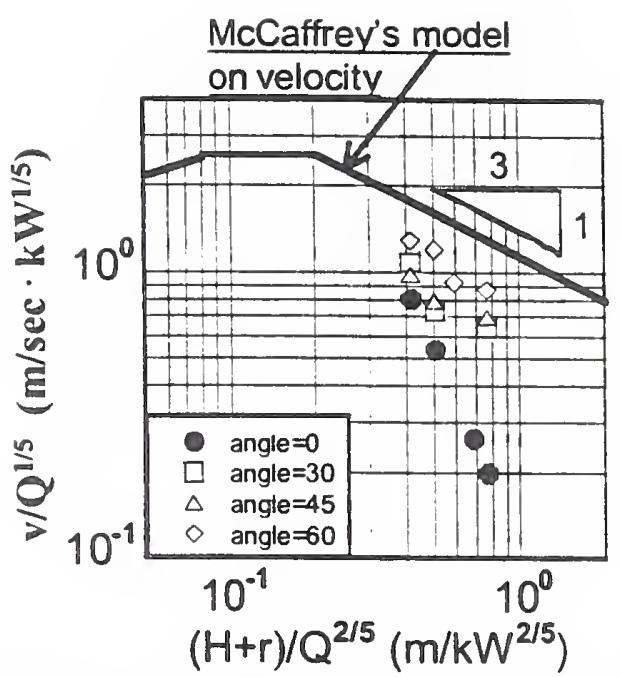

Figure 7.b Distribution of the flow velocity normalized by $Q^{1 / 5}$ along the trajectory including flame and ceiling jet regions. Thick line is given based on McCaffrey's model on flame and plume. $\mathrm{H}=1.5 \mathrm{~m}$ and $\mathrm{Q}=20 \mathrm{~kW}$

from the one of Heskestad-Delicatsios' model. This discrepancy may be given by the difference of the ceiling material used.

For the perpendicular direction against upslope direction ( $X$-axis cf. Figure 2 ), the dimensionless temperature rise is also modeled as follwing:

$$
\Delta \mathrm{T}_{\text {hord }}^{*}=(\mathrm{a}+0.15 \mathrm{x} \sin \theta / \mathrm{H})^{-18} \quad(0<\theta \leq 90)
$$

where $\mathrm{a}=\left(\Delta \mathrm{T}_{\text {ver }}^{*}\right)^{-18}$

3.5 Correlation between Flow Velocity and Tem-

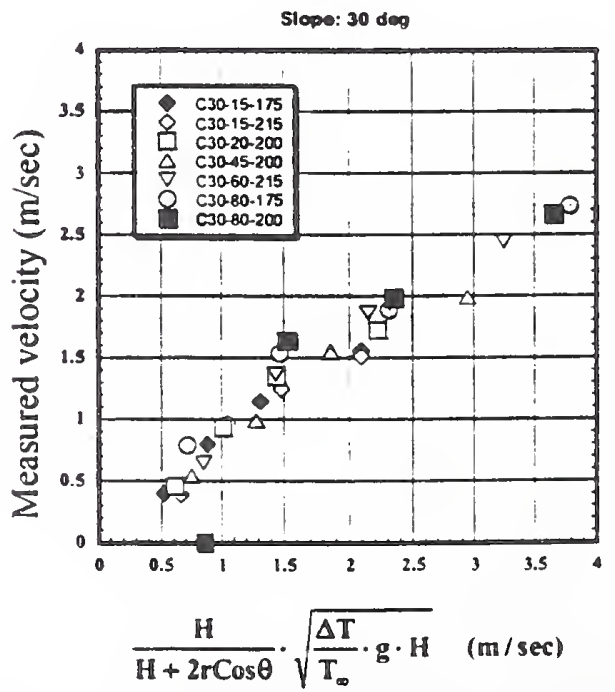

Figure 9 Correlation between measured velocity and temperature based velocity with location modification for slope angle of $30 \mathrm{deg}$. 
perature based flow velocity of $\sqrt{\left(\Delta T / T_{\infty}\right) \cdot g \cdot H}$.

Flow velocity of the hot current resulted from buoyancy of flow produced by a fire source. This mechanism conserved not only in a flame/plume regions but also in ceiling jet region. Figure 7 shows the typical excess temperature distribution along the trajectory including in flame region and consecutive ceiling jet region. $\Delta T$ are plotted against the flow-pass which is total pass length including of height, $H$, and flow pass along the ceil-

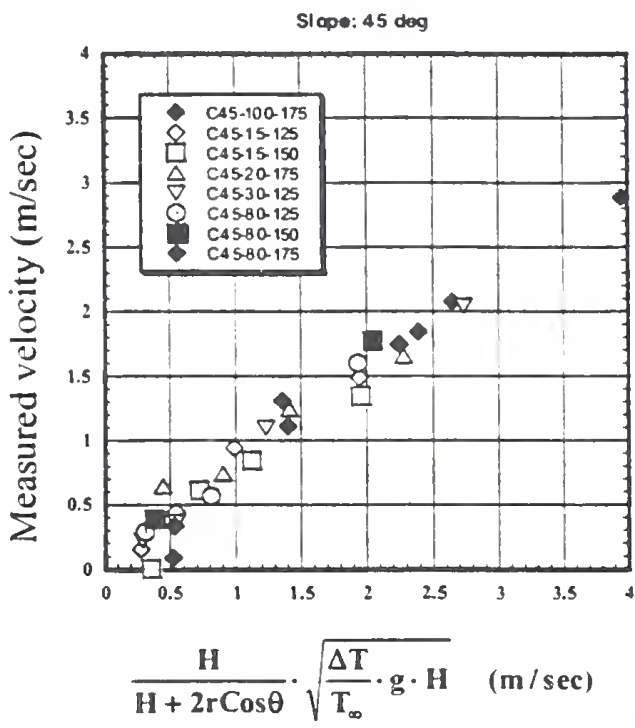

Figure 10 Correlation between measured velocity and temperature based velocity with location modification for slope angle of 45 deg.

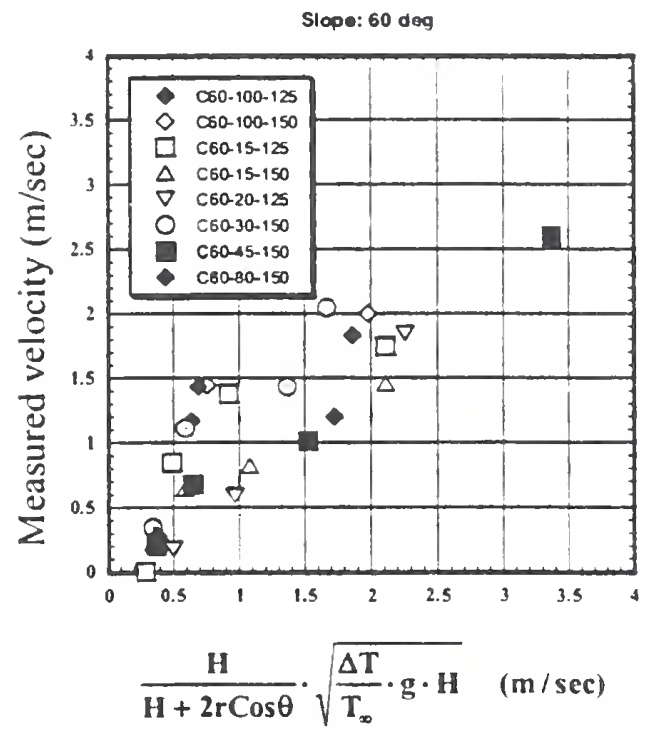

Figure 11 Correlation between measured velocity and temperature based velocity with location modification for slope angle of $60 \mathrm{deg}$. ing r, i.e., $H+r$.

Figure 7 shows clearly that McCaffrey's model [4] of $\Delta T$ decreasing mode along the trajectory pass length,

$$
\Delta \mathrm{T} \propto\left(\mathrm{z} / \mathrm{Q}^{2 / 5}\right)^{-5 / 3}
$$

is applicable not only for flame but also for ceiling jet. However, Figure 7.b shows that McCaffrey's model on upward velocity for flame and plume is not acceptable for velocity for ceiling jet. These two figures imply the necessity of correction on the location which evaulate the flow-pass length including height and pass along the ceiling considering slope of the ceiling. We adopt the term of $\mathbf{H} /(\mathrm{H}+2 \mathrm{r} \cos \theta)$ to evaluate the location for temperature based velocity of $\sqrt{\left(\Delta T / T_{\infty}\right) \cdot g \cdot H}$, as is shown in Figure 8. Plots obtained in the turning region, where high excess temperatures are measured but direction of the flow is not established yet, show some gap from an apparent line which is formed by the gathering of plots obtained in the ceiling region consecutive to turning region. Figure 9 shows the same correlation as shown in Figure 8 illustrating the correlation between measured velocity and temperature based velocity with location modification of $\mathrm{H} /(\mathrm{H}+2 \mathrm{r} \cos \theta)$ for 30 deg sloped ceiling.

Modification term, $\mathrm{H} /(\mathrm{H}+2 \mathrm{r} \cos \theta)$, on location considering the ceiling slope works well to establish the conservation of Froude number.

Taking the same manner to the correlation between measured flow velocity, $v$, and temperature based velocity of $(H /(H+2 r \cdot \operatorname{Cos} \theta)) \cdot \sqrt{\left(\Delta T / T_{0}\right) g H}$ for other sloped ceiling changing the ceiling height. Figures 10 and 11 are illustrated for the slope angles of $45 \mathrm{deg}$ and $60 \mathrm{deg}$, respectively. Both cases show also that the modification term on location including vertical height, $\mathrm{H}$, and sloped flow pass, $r$, along the ceiling surface gave quite good performance to evaluate the flow velocity from the temperature based velocity. Based on the Figures $8-11$, the measured flow velocity is modeled as

$$
v=\alpha \cdot \frac{H}{H+2 r \cdot \operatorname{Cos} \theta} \cdot \sqrt{\left(\Delta T / T_{x}\right) \cdot g \cdot H}
$$

where $\alpha \approx 3 / 4 \sim 7 / 8$, or Froude number is conserved along the trajectory in both regions of vertical flow (flame and plume) and ceiling jet flow independent of the slope angle. 


$$
\mathrm{Fr}=\frac{\mathrm{v} \cdot(\mathrm{H}+2 \mathrm{r} \cdot \operatorname{Cos} \theta)}{\sqrt{\frac{\Delta T}{T_{\infty}} \cdot g \cdot H^{5 / 2}}} \approx \text { const }=\frac{3}{4} \sim \frac{7}{8}
$$

As was shown in Figures 5.a and 7.a, and correlaration obtained and presented in eq. (3), we can estimate the excess temperature, $\Delta \mathrm{T} / \mathrm{T}_{\infty}$, along the trajectory based on heat release rate, $\boldsymbol{Q}$, ceiling height, $H$, slope angle, $\theta$, and flow pass, $r$, along the ceilings. These physical values gave the flow velocity along the ceiling

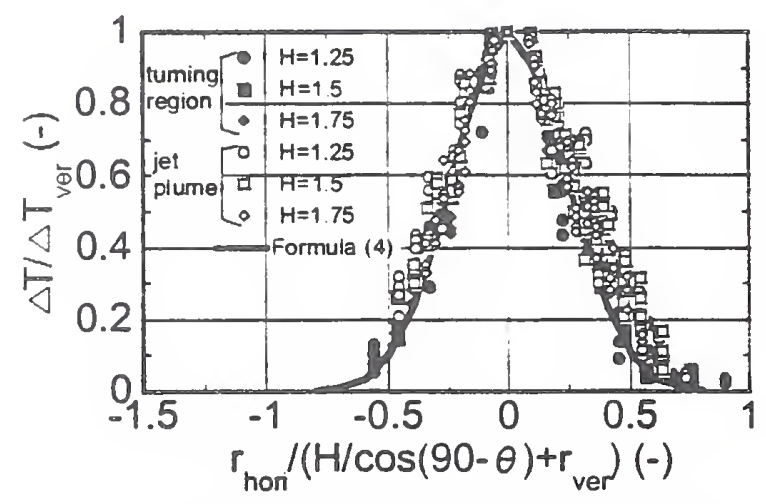

Figure 12.a Temperature Distribution in $X$ Direction (slope angle $=45$ ) $H=1.5 \mathrm{~m}, \mathrm{Q}=20 \mathrm{~kW}$

using eqn. (4) so that we can estimate the detection time of heat detector and also operating time of sprinkler head.

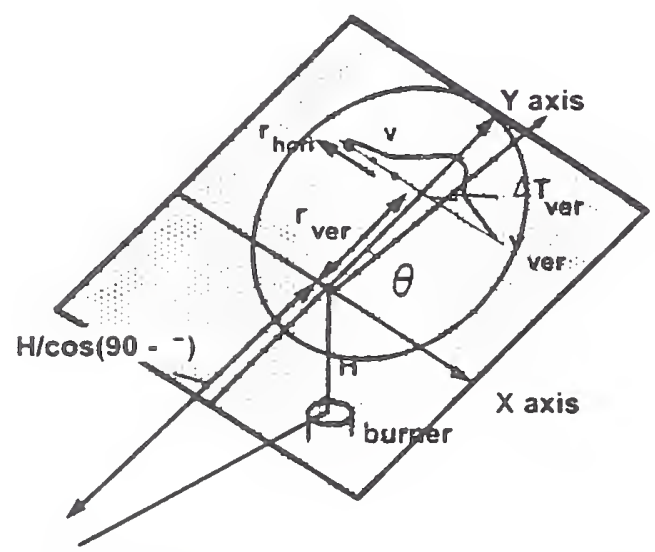

Figure 13 Layout of the coordinates for describe the distributions of excess temperature and flow velocity for perpendicular direction to upslope direction
3.6 Temperature and Flow Velocity for Perpendicular Direction -X Axis-

It is well known that upward gas flow velocity and excess temperature obtained in the plume region are simulated well by normal distributions (or Gaussian) respectively so that we could expected the same characteristic for the ceiling flow as it flows along the sloped ceiling surface. Figure 12.a shows the excess temperature distibution normalized by the maximum excess temperature which obtained along the trajectory of upslope direction ( $Y$-axis). Figure 12.b shows the flow ve-

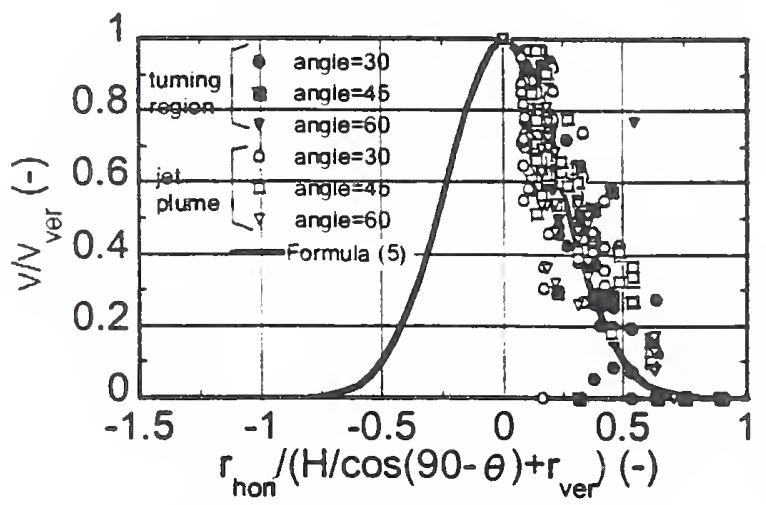

Figure 12.b Velocity Distribution in X Direction, $\mathrm{H}=1.5 \mathrm{~m}, \mathrm{Q}=20 \mathrm{~kW}$

locity distribution for perpendicular direction normalized by the maximum velocity obtained along the upslope trajectory ( $\mathrm{Y}$-axis). Both of these characteristics showed normal distributions as the original points is adopted as in Figure 13. followings:

$$
\begin{aligned}
& \frac{\Delta T}{\Delta T_{\text {ver }}}=\exp \left(-\eta^{2} \beta^{2}\right) \\
& \text { and } \\
& \frac{v}{v_{\text {ver }}}=\exp \left(-\eta^{2} \beta^{2}\right)
\end{aligned}
$$

where $\eta=r_{\text {bort }} /\left(H / \cos (90-\theta)+r_{\text {ver }}\right)$ and $\beta=3$

The temperature and velocity shown by equations (4) and (5) well simulated the experimental temperature and velocity.

\section{Conclusion}

Description model on excess temperature and velocity of the gas flow under the sloped ceiling were established considering the inclined angle. 
The combination of location modification term of $\mathrm{H} /(\mathrm{H}+2 \mathrm{r} \cos \theta)$ and temperature based flow velocity, $\sqrt{\left(\Delta T / T_{\infty}\right) \cdot g \cdot H}$, gave conservation of Froude number for ceiling jet except turning region independent of slope angle. This correlation is excellent tool to predict the response time of the fire detectors (heat detector) and operation time of sprinkler which are mounted on the ceiling with and without slope angle.

McCaffery's model on excess temperature is applicable not only for flame and plume regions (vertical flow part) but also for the ceiling jet flow independent of the slope. This implies that there is no necessary to change the models to estimate excess temperature along the trajectory, i.e. vertical flow part (flame, intermittent flame and plume) by McCaffery's model and ceiling jet (horizontal ceiling) by Alpert's model.

\section{Nomenclature}

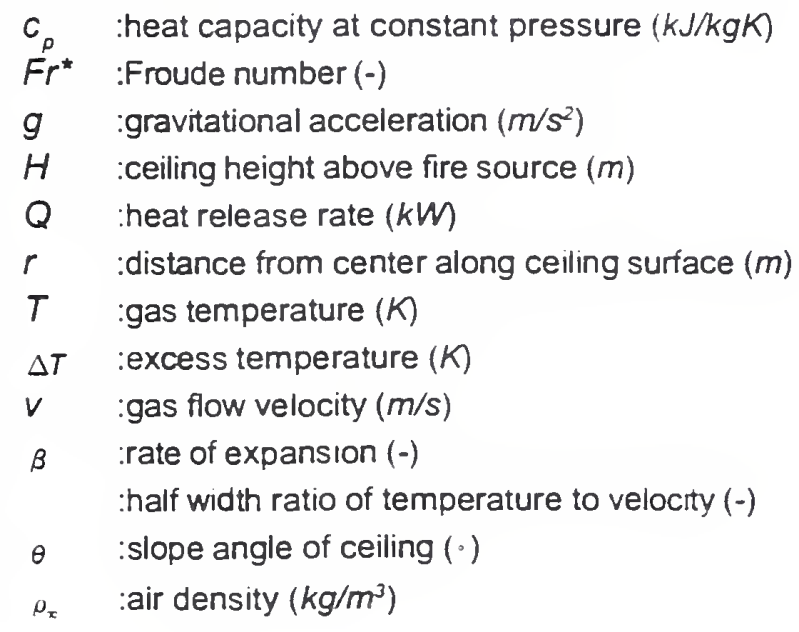

\section{Subscripts}

ver :along vertical axis ( $Y$-axis)

hori :along horizontal axis (X-axis)

- :ambient, outside ceiling jet or plume flows

Superscripts

:dimensionless quantity

\section{References}

[1] R.L.Alpert: Calculation of Response Time of Ceiling-Mounted Fire Detectors, Fire Technology, Vol.8,181-195,1972

[2] G. Heskestad and Michael A.Delichatsıos : The Ini tial Convertive Flow in Fire, 17th International Sym posium on Combustion, Combustion Institute, Pitts burgh (1978)

[3] David D.Evans :Ceiling Jet Flows, The SFPE Hanbook of FIRE PROTECTION ENGINEERING, Ver.1, 1963

[4] McCaffery B.J. :Purely Buoyant Diffusion Flames, NBSIR79-1910, 1979 


\title{
Integrating Fire Systems With Other Building Automation and Control Systems
}

\author{
Steven T. Bushby \\ National Institute of Standards and Technology \\ Building and Fire Research Laboratory \\ Gaithersburg, MD 20899
}

\begin{abstract}
There are many economic and operational reasons to integrate fire systems with other building automation systems. Integration of this kind requires communication standards and careful design practices. BACnet ${ }^{\mathrm{TM}}$ is an internationally recognized communication protocol standard specifically designed for integrating building automation and control systems. Thousands of BACnet systems can be found around the world and its popularity is growing. Newly proposed additions to BACnet make it very well suited for integrating fire systems with other building automation systems.

Even with communication standards there are other design issues that need to be addressed in order to assure the integrity of fire systems when they are integrated with other building systems. Best design practices, testing procedures and building codes need to be modernized to accommodate integrated building systems.
\end{abstract}

\section{INTRODUCTION}

The technology of building automation and control systems has advanced rapidly over the past fifteen years. Today's technology provides building owners and designers with a rich assortment of options and flexibility. State-of-the-art building automation and control systems are characterized by powerful personal computer workstations and intelligent distributed controllers that process complex algorithms quickly and efficiently. These advances have taken place across a variety of building services including heating, ventilating, and air conditioning (HVAC) control systems, lighting control systems, access control systems, and fire detection systems.

In spite of these advances, building owners have been frustrated by the inability to bid projects competitively and to integrate innovative products made by different manufacturers in ways that best suit the unique needs of their facility. The main obstacle has been incompatible proprietary communication protocols. The adoption of BACnet [1] as the standard communication protocol for integrating building control products has changed the industry and opened the door to new innovation in building control technology and true integration of previously isolated building systems.

In the United States, the National Electrical Manufacturer's Association (NEMA) Signaling, Protection, and Communication Section (3SB) has endorsed the use of BACnet as the preferred way to integrate fire systems with other building control systems. The National Fire Protection 
Association (NFPA) is in the process of revising Standard 72 [2] to address design issues related to integrating fire systems with other building systems. First generation BACnet fire system products are already available in the marketplace in the United States and in Europe. These are clear indications of interest in integrating fire systems with other building systems and in using the BACnet protocol as a means to accomplish that goal.

\section{A BACmet OVERVIEW}

BACnet is a standard communication protocol developed by the American Society of Heating Refrigerating, and Air-Conditioning Engineers (ASHRAE). It has been adopted as a pre-standard by the European Community [3,4] and has been proposed as an ISO standard. Today there are over 60 companies with registered BACnet vendor identifiers. These companies are located in North America, Europe, Asia, and Australia. Commercial BACnet product offerings range from gateways that connect proprietary systems, to complete product lines that use BACnet as the primary or sole means of communication. There are thousands of installed systems ranging in complexity from a single gateway to very large office buildings with top-to-bottom native BACnet systems, to campus or city wide systems linking multiple buildings. BACnet products include HVAC controls, lighting controls, and fire detection systems.

Fundamentally, BACnet, like any communication protocol, is a set of rules that provide a way to exchange information. BACnet was designed and optimized specifically to meet the needs of building automation and control applications and to convey the data needed by these applications including, but not limited to: hardware binary input and output values; hardware analog input and output values; software binary and analog values; schedule information; alarm and event information; files; and control logic. BACnet does not define the internal configuration, data structures, or control logic of the controllers.

BACnet is designed to be scalable from very small low-cost devices to very large complex systems that may involve thousands of devices and multiple buildings located anywhere in the world. It achieves this by combining an object oriented representation of the information to be exchanged, flexible choices for local area network (LAN) technology, an ability to interconnect local area networks, and an ability to use internet protocols (IP) protocols to link buildings over wide area networks. The structure of the BACnet protocol and its relationship to the Open Systems Interconnection (OSI) - Basic Reference Model [5] is shown in figure 1.

BACnet represents the information and functions of any device by defining collections of related information called "objects", each of which has a set of properties that further characterize it. For example, an analog input is represented by a BACnet Analog Input object that has a set of properties that include its present value, sensor type, location, alarm limits, and others. Some properties are required and others are optional. A device is represented by an appropriate collection of network visible objects. Once the information and functionality of a device has a common appearance on the network in terms of standard objects and properties, it is then possible to define messages that can be used to access and manipulate this information in a standard way. This combination of standard objects and standard messages to access and manipulate their properties make up the BACnet application layer. 
BACnet Layers

\begin{tabular}{|c|c|c|c|c|}
\hline \multicolumn{3}{|c|}{ BACnet Application Layer } \\
\hline \multicolumn{3}{|c|}{ BACnet Network Layer } \\
$\begin{array}{c}\text { ISO 8802-2 (IEEE 802.2) } \\
\text { Type 1 }\end{array}$ & MS/TP & PTP & \multirow{2}{*}{ LonTalk } \\
\cline { 1 - 1 } $\begin{array}{c}\text { ISO 8802-3 } \\
\text { (IEEE 802.3) }\end{array}$ & ARCNET & EIA - 485 & EIA - 232 & \\
\hline
\end{tabular}

Equivalent

OSI Layers

\begin{tabular}{|l|}
\hline Application \\
\hline Network \\
\hline Data Link \\
\hline Physical \\
\hline
\end{tabular}

Figure 1. BACnet Protocol Architecture

Once the information to be exchanged and message structures are defined, it is necessary to provide a way to transfer the information from one place to another. BACnet provides a choice of five LAN technologies to meet this need. Several choices are provided because different building control applications have different cost and performance constraints that must be met. A single network technology cannot meet the needs of all applications. A LAN is defined by a combination of the Data Link and Physical layers of the OSI model. The LAN options available in BACnet are shown in figure 1 .

The first option is ISO 8802-3, better known as "Ethernet". It is the fastest option and is typically used to connect workstations and high-end field devices. The second option is ARCNET which comes in modestly high speeds or in slower, lower cost versions. BACnet defines the MS/TP (master-slave/token-passing) network designed to run over twisted pair wiring. Echelon's proprietary LonTalk network can also be used. The Ethernet, ARCNET and LonTalk options all support a variety of physical media. BACnet also defines a dial-up or "point-to-point" protocol called PTP for use over phone lines or hardwired EIA-232 connections.

A key point is that BACnet messages are the same no matter which LAN is used. This makes it possible to easily combine LAN technologies into a single system. The purpose of the network layer is to provide a way to make such interconnections. It is common in large systems to combine high speed (and high cost) networks with lower speed (and lower cost) networks in a single system. Such a system is shown in figure 2. Figure 2 also illustrates that BACnet has wide area networking capability that is implemented using IP.

\footnotetext{
${ }^{1}$ Certain trade names and company products are mentioned in the text in order to specify adequately the equipment used. In no case does such an identification imply recommendation or endorsement by the National Institute of Standards and Technology, nor does it imply that the products are necessarily the best for the purpose.
} 


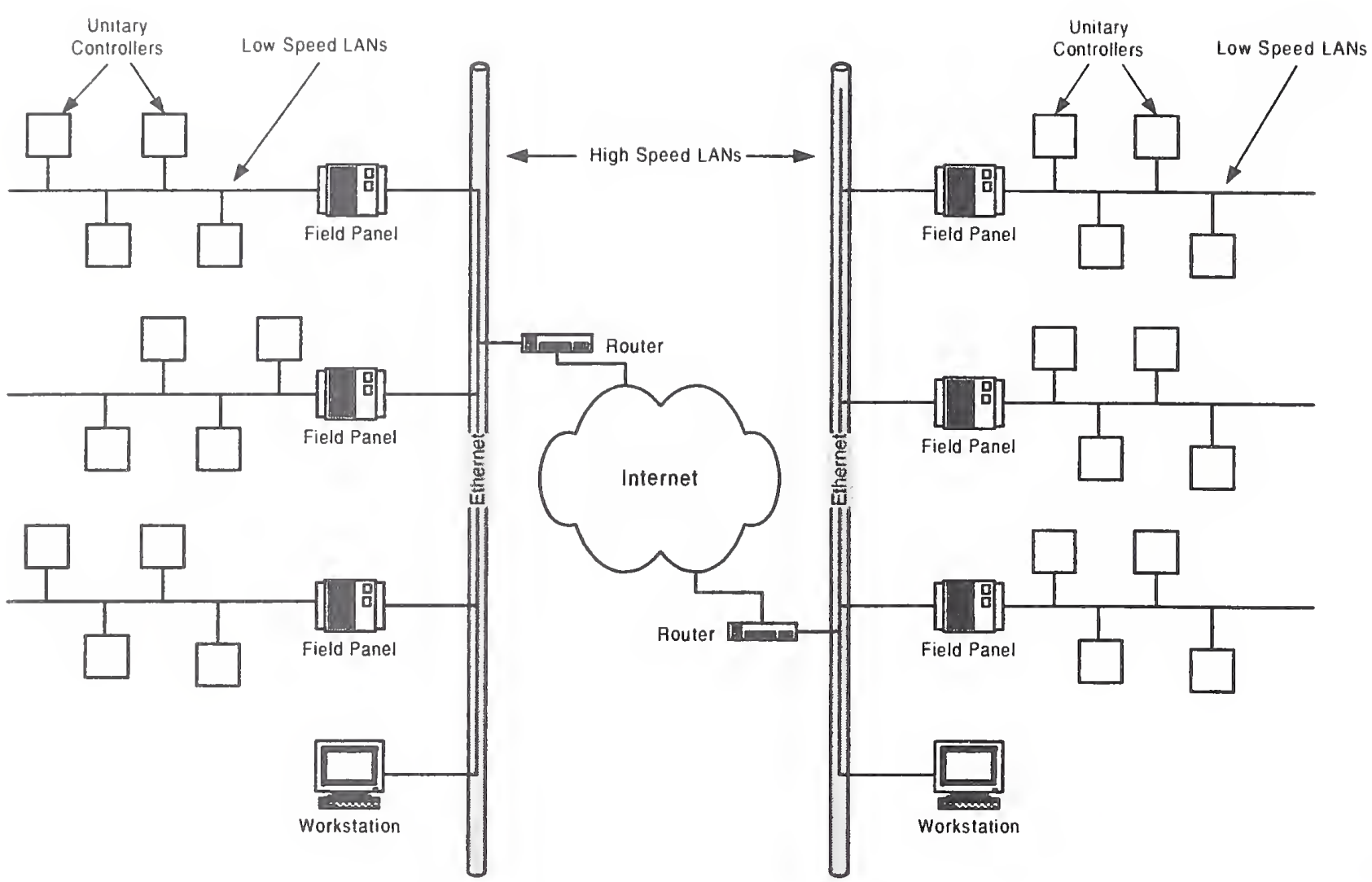

Figure 2. A Hierarchical Building Control System Structure

In principle, BACnet messages can be transported by any network technology. This means that technologies that have not even been invented yet can be used in the future to convey BACnet messages and they can be integrated into today's systems in the same way that multiple existing network technologies can be combined today. This lack of dependence on today's technology is a very important feature of BACnet.

The object-oriented structure also provides a way to add new application functionality to BACnet by defining new objects and/or new application services. This is being done to add functionality needed for fire systems. Two new BACnet objects, Life Safety Device, and Life Safety Zone have been developed. The Life Safety Device object represents the features of an individual detection or enunciation device. The Life Safety Zone object represents the status of a collection or "zone" of life safety devices. When these objects detect an alarm, the alarm status latches until a reset command is executed. A new application service has also been developed that provides a way to reset latched alarms and to silence enunciating devices. All of these additions were developed with assistance from the fire industry and have been approved by the BACnet committee. They are currently undergoing a public review process and are expected to be approved as part of the BACnet standard [6]. 
More detailed information about BACnet concepts and structure may be found elsewhere [7]. There is also tutorial information and an extensive bibliography available on a web page maintained by the BACnet committee (www. BACnet.org).

\section{WHY INTEGRATE FIRE SYSTEMS WITH OTHER BUILDING SYSTEMS?}

There are many reasons for integrating fire systems with other building automation and control systems. Examples include smoke control, single seat access to building information, easier maintenance, sharing sensor data, obtaining information about the location of people during an emergency, and providing infrastructure for new technology to improve performance and safety.

Fire detection systems have been integrated with door locks and with HVAC fan and damper controls for smoke management for several years but these systems have relied on relays controlled by the fire system to override the normal controls. This kind of integration has primarily involved constant volume HVAC systems and required only on/off control of fans and dampers to be moved to fully open or fully closed positions.

Many modern HVAC systems are far more complex. Variable air volume systems are used to reduce energy consumption. These systems require sophisticated control algorithms to operate either a continuously variable speed fan or inlet guide vanes to control the static pressure in the supply air duct. Variable air volume boxes control the airflow from the supply duct into individual rooms by modulating dampers. The control algorithms for these systems are complicated and require interlocks and safeties to prevent over stressing ductwork in the event that dampers do not open when fans are turned on. Smoke management is much more complicated with these systems and outside of the capability of most fire systems. What is needed is a way for the fire system to command the HVAC control system to enter a smoke control mode and let the HVAC controllers manage the equipment.

New sensors are being developed that can recognize various contaminants in the air that can represent a fire signature or a hazardous contaminant that poses a life safety threat. In an integrated system these sensors could be used by the HVAC control system to control ventilation rates with no adverse impact on their life safety functions. Multiple uses for the same information will make it more cost effective to implement new sensor technology.

In some buildings access control systems monitor the location of building occupants. Providing access to this information to the life safety systems could be very helpful in an emergency. Emergency response personnel would know where to look for occupants who need to be evacuated. They could also reduce the risk to themselves by avoiding dangerous areas where no people are present.

Research is now underway at the National Institute of Standards and Technology (NIST) to develop a new generation of smart fire panels that can make use of sensor data from an integrated system to calculate heat release rates in a fire. Using this information, a fire model in the panel can predict how the fire will grow and spread. These predictions can be used by emergency response personnel to plan a strategy for fighting the fire. It could even be transmitted 
by the building systems to fire stations or fire trucks so that planning can begin before emergency personnel reach the site. This could significantly improve response time, saving lives and reducing property loss.

For all of these reasons and probably others, integrating fire systems with other building systems makes a lot of sense. The technology is already being driven in that direction by market forces.

\section{INTEGRATION ISSUES THAT NEED TO BE ADDRESSED}

There are several important integration issues that need to be addressed if these potential benefits are to be realized. The primary concerns are ensuring the integrity of fire systems in emergencies and isolating them from interference caused by failures of other building systems, meeting building code and Underwriters Laboratory (UL) listing requirements, and regulating and tracking human responses to alarms and trouble conditions.

Maintaining the integrity of the fire system and protecting it from failures in other building systems is primarily a matter of system design practice. Today this is being handled by using a gateway to isolate the fire system from outside interference. All of the components of the fire system reside on one side of the gateway and communicate using proprietary protocols in the same way that they did before BACnet. The BACnet gateway provides a way for other building systems to get information from the fire system but protects the fire system from interference from outside. This provides the necessary protection but it also limits the integration possibilities.

An alternative approach is to develop best design practices for constructing networks of integrated systems. By appropriate selection of network technology and appropriate use of routers and bridges to filter traffic, interference problems and concerns about guaranteed access to network bandwidth in an emergency can be effectively eliminated. Business network systems commonly use these techniques today and there is no reason why they cannot be applied to building automation systems.

Having fire systems tested by UL and listed for their intended purpose is an expensive and timeconsuming practice. It is unrealistic to expect manufacturers of other building automation devices to absorb this expense when their products are not directly involved in detecting or responding to a fire just because they can communicate with listed fire devices. The testing and listing procedures need to be updated to recognize this reality. By combining good design practices with tests that ensure the integrity of the fire system under conditions that can occur assuming that the design practices are followed, safety concerns can be satisfied without sacrificing the benefits of integration. In some locations building codes may need to be modified so that they are based on performance criteria instead of prescriptive requirements.

In fire systems it is very important to ensure that only authorized personnel can silence alarms, reset alarms, and perform other operations that significantly affect the performance or status of the fire system. Traditionally this has been done by having dedicated fire system workstations that provide the operator with capabilities that are assigned when the operator logs in. In an 
integrated system there may be many workstations that have the ability to send messages that are important in this regard. Fire panels need to be protected from accidental or intentional disruption from other devices or workstations in the building. BACnet provides mechanisms for authenticating messages but they are not widely implemented. This is another design issue that needs to be addressed.

\section{INTERNATIONAL STANDARDS ACTIVITIES}

It was previously mentioned that BACnet has been adopted as a standard in the United States and as a pre-standard in the European Community. The International Organization for Standardization (ISO) Technical Committee 205 is deliberating the adoption of BACnet as a world standard. This is being done as part of the activities of Working Group 3, Building Control System Design. The participants in this activity include representatives from the United States, Europe, Japan, and Australia. BACnet is now at the working draft stage and is expected to advance to the committee draft stage soon. The ISO activities are being coordinated with the ongoing maintenance of BACnet in the United States. The intention is to incorporate into the U.S. standard any additional features needed to obtain international acceptance of the protocol. It is also expected that any additions that come from the continuous maintenance process in the U.S. will be incorporated into the ISO standard. An effort is being made to coordinate BACnet testing and certification programs in Europe and the U.S. There is a strong international consensus that it is in everyone's interest to be able to freely market BACnet products anywhere in the world. A common standard and reciprocal certification recognition are critical if this is to happen.

\section{SUMMARY}

There are a variety of important reasons for integrating fire systems with other building automation systems. These include smoke control, single seat access to building information, easier maintenance, sharing sensor data, obtaining information about the location of people during an emergency, and providing infrastructure for new technology to improve performance and safety. A standard communication protocol is a critical infrastructure component to make this integration possible. BACnet is such a protocol and it is gaining popularity around the world.

Even with communication standards there are other issues that need attention. Systems must be designed and maintained in ways that will assure the integrity of the fire system even when other components of the building automation system fail. It is also necessary to design the system so that bandwidth is available to the fire system when an emergency arises. Best practice design guidelines can meet these needs. UL testing and listing procedures need to be updated to address open integrated systems. In some cases building codes may need to be revised to performancebased approaches.

Market forces are already pulling the industry in the direction of integrated systems. As new technology is developed that adds capabilities because of the integration, the pressure to integrate systems will grow. The end result will be buildings that are easier to operate and are safer for the occupants. 


\section{REFERENCES}

1. ANSUASHRAE Standard 135-1995: BACnet - A Data communication Protocol for Building Automation and Control Networks. American Society of Heating Refrigerating, and AirConditioning Engineers, Inc. 1793 Tullie Circle N.E., Atlanta, Georgia 30329-2305.

2. ANSI/NFPA Standard 72-1999: National Fire Alarm Code. National Fire Protection Association 1 Batterymarch Park, Quincy, Massachusetts 02269-9101.

3. ENV 1805-1: European Committee for Standardization.

4. ENV 13321: European Committee for Standardization.

5. ISO 7498, Information Processing Systems - Open Systems Interconnection - Basic Reference Model, International Organization for Standardization, 1984.

6. Addendum $\mathrm{c}$ to ASHRAE Standard 135, First Public Review Draft, 2000. American Society of Heating, Refrigerating, and Air-Conditioning Engineers, Inc. Atlanta, Georgia 303292305.

7. Bushby, S. T., "BACnet ${ }^{\mathrm{TM}}$ : a standard communication infrastructure for intelligent buildings," Automation in Construction 6 (1997). Elsevier, pp. 529-540. 


\title{
MULTI-FUNCTION SENSING FOR CYBERNETIC BUILDING SYSTEMS
}

\author{
William L. Grosshandler \\ National Institute of Standards and Technology \\ Building and Fire Research Laboratory \\ Gaithersburg, MD 20899 U.S.A.
}

\section{INTRODUCTION}

Building control companies, equipment and system manufacturers, energy providers, utilities, and design engineers are under increasing pressure to improve performance and reduce costs by developing building systems that integrate more services, including energy management, fire and security, environmental control and people movement. How these systems communicate, interact, share information, make decisions, and perform in a synergistic and reliable manner is the subject of a large effort at the National Institute of Standards and Technology (NIST) in Cybernetic Building Systems (CBS). A portion of the research is focused on (1) the relationship between the signals from commercially available gas, particle and temperature sensors and the actual thermodynamic state of the room, (2) development of open protocols for the exchange of information among different sensors and building systems, and (3) aiding the fire brigade's attack strategy by effectively displaying the status of a fire on a smart panel capable of suggesting how the fire may evolve. This paper describes recent progress on the first topic (environment sensing), and introduces the third (the smart fire panel). A companion paper by Bushby ${ }^{15}$ at this 15th United States/Japan Natural Resources (UJNR) Panel on Fire Research Safety deals with topic (2), information exchange.

\section{BUILDING ENVIRONMENT SENSING}

The objective of this effort is to permit fire and indoor air quality (IAQ) sensor designers to demonstrate the feasibility of new concepts, to provide the critical link between sensor input and output required for meaningful numerical simulations, and to improve the reliability and performance of fire detection and IAQ control systems. Increasing the number of sensors in a detector is one way to improve system flexibility, provide earlier warning, provide redundancy, and enhance discrimination of nuisance sources ${ }^{1-4}$. Multiple criteria algorithms that consider combinations of threshold values, rate of rise of signals, and statistical characteristics of signals recently have been employed and have begun to appear in commercial products. Typically, these detectors are certified ("listed") via the standard test protocols developed for single-sensor detectors which include full-scale room fire tests in EN 54 part $9^{5}$, and UL $268^{6}$. The enhanced benefits of multi-sensor, multi-criteria detectors over single-sensor detectors are not completely established by such tests. (Little work has been done even to define the applications of IAQ sensing or to the manner in which IAQ sensing should be combined with fire sensing.) A multisensor, multi-criteria fire detector may meet the detection time limits for most or all test fires in EN 54 part 9, implying that such a detector is appropriate for various applications. However, the detector could utilize complex and proprietary algorithms that would make estimation of detector performance in other scenarios difficult. In addition, individual sensor response to nuisance sources combined with algorithm processing may enhance or degrade false alarm susceptibility. 
The fire emulator/detector evaluator $(\mathrm{FE} / \mathrm{DE})^{7}$ is being developed at NIST to address issues concerning multi-sensor, multi-criteria detectors and combination IAQ/fire sensors. The FE/DE, shown schematically in Fig. 1, provides a controlled environment where sensors can be exposed to fire signatures, indoor air pollutants, and nuisance sources. Increasing temperature, changing velocity, and varying particulate and chemical species concentrations at the detector location are some of the variables controlled. The device has been used to evaluate the smoke entry lag effects of detectors at low to moderate flows ${ }^{8}$. Analog output detectors (detectors that can provide a continuous output signal to a computer) were exposed to square wave changes in smoke concentration at various fixed velocities and fixed ambient temperature. A two parameter model was developed to capture the time lag which was observed to be substantial at low flow velocities $(<0.05 \mathrm{~m} / \mathrm{s})$. The exposure of sensors to nuisance aerosol exposures is also underway ${ }^{9}$.

Environmental signatures at the sensor location to be emulated in the FE/DE can come from fullscale experiments or numerical simulations of the smoke, gas, and heat transport from a fire or other source. Cleary et al. ${ }^{10}$ varied the velocity, temperature, and smoke concentration over time in the FE/DE to demonstrate that a test fire exposure can be emulated in a repeatable manner, and that a multi-sensor, multi-criteria detector's response can be evaluated. Examples of their results are reproduced here.

Test fire number four (TF 4) from EN54 part 9 is a polyurethane foam fire consisting of three mats ( $50 \mathrm{~cm}$ by $50 \mathrm{~cm}$ by $2 \mathrm{~cm}$ thick stacked on top of one another) that exhibits a peak heat release rate of approximately $50 \mathrm{~kW}$ and produces a large amount of smoke ${ }^{11}$. While smoke and temperature values at a standard detector location have been reported in the literature, velocity measurements are not available ${ }^{11,12}$. To overcome this deficiency, computational fluid dynamics calculations of the fire were conducted to predict the velocity profile at the detector location, as well as the time-varying temperature ${ }^{10}$. Figure 2 shows the simulated velocity profile and the duct velocity in the FE/DE. (In order to maintain an increasing smoke concentration, the peak duct velocity was intentionally reduced in order to lower the smoke dilution factor.) Also shown in Fig. 2 is the simulated temperature profile, the full-scale room measurement, and the profile reproduced in the FE/DE. Near the end of the test, the full-scale room temperature starts to fall as the fire dies out, whereas the temperature profile reproduced in the FE/DE does not fall because of the slow cool down of the heating elements.

The FE/DE light extinction measurements ${ }^{10}$ were found to be almost a factor of two lower than values produced in full-scale room tests. This discrepancy was attributed partially to the different light sources used. (Dobbins et al. ${ }^{13}$ reported specific extinction measurements of crude oil pool fire smoke to be $7.8 \mathrm{~m}^{2} / \mathrm{g}$ for light at $630 \mathrm{~nm}$, the wavelength of the extinction measurement in the FE/DE, and $5.1 \mathrm{~m}^{2} / \mathrm{g}$ at a wavelength of $1000 \mathrm{~nm}$, close to the wavelength used in the EN54 test) In addition, the FE/DE optical density is limited by the smoke produced in the propene burner. A redesign of the burner damper controls is planned to permit higher smoke concentrations at the test section.

The multi-sensor detectors used in the study were commercially available units that contained individual photo-electric light scattering, ionization, and heat sensors. The output for each sensor was transmitted at about $2 \mathrm{~s}$ intervals. The particle sensors were found to be linear 


\section{Exhaust}
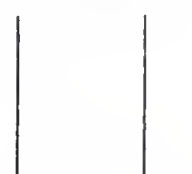

\section{Honeycomb}

Test Section Flow Straightener
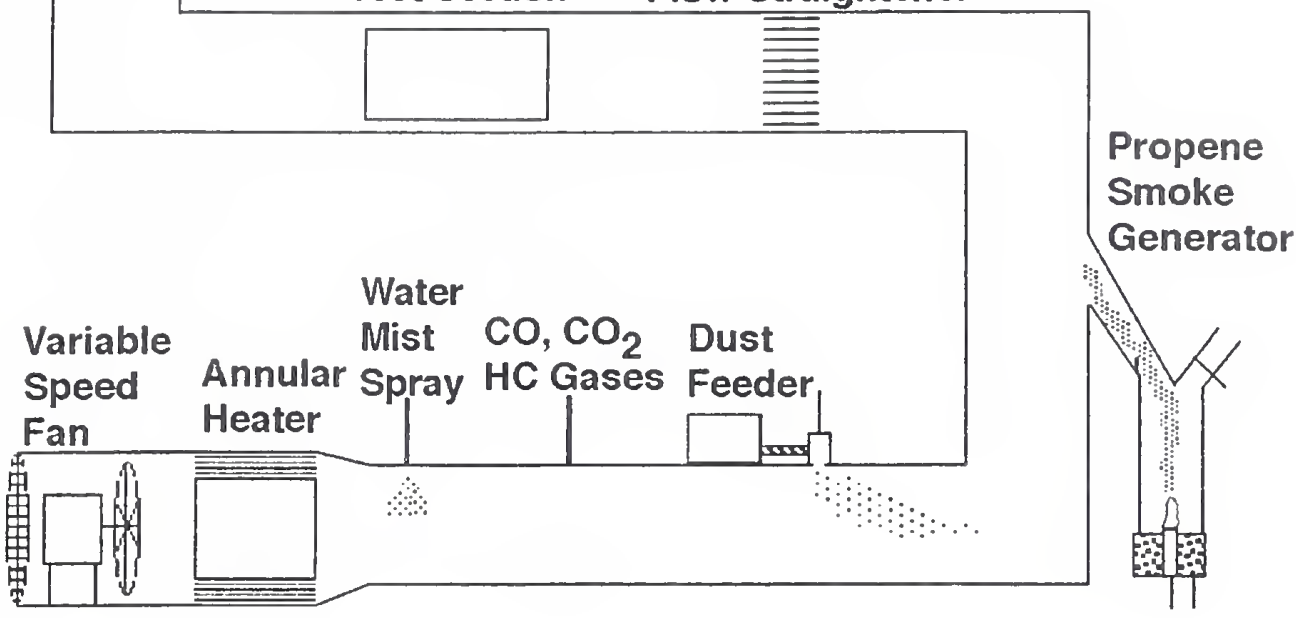

Figure 1. Schematic of the Fire Emulator/Detector Evaluator (FE/DE).
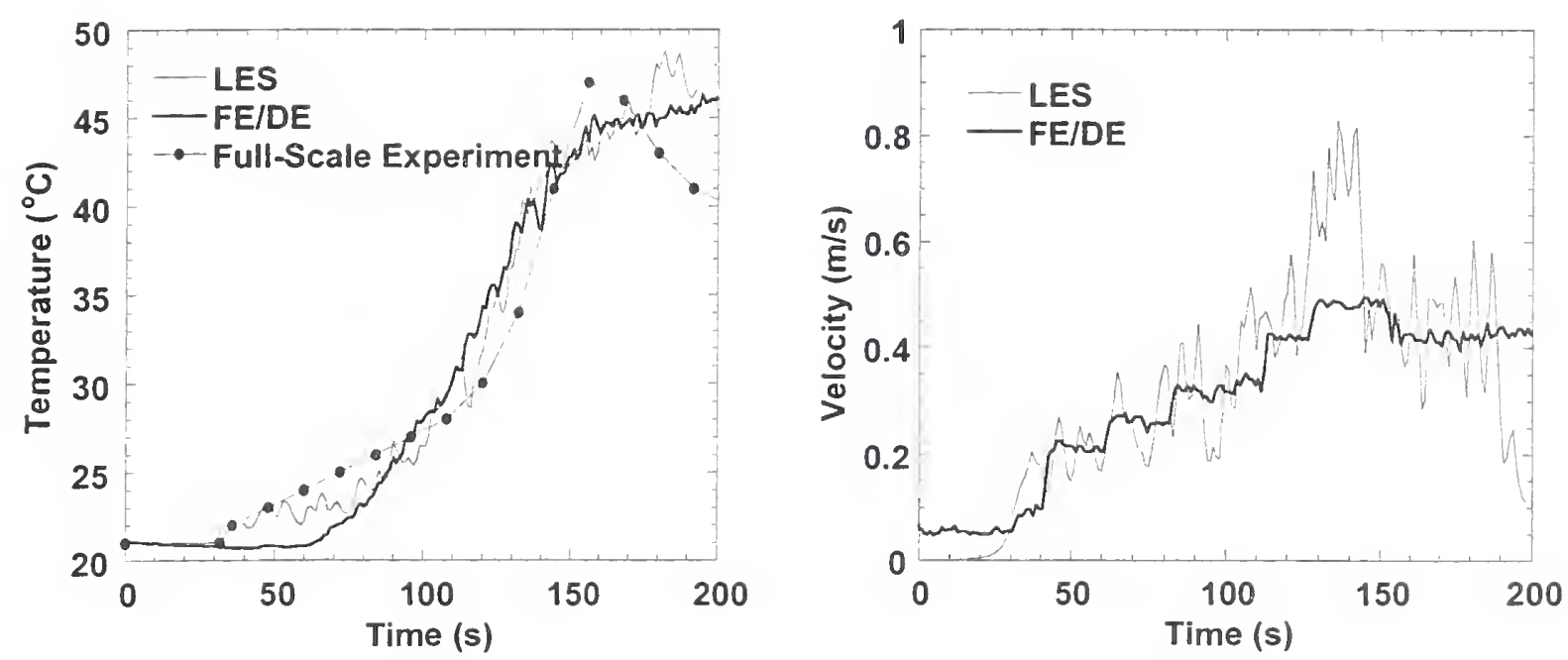

Figure 2. Temperature and velocity profiles; FE/DE compared to large-eddy simulation (LES) and full-scale room test (temperature only). See reference 10 for discussion of uncertainty. 
functions of optical density for smoke produced by the propene burner, while the heat sensor output was proportional to the temperature in the test section.

Figures 3 shows the detector output along with the extinction and temperature values recorded at the test section plotted vs. time for a typical test. The photo-electric and ionization sensor outputs closely follow the optical density measured outside the detector. In this scenario the velocity profile quickly rises to over $0.2 \mathrm{~m} / \mathrm{s}$ where little smoke entry time lag is expected. The output of the photo-electric sensor and the ionization sensor are similar in shape and magnitude. There is a noticeable time lag associated with the thermistor used as the heat sensor compared to the thermocouple measurement, indicating a significant difference in thermal inertia between the two devices.

The left plot in Fig. 4 shows the test section temperature versus time for each of six experiments, T1-T6. Satisfactory repeatability is indicated by the narrow spread among the curves. The optical density (a 15 point running average was used to smooth the curves) is shown at the right of Fig. 4. Some run-to-run variation in the optical density should be reduced by the new smoke control strategy.

The detector used in this study employed a proprietary algorithm to combine the signals from the individual sensors with an alarm threshold based on multiple criteria. The time-to-alarm for the six different tests is indicated in Fig. 4. The values ranged from $165 \mathrm{~s}$ to $181 \mathrm{~s}$, a window of time narrow enough to discriminate between the performance of different designs.

\section{INVERSE FIRE MODEL AND DEVELOPMENT OF A SMART FIRE PANEL}

Fire fighting in large structures such as apartment, office, and commercial buildings is complicated by lack of information about fire fighters inside the building and the extent of the fire within the structure. Most buildings of this type have installed fire detection systems that supply limited information from fire detectors in the building to a fire alarm panel generally located in the lobby of the building and to a fire command center -- a room from which fire department operations in the building can be controlled. The information available today and likely to be available in the near future in new buildings with advanced sensors can be used to improve the fire service response and improve the safety of the fire fighting effort.

In cooperation with fire service organizations, major fire departments and the fire alarm industry, NIST is examining the capabilities to display and use information available today in buildings. Through virtual demonstrations NIST will provide insight into the capabilities that could be developed and widely disseminated through a new standard interface. In part through continued focus group interactions with the fire fighters and their organizations, a plan will be developed for the technology needed to make fire system and building information as useful as possible for efficient and safe fire fighter operations.

In addition to evaluating new sensors and detection systems in the FE/DE as described above, a means to interpret data from multiple sensors over time is required. The objective is to identify 


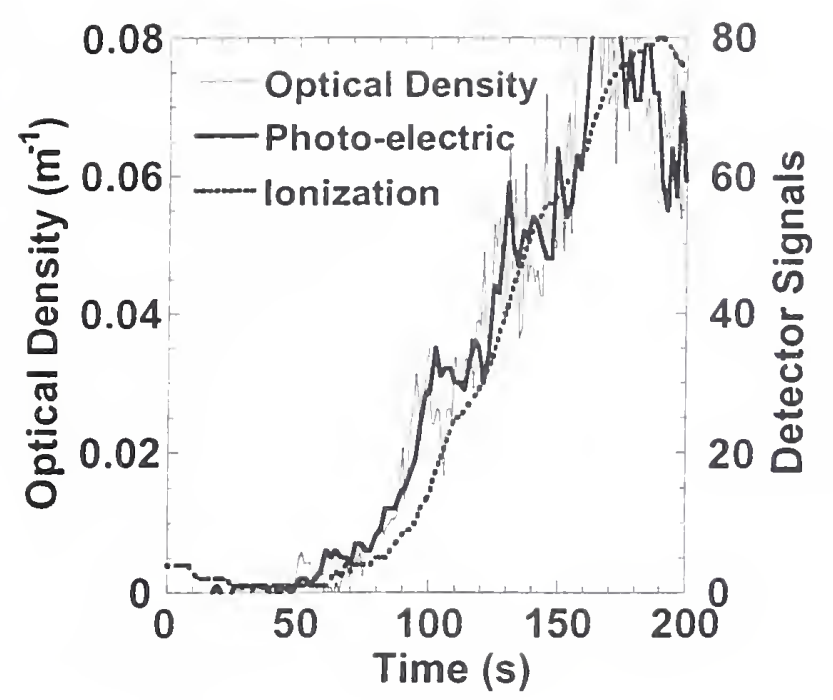

(a)

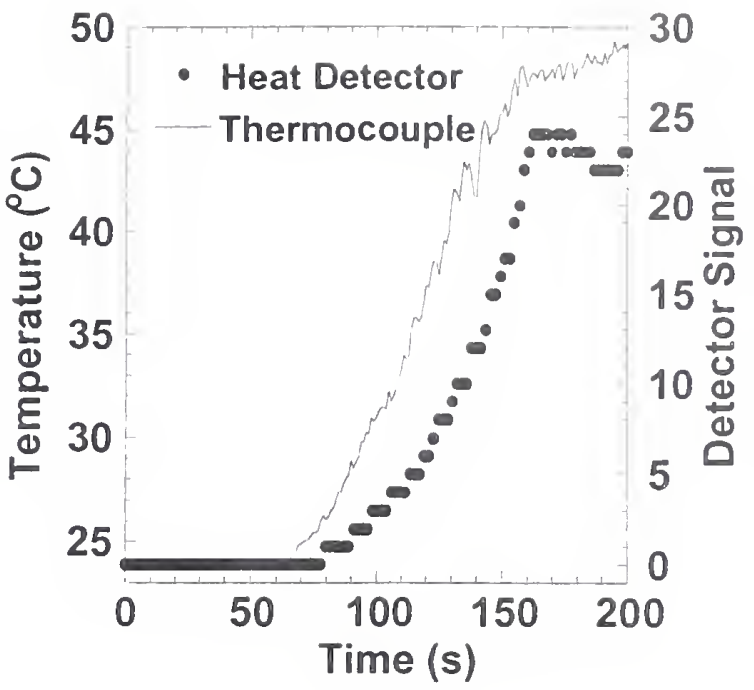

(b)

Figure 3. Detector response to emulated TF 4 conditions. See reference 10 for discussion of uncertainty.
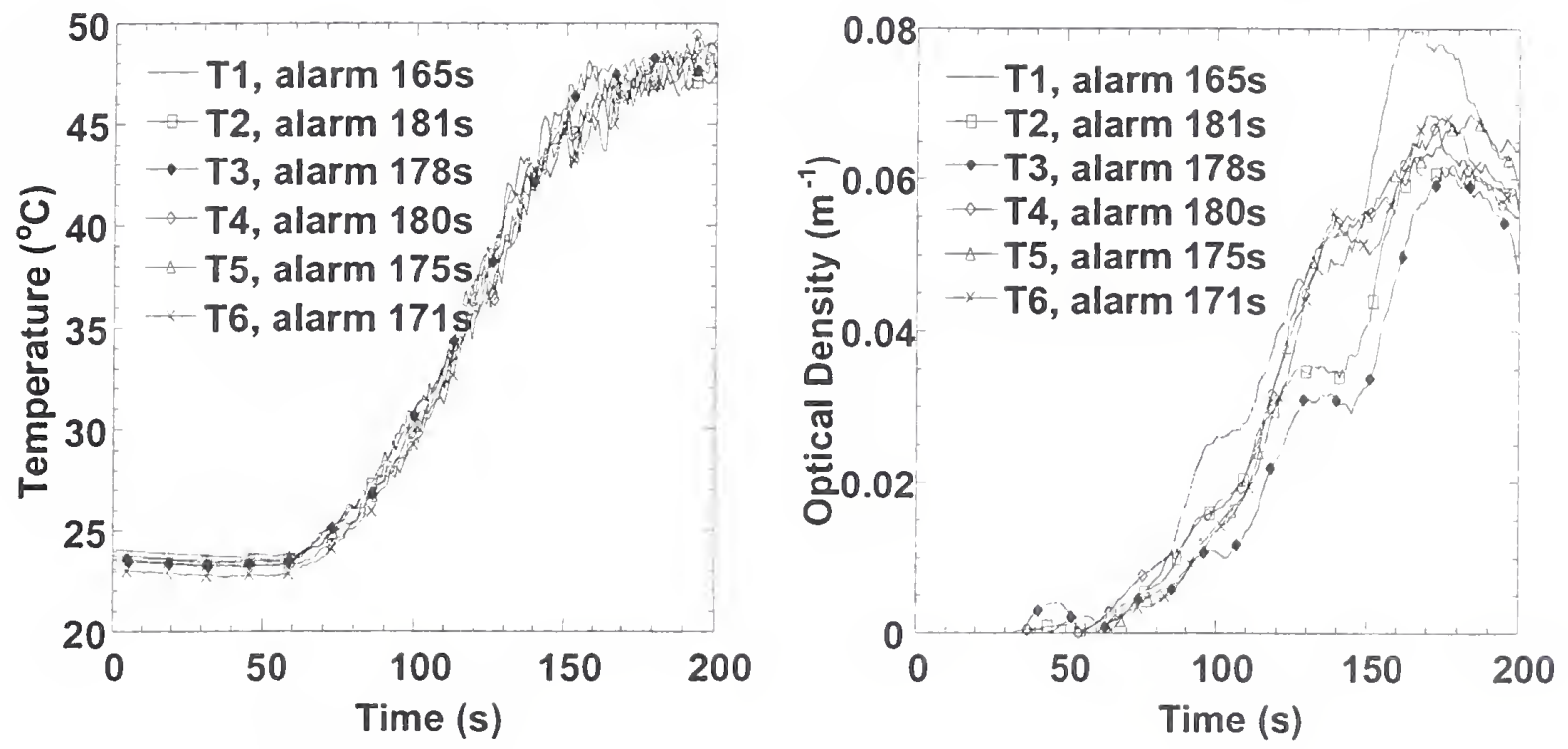

Figure 4. Smoothed temperature and optical density data vs. time using FE/DE; six duplicate tests. Range of times to alarm is from $165 \mathrm{~s}$ to $181 \mathrm{~s}$. See reference 10 for discussion of uncertainty. 
if a fire is present in the building or not, and if present, where it is located, how fast it is growing, and which regions of the building are likely to be hazardous to the occupants or fire fighters. An inverse fire model is being developed at NIST for this purpose. Version 1 of the model will use the output from smoke and heat detectors (or a data file simulating detector signals) to determine the heat release rate, and the temperature and depth of the smoke layer in each affected room as a function of time. A second version is envisioned that will include additional fire and detection system phenomena such as signals from $\mathrm{CO} / \mathrm{CO}_{2}$ sensors, heat and smoke transport through the building ventilation system, prediction of flashover, window breakage, wall failure, ceiling jets in other rooms, etc. The decision concerning which of the additional fire phenomena to include will be based on the impact that the inclusion of each fire phenomena will have on hazard analysis and the experimental basis available for model testing. The model will be tested in part using the Virtual Cybernetic Building Testbed (VCBT). The VCBT is a computer simulated building environment that includes ventilation systems, fire panels, and heating/cooling systems to mimic the operation of an actual building.

Many fire departments report that they seldom use features that are provided by the current generation of fire panels because of the multitude of system interfaces that exist. Displays and controls are not consistent and there is no time to study the manuals. NIST, through a cooperative research project with the National Electrical Manufacturer's Association and major alarm panel manufacturers, is developing the technical basis for establishing a standard interface. $^{14}$

The first step is to determine the information needs of the fire service. In a series of meetings, participants were asked what they want to know, when do they need to know it, and how do they want the information presented. The answers were categorized by needs at dispatch, upon arrival at the scene, and during the incident. The information on functions and system components would be displayed via icons, standardized in the National Fire Alarm Code (NFPA 72), but with the freedom to use graphical displays over hard buttons, labels on hard buttons with lights, or on touch screens. The initial set of icons proposed is based upon current practice and NFPA 170. The icons need to represent three states: if the function is present, present and not active, present and active. Caution was suggested regarding the use of color for these states with the knowledge that some fire fighters are colorblind.

A prototype panel is being assembled to capture the ideas discussed at these meetings. It will incorporate features and arrangements that would be part of any proposed standard and demonstrate optional approaches. An example display is shown in Fig. 5. Two other windows can be addressed which display a plan view of the floor of origin and a building elevation view.

Information available for display at the incident will depend upon the type and extent of fire protection system installed, and the sophistication of the building control systems. A new fire panel designed using the guidance provided by this research effort should be useful for older zoned systems as well as for more modern point addressable devices, and adaptable to exploit whatever new building controls and sensors are on the horizon. Eventually it is anticipated that inverse fire models will be able to digest this abundance of data and make highly reliable assessments of the building conditions and fire fighting options. 


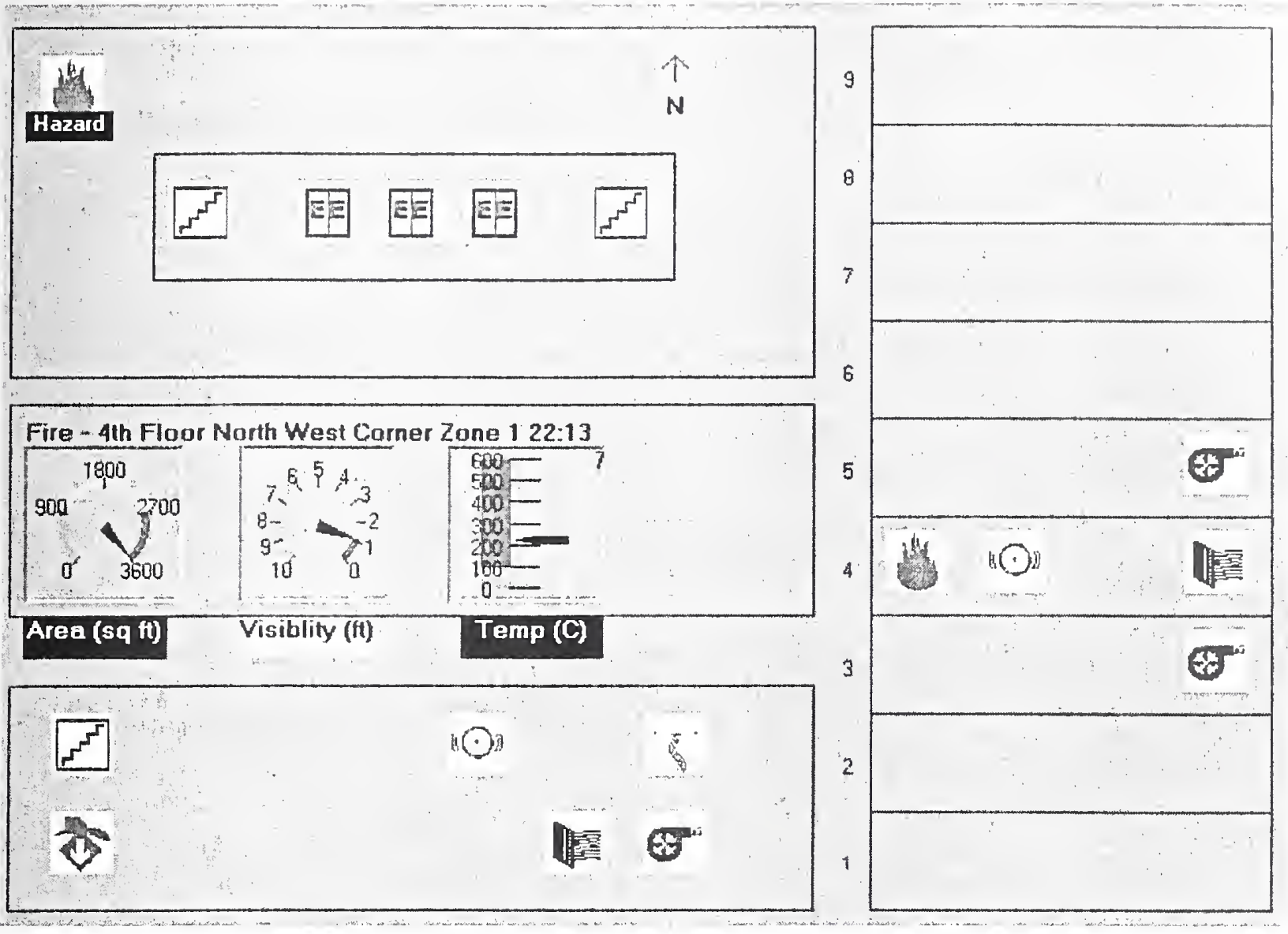

Figure 5. Prototype of a standard fire service interface in a nine story building. Refer to Bukowski ${ }^{14}$ for a definition of symbols.

\section{ACKNOWLEDGEMENTS}

Some of the material in this paper is taken verbatim from articles by Cleary et al. ${ }^{10}$ and Bukowski $^{14}$, and from BFRL project descriptions by George Kelly and William Davis. These authors' permission to reproduce those portions is gratefully acknowledged.

\section{REFERENCES}

1. Heskestad, G., and Newman, J. S., Fire Detection Using Cross-Correlations of Sensor Signals," Fire Safety Journal, Vol. 18, No. 4, 355-374, 1992.

2. Milke, J.A., and McAvoy, T.J., "Analysis of Signature Patterns for Discriminating fire Detection With Multiple Sensors," Fire Tech., Vol 31, No.2, May/June, 1995.

3. Pfister, G., "Multisensor/Multicriteria Fire Detection: A New Trend Rapidly Becomes State of the Art," Fire Tech., Vol. 33, No. 2, May/June, 1997. 
4. Gottuk, D.T., Peatross, M.J., Roby, R.J., and Beyler, C.L., "Advanced Fire Detection Using Multi-signature Alarm Algorithms," International Conference on Automatic Fire Detection "AUBE '99", 11th, March 16-18, 1999, Gerhard Mercator University, Duisburg, Germany, Luck, H., Editor, pp. 237-246, 1999.

5. EN 54: Components of Automatic Fire Detection Systems, European Committee for Standardization, Part 9, 10 p., July 1982.

6. UL 268, "Smoke Detectors for Fire Protective Signaling Systems," Fourth Edition, Underwriters Laboratories, Inc., Northbrook, IL, Dec. 30, 1996.

7. Grosshandler, W., "Towards the Development of a Universal Fire Emulator-Detector Evaluator," Fire Safety Journal Vol. 29, pp. 113-128, 1997.

8. Cleary, T., Chernovsky, A., Grosshandler, W., and Anderson, M., "Particulate Entry Lag in Spot-Type Smoke Detectors," Fire Safety Science Proceedings, $6^{\text {th }}$ International Symposium, Poitiers, France, July 5-9, 1999.

9. Cleary, T., Grosshandler, W., and Chernovsky, A., "Smoke Detector Response to Nuisance Aerosols," International Conference on Automatic Fire Detection "AUBE '99", 11th, March 16-18, 1999, Gerhard Mercator University, Duisburg, Germany, Luck, H., Editor, pp. 32-41, 1999.

10. Cleary, T., Anderson, M., Averill, J. and Grosshandler, W., "Evaluating Multi-Sensor Fire Detectors In The Fire Emulator/Detector Evaluator," $8^{\text {th }}$ International Fire Science and Engineering Conference, Interflame'99, June 29- July 11999 Edinburg, Scotland.

11. Andersson, P., and Holmstedt, G., "CFD-Modelling Applied to Fire Detection Validation Studies and Influence of Background Heating," International Conference on Automatic Fire Detection "AUBE '95", 10th, April 4-6, 1995, Gerhard Mercator University, Duisburg, Germany, Luck, H., Editor, pp. 429-438, 1995.

12. Ahonen, A., and Sysiö, P., "A Run-In Test Series of a Smoke Test Room," Technical Research Center of Finland, Research Report 139, Espoo, Finland, 1983.

13. Dobbins, R.A., Mulholland, G.W., and Bryner, N.P., "Comparison of a Fractal Smoke Optics Model with Light Extinction Measurements," Atmospheric Environment, Vol. 28, No. 5, pp. 889-897, 1994.

14. Bukowski, R.W., "Development of a Standardized Fire Service Interface for Fire Alarm Systems," Fire Protection Engineering, (in press, 2000).

15. Bushby, S., "Integrating Fire Systems with Other Building Automation and Control Systems," 15th UJNR, March 2000. 


\title{
Forest Fires in Boreal Forest - the Alaska Taiga
}

\author{
Hiroshi HAYASAKA \\ Graphics \& Fire Science Division, Graduate School of Engineering \\ Hokkaido University, Sapporo, 060-8628, Japan
}

\begin{abstract}
This paper describes results of FROSTFIRE, a forest fire experiment carried out in July 1999 and also surveys results of the Donnelly Flats forest fire in June 1999. An investigation of the Donnelly Flats forest fire site found that the main bumt matter were branches with needles of black spruce and mosses and lichen which cover the ground. On the basis of these results, a vegetation investigation was carried out before the FROSTFIRE experiment. The following items were measured : weight of branches with needles of two black spruce trees and the thickness of mosses which covered the surface around the trees. Thunder storm observations by video camera from the Poker Flat mountain top recorded multiple lightning strikes. After the storm, three plumes from forest fires were observed in different directions and the probability of ignition of forest fires by the lightning is discussed. Finally, the combustion calculations using mean tree densities of black spruce and mean thickness of mosses estimate the quantity of $\mathrm{CO}_{2}$ released in forest fires in Alaska.
\end{abstract}

KEYWORDS : Forest Fire, Boreal Forest, Taiga, FROSTFIRE, Lightning, Black Spruce, Moss

\section{INTRODUCTION}

The taiga is the common term for coniferous forest zones, and this kind of forest covers over one third of all woodland on the Earth. The Eurasian Continent has 55\% of the taiga and North America $40 \%$. About two thirds of taiga grows on permafrost [1]. Forest fires occur frequently in taiga and has come to general notice because of global warming by carbon dioxide $\left(\mathrm{CO}_{2}\right)$ which has become an important issue. The average area burnt annually by forest fires in Canada since 1918 is about two million ha [2]. The maximum annual burnt area is nearly eight million ha, almost equal to the area of Hokkaido, a major island of Japan. To understand the effect of forest fires, forest fire experiments in actual forests have been carried out in Russia, Canada, the U.S.A.. and elsewhere to answer questions such as "Is the forest a source of absorption or a source of emission of $\mathrm{CO}_{2}$ ?" [3,4] . Especially, the effect of climatic variations due to forest fires and destruction of the taiga of the Far East in Russia will influence Japan directly as it is located at the edge of far eastern Russia. The forests ruined by forest fires in Russia become lakes and marsh called "Alas" if 
the ice content in the ground is high. Once Alas is formed, recovery to forest is very difficult. Further, methane gas bound in the permafrost is discharged by taiga fires [5]. As a result, forest fires in the taiga are related to decreases in fixed $\mathrm{CO}_{2}$ due to the loss of forests, increases in the emission of $\mathrm{CO}_{2}$ from the fires, and increases in the emissions of methane from the permafrost, overall making it impossible to disregard the effect on global warming. The authors made detailed observations of vegetation and thunder storms in the so-called FROSTFIRE experiment [6] area before the forest fire experiments. The weight of twigs and needles of black spruce were measured and several thermocouples were placed on a tree to measure temperatures during the fire. Survey results of a large-scale forest fire area near Delta Junction, Alaska [7] are also reported. The report focuses on basic questions like: What burns in the forest fire? and what is the ignition mechanism? The burning characteristic of forest fires and the discharge of carbon dioxide with forest fires is discussed.

\section{EXPERIMENT}

\subsection{Outline of the FROSTFIRE Experiment}

FROSTFIRE is a cooperative research project planned by Alaska University Fairbanks, the USDA Forest Service, the U.S.A. Pacific Northwest Research Station, and others to clarify phenomena with forest fires in boreal forests. The forest fire experiment was carried out in the research area (Caribou-Poker Creeks Experimental Watershed), in the vicinity of Fairbanks in Alaska July 8 15,1999 . The burn area was about 890 ha (about $3 \mathrm{~km}^{2}$ ) mainly on Little Poker Creek, as shown in Figure 1. The experiment was finished when the burnt area reached about $40 \%$ of the total scheduled area [6].

\subsection{Measurements and Items for Observation}

Some fundamental questions must be clarified when considering forest fires : What is the fuel? How does it burn? What is the ignition mechanism? To answer these questions and to understand how a forest fire progresses, the following items were covered. Vegetation mapping before the fire test, estimates of the fuel weight, temperature measurements during the fire test, infrared image measurements by thermal camera, and reinvestigation after the fire test. Observation of lightning as the cause of ignition of forest fires in Alaska and on site investigation of a large forest fire were also carried out .

\section{EXPERIMENTAL RESULTS AND DISCUSSION}




\subsection{Vegetation Survey}

The climatic province in this research area is subarctic (Dfc), and it is in a discontinuous permafrost terrain in the polar coniferous forest zone. The main trees in this area are black spruce, white birch, and alpine vegetation. One (target) tree was chosen as a typical spruce forest tree of the FROSTFIRE experiment area. The location of the tree measured with the GPS was $65^{\circ}$ 09'29" North Latitude. $147^{\circ} 29^{\prime} 10^{\prime \prime}$ West Longitude, and the area around the target tree was chosen for investigation. The area is a square with side length ten meters. Vegetation mapping was made as shown in Figure 2. The area had seventy trees with heights exceeding one meter, sixty three trees out of the seventy were black spruce (density 0.63 black spruce $/ \mathrm{m}^{2}$ ), and the remaining seven trees were white birch. The average diameter of the black spruce at breast-height was $6 \mathrm{~cm}$, and the average height $6.4 \mathrm{~m}$. Two black spruce near the area were cut off. Their height were $7.1 \mathrm{~m}$ and $10.8 \mathrm{~m}$ and the breast-height diameters were $9 \mathrm{~cm}$ and $17 \mathrm{~cm}$. The base diameter of the two trees were 9.9 and $22.9 \mathrm{~cm}$ and the two trees had 65 and 73 annual growth rings respectively. The photograph in Figure 3 [6] is of typical spruce forest in the test area, the black spruce is lank and grow thickly ( about three trees $/ \mathrm{m}^{2}$ ). The black spruce spread branches in all directions at every height, pine bulk masses in the crown, and branches near the ground are nearly all dead and covered by lichen.

\subsection{Measurement of Fuel}

\subsubsection{Investigation of a Large Forest Fire Site}

On June 11th, 1999, there was a forest fire near Delta Junction, Alaska which kept burning for about a week, and consumed about 7300 ha of forest. The authors visited this large-scale forest fire site [7] . Black spruce was the most common tree also in this forest, and the Figure 4 photograph [6] from the FROSTFIRE experiment looks very much like the forest at Delta Junction after the forest fire.

As a result of the inspection of the forest fire site, it was determined that :

1. The trunks of trees, except fallen trees, do not burn. The bark protects the trunks from flames.

2. Twigs with needles of black spruce burn (Figure 4) .

3. Thick branches do not burn (Figure 4) .

4. The bark is subject to slight burns, maybe depending on the fire conditions.

5. Moss which covers the ground at a thickness of about $10 \mathrm{~cm}$ burns.

6. Lichen on branches and ground burn.

These results allow the conclusion that the main fuels of a forest fire in this kind of taiga are moss and lichen on the ground, foliage and twigs on the thick branches of trees. Thus, a forest fire in the taiga may be termed a "foliage, twig, and moss fire" rather than a "forest fire" . 


\subsubsection{Gravimetry of Branches with Needles}

The weight of branches and needles, and the number of branches of the two cut down black spruce trees referred to in 3.1 were measured at one meter intervals from bottom to top.

The weight of branches with needles was about $1 \mathrm{~kg}$ to several $\mathrm{kg}$ per meter of tree. The gross weight of the branches with needles was $9.67 \mathrm{~kg}$ for the first tree and $39.1 \mathrm{~kg}$ for the second tree, the total almost proportional to the square of the trunk diameter at breast height. Figure 5 has the dimensionless height of the two trees as the $\mathrm{X}$-axis and the dimensionless weight as the $\mathrm{Y}$-axis, and shows the weight distribution. Figure 5 shows that branches with needles in the central part of the trees were heavier than in the other parts.

\subsubsection{Gravimetry of Twigs with Needles}

It was noted that large branches usually do not burn during forest fires. Twigs with needles were removed from these moderately sized branches, and the weights were measured. The result showed that twigs comprised $70-75 \%$ of the total, indicating that about $25-30 \%$ of the weight of branches with needles remains unburned during usual forest fires.

\subsubsection{Survey of Mosses}

Mosses in the area of the Forest Fire has an average thickness of about $10 \mathrm{~cm}$, making the leaves, stems, and roots of the moss good heat insulators for the permafrost. However, during fires, flames remain on the moss surface and can easily spread over the moss surface as the moss acts as an insulator. This situation is observed in the lower part of Figure 3. Surface flames may help the ignition of black spruce twigs with needles. Smoldering combustion seems to start inside the moss. Smoldering in the moss layer is a relatively slow combustion which lasts longer because the moss layer is a good insulator. A $14 \times 14 \mathrm{~cm}, 4 \mathrm{~cm}$ thick moss sample was collected at the FROSTFIRE experimental site, and the density in the natural dried state was $25 \mathrm{~kg} / \mathrm{m}^{3}$.

\subsection{Observation of Forest Fire and Thunder}

The FROSTFIRE experimental site can be seen from Poker Flat and observations were carried out from the roof of the rocket launch observation facilities at Poker Flat (Figure 1) when cumulonimbus clouds formed in the afternoon of July fourth, 1999.

Dozens of thunder claps and dozens of lightning strikes were noted and at about $14: 20$, a white mushroom shaped plume produced by a forest fire on the ridge in the mountain at azimuth $238^{\circ}$ was observed. Afterwards, two plumes from other forest fires were also confirmed, one small and one relatively large. All the forest fires extinguished naturally after several hours. The probability of ignition by lightning is considered to be about $1 / 100$, but it seemed higher here when small ignitions are included. There are further questions such as what is ignited by the lightning ? And 
how does the lightning ignite trees or moss? . Further observations will be made to establish the lightning ignition mechanism.

\subsection{Heat Energy Generated by Forest Fires}

\subsubsection{Calorific Value of Twigs with Needles}

Considering the tree density of the black spruce, that the weight of twigs with needles is proportional to the square of the diameter of the trunk, the proportion of combustibles that are twigs with needles etc., it is possible to estimate the calorific value per unit area of spruce forest by the following equation, assuming that all combustibles are cellulose :

(Heat generated by combustion of twigs with needles per unit area, $\mathrm{kJ} / \mathrm{m}^{2}$ ) $=$ (number of trees per unit area, number of trees $/ \mathrm{m}^{2}$ ) X (mean weight of combustible material, $\mathrm{kg} / \mathrm{tree}$ ) X (mean calorific value of combustible material, $\mathrm{kJ} / \mathrm{kg}) \fallingdotseq 2 \mathrm{~kg} / \mathrm{m}^{2} X 16,090 \mathrm{~kJ} / \mathrm{kg}=32,180 \mathrm{~kJ} / \mathrm{m}^{2}$

\subsubsection{Calorific Value of Moss}

The calorific value of moss including lichen on the forest floor can be similarly calculated by using the following equation when the mean thickness of the moss cover is assumed as $10 \mathrm{~cm}$ :

(Heat generated by combustion of moss per unit area, $\left.\mathrm{kJ} / \mathrm{m}^{2}\right)=$ (moss density, $\mathrm{kg} / \mathrm{m}^{3}$ ) X (mean thickness of moss, $\mathrm{m}$ ) $\mathrm{X}$ (mean calorific value of combustible material, $\mathrm{kJ} / \mathrm{kg}$ ) $\fallingdotseq 25 \mathrm{~kg} / \mathrm{m}^{2} \mathrm{X}$ $0.1 \mathrm{~m} \times 16,090 \mathrm{~kJ} / \mathrm{kg}=40,225 \mathrm{~kJ} / \mathrm{m}^{2}$

\subsubsection{Maximum Heat Generated by Forest Fires}

If the above mentioned twigs with needles and mosses including lichen were completely bumt, the maximum heat generated by a forest fire will be the sum of the above two values. (Maximum heat generated by forest fire per unit area, $\mathrm{kJ} / \mathrm{m}^{2}$ ) $=32,180 \mathrm{~kJ} / \mathrm{m}^{2}+40,225 \mathrm{~kJ} / \mathrm{m}^{2}=72.4 \mathrm{MJ} /$ $\mathrm{m}^{2}$

It becomes $11.3 \mathrm{MJ} / \mathrm{m}^{3}$ per meter of tree, when an average height of $6.4 \mathrm{~m}$ is considered.

\subsubsection{Head Fire Rate of Spread}

Generally, the head fire rate of spread ( $\mathrm{m} / \mathrm{min}$, HFRS for short) is used to express the rate of spread of forest fires. The HFRS in surface fires is $0.6 \sim 3.4 \mathrm{~m} / \mathrm{min}$, and becomes about $6 \mathrm{~m} / \mathrm{min}$ in the most intense crown fire. As a result, a one meter square area will be burnt out in $17.6 \sim 100$ seconds when the fire is a surface fire and the progress is linear.

\subsection{Carbon Dioxide Quantities Discharged from Forest Fires}

When it is assumed that cellulose is completely burnt in air, the amount of discharged carbon 
dioxide can be calculated as $2.16 \mathrm{~kg} / \mathrm{kg}$ of fuel. With this result, the maximum $\mathrm{CO}_{2}$ discharge in a forest fire in a boreal forest will be $9.7 \mathrm{~kg} / \mathrm{m}^{2} \quad(26.6 \mathrm{tC} / \mathrm{ha})$. However, combustion conditions of usual forest fires are very far from complete combustion because black and white smoke is always observed and the layer of unburned charcoal on the ground is not thin. The establishment of more accurate estimates of $\mathrm{CO}_{2}$ discharge from forest fires seems to remain as a future problem. Here an accurate estimate appears very important when attempting to determine whether forests are $\mathrm{CO}_{2}$ emission or absorption sources.

\section{CONCLUSIONS}

The FROSTFIRE forest fire experiment in the taiga zone of Alaska, U.S.A., has helped clarify the conditions of boreal forest fires by conducting field research of the vegetation, thunderstorm observations before the fire, observation of large forest fire areas, etc. This year, 2000, Russian taiga field research is scheduled to observe forest fires occurring in the Russian taiga.

The research reported here has been conducted as a science research activity of Japan. The project title is "Permafrost disturbance and induced emissions of greenhouse gases - tasks for predictive and controlling technique establishment - " supported by the Agency of Science and Technology, JAPAN. The project leader is Professor M. Fukuda, Institute of Low Temperature Science, Hokkaido University, Sapporo, Japan. I would like to thank to Mr. Masahiko Shinohara for his assistance.

\section{REFERENCES}

(1) World Encyclopedia (in Japanese) , CD-ROM edition, Hitachi Digital Heibonsha, 1998.

(2) Canadian forest service information from : http ://fms.nofc.nrcan.gc.ca/index.html Http :// nofc.cfs.nrcan.gc.ca/fire/cwfis/stats/1995007.gif.

(3) Bor Forest Island Fire Experiment, "Fire in Ecosystems of Boreal Eurasia", Kluwer Academic Publishers, 13, 1996.

(4) Canadian forest service, "NWT Int. Crown Fire Modelling Experiment (ICFME) ", http :/ /nofc.cfs.nrcan.gc.ca/fire/fmn/nwt/

(5) Fukuda, M., "Northern Siberia", Iwanami, Tokyo (in Japanese) , 1996.

(6) FROSTFIRE Home Page, http ://www.fsl.orst.edu/fera/frostfire.html, 1999.8

(7) Alaska Fire Service, http ://fire.ak.blm.gov/ 


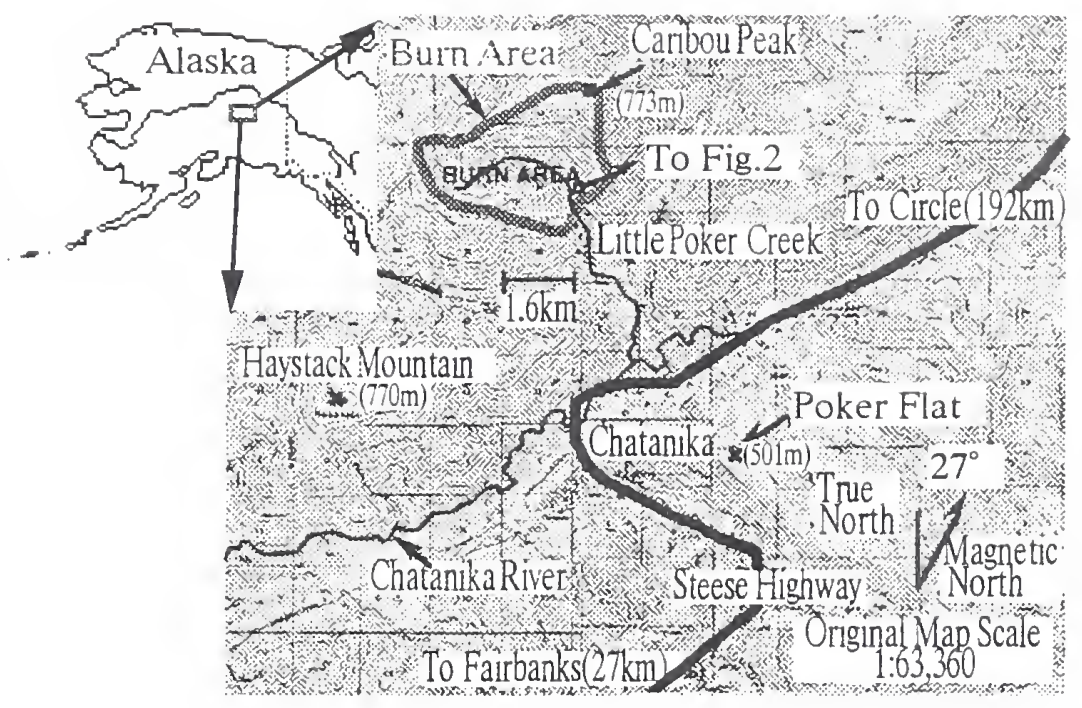

Fig. 1 Map of the FROSTFIRE Experimental Site and Chatanika Area

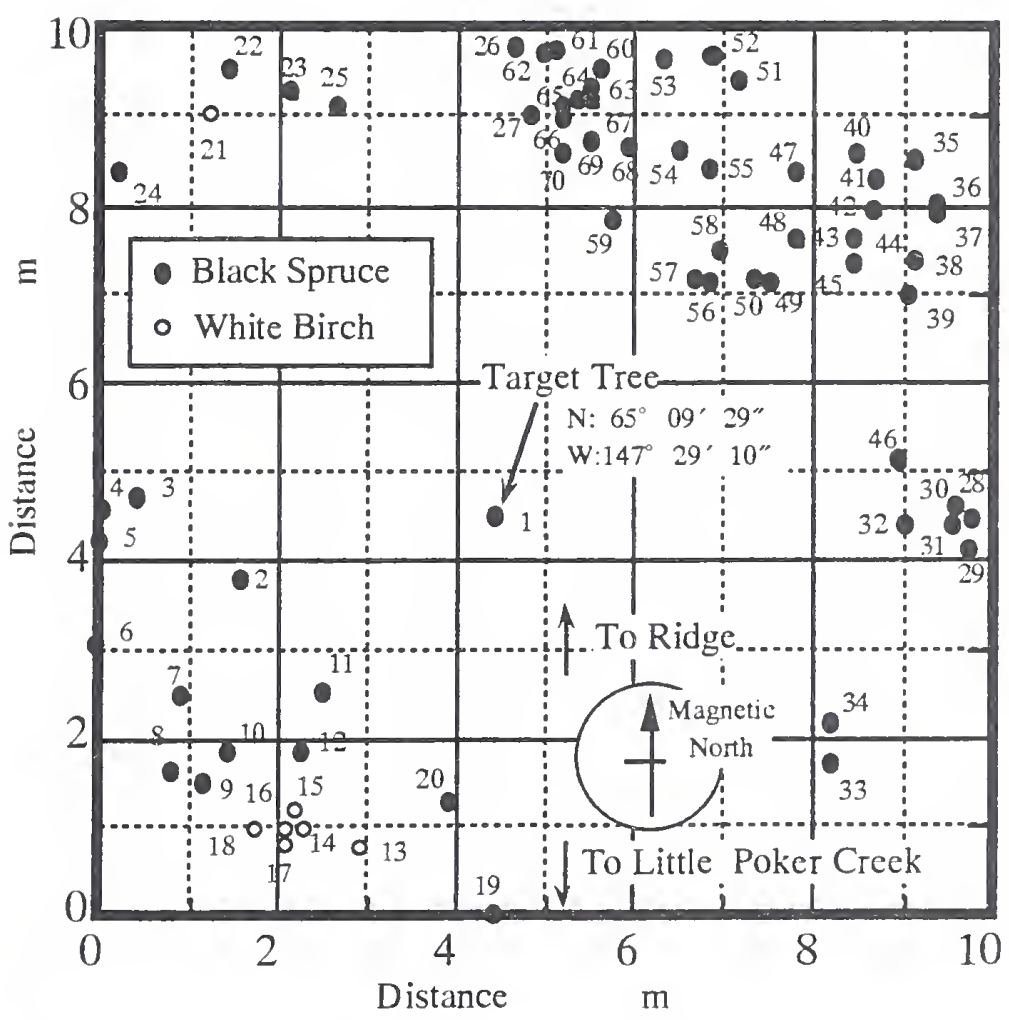

Fig. 2 Vegetation Mapping at the FROSTFIRE Experimental Site 
(8/8-Hayasaka)

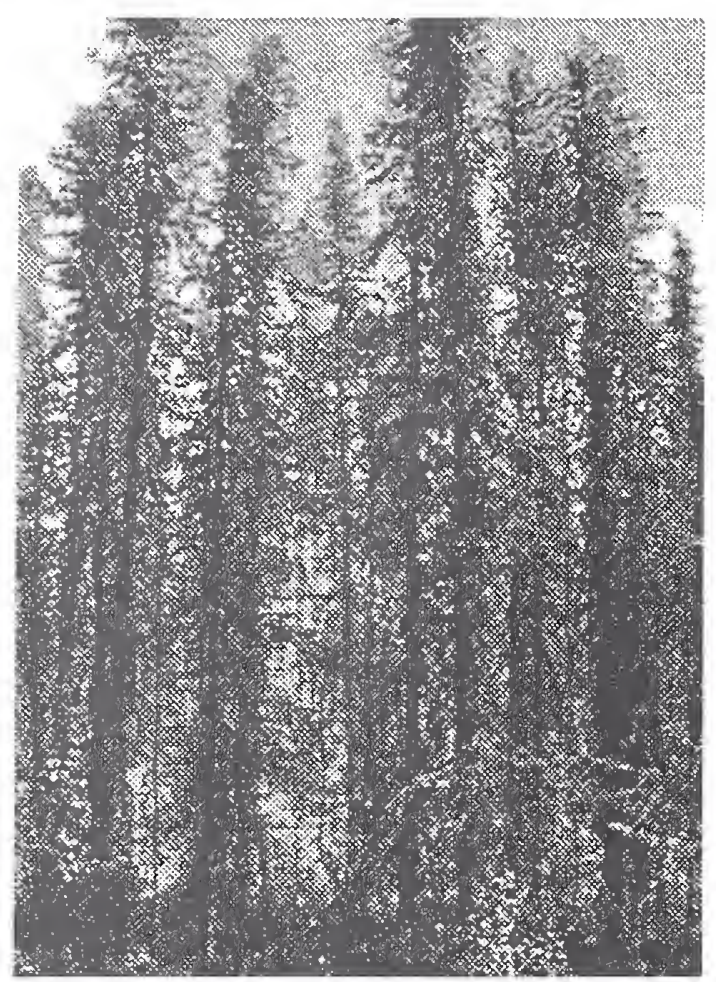

Fig. 3 Typical Appearance of Black Spruce Forest at the Start of the Fire [6]

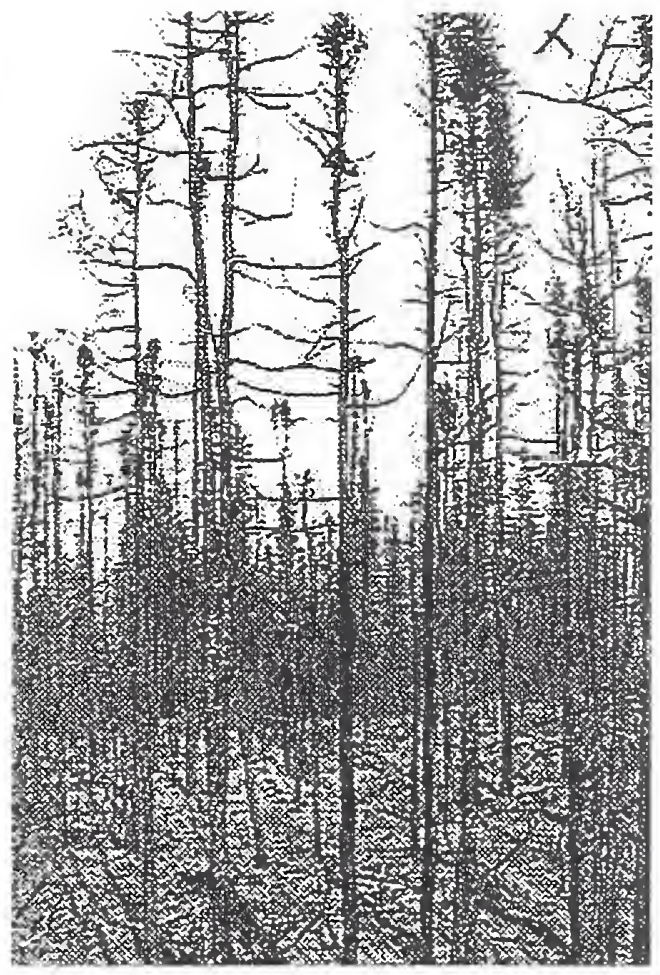

Fig. 4 Typical Appearance of Black Spruce Forest after Forest Fire [6]

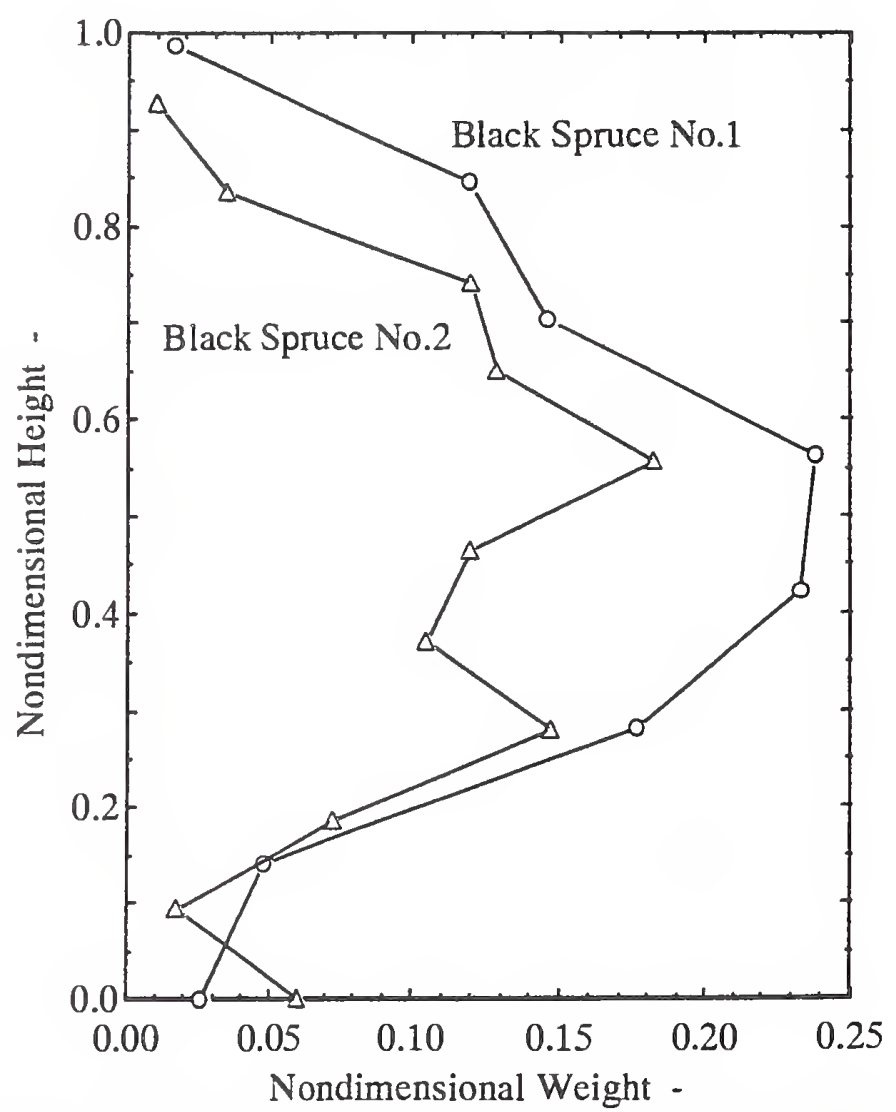

Fig. 5 Weight Distribution of Black Spruce Twigs with Needles 


\title{
Fire SPREAD BY BRAND SPOTTING
}

\author{
Patrick J. Pagni and John P. Woycheese \\ Mechanical Engineering Department \\ University of California \\ Berkeley, CA 94720-1740 USA
}

\section{Introduction}

Burning brands, lofted above large fires and propagated by the prevailing winds, can cause spot ignitions far from the flame front. These distant and unexpected fires are an important mechanism for fire spread in postearthquake and urban/wildland intermix fires. The 20 October Oakland Hills Fire quickly overwhelmed fire fighting efforts, in part due to brand propagation and spotting hundreds of meters ahead of the fire front [1]. Although spotting has received considerable attention from the forest fire community [2-7], little research quantifies brand propagation from structures or rubble piles.

Fire spread by brand spotting consists of three elements: lofting, propagation, and deposition with fire initiation. Previous research has either de-coupled the lofting and propagation phases[8-12] or added simple linear combinations of plume and ambient winds $[5,6,8]$ due to the complex nature of the velocity field around and above large fires. New models are now available that utilize Large Eddy Simulation (LES) to enable calculation of terrain, ambient wind, and atmospheric effects on large fire plumes [13-15].

LES models require a number of brand characteristics to calculate spotting location distances accurately.

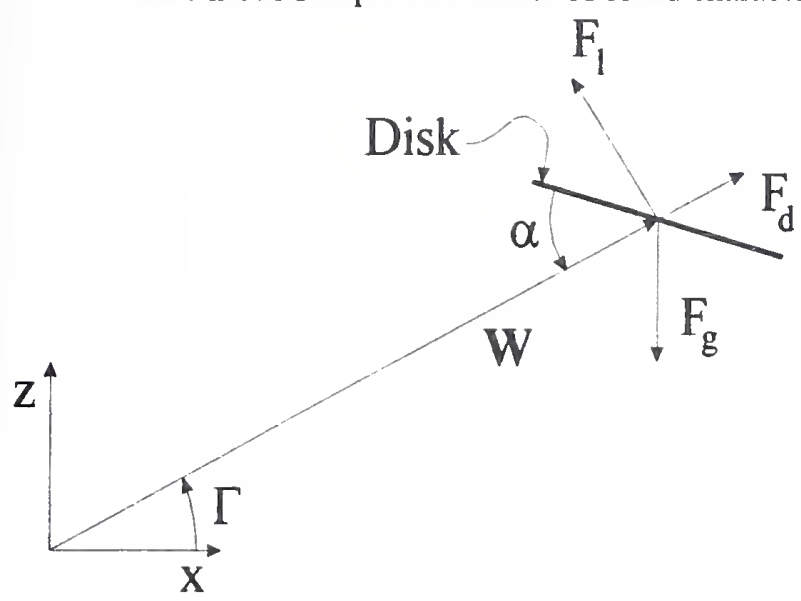

Figure 1: Summary of the forces acting on a combusting brand in an irrotational relative velocity field, $W$
The heterogeneous combustion of brands, coupled with size and shape histories, present considerable research challenges. Initial brand conditions such as size, shape, and material properties are assumed $[2,5,8-12]$. The gravitational and aerodynamic forces can be approximated analytically. To describe these forces, the brand shape, size, mass, and drag and lift coefficients are required as functions of time. The forces to which the brand is subjected are illustrated in Fig. 1, which can be expanded to three dimensions. Drag acts in the direction of relative velocity, $\mathbf{W}$, which is the difference between the brand velocity and that of the surrounding velocity field. Lift acts perpendicular to drag, and the force due to gravity pulls the disk downward. Note that non-rotating spherical and cylindrical brands, which have axes of symmetry perpendicular to the relative velocity field in their most stable orientation, will not have lift; the lift and drag forces for disks are dependent on the angle of attack, $\alpha$ [16].

Prior to lofting and propagation, brands are usually assumed to be well-formed; i.e., combustion will have smoothed corners and other sharp edges, so that lofted brands will primarily consist of spheres, cylinders, and disks. Previous research and experiments have concentrated on the former two shapes [2-11, 17-21]; from Fig. 2, however, it can be seen that more massive brands can be lofted as disks than as spheres or cylinders. The small drag coefficient and large mass-to-cross-sectional-area ratio severely limits the propagation range of spheres relative to the other shapes; likewise, the weight-to-drag ratio of cylinders falls short of that for disks. Therefore, this paper focuses on disks and the experimental determination of their combustion histories.

There are two stages to brand combustion: flaming combustion, and surface, or glowing, combustion. Not all wood types utilize both combustion phenomena. In the flaming mode, pyrolysis appears to cause significant mass loss with little change in the brand dimension. After this initial period, the pyrolysis rate becomes restricted by char formation. The brand size then decreases slowly as char is consumed by surface combustion. Glowing 
combustion provides mass and size changes until combustion can no longer be sustained or until the brand is completely consumed.

\section{Experimental Procedure}

The primary goal of this work is to provide experimental brand size and shape data as a function of time for comparison with a variety of combustion models [12]. There have been several experiments to provide the mass and/or terminal velocity for brands, but there is a lack of data for size and shape change. These experiments are being conducted with two methodologies: videographic and gravimetric.

Table 1: Experiments to Self-Extinguishment, by Length-to-Diameter Ratio

\begin{tabular}{|l|c|c|c|c|c|c|}
\hline \multirow{2}{*}{$\begin{array}{l}\text { Wood } \\
\text { Type }\end{array}$} & \multicolumn{3}{|c|}{$50 \mathrm{~mm}$ diameter } & \multicolumn{3}{c|}{$25 \mathrm{~mm}$ diameter } \\
\cline { 2 - 7 } & $1 \mathrm{~m} / \mathrm{s}$ & $2 \mathrm{~m} / \mathrm{s}$ & $4 \mathrm{~m} / \mathrm{s}$ & $1 \mathrm{~m} / \mathrm{s}$ & $2 \mathrm{~m} / \mathrm{s}$ & $4 \mathrm{~m} / \mathrm{s}$ \\
\hline Oak & $1: 3,1: 9$ & $1: 3,1: 9$ & $1: 3,1: 9$ & $1: 3$ & $1: 3$ & $1: 3$ \\
\hline Fir & $1: 3,1: 9$ & $1: 3,1: 9$ & $1: 3,1: 9$ & $1: 3$ & $1: 3$ & $1: 3$ \\
\hline $\begin{array}{l}\text { Cedar } \\
\text { (WRC) }\end{array}$ & & & & $1: 3$ & $1: 3$ & $1: 3$ \\
\hline Balsa & $1: 3,1: 9$ & $1: 3,1: 9$ & $1: 3,1: 9$ & $\mathbf{1 : 3}$ & $\mathbf{1 : 3}$ & $1: 3$ \\
\hline $\begin{array}{l}\text { Dense } \\
\text { Balsa }\end{array}$ & $1: 3$ & $1: 3$ & $1: 3$ & & & \\
\hline
\end{tabular}

In the videographic experiments, data for brand size and shape histories is being developed to provide empirical data for the confirmation of combustion models. Data has been gathered at constant velocities with $\alpha=$ $90^{\circ}$ on burning brands with diameters of 25 and $50 \mathrm{~mm}$, the range expected for the majority of plume-born brands. Video journals of the brands, taken from two perpendicular views, are used to obtain size changes as functions of time. The videos also record the transitions from flaming to glowing combustion and from full to single-sided combustion. Experiments are being conducted for a range of wood types, brand sizes, and relative velocities - a representative sample is shown in Table 1. All of these data are for end-grain disks. Additional experiments have been performed on transverse-grain disks, with disappointing repeatability. The chosen wood species provide a full range of physical charateristics, including density, thermal inertia, and void space. Figure 3 shows the terminal velocities for several shapes and wood species. Previous analyses have shown that the relative velocity is frequently the terminal velocity. The densities for the experiments conducted are indicated by the vertical dashed lines.

A set of gravimetric experiments is being conducted to determine brand mass, shape, and size as functions of time for a variety of wood types at various wind tunnel speeds. Disk brands are mounted in the wind tunnel and allowed to burn for a set period of time, after which the brand is removed and immerse in $\mathrm{CO}_{2}$. The final brand size, shape, and weight is compared to initial values and is used to determine the mass history, and to provide more complete data for size and shape histories, for a number of size, velocity, and wood combinations.

\section{Results}

Figure 4 provides a side-by-side comparison of two similar experiments conducted on different wood types: fir and cedar. Both experiments were conducted on samples that were $25 \mathrm{~mm}$ in diameter and $8 \mathrm{~mm}$ thick (length-to-diameter ratio of 1:3) in a velocity field of $1.8 \mathrm{~m} / \mathrm{s}$. The douglas fir sample extinguished approximately 90 sconds after insertion in the wind tunnel, and retained nearly half of its initial mass; the western red cedar sample burned to completion after 210 seconds. These samples illustrate the two paths that different wood samples followed. The more dense samples of oak and douglas fir flame for a longer time, but, in general, do not transition to surface combustion. Complete combustion rarely occurs without significant, persistent surface combustion on the upwind face of the brand. As a result, these samples self-extinguished before a large fraction of their initial mass had combusted. The side and wake flames visible after 20 seconds have elapsed cause the sample to form a truncated cone. At lower speeds, the remaining sample is completely charred, with cupping at the back and bowing at the font. At higher speeds, more than half of the sample is either slightly discolored or virgin wood underneath a thin film of char; at speeds above $4 \mathrm{~m} / \mathrm{s}$, the combusion period is too short to cause shape change. 
Wood with lower density, such as cedar and balsa, transition from flaming to surface combustion, with the flaming combustion ending relatively early in the brand lifetime. In most cases, the surface combustion starts around the front edge of the brand, and grows to include the entire face. Before the flaming ends, surface combustion commences on the back edge and the brand forms a glowing ellipsoid, as seen in Fig. 4. Unlike flaming combustion, glowing is most active on the face of the sample; the front edges and face combust at a higher rate than the rest of the sample, and the brand forms a truncated hemisphere - with flat edge to back - later in its liftime. Nearly all of the low-density samples, at all tested speeds, burned to completion.

To develop a mass history for a certain wood type, size, and relative velocity, samples are removed from the wind tunnel and extinguished using $\mathrm{CO}_{2}$. Once extinguished, the samples are weighed and measured. To preserve the specimens for detailed analysis, they are not reignited. Fresh samples are introduced to the same wind tunnel conditions and extracted at later times. A representative mass history for douglas fir is given in Fig. 5. Some of the samples are extinguished immediately after ignition to determine the mass lost during the ignition process; this amounted to $3-4 \%$ of the dry mass for fir. Allowing some samples to burn to completion provides the time to self-extinguishment. Other samples are extinguished after a fraction of the average self-extinguishment time to determine the average mass, shape, and size history during combustion. Similar experiments will be conducted for balsa and western red cedar as indicated by the bold entries in Table 1 .

The transition time from flaming to surface combustion is illustrated in Fig. 6 for different wood types as a function of relative velocity, while the time to self-extinguishment, or brand extinction time, is shown in Fig. 7. The time of transition from flaming to surface combustion (or immediate extinction) decreases as the relative velocity increases for all wood types. It also appears to be a function of density or thermal inertia, with the flaming time increasing with increasing density. For douglas fir, the extinction time is closely linked to flaming combustion. Typically, fir does not transit to surface combustion when the flames extinguish. The increase in extinction time at $2.4 \mathrm{~m} / \mathrm{s}$ is the result of an anomaly where an area less than five $\mathrm{mm}^{2}$ continued to burn for tens of seconds after the flames ceased. At 1 and $4 \mathrm{~m} / \mathrm{s}$, oak burned in much the same fashion; at $2 \mathrm{~m} / \mathrm{s}$, however, a small ring of surface combustion formed around the back edge of the brand, due to favorable recirculation velocities downwind of the brand, increased the combustion time by $50 \%$. The mass loss and size change during this latter combustion period was small. Both the flaming and the extinction times for both varieties of balsa decreased with increasing velocity. Glowing combustion represents a significant fraction of the total brand lifetime. These samples burned to completion. The mass fraction at extinction, or residual mass, for 50-mm-diameter, 16-mm-thick oak and fir disks is shown in Fig. 8 as a function of relative velocity. The increase in residual mass with increasing velocity as is expected.

\section{Conclusions}

Of the species examined here, the lighter wood species, western red cedar and balsa, appear to burn to completion via glowing surface combustion. The denser wood species, oak and douglas fir, self-extinguish once flaming ceases with considerable residual mass. There is also a strong dependence on wood grain orientation. All of the data in these figures were obtained with an end grain facing the relative velocity vector. Preliminary experiments with transverse grain facing the relative velocity vector show that these also tend to burn primarily where the end grain is exposed; i.e., at the edge. It is possible that the brands with the longest lifetimes will be those with relatively little shape, size, and mass change that are glowing only on a small portion of the disk edge. This seems to further indite cedar shakes and shngles, which start with an aerodynamically advantageous shape, burn well via surface glowing after flaming ceases, and have grain orientations that encourage edge burning.

This is a work in progress. Approximately one-third of the experiments in Table 1 remain to be done. Wood is a difficult experimental material. Perhaps a better approach would have been to start with these experiments, rather than with analytical studies [10-12]. Different species and grain orientations need further exploration. Aerodynamic effects such as tumbling, i.e., varying angle of attach, and varying velocity require study. Future burning models for various brand shapes developed from these experiments may be inserted as Lagrangian particles into LES fire plume models [13-15], which describe the interaction of the flow field from large fires with complex terrain and ambient winds, to develop probabilistic distributions of spot fires given fire, fuel, geographic, and atmospheric parameters. 


\section{Acknowledgements}

We are grateful for the continuing financial support provided by the Building and Fire Research Laboratory of the National Institute of Standards and Technology, U.S.D.O.C., under Grant No. 60NANB80D0094, and by a student grant from the Educational and Scientific Foundation of the Society of Fire Protection Engineers.

\section{References}

1. Pagni, P.J., "Causes of the 20" October 1991 Oakland Hills Conflagration," Fire Safety Journal, 21:4, 331-340, 1993.

2. Muraszew, A., "Firebrand Phenomena," Aerospace Report No. ATR - 74 (8165-01) -1, The Aerospace Corporation, El Segundo, 1974.

3. Muraszew, A., Fedele, J.B., and Kuby, W.C., "Firebrand Investigation," Aerospace Report ATR-75 (7470) -1, The Aerospace Corp., El Segundo, CA, 1975.

4. Muraszew, A., and Fedele, J.B., "Statistical Model for Spot Fire Hazard," Aerospace Report No. ATR - 77 (7588) -1, The Aerospace Corporation, El Segundo, 1976.

5. Albini, F.A., "Spot Fire Distance From Burning Trees: A Predictive Model," General Technical Report No. INT - 56, USDA Forest Service Intermountain Forest and Range Experiment Station, Ogden, UT, 1979.

6. Albini, F.A., "Potential Spotting Distance from Wind-Driven Surface Fires," USDA Forest Service Research Paper INT-309, USDA, 1983.

7. Albini, F.A., "Transport of Firebrands by Line Thermals," Combustion Science and Technology, 32, 277-288, 1983.

8. Tarifa, C.S., del Notario, P.P., and Moreno, F.G., "On the Flight Paths and Lifetimes of Burning Particles of Wood," Tenth Symposium (International) on Combustion, 1021-1037, The Combustion Institute, 1965.

9. Tarifa, C.S., del Notario, P.P., Moreno, F.G., and Vill, A.R., "Transport and Combustion of Firebrands," Final Report of Grants FG-SP-114 and FG-SP-146, Vol. 2, USDA, Madrid, 1967.

10. Woycheese, J.P., Pagni, P.J., and Liepmann, D., "Brand Propagation From Large-Scale Fires," Journal of Fire Protection Engineering, 1998, in review.

11. Woycheese, J.P., Pagni, P.J., and Liepmann, D., "Brand Lofting Above Large-Scale Fires," Proceedings of the Second International Conference on Fire Research and Engineering, 137-150, Society of Fire Protection Engineers, Washington, 1998.

12. Woycheese, J.P., and Pagni, P.J., "Combustion Models for Wooden Brands," Proceedings of the Third International Conference on Fire Research and Engineering, 53-71, Society of Fire Protection Engineers, Washington, 1999.

13. McGrattan, K.B., Ferek, R.J., and Uthe, E.E., "Smoke Plume Trajectory from In Situ Burning of Crude Oil Field Experiments," Proceedings of the First International Conference on Fire Research and Engineering, ed. D. Peter Lund, 47-52, Society of Fire Protection Engineers, Orlando, FL, 1995.

14. McGrattan, K.B., Rehm, R.G., Tang, H.C., and Baum, H.R., "A Boussinesq Algorithm for Buoyant Convection in Polygonal Domains," NISTIR 4831, National Institute of Standards and Technology, Gaithersburg, MD, 1992.

15. McGrattan, K.B., Baum, H.R., Walton, W.D., and Trelles, J., "Smoke Plume Trajectory from In Situ Burning of Crude Oil in Alaska - Field Experiments and Modeling of Complex Terrain," NISTIR 5958, National Institute of Standards and Technology, Gaithersburg, MD, 1997.

16. Hoerner, S.F., Fluid-Dynamic Drag, Published by author, 1958.

17. Lee, S.-L., and Hellman, J.M., "Firebrand Trajectory Study Using an Empirical Velocity-Dependent Burning Law," Combustion and Flame, 15:3, 265-274, 1970.

18. Lee, S.-L., and Hellman, J.M., "Study of Firebrand Trajectories in a Turbulent Swirling Natural Convection Plume," Combustion and Flame, 13:6, 645-655, 1989.

19. Phillips, A.M., and Becker, H.A., "Pyrolysis and Burning of Single Sticks of Pine in a Uniform Field of Temperature, Gas Composition, and Gas Velocity," Combustion and Flame, 46, pp. 221-251, The Combustion Institute, 1982.

20. Becker, H.A., and Phillips, A.M., "Burning of Pine in Wind at $357-857 \mathrm{C}$ and $3-18 \mathrm{~m} / \mathrm{s}$ : The Wave Propagation Period," Combustion and Flame, 58, pp. 273-289, The Combustion Institute, 1984.

21. Tse, S.D., and Fernandez-Pello, A.C., "On the Flight Paths of Metal Particles and Embers Generated by Power Lines in High Winds - A Potential Source of Wildland Fires," Fire Safety Journal, 30:4, pp. 333-356, 1998. 


\section{Figures and Tables}

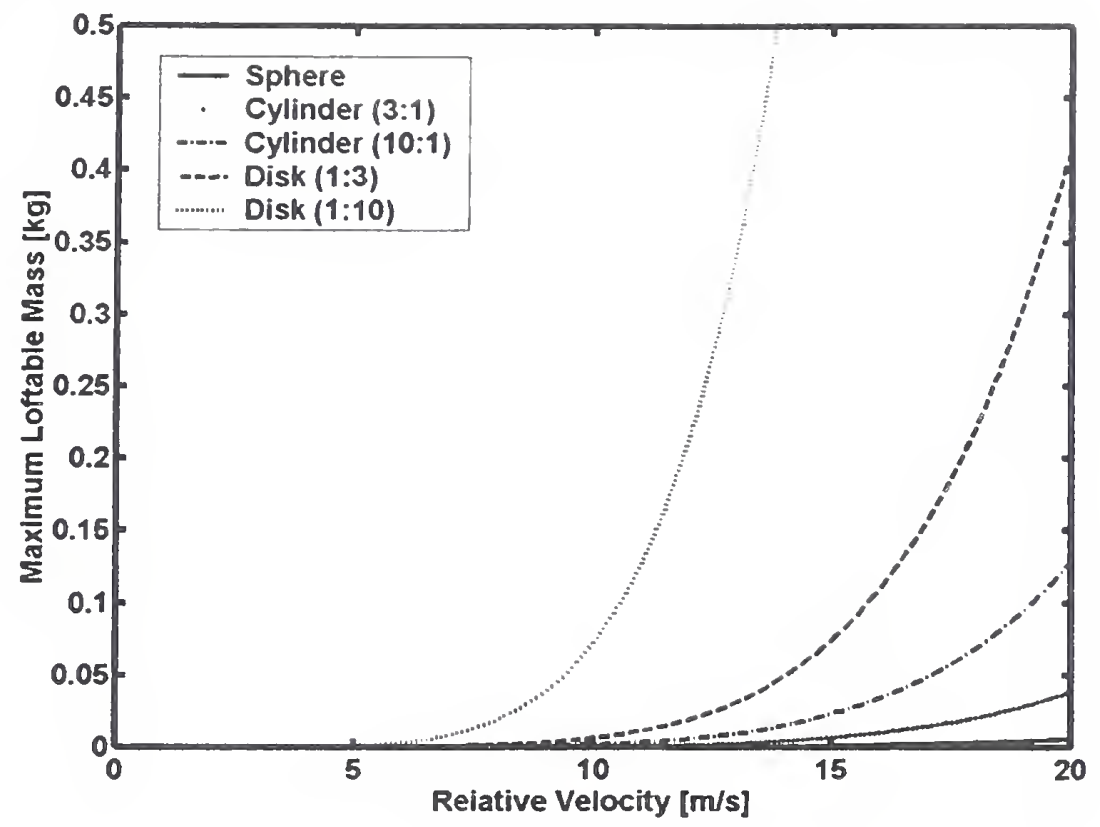

Figure 2: Maximum loftable mass for a given relative velocity as a function of brand shape for a diameter of $50 \mathrm{~mm}$ and length-to-diameter ratio as indicated.

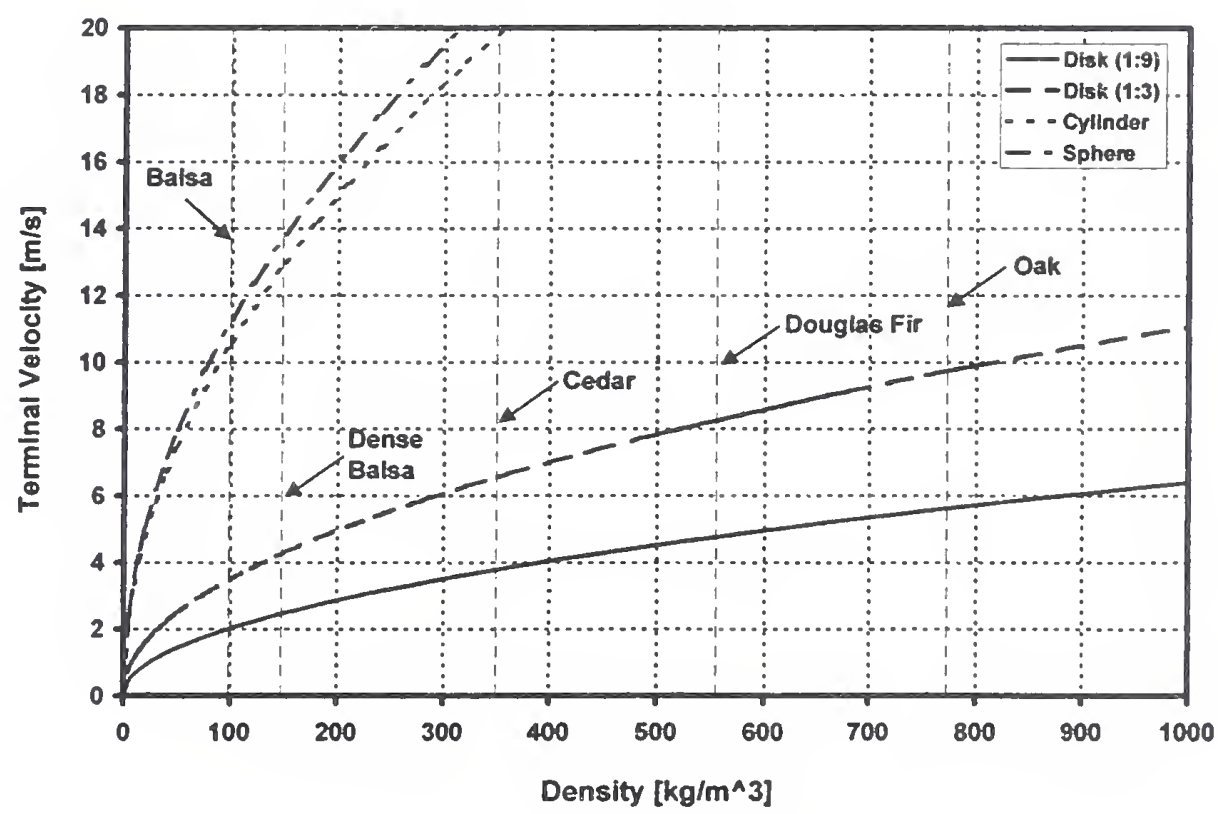

Figure 3: Terminal velocity for brands with a diameter of $50 \mathrm{~mm}$ and thickness-to-diameter ratio for disks as given; length does not affect terminal velocity for cylinders. Disk terminal velocity depends only on thickness for a given sample density. 25-mm-diameter disks have terminal velocities that are smaller by a factor of $\sqrt{2}$. 


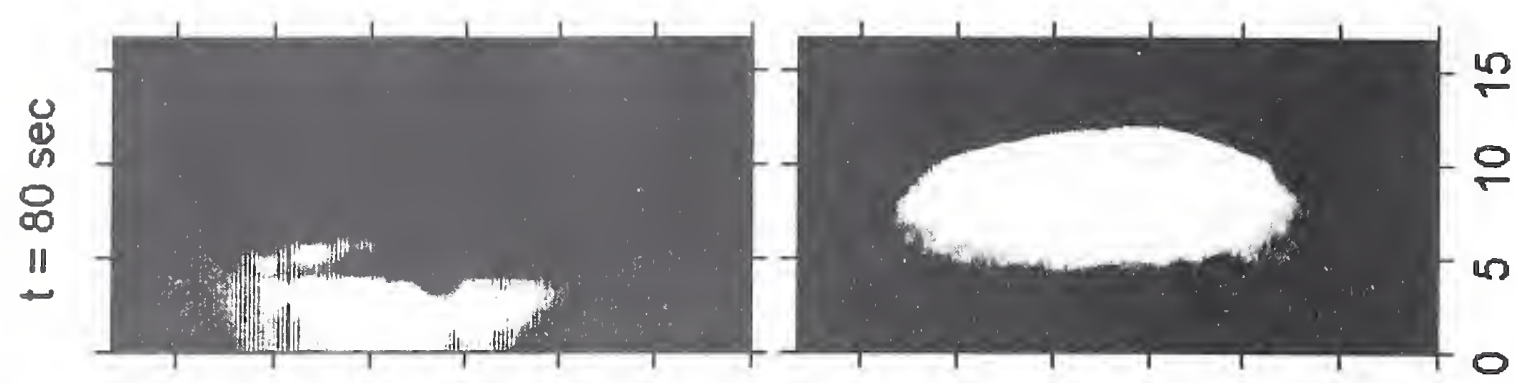

$n$
0
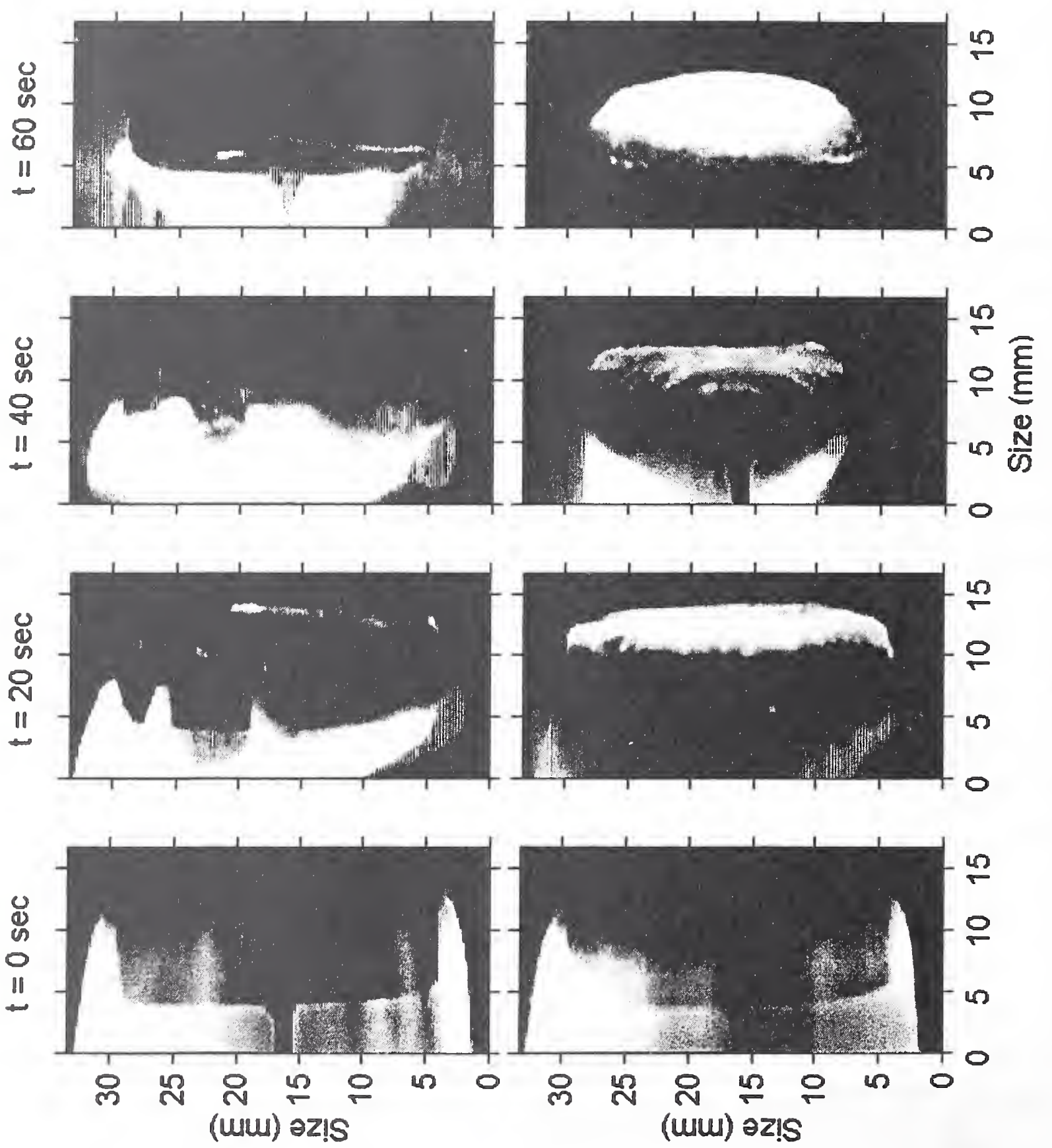

d!I

depəo 


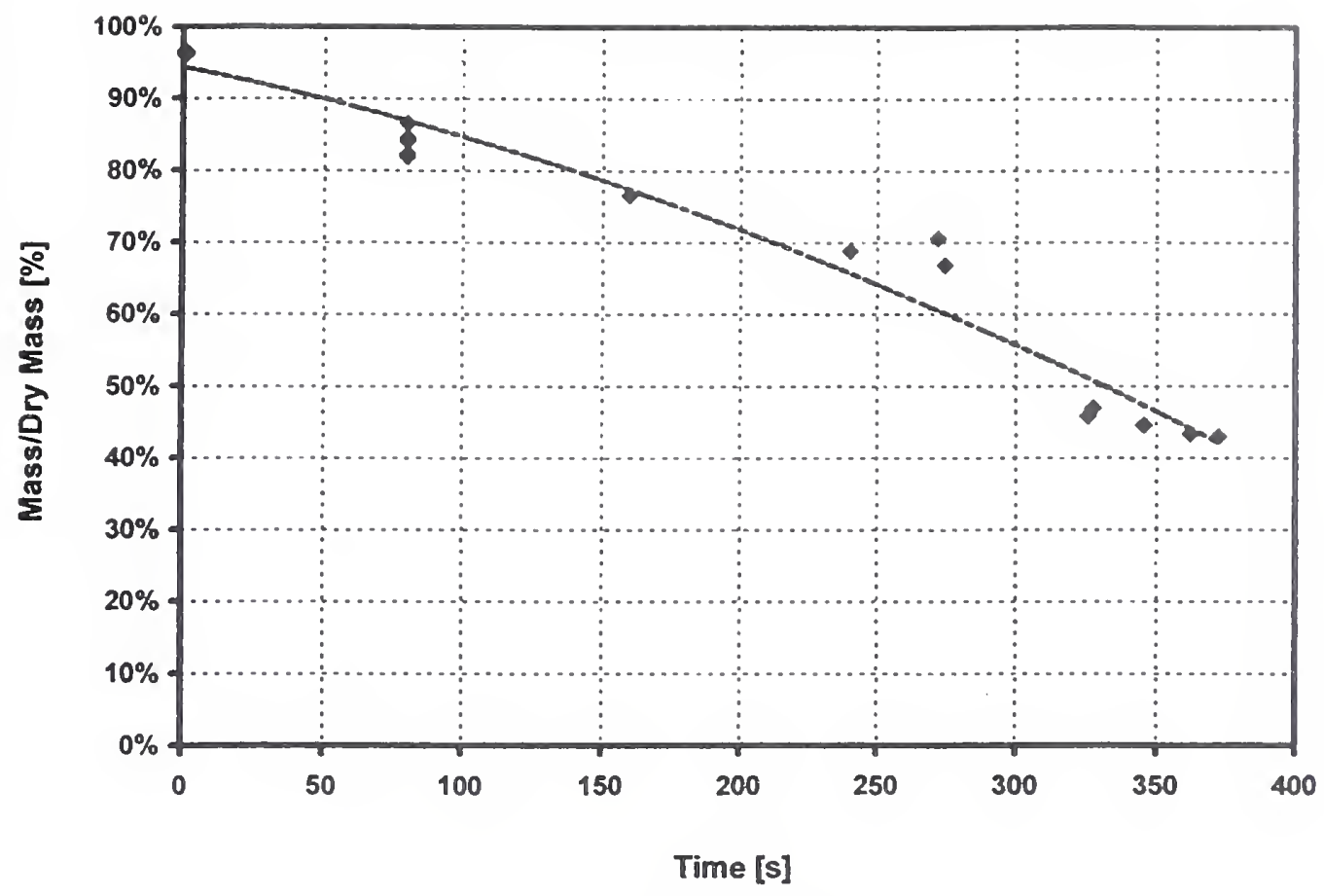

Figure 5: Mass history for $50 \mathrm{~mm}$ diameter, $16 \mathrm{~mm}$ thick Douglas Fir disks. Experiments were terminated at $0,80,160$, and 240 seconds by immersing the samples in $\mathrm{CO}_{2}$. Data for times longer than $240 \mathrm{~s}$ represent samples that self-extinguished.

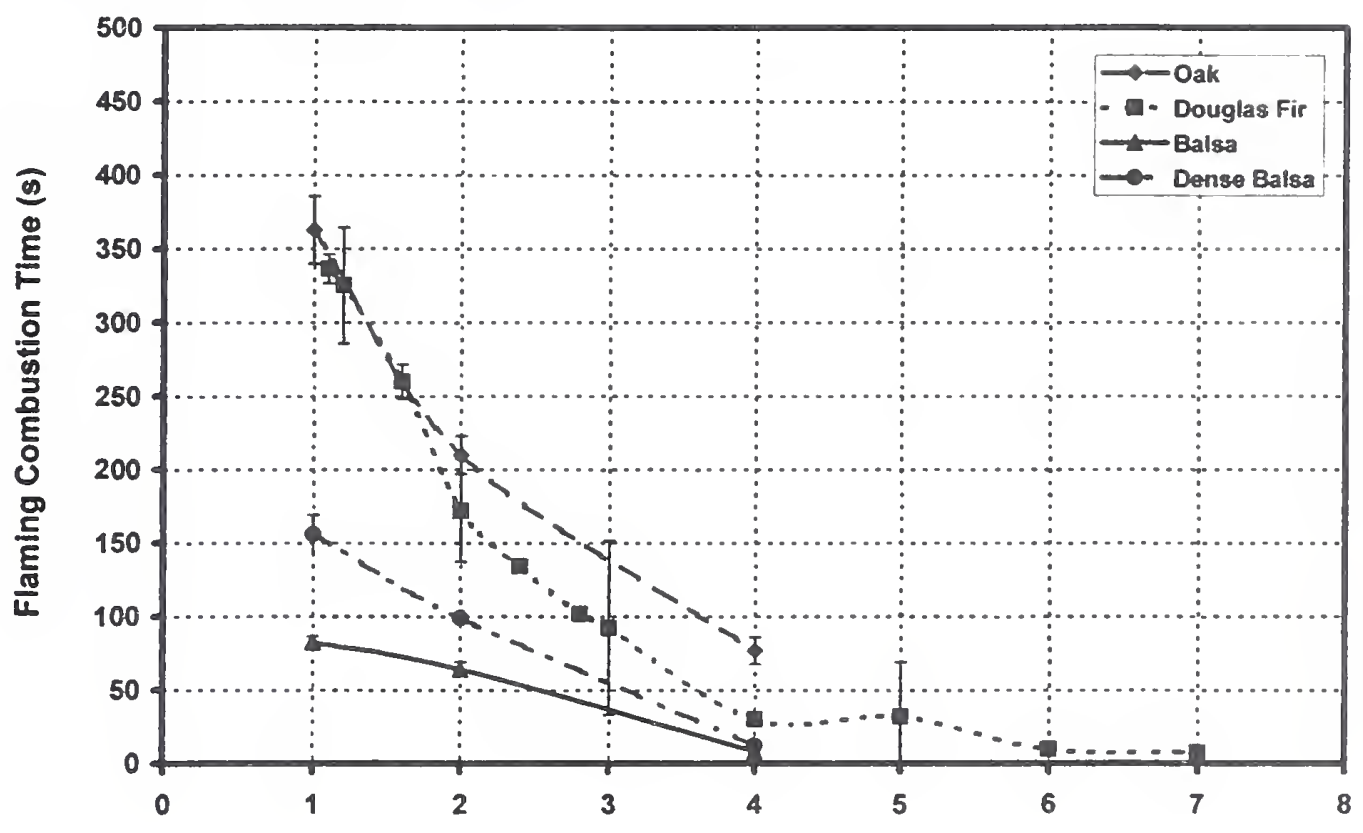

Relative Velocity $[\mathrm{m} / \mathrm{s}]$

Figure 6: Time at which flaming combustion ceases as a function of relative velocity for a variety of wood types, where the initial diameter is $50 \mathrm{~mm}$ and the thickness is $16 \mathrm{~mm}$. 


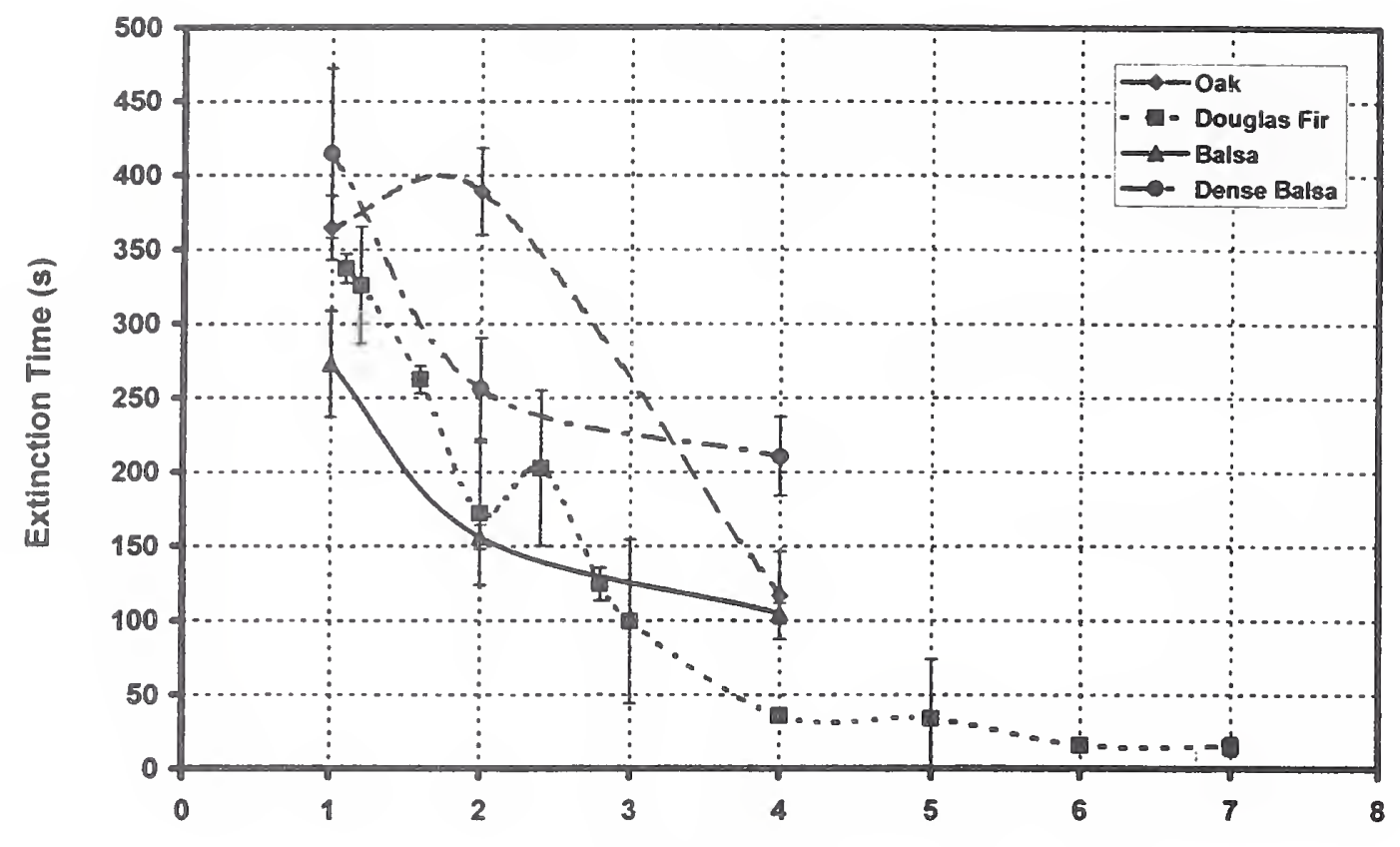

Relative Velocity [m/s]

Figure 7: Average time at which brand self-extinguished as a function of relative velocity and wood type for disks $50 \mathrm{~mm}$ in diameter and $16 \mathrm{~mm}$ thick. Error bars denote standard deviation of 2 to 7 repetitions.

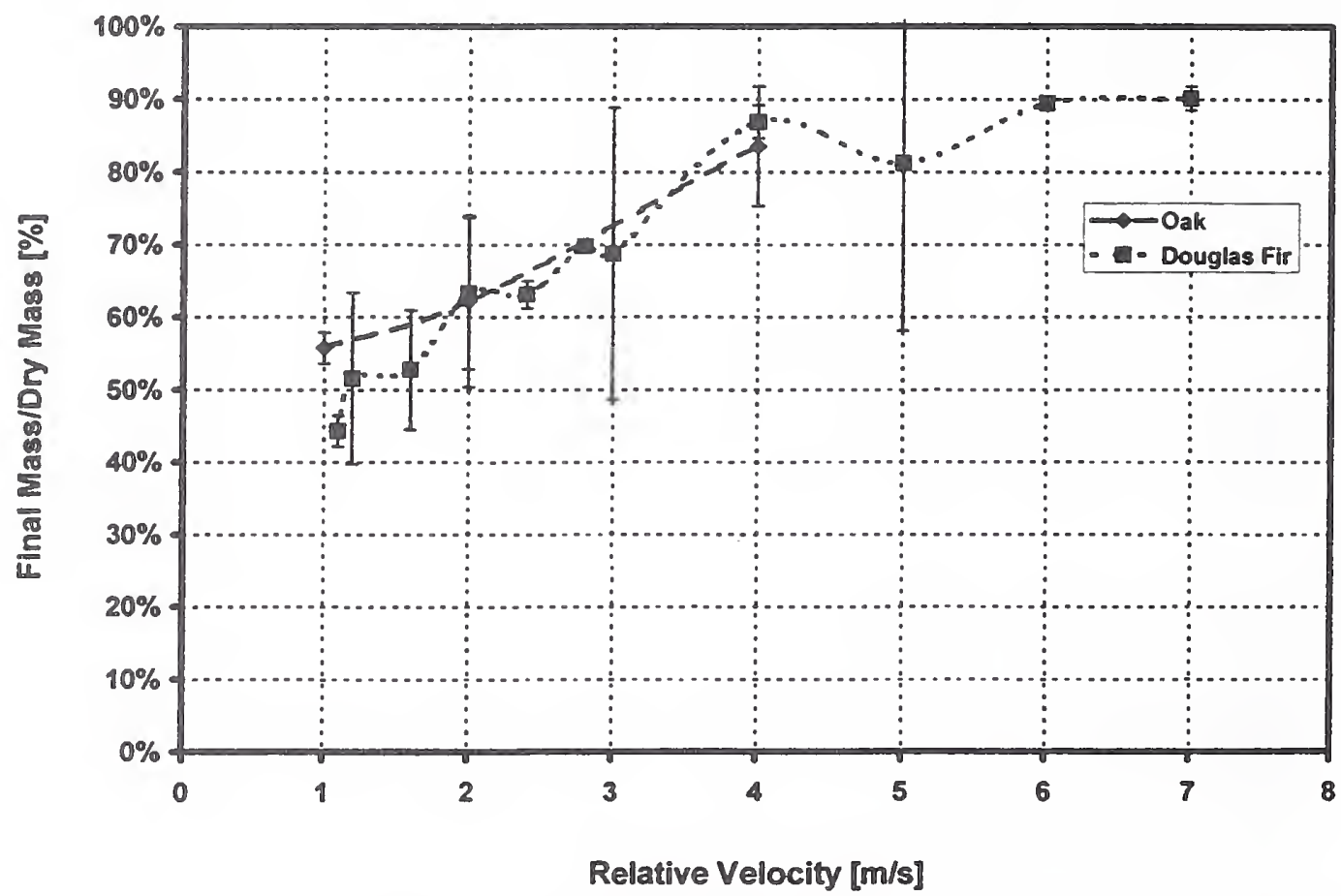

Figure 8: Percentage of dry mass at self-extinguishment as a function of relative velocity for Oak and Douglas Fir disks, $50 \mathrm{~mm}$ in diameter and $16 \mathrm{~mm}$ thick. Balsa samples burned to completion. 


\title{
Revision of Zone Fire Model BRI2 for New Evaluation System
}

\author{
Kazunori Harada and Daisaku Nii \\ Dept. of Architecture and Environmental Design, Kyoto University \\ Yoshida-honmachi, Sakyo-ku, Ky oto 606-8501 Japan \\ Takeyoshi Tanaka \\ Disaster Reduction System, Disaster Prevention Research Institute, Ky oto University \\ Gokasho, Uji, 611-0011 Japan \\ Shigeru Yamada \\ Fujita Corp., 4-6-15 Sendagaya, Shibuya-ku, Tokyo 151-8570 Japan
}

\begin{abstract}
The revision of zone fire model BRI is undergoing. This paper summarizes the historical development of BRI2, while pointing out the needs for improvement in the aspect of physical sub-models. The possibility of inclusion of the species yield model as a function of equivalence ratio (normalized fuel air ratio), convective heat transfer model between wall surface and smoke, upward hot current along the rear (non- heated) surface of thin wall elements, effectiveness of mechanical smoke exhaust systems, and so on.
\end{abstract}

\section{INTRODUCTION}

Zone fire models are one of the important tools for fire safety engineering (FSE). So far, the development of the zone fire models accelerates the spread of FSE. Contrary, the expansion of FSE rouses the needs for further revision of the code in order to cover more complex and difficult problems. In Japan, a computer code BRI2 has been in this cycle.

At this moment, the world of fire safety is moving toward the performance- based system. Performance-based code is one of the mainstreams of moving. Reflecting the change in circumstance, the zone model code BRI2 is being revised so as to fit to the new system, namely so as to includes more performance-related physics and to evaluate the effectiveness of new type of construction. This paper briefly summarizes the historical development of BRI2, current activities to revise BRI2 and possible future development.

\section{HISTORICAL DEVELOPMENT}

Before we discuss the possible revision of zone models, we look back the history of BRI2 briefly. The code was developed to meet the needs in fire engineering. The prototype was developed by Tanaka in $1976^{1)}$. The motivation was to evaluate and indicate the degree of fire safety of apartment houses to those who design, construct or buy them. Typical example calculation result is shown in Figure 1. In this stage of development, calculation was limited only to relatively small-scale apartment houses ${ }^{2)}$ 
During the Ministry of Construction's developmental project on Total Fire Safety Design System, full-scale smoke experiments were carried out. The validity of BRI2 was checked against experiments in those tests. Figure 2 shows one of the verification results ${ }^{3)}$. After the validation to large-scale spaces, BRI2 got more popularity to FSE for commercial buildings.
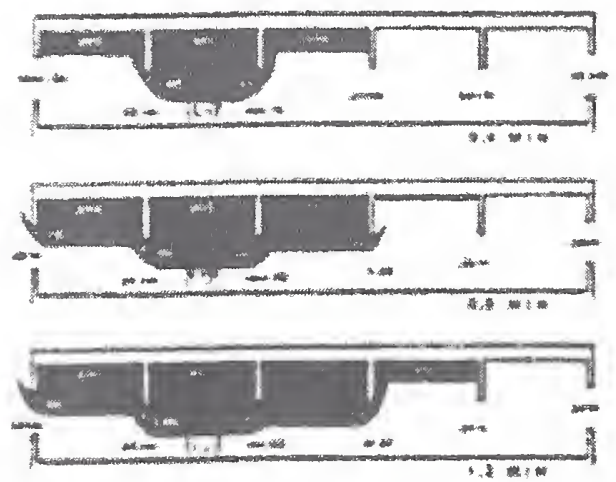

Figure 1 Calculation Results by Prototype code TANAKA (1976-78)

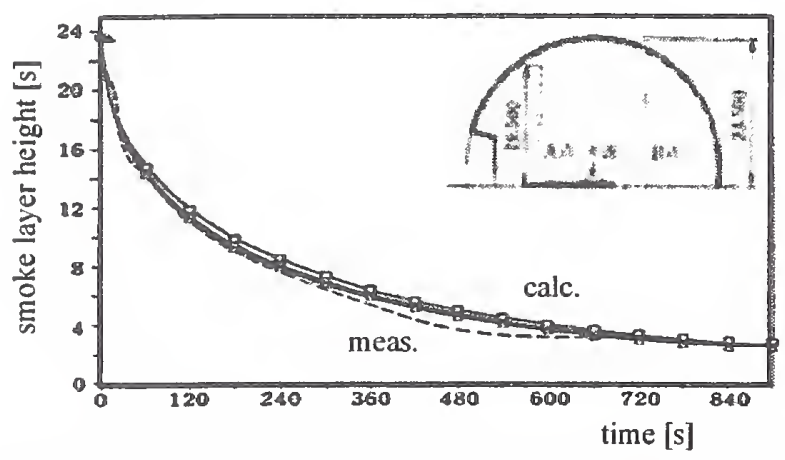

Figure 2 Smoke Filling Experiment at Tsukuba Exhibition Pavilion (1986)

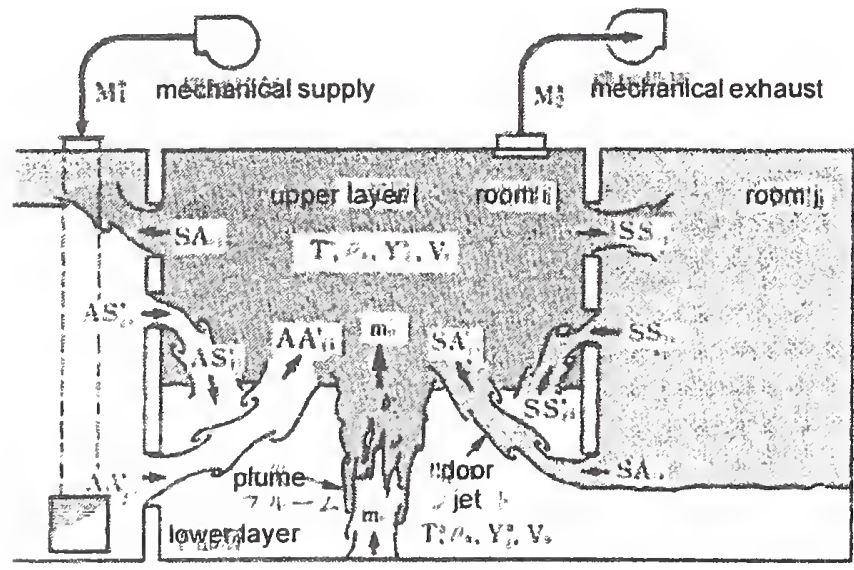

Figure 3 Schematics of Existing Code BRI2T 
Then it is not surprising that building designers and engineers hopes to include smoke management provisions such as smoke compartment, smoke exhaust system and so on. The work was completed by Nakamura and Tanaka) in 1989. The schematic idea is shown in Figure 3, which is still up to date. After Nakamura and Tanaka's work, the code was made open to fire engineering community for FSE purposes. An important issue is that through the development, standard fire (default design heat release rate) was established for use in BRI2 and other zone-type smoke calculations.

\section{REVISION OF BRI2}

After about ten years of BRI2 for practical use in FSE, innovations were made in fire provisions as well as building construction and materials. Thus there is a need to revise the code in order to follow up to today's construction technology. At the same period, bases for sub-models were established to replace or to add some sub-models.

In order to revise the BRI2 to fit to new system, a research Working Group was established under the closure of Building Center of Japan. All the members are volunteers from university and industry. The list of participants is in Appendix-1. Before starting actual revision, the member discussed the target for revision. The following list specifies the needs of revision that we consider at this moment. They are classified into three categories- physics, numerics and utilization.

\subsection{Revisions to Adding/Replacing sub-models to Describe Better Physics}

The first category is concerned with the replacement and/or addition of sub-models to calculate physical phenomena better.

\section{(1) Species Yield Model (EQIVRT, SPECS2)}

The combustion process would be altered by the air supply to fire source. To reflect this effect, combustion model is revised to give variable species $\left(\mathrm{CO}, \mathrm{CO}_{2}, \mathrm{H}_{2} \mathrm{O}\right.$ and soot) yield. By altering the parameters in the combustion model, species yield could be approximated with reasonable accuracy as shown in Figure 4. The functional forms of the parameters are proposed by Yamada and Tanaka, ${ }^{6,7}$ as shown in Table 1. Putting these formulas into the combustion model shown in Figure 5, species release rate could be estimated.

Table 1 Ratio of perfect combustion, soot, CO, CO2 and Water Vapor Formation

\begin{tabular}{lll}
\hline & $\Phi \leq 1$ (fuel control) & $\Phi>1$ (Oxygen control) \\
\hline Ratio of perfect combustion & $r=1-0.25^{(1 / \phi)^{2}}$ & 0.75 \\
Ratio of soot residual & $s=0.4$ & $1-0.6^{(1 / \phi)^{2}}$ \\
Ratio of CO formation & $p_{1}=0.6$ & $0.6 \sqrt{\Phi}$ \\
Ratio of $\mathrm{CO}_{2}$ formation & $p_{2}=0.1$ & 0.1 \\
Ratio of $\mathrm{H}_{2} \mathrm{O}$ formation & $q_{1}=0.25$ & $0.25 \sqrt{\Phi}$ \\
\hline
\end{tabular}




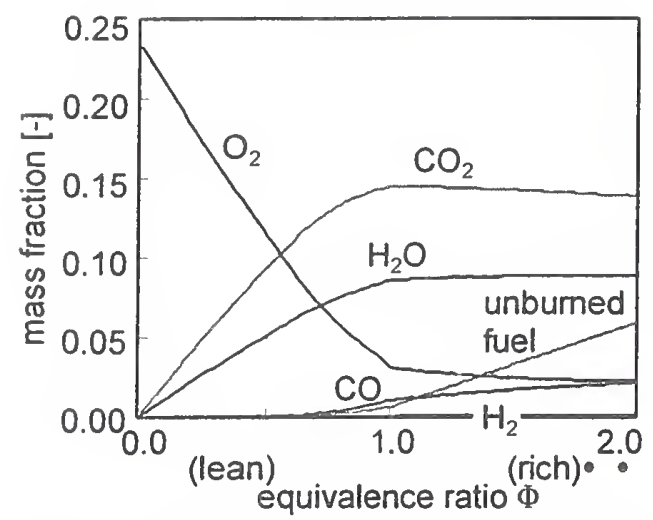

Figure 4 Equivalence Ratio versus mass fraction of Chemical Species of Propane Fire ${ }^{8)}$

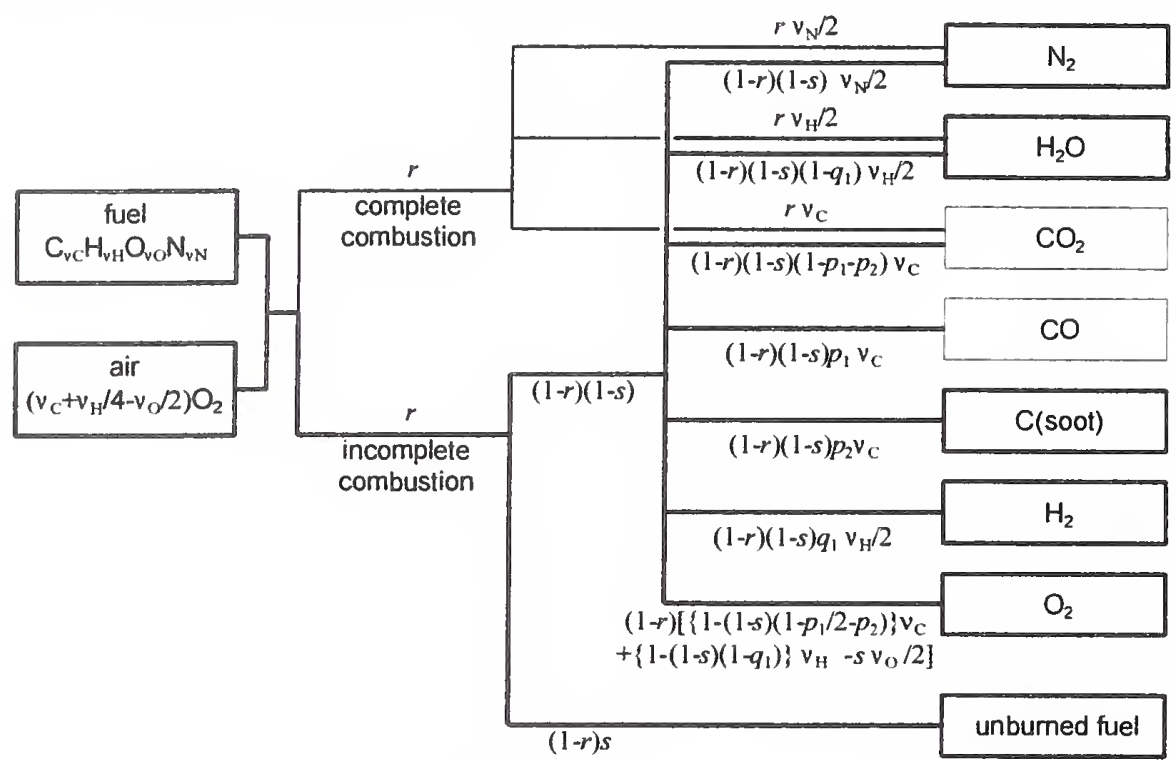

Figure 5 Combustion Model in BRI2

\section{(2) Convective Heat Transfer Coefficient (CHTRAN)}

The convective heat transfer coefficient is dependent on the magnitude of velocity field. As to the room of fire origin, experimental correlation is derived by Yamada et $a l^{9)}$ as

$h_{c}=\left\{\begin{array}{ll}8.3 \times 10^{-3} & \left(Q^{*}<2 \times 10^{-3}\right) \\ 0.1 Q^{* 2 / 5} & \left(2 \times 10^{-3} \leq Q^{*}\right)\end{array} \quad\left[\mathrm{kW} / \mathrm{m}^{2} . \mathrm{K}\right]\right.$

where the non-dimensional heat release rate is

$Q^{*}=\frac{Q}{c_{p} \rho_{0} T_{0} \sqrt{g} L^{5 / 2}}=\frac{Q}{1116\left\{(\text { room volume })^{1 / 3}\right\}^{5 / 2}}$.

This change will results in increasing heat flux to the compartment boundary in the early stage of fire. 


\section{(3) Door Jet Plume (DPLUM)}

Existing version approximates the mass flow rate of door jet plumes by an unconfined wall plumes by putting its origin at the level of pressure center. However experiments by Yamaguchi et $\mathrm{al}^{(0)}$ indicated that the origin should locates at the height $(1 / 3)$ of the door jet thickness.

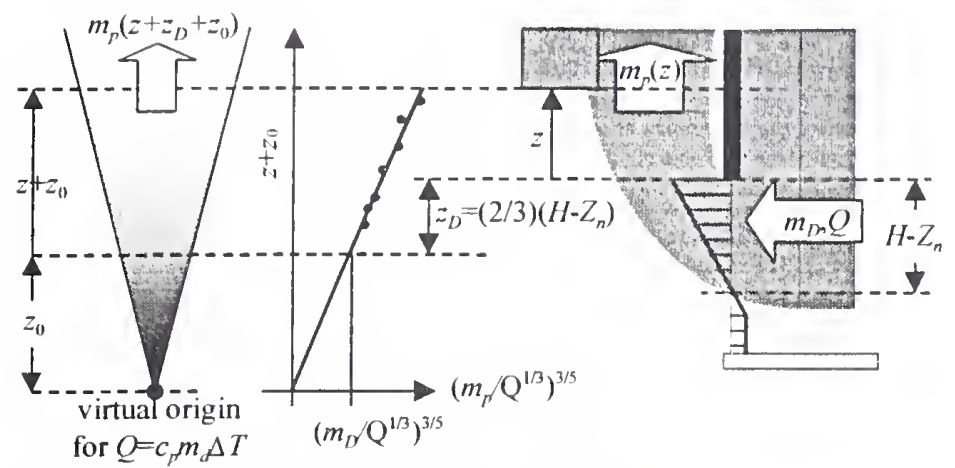

Figure 6 Mass Flow Rate of Door Jet Plume

\section{(4) Heat Penetration through Thermally Thin Elements (WPLUME)}

Quite often, fire and smoke compartmentation is provided by thermally thin elements such as shutters, wired glass. In those situations, heat penetrates through the element to result in upward wall plume along the non- fireside surface. Even if smoke is not contained in the wall plume, it an easily cause danger. To evaluate these phenomena, a model was developed to combine heat conduction, radiant heat transfer between thin elements and surrounding fire gas and upward wall plume ${ }^{i 1)}$. By virtue of this sub-model, we can evaluate the effectiveness of new separation elements such as insulated glass, silicate-coated screen shutters. Schematic idea is shown in Figure 6, followed by an example calculation result in Figure 8. In this example, the corridor is easily contaminated by penetrated heat, not by smoke leakage.

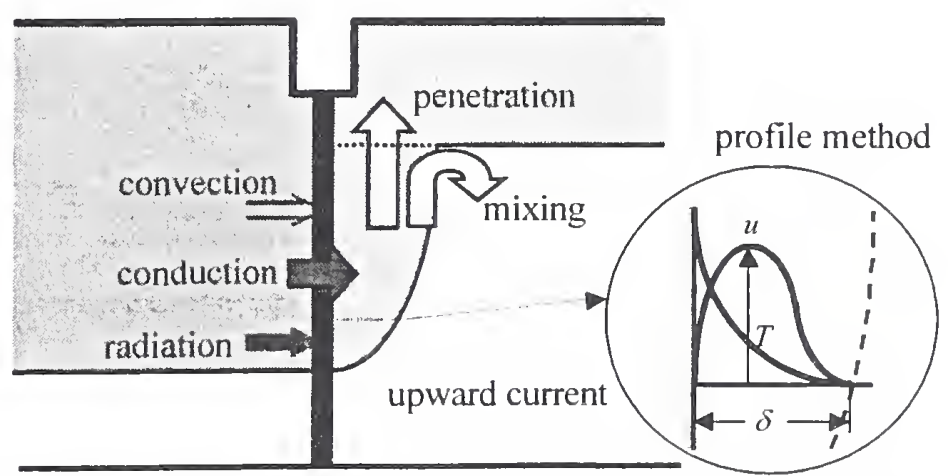

Figure 7 Heat Conduction through Thermally Thin Elements and Upward Current 


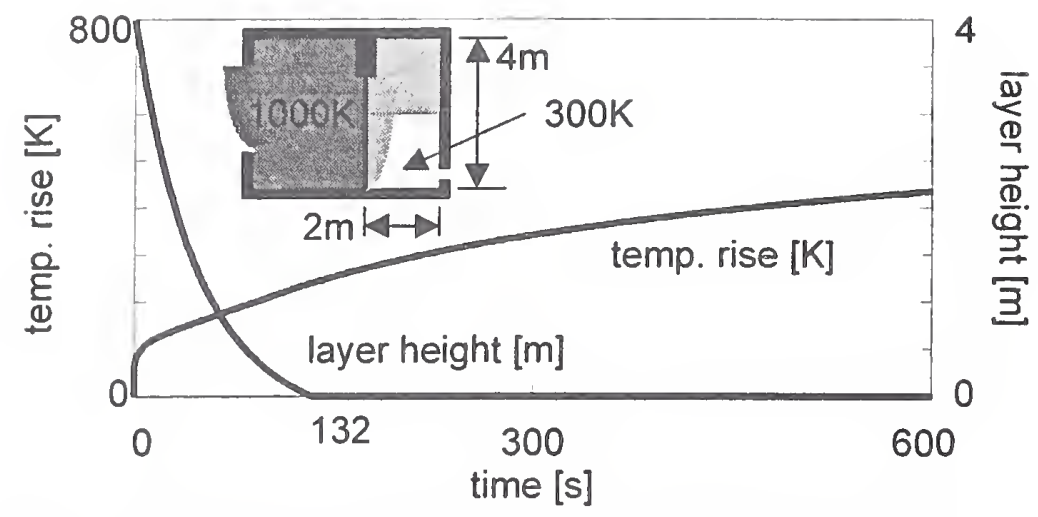

Figure 8 Calculation Example of Hot-Air Filling in a Corridor

\section{(5) Smoke Vent Effectiveness (SMCSYS)}

In the zone type smoke calculations, smoke exhaust is modeled as a sink of mass at the upper layer. However, if the rate of exhaust is large enough, air is induced from the lower layer, which reduces the efficiency of smoke exhaust. The efficiency of smoke vent (exhaust smoke volume / total vented volume) would be (see Figure 9 for symbols)

$\beta=1-V_{a} / V_{e x}=\left\{\begin{array}{cc}d_{s} / R_{c r} & \left(d_{s}<R_{c r}\right) \\ 1 & \left(R_{c r}<d_{s}\right)\end{array}\right.$,

where $R_{c r}$ is the critical radius to prevent the air from being entrained into exhaust flow, which is derived by expanding the concept of Spratts et al ${ }^{12)}$. In a simple manner, critical radius is approximated by as long as the smoke temperature is not so high,

$R_{c r}=\frac{1}{(1.33)^{1 / 3}(\Delta \rho g)^{1 / 6}} V_{e x}^{1 / 3} d_{s}^{1 / 6}$.

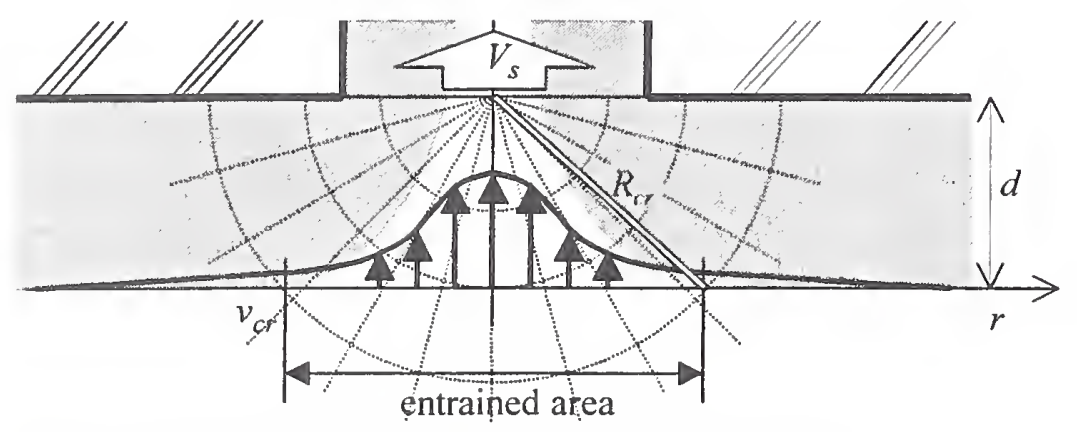

Figure 9 Potential Flow into Mechanical Smoke Vent ${ }^{13)}$

\subsection{Revisions to Increase the Robustmess (VENTLE)}

The existing version of BRI2 is not robust enough to yield reasonable results for "any" combination of input data. In a practical sense, robustness of the numerical code is desirable. 
One of the reasons for insufficient robustness is the convergence criteria for Newton-Raphson iteration procedure. The program uses

(error in mass balance in each layer) $<$ (tolerance limit)

as a criteria for convergence. However, this type of criteria is sometimes too severe to achieve.

Thus it is reasonable to use

(error in mass balance in each layer) / (opening area) < (tolerance limit)

in order to adjust the tolerance limit depending on the stiffness of the problem.

\subsection{Revisions to Increase the Utilization}

There are several points that are minor, but important in the viewpoint of practitioners.

\section{(1) Control Sequence of Active Fire Provisions (OPENDT)}

The control sequence of fire doors and/or shutters will be included in a manner that simulates intended behavior. Change in opening height is included in addition to the change in width.

\section{(2) Smoke Control Sequence (SMCLDT)}

As to the mechanical smoke control systems, the time to trigge, time to normal operation will be included in the sequence of smoke control system. This sub-model reflects the popularization of active (intelligent) fire control.

\section{(3) Other Proposed Changes}

There are other points to be revised. For example, the followings are under consideration.

Inclusion of $t^{2}$-fires in design fires (FIREDT, FPLUME)

Combustion Rate in Gasified Volatile (GPBRAT)

Modeling of long corridor by using virtual openings (adding new rule ?)

Horizontal Openings (OPENDT)

\section{FUTURE DEVELOPMENT}

New version of the BRI2 is not ready for use at the moment of describing this text. However we will finish the task soon to make the new code available in our new performance- based system. As it is at present, new version will again be an open program including its source code. We believe that open system will be an effective way to keep the FSE in good condition.

\section{ACKNOWLEDGEMENTS}

The authors would like to thank all the members and observers of the Working Group for Revision of Smoke Propagation Programs at the Building Center of Japan. Also we acknowledge to Dr. John Rocket for his comments to BRI2T, which assisted our development. 


\section{APPENDIX List of Participants on the Revision of Smoke Propagation Programs}

Coordinator: Takeyoshi Tanaka, Prof., Kyoto Univ.

Members : $\quad$ Takayuki Matsushita, Dr., Assoc. Prof., Kobe University

Kazunori Harada, Dr., Assoc. Prof., Ky oto University

Shigeru Yamada, Dr., Fujita Corp.

Hisaya Nagai, Dr., Instructor, Nagoya Univ.

Yoshifumi Ohmiya, Dr., Building Research Inst.

Ken Matsuyama, Dr., Instructor, Science Univ. of Tokyo

Akiko Nakamichi, General Building Research Corporation of Japan

Hideyuki Iwasaki, Building Center of Japan

Observers : $\quad$ Masahiro Morita, Dr., Assoc. Prof., Science Univ. of Tokyo

Hiroyuki Sunahara, Yamato Protec Co.,

Shigeki Shimomura, Matsushita Electric Works

Junichi Watanabe, ibid

Daisaku Nii, Graduate Student, Kyoto University

Keisuke Himoto, Graduate Student, Kyoto University

\section{REFERENCES}

1. Tanaka, T., A Mathematical Model of a Compartment Fire, BRI Research Paper, No. 70, 1976

2. Tanaka, T., A Model on Fire Spread in Small Scale Buildings, BRI Research Paper, No. 79 and 84,1978

3. Building Center of Japan, Total Fire Safety Design of Buildings, 1986 (in Japanese)

4. Nakamura K., Tanaka, T., A Model for Predicting Smoke Transport in Buildings, Report of the Building Research Institute, No. 123, 1989

5. Building Center of Japan, Computer Programs for Practical Calculations of Some Spread and Evacuation, Second Edition, 1992 (in Japanese)

6. Tanaka, T., Yamada, S., "A Model for Predicting the Yield of Carbon Monoxide in Fire", Journal of Architecture, Planning and Environmental Engineering, Architectural Institute of Japan, No. 447, pp. 1-8, 1993 (in Japanese)

7. Yamada, S., Tanaka, T., "A Model for Predicting the Concentrations of Carbon Monoxide in Transient States", Journal of Architecture, Planning and Environmental Engineering No. 458, pp. 1-8, 1994 (in Japanese)

8. Yamada, S., Tanaka, T., Some Refinement of BRI2 Code - Incorporating CO Yield Model -", Proc. 12th Joint Panel Meeting of the UJNR Panel on Fire Research and Safety, pp. 26- 33, 1992

9. Yamada, S., Tanaka, T., Yoshino H., "Convective Heat Transfer in the Early Stage of Fires in Small Scale Compartments", Journal of Architecture. Planning and Environmental Engineering Architectural Institute of Japan, No. 495, pp. 1-8, 1997 (in Japanese)

10. Yamaguchi, J. Hosozawa, T., Tanaka, T., Wakamatsu, T., "Investigations into Entrainment of Opening Jet Plumes", Journal of Architecture. Planning and Environmental_Engineering Architectural Inst. of Japan, No. 511, pp. 1-8, 1998 (in Japanese)

11. Nii, D., Harada, K., Tanaka, T., Hokoi, S., Nagai, H., "Development of a Model for Coupled Smoke Propagation and Heat Penetration through Fire Shutters", Proc. of JAFSE Spring Meeting (to be published in Japanese), 2000

12. Spratt, D., Heselden, A., J., M., Efficient Extraction of Smoke from a Thin Layer Under a Ceiling, Fire Research Note, No. 1001, Fire Research Station, Feb., 1974

13. Yamaguchi, J., (private communication), 1999 


\title{
Heating, Spalling Characteristics and Residual Properties of High Performance Concrete
}

\author{
Long T. Phan, James R. Lawson, Frank L. Davis \\ National Institute of Standards and Technology \\ Building and Fire Research Laboratory
}

\begin{abstract}
This paper describes results of NIST's experimental program to study effects of elevated temperature exposure on residual mechanical properties of high-performance concrete (HPC). The cylindrical test specimens were made from four mixtures with water-to-cementitious material ratio $(w / \mathrm{cm})$ ranging from 0.22 to 0.57 , and room-temperature compressive strength ranging from $51 \mathrm{MPa}$ to $93 \mathrm{MPa}$. Two of the mixtures contained silica fume. The specimens were heated to an interior temperature of $450{ }^{\circ} \mathrm{C}$, at a heating rate of $5{ }^{\circ} \mathrm{C} / \mathrm{min}$. Elastic modulus and compressive strength were measured after cooling to room temperature. Results indicate that, within the range of compressive strength examined (51 MPa to 93 $\mathrm{MPa}$ ), HPCs with higher original strength (lower $w / \mathrm{cm}$ ) and with silica fume have higher relative residual strength after elevated temperature exposure than those with lower original strength (higher $w / \mathrm{cm}$ ) and without silica fume. The differences in modulus of elasticity are less significant. However, the potential for explosive spalling increased in HPC specimens with lower $w / c m$ and silica fume.
\end{abstract}

\section{INTRODUCTION}

High-performance concrete (HPC) can be manufactured by most concrete plants due to the availability of a variety of additives such as silica fume, fly ash, blast furnace slag, and water reducing admixtures. HPC often offers significant economic, architectural, and structural advantages over conventional concrete, and is being used more widely in structural applications, especially when high durability is desired.

It is well established that mechanical properties of concrete in general are adversely affected by high temperature exposure (Ref. 1 to 10). However, the effects of high temperature exposure on HPC's mechanical properties have been found to be more pronounced than the effects on conventional concrete. More importantly, when exposed to relatively rapid heating (above $1^{\circ} \mathrm{C} / \mathrm{min}$ ), $\mathrm{HPC}$ has been found to be more prone to spalling failure. Spalling failures in laboratory conditions have been characterized from being progressive (continuous spalling of small layers on the specimen's surface) to explosive (sudden disintegration of the specimen accompanied by the release of a large amount of energy which projects the broken concrete fragments with high velocity). It has been theorized that the higher susceptibility of HPC to explosive spalling at high temperature is due, in part, to its lower permeability, which limits the ability of water vapor to escape from the pores. This results in a build-up of vapor pressure within the concrete. As heating increases, the pore pressure also increases. This increase in vapor pressure continues until the internal stresses become so large as to result in sudden, explosive spalling. Spalling, however, has been observed on an inconsistent basis. Often, explosive spalling has occurred to only a few HPC specimens from a larger group of specimens that were subjected to identical testing conditions. This erratic behavior makes it difficult to predict with certainty under what conditions HPC will fail by explosive spalling.

NIST is conducting a multi-year research program that aims to develop a fundamental understanding of the effects of elevated temperature exposure on HPC performance and to quantify the influences of different concrete parameters on the spalling potential and engineering properties of HPC. This paper presents the results that deal with the residual mechanical properties of HPC exposed to elevated temperatures. 


\section{EXPERIMENTAL PROGRAM}

This portion of the test program examines the effects of $w / \mathrm{cm}$ and the presence of silica fume on the residual properties and spalling tendency of HPC exposed to elevated temperatures.

All tests were performed under the steady-state temperature test condition following the test method shown in Figure 1. The concrete cylinder is heated without loading to a target temperature $\mathrm{T}$ using a constant ambient heating rate of $5^{\circ} \mathrm{C} / \mathrm{min}$. The ambient temperature is then held constant for a period of time $t_{l}$ until a steady-state temperature condition has been reached in the specimen. The specimen is subsequently allowed to cool to room temperature and is loaded to failure in uniaxial compression. A "steady-state" temperature condition is defined as when the temperature at the center of the specimen is within $10{ }^{\circ} \mathrm{C}$ of the target temperature and the difference between the surface and center temperatures is less than $10^{\circ} \mathrm{C}$.

All specimens were made using ASTM Type I portland cement, crushed limestone aggregate (13 $\mathrm{mm}$ nominal maximum size) with a fineness modulus (FM) of 5.40, natural sand with an FM of 2.85, silica fume, and a high range water-reducing admixture (HRWRA). The silica fume is in the form of a slurry with a density of $1.42 \mathrm{~g} / \mathrm{cm}^{3}$ and a $54 \%$ silica fume concentration (by mass).

The specimens were made of four concrete mixtures, designated mixtures I to IV. Mixture I had the lowest $w / \mathrm{cm}$ of 0.22 and contained $10 \%$ of silica fume by mass as cement replacement. Mixtures II and III had the same $w / \mathrm{cm}$ of 0.33 , and were designed to have similar strength but differ by the inclusion of silica fume (mixture II contained $10 \%$ of silica fume, while mixture III contained no silica fume). Mixture IV had the highest $w / \mathrm{cm}$ ratio of 0.57 and contained no silica fume. The mixture proportions and properties of fresh and hardened concrete are shown in Table 1. Initial moisture contents represent the amount of free water in the concrete and were obtained by drying small concrete samples (400-day old samples) at $105^{\circ} \mathrm{C}$ until the difference in mass losses between measurements is negligible $(\leq 0.1 \%)$.

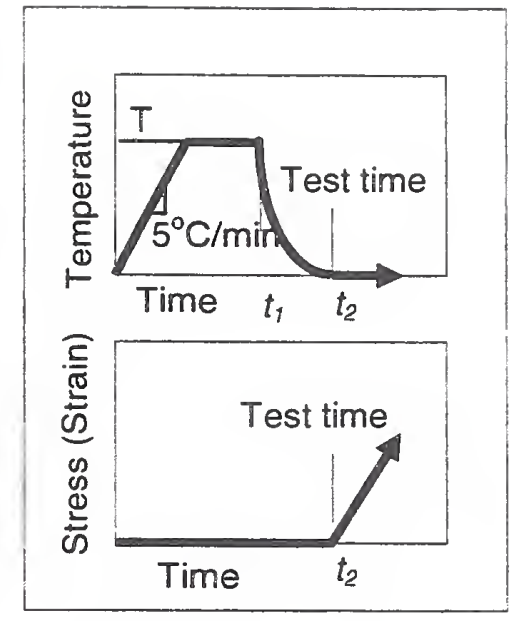

Figure 1. Residual property test method

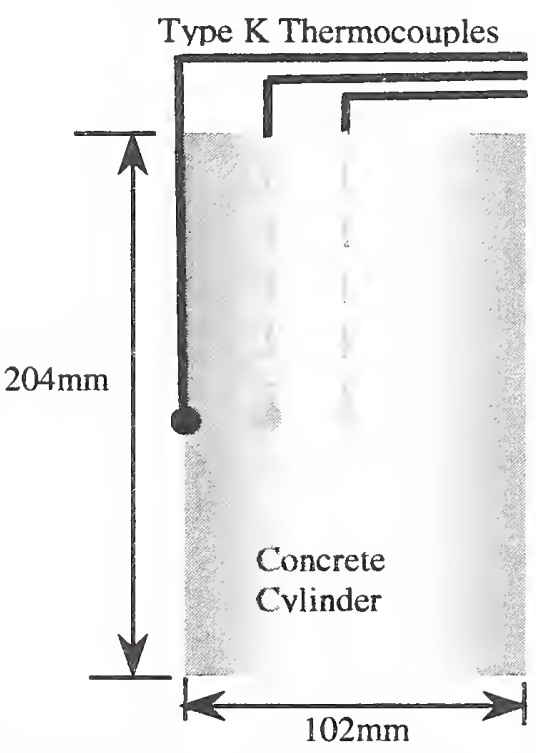

Figure 2. Specimen dimensions and instrumentation scheme

All test specimens were $102 \mathrm{~mm}$ by $204 \mathrm{~mm}$ cylinders. The specimens were cured under water at room temperature (nominally $23{ }^{\circ} \mathrm{C}$ ) until close to test time. Two specimens from each concrete mixture were instrumented with three thermocouples to develop the internal temperature profiles on the cross section of the test specimens (see Figure 2) and establish the heating regimen. Dynamic elastic modulus was measured using the impact-resonance method in ASTM C 215. Compressive strengths were measured according to ASTM C 39 and the ends of the cylinders were ground flat prior to heating.

\section{EXPERIMENTAL RESULTS}

Table 2 summarizes the measurements of heat-induced mass loss and changes in dynamic elastic modulus and compressive strength of the test specimens. Measurement accuracy is expressed in terms of standard 
deviation (SD) and coefficients of variation (CV), which are also listed in Table 2. The convention used in naming the test specimens is as follows:

Test Method - Concrete Mixture - Target Core Temperature - Specimen Number
(Residual Strength)
(I to IV)
$\left(23^{\circ} \mathrm{C}\right.$ to $\left.450^{\circ} \mathrm{C}\right)$
$(1,2,3 \ldots)$

Table 1. Concrete Mixture Proportions and Properties

\begin{tabular}{|c|c|c|c|c|}
\hline Materials and Properties & $\begin{array}{l}\text { Mixture I } \\
(w / c m=0.22)\end{array}$ & $\begin{array}{l}\text { Mixture II } \\
(w / c m=0.33)\end{array}$ & $\begin{array}{l}\text { Mixture III } \\
(w / c m=0.33)\end{array}$ & $\begin{array}{l}\text { Mixture IV } \\
(w / c m=0.57)\end{array}$ \\
\hline $\begin{array}{l}\text { Cement } \\
\text { Water } \\
\text { Coarse Aggregate } \\
\text { Fine Aggregate (SSD) } \\
\text { Silica Fume } \\
\text { HRWRA } \\
\end{array}$ & $\begin{array}{l}595.9 \mathrm{~kg} / \mathrm{m}^{3} \\
133.0 \mathrm{~kg} / \mathrm{m}^{3} \\
845.8 \mathrm{~kg} / \mathrm{m}^{3} \\
733.6 \mathrm{~kg} / \mathrm{m}^{3} \\
65.7 \mathrm{~kg} / \mathrm{m}^{3} \\
400 \mathrm{ml} / \mathrm{m}^{3}\end{array}$ & $\begin{array}{l}595.9 \mathrm{~kg} / \mathrm{m}^{3} \\
198.6 \mathrm{~kg} / \mathrm{m}^{3} \\
845.8 \mathrm{~kg} / \mathrm{m}^{3} \\
733.6 \mathrm{~kg} / \mathrm{m}^{3} \\
65.7 \mathrm{~kg} / \mathrm{m}^{3} \\
354 \mathrm{ml} / \mathrm{m}^{3}\end{array}$ & $\begin{array}{l}661.6 \mathrm{~kg} / \mathrm{m}^{3} \\
198.6 \mathrm{~kg} / \mathrm{m}^{3} \\
845.8 \mathrm{~kg} / \mathrm{m}^{3} \\
733.6 \mathrm{~kg} / \mathrm{m}^{3} \\
0 \\
154 \mathrm{ml} / \mathrm{m}^{3}\end{array}$ & $\begin{array}{l}376.4 \mathrm{~kg} / \mathrm{m}^{3} \\
213.0 \mathrm{~kg} / \mathrm{m}^{3} \\
853.8 \mathrm{~kg} / \mathrm{m}^{3} \\
868.2 \mathrm{~kg} / \mathrm{m}^{3} \\
0 \\
0\end{array}$ \\
\hline $\begin{array}{l}\text { Fresh Concrete } \\
\text { - Slump } \\
\text { - Air Content } \\
\text { Hardened Concrete } \\
\text { - Initial Moisture Content } \\
\text { - Compressive Strength: } \\
\text { 28-day } \\
\text { 58-day } \\
\text { 400-day } \\
\text { - Dynamic Elastic Modulus } \\
\text { 58-day } \\
\text { 400-day }\end{array}$ & $\begin{array}{l}235 \mathrm{~mm} \\
3.2 \% \\
5.03 \% \\
75.3 \mathrm{MPa} \\
86.7 \mathrm{MPa} \\
92.5 \mathrm{MPa} \\
34.4 \mathrm{GPa} \\
47.2 \mathrm{GPa}\end{array}$ & $\begin{array}{l}230 \mathrm{~mm} \\
2.8 \% \\
6.07 \% \\
66.0 \mathrm{MPa} \\
79.5 \mathrm{MPa} \\
87.9 \mathrm{MPa} \\
37.2 \mathrm{GPa} \\
43.7 \mathrm{GPa}\end{array}$ & $\begin{array}{l}35 \mathrm{~mm} \\
2.0 \% \\
6.26 \% \\
53.2 \mathrm{MPa} \\
58.9 \mathrm{MPa} \\
75.5 \mathrm{MPa} \\
36.7 \mathrm{GPa} \\
44.1 \mathrm{GPa}\end{array}$ & $\begin{array}{l}75 \mathrm{~mm} \\
2.5 \% \\
7.33 \% \\
40.6 \mathrm{MPa} \\
41.9 \mathrm{MPa} \\
50.6 \mathrm{MPa} \\
34.4 \mathrm{GPa} \\
36.7 \mathrm{GPa}\end{array}$ \\
\hline
\end{tabular}

\section{Heating Behavior}

Figures 3 and 4 provides information on temperature development and moisture (evaporated capillary pore water and chemically bound water) movement inside the concrete cylinders during heating to a target temperature of $450^{\circ} \mathrm{C}$. In Figure 3, the thick solid line represents the ambient temperature inside the furnace. The thin solid line is the temperature measured on the cylinder surface. The broken dashed line is the temperature at a point inside the cylinder, $25 \mathrm{~mm}$ from the surface (middepth). The dotted line is the temperature at the center of the cylinder, $51 \mathrm{~mm}$ from the surface.

Figure 4 shows the thermal gradient between the surface and center of the cylinder during heating. The first two vertical dashed lines from the left indicate perturbations in the rates of temperature rise between the surface and center of the cylinder ( $1 \mathrm{hr}: 15 \mathrm{~min}$ and $\mathrm{l} \mathrm{hr}: 55 \mathrm{~min}$ ). These coincide with concrete temperatures at the center of the cylinders of slightly above $100{ }^{\circ} \mathrm{C}$ and approximately $205{ }^{\circ} \mathrm{C}$, as indicated by the two vertical dashed lines at the same times on Figure 3 . The perturbations in rates of temperature rise at surface and center of the cylinder are believed to be due to the rapid release of free water and chemically bound water at these two temperatures. At slightly above $100{ }^{\circ} \mathrm{C}$, free water in the concrete begins to evaporate rapidly. A moisture front is driven by the heat toward the core of the specimen, causing a decrease in the rate of temperature rise at the specimen center and thus an increase in the thermal gradient between the specimen's surface and center. Beginning at approximately $205{ }^{\circ} \mathrm{C}$, significant chemically-bound water is released. This caused a similar decrease in the rate of temperature rise at the core, as marked by the second dashed line in Figures 3 and 4 . The thermal gradient between the 
specimen surface and center reaches a maximum of $36^{\circ} \mathrm{C}$ after $2 \mathrm{hr}: 20 \mathrm{~min}$ of heating, at a corresponding center temperature of $270^{\circ} \mathrm{C}$. After this point, the rate of temperature rise on the surface begins to decrease faster than that of the core, causing the thermal gradient to decrease as shown in Figure 4. This trend continues until a true steady-state thermal condition develops after $4 \mathrm{hr}$ of heating, when the surface-to-core thermal gradient is reduced to zero. After $5 \mathrm{hr}: 15 \mathrm{~min}$ of heating, the specimen core reaches the target temperature of $450^{\circ} \mathrm{C}$ and is about $6^{\circ} \mathrm{C}$ higher than the concrete surface.

Heat-induced mass losses for all four concrete mixtures are shown in Figures 5 and 6. Figure 5 shows mass losses obtained from thermogravimetric analysis (TGA) of small samples (approximately $100 \mathrm{mg}$ each) taken from the four concrete mixtures (ref. 10). Figure 6 shows mass losses obtained from heating full cylinders at $5{ }^{\circ} \mathrm{C} / \mathrm{min}$. The two vertical dashed lines in each figure indicate temperatures at which there were changes in rates of mass loss. The TGA results show that, beginning at slightly above $100{ }^{\circ} \mathrm{C}$ (first vertical dashed line in Figure 5), all four mixtures sustain similar temperature rates and amounts of mass loss. This coincides with the changes in the rates of temperature rise between the surface and center of the cylinder due to rapid removal of free water as discussed above (see Figure 3). A slower rate of mass loss begins at about $215^{\circ} \mathrm{C}$ (second vertical dashed line in Figure 5) for all four concrete mixtures. While the mass loss

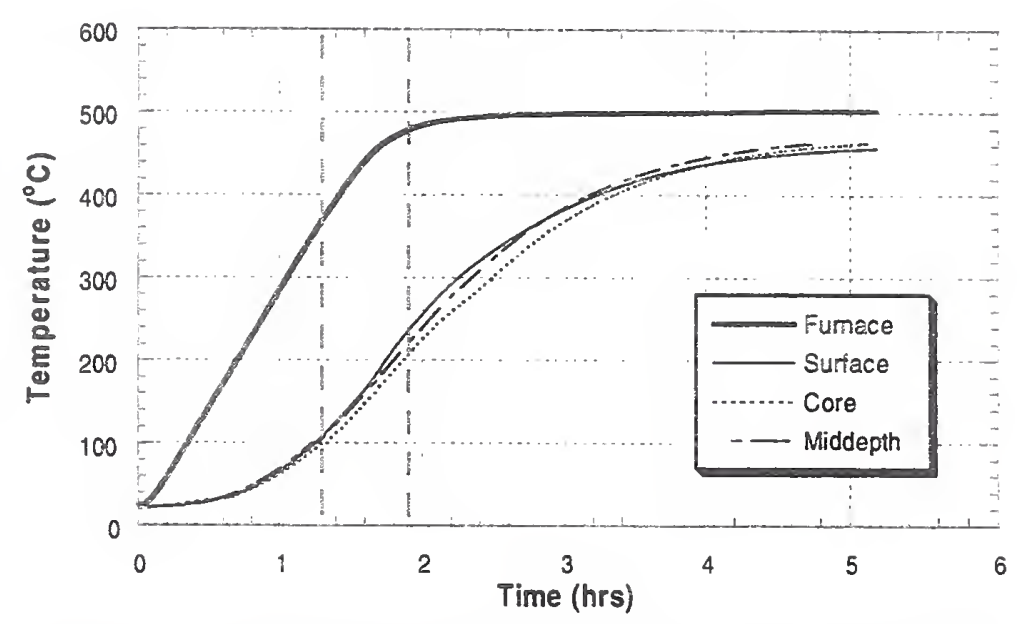

Figure 3. Temperature development inside mixture I cylinder

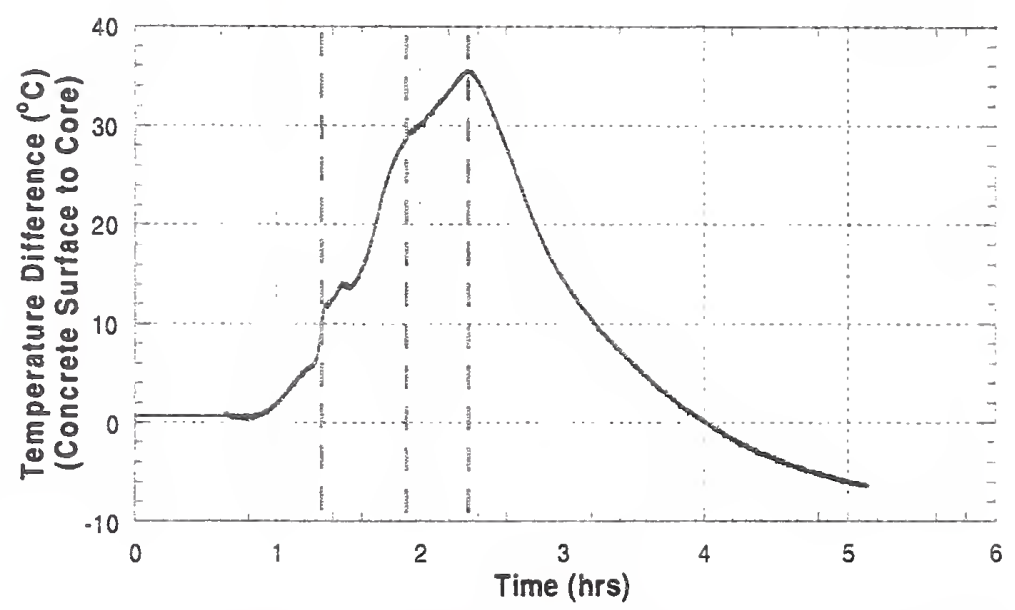

Figure 4. Thermal gradient between surface and core of mixture I cylinder rates were not significantly different for the four mixtures, the amounts of mass loss varied. Mixtures III and IV $(w / \mathrm{cm}=0.33$ and 0.57 , respectively), which contained no silica fume, sustained similar but larger loss than mixtures I and II $(w / c m=0.22$ and 0.33$)$, which contained silica fume. As discussed above, the mass losses at this stage are due primarily to the release and evaporation of chemically bound water in the concrete samples. Figure 6 shows mean mass losses in the specimens. The results show that mass losses in mixture III and IV specimens follow the same two stages that begin at slightly above $100^{\circ} \mathrm{C}$ and $200{ }^{\circ} \mathrm{C}$ as observed in the TGA measurements, with the mixture IV specimen sustaining the highest amount of mass loss. However, the changes in rate of mass loss for mixtures I and II at above $200^{\circ} \mathrm{C}$ are less apparent, with the mixture I specimen sustaining no change in rate of mass loss up to $300^{\circ} \mathrm{C}$. It should be noted that mass loss data for mixture I specimens at $450{ }^{\circ} \mathrm{C}$ are not available due to explosive spalling of all three specimens while being heated to that target temperature. More detailed discussion concerming the explosive spalling of this group of specimens is given in the next section. 
Recall that the initial free water moisture contents for the four concrete mixtures ranged between $5.0 \%$ for mixture I and 7.3 $\%$ for mixture IV (see Table 1). The ranges of free water losses in all four concrete mixtures are represented by the horizontal band in Figures 5 and 6 (at normalized masses of 0.93 and 0.95 ). The TGA results, shown in Figure 5, indicate that all four mixtures sustained significant loss of free water and chemically bound water at about $215{ }^{\circ} \mathrm{C}$ (marked by the second vertical dashed line). However, the results of heating full-size specimens, shown in Figure 6, indicate that while specimens of mixtures II, III, and IV appear to lose most of this free water at $215{ }^{\circ} \mathrm{C}$, the water in mixture I specimen was not completely lost at this temperature (only $4 \%$ loss). Similarly, but to a lesser extent, the mixture II specimens also experienced a slightly more restrictive process of water loss (5.5 $\%$ ) compared with the TGA result. These differences in mass loss between the TGA samples and the heated cylinders indicate that, while mixture III and IV cylinders have little problem losing water during heating to high temperatures, the silica fume containing mixture I and, to a lesser extent, mixture II cylinders will have a more restrictive water loss process and could thus develop significant internal pressures (leading to spalling).

\section{Spalling Characteristics}

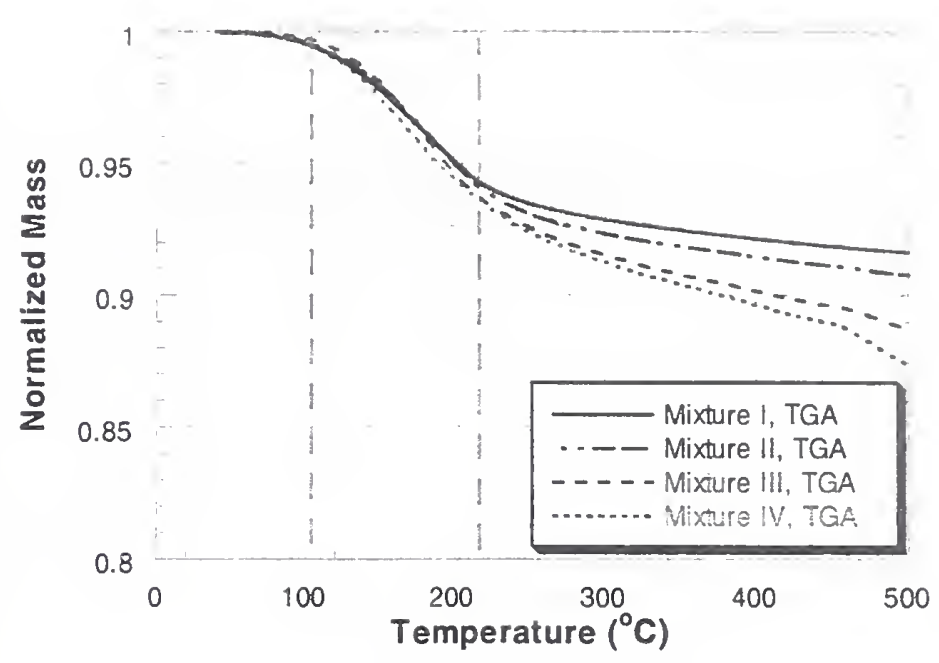

Figure 5. Mass losses from TGA

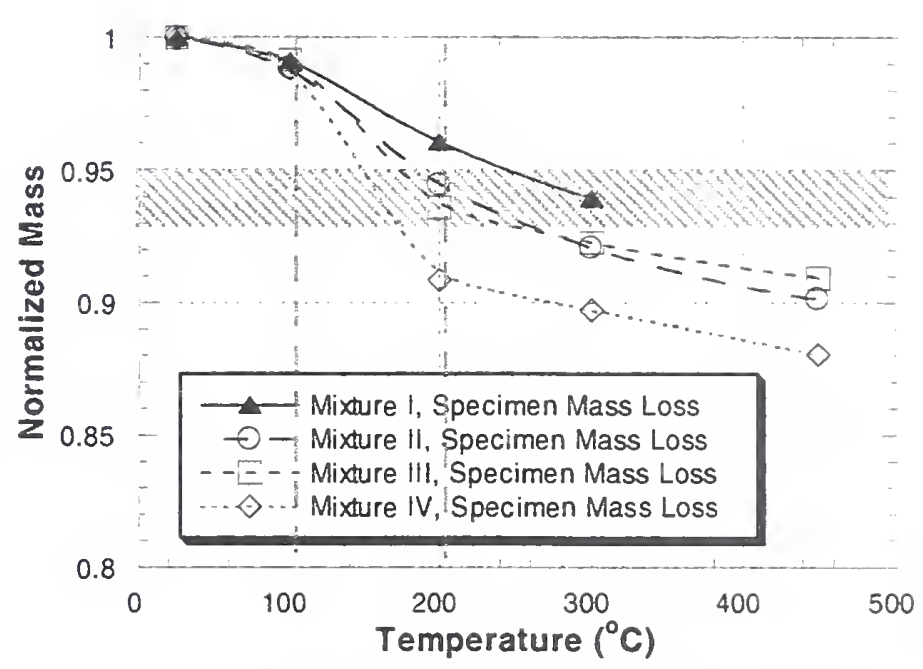

Figure 6. Mass losses from heating of full-size cylinders

As listed in Table 2, explosive spalling occurred during heating of five specimens, four of mixture I concrete and one of mixture II. Both mixtures I and II contained 10 percent of silica fume as cement replacement. Explosive spalling is characterized by the sudden disintegration of the specimens into fine fragments. This disintegration is accompanied by a sharp loud sound and the release of a large amount of energy that projects the small concrete fragments at high velocity in all directions. Reconstruction of the exploded specimens shows that the largest remaining piece in all cases is the concrete core, which measured approximately $70 \mathrm{~mm}$ at maximum width and $120 \mathrm{~mm}$ at maximum length. An approximately 20 -mm thick outer shell of fragmented concrete surrounds this core. The depth of approximately $20 \mathrm{~mm}$ appears to be the location of the primary fracture surface. Figure 7 shows the fragments of an exploded specimen and a schematic of the cracking patterns in a reconstructed specimen.

Of the four exploded mixture I specimens, one belongs to a group of five specimens with a target temperature of $300{ }^{\circ} \mathrm{C}$ (specimen RS-I-300-2). This specimen exploded at $2 \mathrm{hr}: 5 \mathrm{~min}$ into the heating 
process, with the furnace temperature being maintained at $300{ }^{\circ} \mathrm{C}$ and the temperature at the center of the cylinder was $240^{\circ} \mathrm{C}$. The other three exploded mixture I specimens belong to the group of three specimens being heated to $450^{\circ} \mathrm{C}$ (specimens RS-I-450-1 to 3). These specimens exploded when the centers of the cylinders reached temperatures ranging from $240{ }^{\circ} \mathrm{C}$ to at $280{ }^{\circ} \mathrm{C}$. The exploded mixture II specimen (RS-II-300-4) belongs to the group being heated to $300{ }^{\circ} \mathrm{C}$. This cylinder exploded when the temperature at its center reached $275^{\circ} \mathrm{C}$. The temperature range in which explosive spalling occurred in mixture I specimens is superposed on the temperature profile history (Figure 5) and thermal gradient history (Figure 6) as shown in Figures 8 and 9. As can be seen in Figure 9, the

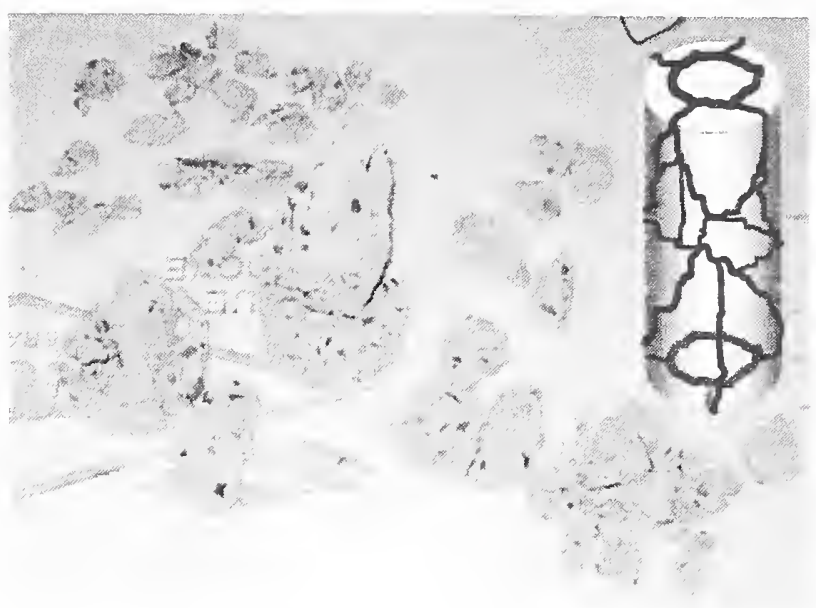

Figure 7. Remnants of an exploded cylinder and rendering of the fracture formation temperature range in which explosive spalling occurred coincides with the time when the maximum thermal gradient between the specimen surface and center occurred. This suggests that, while internal pore pressure may be the primary cause for the explosive spalling of the specimens, as evidenced by the high velocity with which the concrete fragments were projected at failure, the buildup of thermally induced strain energy was also at a maximum at this time, and thus thermal stress might have a secondary role in this failure.

\section{Residual Mechanical Properties}

Compressive strengths of unheated $\left(23^{\circ} \mathrm{C}\right)$ and heated specimens, normalized with respect to the mean strengths of the unheated specimens, are plotted with respect to the target temperatures in Figure 10. The individual test data are shown by symbols and the means by lines. As shown in Figure 10, relative compressive strengths of mixtures III and IV concretes varied similarly with increasing temperature. The strength reduction in these two mixtures can be characterized by an initial strength reduction of between $25 \%$ to $30 \%$ at 100 ${ }^{\circ} \mathrm{C}$. This is followed by no significant change in relative compressive strength between $100{ }^{\circ} \mathrm{C}$ to $300{ }^{\circ} \mathrm{C}$. Further reduction in compressive strength occurs at temperatures above $300^{\circ} \mathrm{C}$. Exposure to $450^{\circ} \mathrm{C}$ caused a $50 \%$ loss in compressive strength for mixtures III and IV.

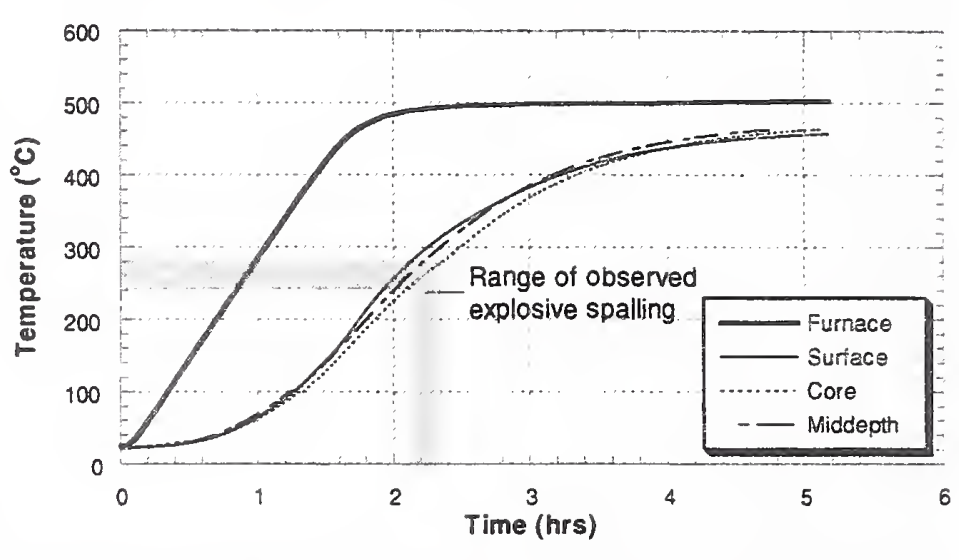

Figure 8. Temperature and time ranges of observed explosive spalling in mixture I specimens

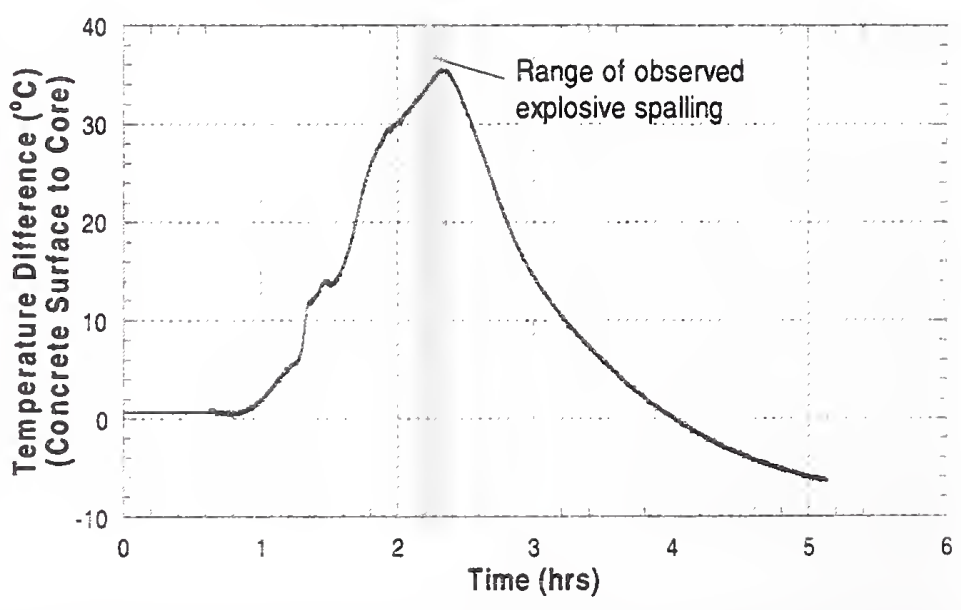

Figure 9. Range of thermal gradient when explosive spalling occurred 
The concretes with silica fume, mixtures I and $\mathrm{II}$, had similar strength reductions of between $10 \%$ to $15 \%$ at $100{ }^{\circ} \mathrm{C}$. At temperatures above $100{ }^{\circ} \mathrm{C}$, the relative strength of mixture II continued to drop almost linearly - with increasing temperature, while mixture I experienced a strength recovery at temperatures between $100{ }^{\circ} \mathrm{C}$ and $200{ }^{\circ} \mathrm{C}$. Between $200{ }^{\circ} \mathrm{C}$ and $300^{\circ} \mathrm{C}$, the relative strength of mixture I decreased at a similar rate as that of mixture II. However, mixture I sustained only $10 \%$ to $20 \%$ strength loss at $300{ }^{\circ} \mathrm{C}$, while the strength loss for mixture II was at $30 \%$ to $35 \%$ at this temperature. At $450^{\circ} \mathrm{C}$, mixture II sustained a similar amount of strength loss, about $50 \%$, as for mixtures III and IV. Analysis of variance shows that, at $100{ }^{\circ} \mathrm{C}$, mixtures I and II had similar relative strength loss. This strength loss was less than that of mixtures III and IV. At $200^{\circ} \mathrm{C}$, mixture I had the least relative strength loss, while mixtures II, III, and IV sustained similar strength loss. This trend continued at $300^{\circ} \mathrm{C}$, with mixture III sustained a slightly less strength loss than mixtures II and IV. Compressive strength data for mixture I at $450{ }^{\circ} \mathrm{C}$ was not available due to explosive spalling of the entire group of specimens (RS-450-I-1 to 3). Data for mixtures II, III, and IV shows no different in relative strength at this temperature.

These results indicate that, within the ranges of original compressive strengths (51 $\mathrm{MPa}$ to $93 \mathrm{MPa}$ ) and $w / \mathrm{cm}$ ratios $(0.22$ to 0.57$)$ studied in this program, concrete with higher original compressive strength, or lower $w / \mathrm{cm}$ ratio, experienced less relative strength loss due to high temperature exposure than concrete with lower original compressive strength. In concretes with similar $w / \mathrm{cm}$ ratio and strength (mixture II and III), the presence of silica fume appears to result in lower strength loss up to the temperature of 200 ${ }^{\circ} \mathrm{C}$.

Figure 11 shows the variation of residual dynamic modulus of elasticity with increasing temperatures. The symbols in Figure 11 represent individual test data, and the lines represent the means. As shown in this figure, the relative dynamic modulus of elasticity of the four mixtures decreased similarly with increasing temperature. Between room temperature $\left(23^{\circ} \mathrm{C}\right)$ and 300 ${ }^{\circ} \mathrm{C}$, the dynamic modulus of elasticity for all mixtures decreased by more than $50 \%$. Between $300{ }^{\circ} \mathrm{C}$ to $450{ }^{\circ} \mathrm{C}$, the rate of elastic modulus reduction decreased.

Mixtures II and III, which have similar room-temperature compressive strengths (81 MPa and $72 \mathrm{MPa}$, respectively), display

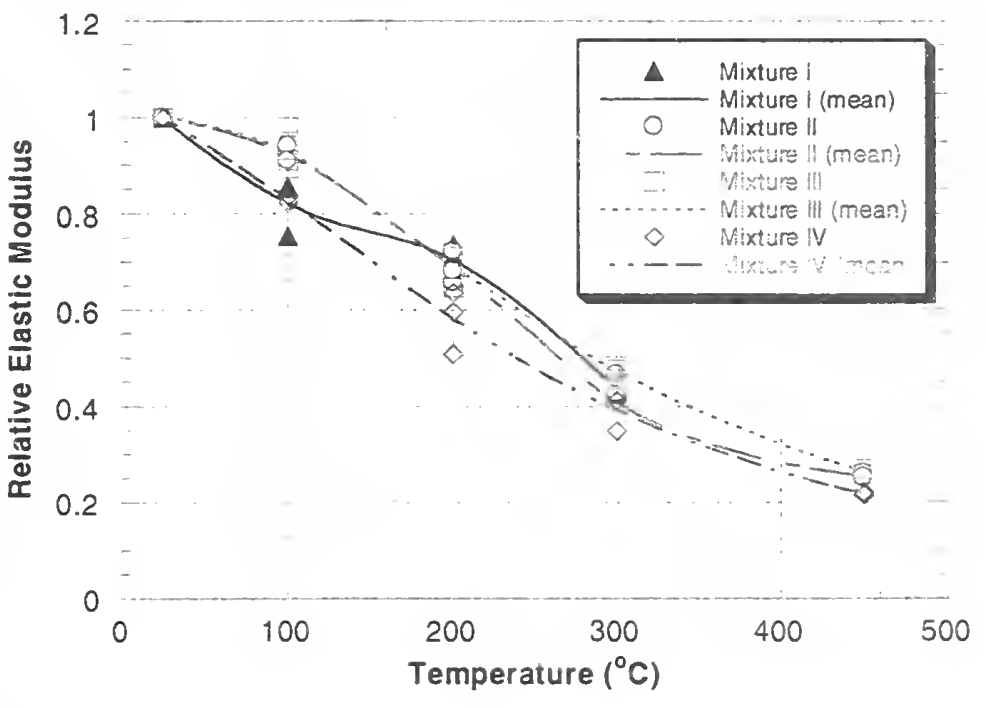

Figure 11. Residual relative dynamic modulus of elasticity vs. temperature 
Table 2. Summary of test results

\begin{tabular}{|c|c|c|c|c|c|c|c|c|c|c|c|}
\hline & Test Name & $\begin{array}{l}\text { Mass } \\
\text { Loss } \\
(\%) \\
\end{array}$ & $\begin{array}{l}\text { SD/CV } \\
(\%) \text { of } \\
\text { Mass } \\
\text { Loss } \\
\end{array}$ & $\begin{array}{c}\text { Edyn } \\
\text { Before } \\
\text { Heating } \\
(\mathrm{Pa}) \\
\end{array}$ & $\begin{array}{c}\text { Edyn After } \\
\text { Heating } \\
(\mathrm{Pa})\end{array}$ & $\begin{array}{c}\text { Residual } \\
\text { Edyn } \\
(\%) \\
\end{array}$ & $\begin{array}{c}\text { SD/CV } \\
\text { (\%) of } \\
\text { Residual } \\
\text { E }\end{array}$ & $\begin{array}{c}\text { Test } \\
\text { Strength } \\
\text { (MPa) }\end{array}$ & $\begin{array}{c}\text { Residual } \\
\text { Strength } \\
(\%) \\
\end{array}$ & $\begin{array}{c}\text { SD/CV } \\
\text { (\%) of } \\
\text { Residual } \\
\text { Strength }\end{array}$ & Spalling \\
\hline 选 & 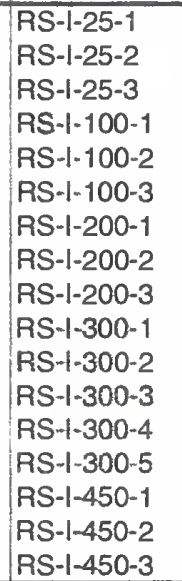 & $\begin{array}{l}0.00 \\
0.00 \\
0.00 \\
1.02 \\
0.75 \\
0.84 \\
4.38 \\
3.57 \\
3.85 \\
6.19 \\
\\
6.02 \\
6.07 \\
5.94\end{array}$ & $.14 / 15.8$ & $\begin{array}{l}4.73 E+10 \\
4.71 E+10 \\
4.71 E+10 \\
4.60 E+10 \\
4.41 E+10 \\
4.24 E+10 \\
4.46 E+10 \\
4.68 E+10 \\
4.67 E+10 \\
4.61 E+10 \\
4.70 E+10 \\
4.54 E+10 \\
4.71 E+10 \\
4.72 E+10 \\
4.81 E+10 \\
4.65 E+10 \\
4.59 E+10\end{array}$ & $\begin{array}{l}3.47 E+10 \\
3.76 E+10 \\
3.63 E+10 \\
2.98 E+10 \\
3.45 E+10 \\
3.34 E+10 \\
2.02 E+10 \\
\\
1.97 E+10 \\
2.00 E+10 \\
2.05 E+10\end{array}$ & $\begin{array}{l}100.0 \\
100.0 \\
100.0 \\
75.5 \\
85.2 \\
85.7 \\
66.7 \\
73.6 \\
71.4 \\
43.8 \\
\\
43.3 \\
42.4 \\
43.5\end{array}$ & $0.6 / 1.4$ & $\begin{array}{l}90.56 \\
90.60 \\
96.40 \\
75.64 \\
80.34 \\
85.92 \\
93.29 \\
87.84 \\
87.08 \\
82.85 \\
\\
76.41 \\
82.19\end{array}$ & \begin{tabular}{|l}
100.0 \\
100.0 \\
100.0 \\
81.8 \\
86.8 \\
92.9 \\
100.8 \\
94.9 \\
94.1 \\
89.5 \\
\end{tabular} & $\begin{array}{l}3.6 / 3.8 \\
3.8 / 4.4\end{array}$ & $\begin{array}{l}\text { YES } \\
\text { YES } \\
\text { YES } \\
\text { YES }\end{array}$ \\
\hline 焉 & 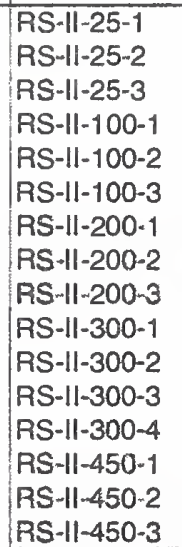 & $\begin{array}{l}0.00 \\
0.00 \\
0.00 \\
1.22 \\
1.13 \\
1.09 \\
6.03 \\
5.08 \\
5.55 \\
8.09 \\
7.80 \\
7.91\end{array}$ & $\begin{array}{r}.07 / 5.8 \\
.48 / 8.6 \\
.15 / 1.8\end{array}$ & $\begin{array}{l}4.32 E+10 \\
4.39 E+10 \\
4.40 E+10 \\
4.25 E+10 \\
4.17 E+10 \\
4.36 E+10 \\
4.34 E+10 \\
4.29 E+10 \\
4.37 E+10 \\
4.40 E+10 \\
4.31 E+10 \\
4.30 E+10 \\
\\
4.36 E+10 \\
4.50 E+10 \\
4.36 E+10\end{array}$ & $\begin{array}{l}3.94 E+10 \\
3.92 E+10 \\
3.97 E+10 \\
2.86 E+10 \\
3.10 E+10 \\
2.98 E+10 \\
1.88 E+10 \\
1.98 E+10 \\
2.00 E+10 \\
1.13 E+10 \\
1.12 E+10 \\
1.10 E+10\end{array}$ & $\begin{array}{l}100.0 \\
100.0 \\
100.0 \\
92.6 \\
94.1 \\
91.0 \\
65.8 \\
72.1 \\
68.1 \\
42.8 \\
45.9 \\
46.6 \\
\\
26.0 \\
25.0 \\
25.2\end{array}$ & $\left\{\begin{array}{l}1.6 / 1.7 \\
3.2 / 4.6 \\
2.0 / 4.5 \\
0.5 / 2.1\end{array}\right.$ & $\begin{array}{l}88.87 \\
87.66 \\
87.31 \\
78.53 \\
79.11 \\
71.78 \\
67.75 \\
69.84 \\
71.32 \\
58.84 \\
56.62 \\
61.22 \\
\\
41.32 \\
43.78 \\
41.40\end{array}$ & $\begin{array}{l}100.0 \\
100.0 \\
100.0 \\
89.3 \\
90.0 \\
81.6 \\
77.0 \\
79.4 \\
81.1 \\
66.9 \\
64.4 \\
69.6 \\
47.0 \\
49.8 \\
47.1\end{array}$ & $\begin{array}{c}2.6 / 3.9 \\
1.5 / 3.3\end{array}$ & YES \\
\hline $\begin{array}{l}\text { 三 } \\
\frac{\Phi}{3} \\
\frac{x}{x} \\
\frac{x}{z}\end{array}$ & 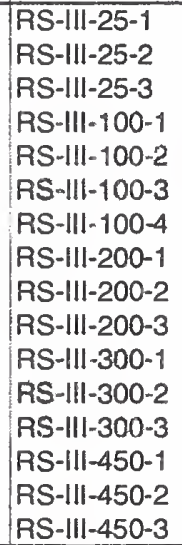 & $\begin{array}{l}0.00 \\
0.00 \\
0.00 \\
0.83 \\
0.69 \\
0.88 \\
0.97 \\
6.73 \\
6.18 \\
6.30 \\
8.09 \\
7.54 \\
7.61 \\
9.31 \\
8.54 \\
9.31\end{array}$ & $\begin{array}{l}.12 / 13.9 \\
.29 / 4.5 \\
.30 / 3.9 \\
.45 / 4.9\end{array}$ & $\begin{array}{l}4.41 E+10 \\
4.34 E+10 \\
4.48 E+10 \\
4.20 E+10 \\
4.13 E+10 \\
4.05 E+10 \\
4.25 E+10 \\
4.33 E+10 \\
4.25 E+10 \\
4.19 E+10 \\
4.24 E+10 \\
4.31 E+10 \\
4.36 E+10 \\
4.33 E+10 \\
4.50 E+10 \\
4.33 E+10\end{array}$ & $\begin{array}{l}3.85 E+10 \\
4.06 E+10 \\
3.88 E+10 \\
3.80 E+10 \\
2.80 E+10 \\
3.05 E+10 \\
2.98 E+10 \\
1.94 E+10 \\
2.08 E+10 \\
2.08 E+10 \\
1.16 E+10 \\
1.17 E+10 \\
1.16 E+10\end{array}$ & $\begin{array}{l}100.0 \\
100.0 \\
100.0 \\
91.8 \\
98.4 \\
95.8 \\
89.4 \\
64.6 \\
71.8 \\
71.0 \\
45.7 \\
48.3 \\
47.7 \\
26.9 \\
25.9 \\
26.9 \\
\end{array}$ & $\begin{array}{l}3.9 / 4.2 \\
4.0 / 5.7 \\
1.4 / 2.9 \\
0.6 / 2.2\end{array}$ & \begin{tabular}{|l|}
75.43 \\
76.54 \\
74.23 \\
58.12 \\
55.94 \\
59.08 \\
53.31 \\
59.58 \\
52.47 \\
56.73 \\
55.54 \\
57.52 \\
53.50 \\
41.75 \\
36.60 \\
38.72
\end{tabular} & $\begin{array}{l}100.0 \\
100.0 \\
100.0 \\
77.1 \\
74.2 \\
78.4 \\
70.7 \\
79.0 \\
69.6 \\
75.2 \\
73.7 \\
76.3 \\
70.9 \\
55.4 \\
48.5 \\
51.3 \\
\end{array}$ & $\begin{array}{l}4.7 / 6.4 \\
2.7 / 3.6 \\
3.4 / 6.6\end{array}$ & \\
\hline$\frac{\geq}{0}$ & $\begin{array}{l}R S-I V-25-1 \\
R S-I V-25-2 \\
R S-I V-25-3 \\
R S-I V-100-1 \\
\text { RS-IV-100-2 } \\
\text { RS-IV-100-4 } \\
\text { RS-IV-200-1 } \\
\text { RS-IV-200-2 } \\
\text { RS-IV-200-3 } \\
\text { RS-IV-300-1 } \\
\text { RS-IV-300-2 } \\
\text { RS-IV-300-3 } \\
\text { RS-IV-450-1 } \\
\text { RS-IV-450-2 } \\
\text { RS-IV-450-3 }\end{array}$ & $\begin{array}{l}0.00 \\
0.00 \\
0.00 \\
1.33 \\
0.88 \\
1.27 \\
9.53 \\
8.96 \\
8.94 \\
9.59 \\
9.93 \\
11.33 \\
11.96 \\
12.30 \\
11.61\end{array}$ & $.24 / 21.1$ & $\begin{array}{l}3.67 E+10 \\
3.67 E+10 \\
3.67 E+10 \\
3.72 E+10 \\
3.70 E+10 \\
3.75 E+10 \\
3.65 E+10 \\
3.65 E+10 \\
3.73 E+10 \\
3.66 E+10 \\
3.70 E+10 \\
3.67 E+10 \\
3.67 E+10 \\
3.63 E+10 \\
3.74 E+10\end{array}$ & $\begin{array}{l}3.05 E+10 \\
3.10 E+10 \\
3.11 E+10 \\
1.85 E+10 \\
2.32 E+10 \\
2.22 E+10 \\
1.27 E+10 \\
1.53 E+10 \\
1.50 E+10 \\
7.96 E+09 \\
7.84 E+09 \\
8.29 E+09\end{array}$ & $\begin{array}{l}100.0 \\
100.0 \\
100.0 \\
82.2 \\
83.6 \\
82.9 \\
50.7 \\
63.6 \\
59.5 \\
34.8 \\
41.2 \\
41.0 \\
21.7 \\
21.6 \\
22.2\end{array}$ & $\begin{array}{l}0.7 / 0.8 \\
6.6 / 11.4\end{array}$ & $\begin{array}{l}51.91 \\
51.03 \\
48.97 \\
35.21 \\
35.16 \\
36.58 \\
38.82 \\
36.45 \\
36.58 \\
34.91 \\
33.15 \\
32.96 \\
27.06 \\
25.46 \\
24.29\end{array}$ & $\begin{array}{l}100.0 \\
100.0 \\
100.0 \\
69.5 \\
69.4 \\
72.2 \\
76.7 \\
72.0 \\
72.2 \\
68.9 \\
65.5 \\
65.1 \\
53.4 \\
50.3 \\
48.0\end{array}$ & $\begin{array}{l}3.0 / 3.0 \\
1.6 / 2.3 \\
2.6 / 3.6 \\
2.1 / 3.2\end{array}$ & \\
\hline
\end{tabular}


almost identical residual dynamic modulus of elasticity. The reduction in modulus of mixtures II and III concretes are consistently less (5\% to $10 \%$ ) than that of mixture IV, which has a room-temperature compressive strength of $47 \mathrm{MPa}$. The reduction in dynamic modulus of elasticity for mixture I $(w / \mathrm{cm}=0.22,98 \mathrm{MPa})$ is less consistent within the range of temperatures examined.

\section{SUMMARY AND DISCUSSIONS}

This study examined the effects of exposure to temperatures up to $450{ }^{\circ} \mathrm{C}$ on the heating behavior, potential for explosive spalling, and residual mechanical properties of four HPC mixtures. The following summarizes experimental results and observations:

- The combination of low $w / \mathrm{cm}$ (0.33 or less) and silica fume appears to increase the potential for explosive spalling in unstressed residual strength tests. The temperatures at the center of the cylinders when explosive spalling occurred were in the range of $240^{\circ} \mathrm{C}$ to $280^{\circ} \mathrm{C}$, slightly beyond the temperatures at which much of the chemically bound water has already been released from the concrete matrix.

- Evidence of a more restricted mass loss process in the cylinders that exploded, coupled with the violent fragmentation of the cylinders, further support the hypothesis that internal pore pressure buildup is the primary cause for explosive spalling. However, the fact that explosive spalling occurred when the maximum thermal gradient also existed in the specimen implies that the buildup of strain energy due to thermal stress might have a secondary role in the explosive spalling mechanism. Whether this secondary role is to delay or to contribute to explosive spalling remains to be quantified (since the aggregates expand with increasing temperature while the cement paste contracts).

- Within the ranges of original compressive strengths (51 MPa to $93 \mathrm{MPa})$ and $w / \mathrm{cm}(0.22$ to 0.57$)$ examined in this test program, HPC with higher original compressive strength, or lower $w / \mathrm{cm}$ ratio, sustained lower relative strength loss due to high temperature exposure than those with lower original compressive strength. In HPC with similar $w / \mathrm{cm}$ and strength (mixture II and III), the presence of silica fume appears to result in lower strength loss up to the temperature of $200{ }^{\circ} \mathrm{C}$.

- Dynamic modulus of elasticity of the four HPC mixtures in this test program decreased similarly with increasing temperature. Between room temperature $\left(23^{\circ} \mathrm{C}\right)$ and $300{ }^{\circ} \mathrm{C}$, the dynamic modulus of elasticity for all mixtures decreased by more than $50 \%$. Between $300{ }^{\circ} \mathrm{C}$ to $450{ }^{\circ} \mathrm{C}$, the rate of modulus reduction decreased.

\section{REFERENCES}

1 Schneider, U.; "Properties of Materials at High Temperatures - Concrete", RILEM - Committee 44 PHT, University of Kassel, Kassel, June, 1985.

2 Phan, L.T.; Carino, N.J.; Duthinh, D.; Garboczi, E., "NIST International Workshop on Fire Performance of High Strength Concrete, NIST, Gaithersburg, MD, February 13-14, 1997 Proceedings," NIST SP 919, Gaithersburg, Maryland, September 1997.

3 Castillo, C.; Durrani, A. J., "Effect of transient high temperature on high-strength concrete," ACI Materials Journal, v.87, n.1, 1990, pp. 47-53.

4 Hertz K., "Danish Investigations on Silica Fume Concretes at Elevated Temperatures," Proceedings of ACI 1991 Spring Convention, March 17-21.

5 Sullivan, P. J. E.; Shanshar, R., "Performance of concrete at elevated temperatures (as measured by the reduction in compressive strength," Fire Technology, v. 28, n. 3, Aug 1992, pp. 240-250.

6 Abrams, M.S., "Compressive Strength of Concrete at Temperatures to $1600^{\circ} \mathrm{F}$," ACI SP 25 , Temperature and Concrete, Detroit, Michigan, 1971. 
7 Furumura, F.; Abe, T.; Shinohara, Y.; "Mechanical Properties of High Strength Concrete at High Temperatures," Proceedings of the Fourth Weimar Workshop on High Performance Concrete: Material Properties and Design, Weimar, Germany, October 4th and 5th, 1995, pp. 237 - 254.

8 Felicetti, R.;Gambarova, P.G.; Rosati, G.P.; Corsi, F.; Giannuzzi, G.; "Residual Mechanical Properties of HSC Subjected to High-Temperature Cycles," Proceedings, 4th International Symposium on Utilization of High-Strength/High-Performance Concrete, Paris, France,1996, pp. 579-588.

9 Phan, L.T., "Fire Performance of High-Strength Concrete: A Report of the State of the Art," NISTIR 5934, National Institute of Standards and Technology, Gaithersburg, Maryland 20899, December 1996.

10 Bentz, D.P., "Fibers, Percolation, and Spalling of High Performance Concrete," accepted by ACI Materials Journal, 2000. 


\title{
Wind Effect on Fire Behavior in Compartment
}

\author{
Tomohiro NARUSE
}

Building Research Institute

Ministry of Construction

Tatehara 1, Tsukuba, Ibakraki, 305-0802, JAPAN

\section{Yuji HASEMI}

School of Science and Engineering

Waseda University

Okubo 3-4-1, Shinjyuku-ku, Tokyo, 169-8555, JAPAN

\begin{abstract}
For the wind effect on the burning cribs in unconfined space and in compartment, it has not been well discussed in spite of its importance. Now we are performing the research project on Disaster Prevention in Town Planning and are planning the fire experiments. In this paper we introduce the state of the art of the experimental results of burning wood cribs in the compartment and in unconfined space using BRI Fire Research Wind Tunnel (BRI FRWT).

In this work it was shown that the mass loss rates of cribs in unconfined space and in compartment with or without ceiling are proportional to wind velocity. And the equivalence ratio $\phi$ varied in the wide range from around 2 (fuel rich) to around 0.5 (air rich).
\end{abstract}

\section{INTRODUCTION}

A lot of studies concerning compartment fire have been done. But the most of them deal with the fire phenomena without wind effect. Because the air plays a very important part in fire phenomena, the wind effect is very important. When the wind blows strongly and fire happens, after windows beak out, fire spreads rapidly and largely, in such cases it happens to become city fire.

The cellulosic materials are the main combustibles of actual fire, and wood crib is general to be used as the fuel in previous experimental work. There are a lot of models to describe mass loss rates of unconfined burning of crib without wind [1-4]. Because in these models the air entering in cribs is one of the parameters governing the mass loss rates of the burning cribs, it is expected that the air entering in cribs by wind will be the parameter, too.

For the wind effect on the burning cribs, Harmathy [5] indicates the effects of forced ventilation on the burning cribs by experiments using air chamber. Because he supplies air into cribs from 4 sides, the result is not clear to apply for the effect of natural wind blowing on the combustibles.

The main purpose of previous work of burning cribs in wind is to make a model of flame length $[6,7]$. But basically it has not been well discussed about the wind effect on the mass loss rates of the burning cribs, even though it is important for fire safety.

For the wind effect on the burning combustibles in compartment, Ogawa et.al. [8] examined experimentally using the Methanol as fuel. But it has not been discussed for the cellulosic materials.

Now we are performing the research project on Disaster Prevention in Town Planning and plan the fire experiments. In this paper we introduce the state of the art of the experimental results of burning wood cribs in the compartment and in unconfined space using BRI FRWT. 


\section{EXPERIMENT}

\subsection{Burning of cribs in unconfined space in wind}

The crib1 $\sim$ crib3 shown in Table 1 were used as the combustible. The two layers of ceramic board of $0.025 \mathrm{~m}$ were put on the table of weighing device for insulation. The nominal wind velocity was $0,2,4,6,9 \mathrm{~m} / \mathrm{sec}$ using BRI FRWT. The three or four sticks of insulation board of $0.01 \mathrm{~m}^{*} 0.01 \mathrm{~m} * 0.45 \mathrm{~m}$ soaked with Methanol were used as the igniter. The weight of crib was measured by load cells (Transducer C2M1-50k, MINEBEA Co., LTD) and the wind velocity was measured by the anemometer (Kanomax Anemomaster Model6141, NIHON KAGAKU KOGYO Co., LTD) at the position of $5 \mathrm{~m}$ windward and $0.97 \mathrm{~m}$ height at the interval of 0.5 second.

Table 1 The specification of crib

\begin{tabular}{rrrrrrrrr}
\hline & $n$ & $N$ & WO & $h$ & $A f$ & $A s$ & $A b$ & vin \\
\hline crib1 & 8 & 6 & 11.42 & 0.18 & 2.2704 & 0.0234 & 0.0676 & 0.586 \\
crib2 & 6 & 8 & 11.42 & 0.24 & 2.4228 & 0.0384 & 0.1024 & 0.676 \\
crib3 & 8 & 11 & 20.64 & 0.33 & 4.1664 & 0.0390 & 0.0676 & 0.793 \\
\hline
\end{tabular}

The stick of $0.03 \mathrm{~m}^{*} 0.03 \mathrm{~m}^{*} 0.5 \mathrm{~m}$ of Douglas fir was used for crib.

The percentage of water content was $7.7 \%$

\subsection{Burning of cribs in compartment in wind}

The crib3 shown in Table 1 were used as the combustible. The enclosure of $0.6 \mathrm{~m}^{*} 0.6 \mathrm{~m} * 0.6 \mathrm{~m}$ (inside dimension) was employed as compartment and had the openings of $0.3 \mathrm{~m}$ width and $0.25 \mathrm{~m}$ height on the center of windward wall and leeward wall. The ceramic fiber board of $0.025 \mathrm{~m}$ was used for the material of wall, ceiling and floor. The experimental condition was the difference of wind velocity and with or without ceiling. The nominal wind velocity was $2,3,4,6,9 \mathrm{~m} / \mathrm{sec}$ using BRI FRWT and in case of $0 \mathrm{~m} / \mathrm{sec}$ the experiments were done in the experimental room to measure heat release rate by oxygen consumption method. The weight of crib was measured by load cells (Transducer C2M1-50k, MINEBEA Co., LTD) installed under the table of which studs penetrating the floor of enclosure and the wind velocity was measured by the anemometer (Kanomax Anemomaster Model6141, NIHON KAGAKU KOGYO Co., LTD) at the position of $5 \mathrm{~m}$ windward and $0.97 \mathrm{~m}$ height at the interval of 0.5 second.

\section{RESULTS AND DISCUSSION}

\subsection{Burning of cribs in unconfined space in wind}

From the scaling laws[9] the requirement for the similarity between the model and the original phenomenon is shown as below. The ratio of buoyant force and inertial force, generally one of the pi-numbers, is shown in Eq. (1).

$$
\pi_{1}=\frac{\rho v^{2}}{\Delta \rho l g}
$$

For the similarity between the model and the original phenomenon, from Eq. (1), Eq. (2) is derived.

$$
\frac{v}{v^{\prime}}=\frac{t}{t^{\prime}}=\left|\frac{l}{l^{\prime}}\right|^{12}
$$

Here the prime indicates the model. Regarding the mass loss rate, Eq. (3) is derived. 


$$
\frac{m}{m^{\prime}}=\frac{\rho g l^{s} t^{\prime}}{\rho^{\prime} g^{\prime} l^{3} t}
$$

Here from Eq. (2), Eq. (3) can be shown as formula (4).

$$
\frac{m}{m^{\prime}} \propto\left\langle\left.\frac{l}{l^{\prime}}\right|^{52}\right.
$$

In previous work there are a lot of models to describe mass loss rate of unconfined burning of cribs without wind $[1-4]$, but there is few models to satisfy the relationship of formula (4).

The experimental results of the mass loss rates of cribs in unconfined space in wind are shown in Fig. $1 \sim 3$. The mass loss rates of 3 kinds of cribs show linear correlation with wind velocity. And Fig.4 shows the relationship among 3 kinds of cribs by dividing the mass loss rate by the exposed surface area of cribs. From these results the next relationship of formula (5) and (6) can be derived.

$$
\begin{aligned}
& \frac{m}{A f} \propto v \\
& \frac{m}{m^{\prime}} \propto \frac{A_{f} v}{A_{f^{\prime}} v^{\prime}} \propto{\frac{l}{l^{\prime}}}^{5 / 2}
\end{aligned}
$$

The result shows the agreement with formula(4) from the consideration of scaling laws for dimensional relationship. The validity of these relationship is shown by Emori and Saito [9]. Furthermore it may be that formula (5) and (6) need non-dimensional parameter including characteristic length.

Then assuming $\Delta T=800, T 0=300$, the air velocity into crib without wind is defined by Eq. (7) and the value of the air velocity is shown in Table 1. And the value of vin is shown in Fig. $1 \sim 3$ as the open symbol.

$$
v_{n n}=\frac{1}{(n-1)(\mathrm{N}-1)} \cdot \frac{T_{0}}{T_{0}+\Delta T} \cdot \sqrt{2 g h \frac{\Delta T}{T_{0}}}
$$

From the experimental observation the air into crib enters from only one side of crib for more than $2 \mathrm{~m} / \mathrm{sec}$ of nominal wind velocity.

The experimental results in compartment show that there is little influence of the thermal environment of enclosure on the mass loss rate, because the mass loss rates do not increase in enclosure and previous work [10] indicates. It is needed for further consideration and interpretation of the combustion phenomena of wood crib.

For $\phi$ assuming $\phi_{s}=0.2[11]$, it varied in the wide range from 1.89 to 0.47 as shown in Table 2, but the mass loss rates can be shown in linear correlation.

\subsection{Burning of cribs in compartment in wind}

It is easy to expect that the mass loss rate in compartment will increase with wind velocity, because basically the mass loss rate of crib increases with wind velocity. But the parameter governing the mass loss rate is the velocity, not the amount of air, the velocity in 
Table 2 The estimated value of $\phi$

\begin{tabular}{cccc}
\hline $\begin{array}{c}\text { nominal wind } \\
\text { velocity }\end{array}$ & crib1 & crib2 & crib3 \\
\hline $0 \mathrm{~m} / \mathrm{s}$ & 1.62 & 1.23 & 1.89 \\
$2 \mathrm{~m} / \mathrm{s}$ & 1.59 & 1.18 & 1.77 \\
$4 \mathrm{~m} / \mathrm{s}$ & 0.95 & 0.71 & 1.10 \\
$6 \mathrm{~m} / \mathrm{s}$ & 0.78 & 0.51 & 0.85 \\
$9 \mathrm{~m} / \mathrm{s}$ & 0.61 & 0.47 & 0.67 \\
\hline
\end{tabular}

compartment is not so simple.

The experimental results are shown in Fig.5 and Fig.6. With or without ceiling, the mass loss rates seem to be linear to wind velocity. However in case with ceiling the inclination of the graph is smaller than that in unconfined space in wind, in case without ceiling the results were almost as same as that in unconfined space. The amount of air entering through the opening is estimated as Eq. (8).

$$
m_{a}=\alpha A v \rho \sqrt{C_{u}-C_{d}} \sqrt{\frac{T_{0}}{2 T_{0}+\Delta T}}+0.526 A \sqrt{H}
$$
Table 3.

For $\phi$ assuming $\phi s=0.2[11]$, it varied in the wide range from 1.65 to 0.58 as shown in

Table 3 The estimated value of $\phi$ in compartment

\begin{tabular}{ccccccc}
\hline nominal wind velocity & $0 \mathrm{~m} / \mathrm{s}$ & $2 \mathrm{~m} / \mathrm{s}$ & $3 \mathrm{~m} / \mathrm{s}$ & $4 \mathrm{~m} / \mathrm{s}$ & $6 \mathrm{~m} / \mathrm{s}$ & $9 \mathrm{~m} / \mathrm{s}$ \\
\hline with ceiling & 1.65 & 1.02 & 0.95 & 0.81 & 0.64 & 0.58 \\
\hline
\end{tabular}

\section{CONCLUSION AND FURTHER WORK}

From this work we could derive the following.

- The mass loss rates of cribs in unconfined space and in compartment with or without ceiling are proportional to wind velocity.

- $\phi$ varied in the wide range from around 2 (fuel rich) to around 0.5 (air rich). following.

It is needed for us to further experimental consideration and interpretation about the

- Burning of cribs in unconfined space in wind :size and length of sticks of crib

- Burning of cribs in compartment in wind :size and number of the opening :direction of wind to the opening

\section{ACKNOWLEDGEMENTS}

The Authors wish to thank Mr. M. Yoshida (BRI) for the cooperation in conducting the experiments.

\section{REFERENCES}

[1] Saito, F., Study on Burning and Smoke Generation Characteristics of Building Materials at Early Stage of Fire. Report of the Building Research Institute No.83 1978

[2] Thomas. P.H., Behavior of Fires in Enclosures-Some Recent Progress, Fourteenth Symposium (International) on Combustion, The Combustion Institute, 1007-1020, 1973

[3] Yamashika, S., Kurimoto, H., Burning Rate of Wood Crib, Report of Fire Research Institute of Japan, No.41, 1976 
[4] Heskestad, G.. Modeling of Enclosure Fires, Fourteenth Symposium (International) on Combustion, The Combustion Institute, 1021-1030, 1973

[5] Harmathy,T.Z., Experimental Study on the Effect of Ventilation on the Burning of Piles of Solid Fuels, Combustion and Flames 31, 259-264, 1978

[6] Thomas,P.H., The Size of Flames from Natural Fires, Ninth Symposium (International) on Combustion, The Combustion Institute, 844-859, 1962

[7] Putnam, A. A., A Model Study of Wind-Blown Free-Burning Fires, Tenth Symposium (International) on Combustion, The Combustion Institute, 1039-1046, 1964

[8] Ogawa,T., at.al., An Experimental Study on Influence of Wind in Burning Behavior of Building Fire, Partl $\sim 3$, Summaries of Technical Papers of Annual Meeting, Architectural Institute of Japan A-2, 199-204, 1999

[9] Emori, R.I., Saito, K., A Study of Scaling Laws in Pool and Crib Fires, Combustion Science and Technology Vol.31, 217-231, 1983

[10] Harmathy,T.Z., A New Look at Compartment Fires, Part1/Part2, Fire Technology, Vol.8, 1972

[11] Naruse,T., Sugahara,S., Estimation of Heat Release in Fire Compartment, The 3rd Asia-Oceania Symposium on Fire Science and Technology, 1998

\section{NOMENCLATURE}

$A$ : area of opening of enclosure $\left(\mathrm{m}^{2}\right)$

$A b$ : total area of opening of bottom of cribs $\left(\mathrm{m}^{2}\right)$

Af : exposed surface area of cribs $\left(\mathrm{m}^{2}\right)$

As : total area of opening of one side of cribs $\left(\mathrm{m}^{2}\right)$

$b$ : stick size $(\mathrm{m})$

$\mathrm{Cu}$ : wind pressure coefficient (windward) (-)

$C d$ :wind pressure coefficient (leeward) (-)

$g$ : gravitational acceleration $\left(\mathrm{m} / \mathrm{s}^{2}\right)$

$h$ : height of crib (m)

$l$ : characteristic length $(\mathrm{m})$

$L$ : length of stick in crib (m)

$m$ : mass loss rate $(\mathrm{kg} / \mathrm{sec})$

$m a:$ mass of air $(\mathrm{kg} / \mathrm{sec})$

$n$ : number of sticks per layer in crib (-)

$N$ : number of layers on crib (-)

$\mathrm{s}$ : spacing between sticks in crib $(\mathrm{m})$

$t:$ time $(\mathrm{sec})$

$T:$ absolute temperature (K)

TO : ambient temperature ( $\mathrm{K})$

$\Delta T:$ excess temperature of gas of the vertical shaft of the crib at the height of crib $(\mathrm{K})$

$U$ : wind velocity $(\mathrm{m} / \mathrm{s})$

$v$ : velocity $(\mathrm{m} / \mathrm{s})$

$\operatorname{vin}$ : the air velocity into crib $(\mathrm{m} / \mathrm{s})$

WO : initial mass of crib $(\mathrm{kg})$

$\alpha$ : flow coefficient (-)

$\rho:$ density $\left(\mathrm{kg} / \mathrm{m}^{3}\right)$

$\phi$ : equivalence ratio $(-)$

$\phi s$ : stoichiometric reacting fuel to air ratio $(-)$ 
Fig.1 Relationship between Wind velocity and Mass loss rate (Crib1: 8sticks * 6layers)
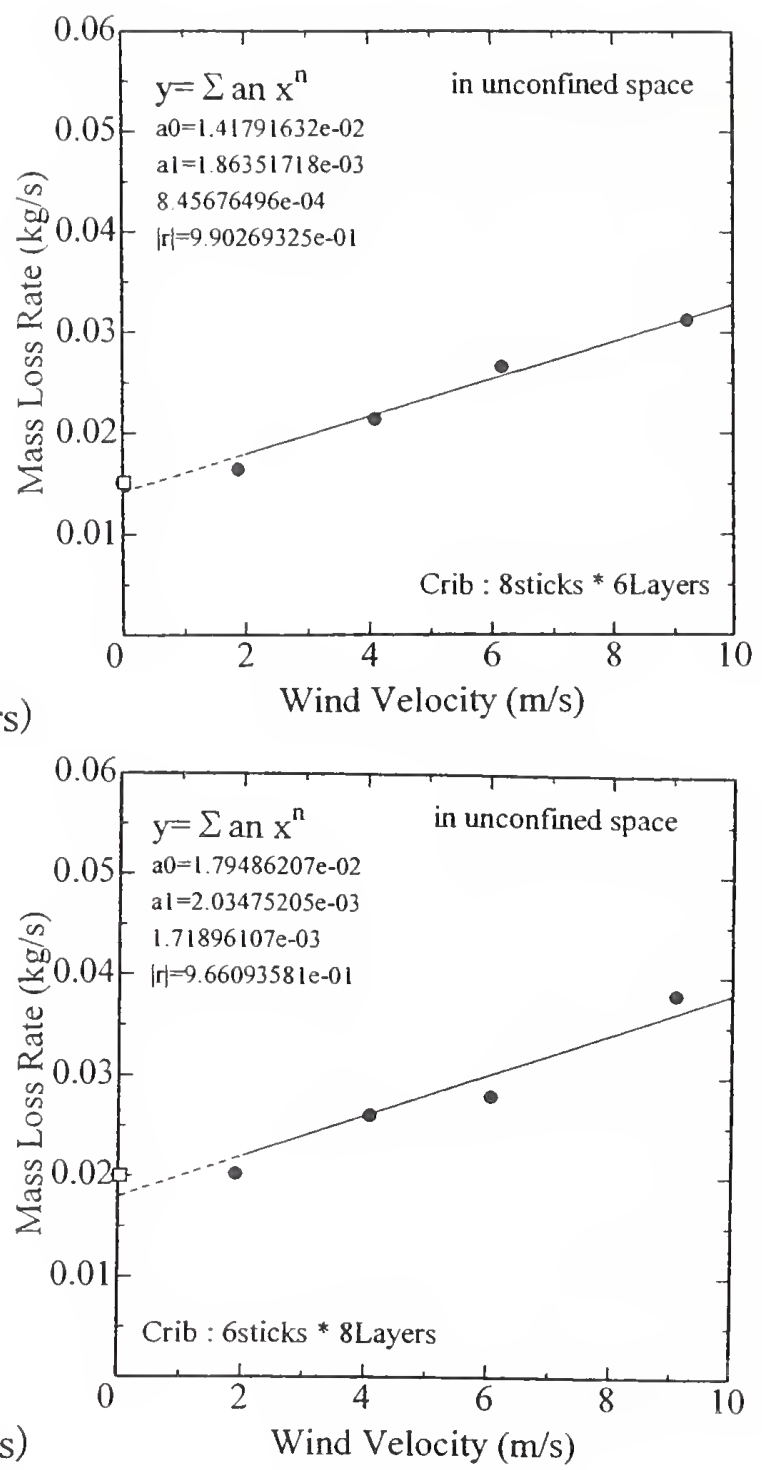

Fig.2 Relationship between Wind velocity and Mass loss rate (Crib2 : 6sticks * 8layers)

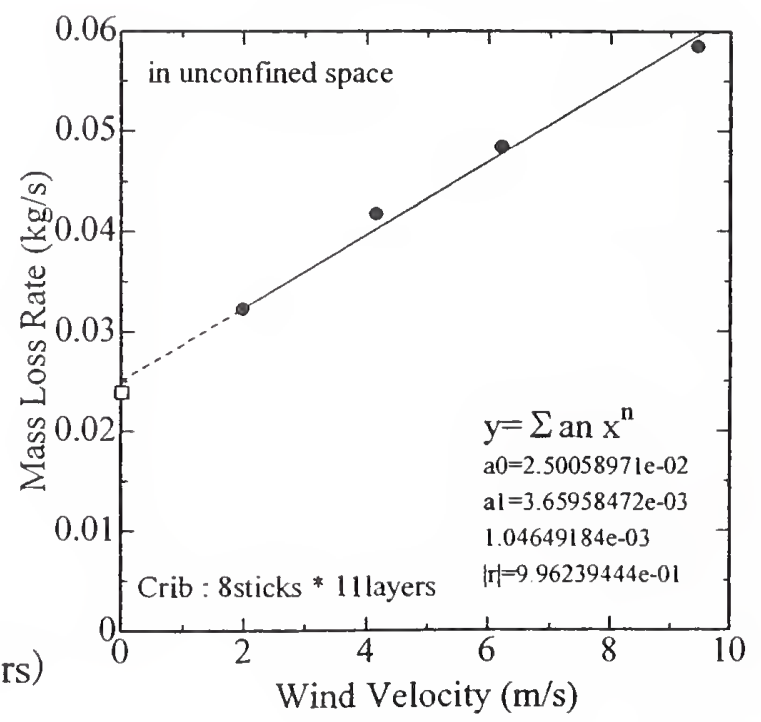


Fig.4 Relationship between Wind velocity and Mass loss rate

Fig.5 Relationship between Wind velocity and Mass loss rate (in the compartment with ceiling)
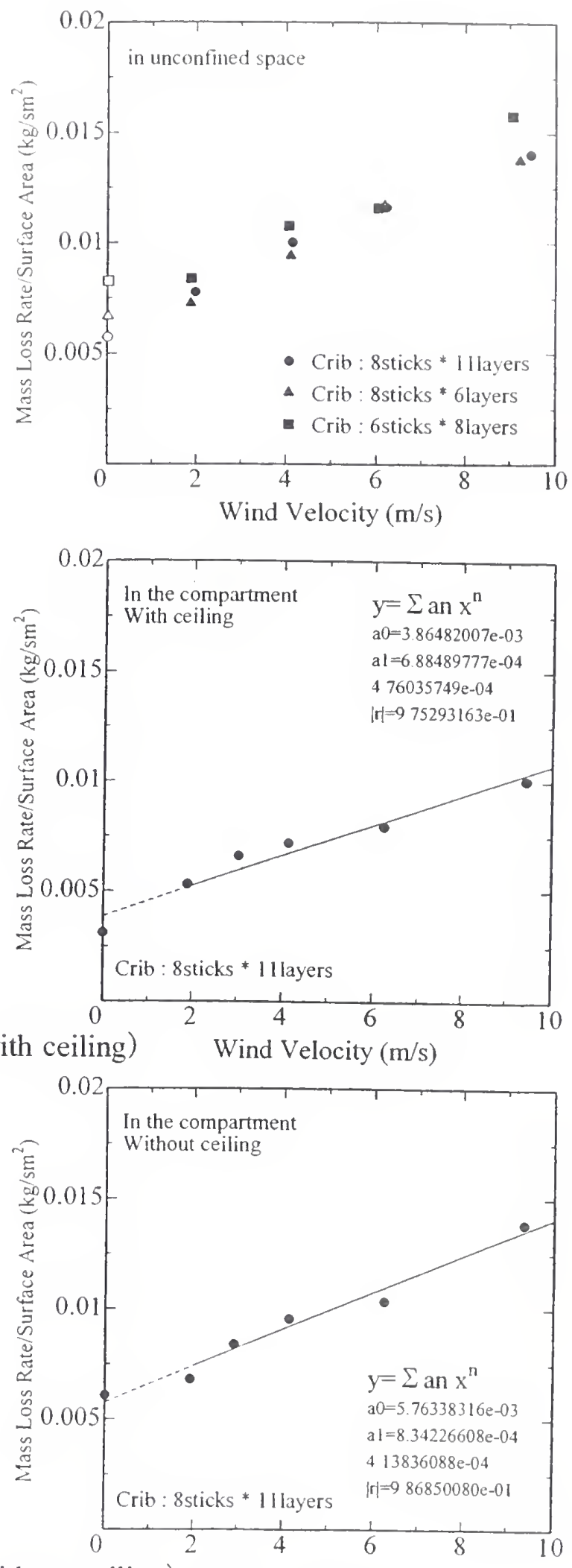

Fig.6 Relationship between Wind velocity and Mass loss rate (in the compartment without ceiling) Wind Velocity $(\mathrm{m} / \mathrm{s})$ 


\title{
Comparison of Combustion Characteristics of Crude oils using Cone Calorimeter
}

\author{
Y. IWATA and H. KOSEKI \\ National Research Institute of Fire and Disaster \\ Ministry of Home Affairs \\ 14-1,Nakahara 3-Chome \\ Mitaka, Tokyo 181-8633 \\ M.L. JANSSENS \\ Department of Fire Technology, \\ Southwest Research Institute \\ 6220 Culebra Road, San Antonio, TX, 78238
}

\begin{abstract}
Small-scale free-burning pool fire experiments were conducted in a Cone Calorimeter to obtain the combustion characteristics of 14 different crude oils. Measurements included heat release rate based on oxygen consumption calorimetry, mass loss rate, radiative heat flux from the flame to a nearby target, liquid fuel temperature and $\mathrm{CO} 2$ and $\mathrm{CO}$ concentrations in the exhaust duct. The effective heat of combustion, radiative heat loss fraction, and smoke yield were calculated on the basis of the measured data. It was found that heat release rate, flame radiation, and smoke yield had relation to the type of crude oil. The effective heat of combustion, radiative heat loss fraction, and extinction coefficient were nearly constant for the range of crude oils evaluated in this program. Heat release rate, mass loss rate, flame radiation, and smoke yield appeared to correlate well with crude oil density.
\end{abstract}

\section{INTRODUCTION}

Fire hazard assessment of crude oil storage facilities is generally based on generic characteristics of the fuel. However, the physical and chemical properties of crude oils, such as density and specific heat, are known to depend on the region of origin and the production lot [1], and crude oil combustion characteristics may therefore vary accordingly. If these variations are significant, fire protection measures based on generic properties may, in some cases, be inadequate. There is little information in the literature concerning combustion characteristics of crude oils. Due to the difficulty of obtaining consistent crude oil samples, only a few systematic studies have been conducted $[2,3]$. The combustion of crude oil is very complex because it is a mixture of many hydrocarbons, and its composition changes constantly as combustion progresses. It would be very convenient if the combustion characteristics of a crude oil could be predicted on the basis of a simple physical property of the fuel. The development of such correlations is one of the objectives of this paper.

The purpose of the research presented in this paper is to get a feel for the magnitude of the variations in burning behavior of crude oils on the basis of small-scale data. If the variations are significant, additional intermediate or large-scale experiments will be needed to enable the development of improved methods for fire protection of crude oil storage facilities and suppression of crude oil tank fires.

Cone calorimeter data were obtained for 14 crude oils and kerosene, and are presented in the following sections. Combustion characteristics were calculated on the basis of the small-scale data. Correlations were developed to predict the combustion characteristics as a function of density. Crude oil density was chosen as the independent variable since it is easily determined, and because it is directly related to the composition of the fuel.

\section{EXPERIMENTAL}

\section{Materials}

Samples of 14 different crude oils were examined. In addition, kerosene was used as a 
benchmark. The names of the crude oils evaluated in the experiments, and their density are given in Table 1. The crude oils used in the experiment were sampled from several storage facilities maintained by the Japan National Oil Corporation for emergency use. They belonged to light or medium density crude oils. High-density crude oils are available in Japan, but they were not examined in this study. Water was removed from the samples to prevent boilover during the experiments.

\section{Cone Calorimeter}

The experiments were conducted in the Cone Calorimeter at Southwest Research Institute (SwRI) in San Antonio, Texas. This Cone Calorimeter was constructed in accordance with the specifications in ASTM E 1354-97, "Standard Test Method for Heat and Visible Smoke Release Rates for Materials and Products using an Oxygen Consumption Calorimeter". However, some modifications were made to the standard protocol, so that small circular pans filled with liquid fuel could be evaluated. A schematic of the apparatus is shown in Figure 1. The fuel pans were $90 \mathrm{~mm}$ in diameter, and $18 \mathrm{~mm}$ in depth. The initial freeboard (the distance between liquid surface and the top of pan) was approximately $1 \mathrm{~mm}$. Fuel was not replenished during the experiment. All experiments were conducted without external heat flux from the cone heater. The heat release rate $\left(\mathbb{H R R}\right.$, in $\left.\mathrm{kW} / \mathrm{m}^{2}\right)$ was determined on the basis of oxygen consumption calorimetry [4]. The mass loss rate (MLR, in $\mathrm{g} / \mathrm{s}$ ) was measured with a load cell. $\mathrm{CO}_{2}$ and $\mathrm{CO}$ concentrations (in volume \%) in the exhaust duct were obtained with Non Dispersive InfraRed (NDIR) analyzers. The extinction coefficient $(k$, in $1 / \mathrm{m})$ was determined on the basis of the absorption by the smoke of a $0.5 \mathrm{~mW}$ HeNe laser beam. A personal computer and data acquisition system was used to obtain the signals of all transducers and instruments at a sampling rate of two seconds.

Additional instrumentation was provided to measure the radiative heat flux from the flame, and the temperature of the liquid fuel. Flame radiation was measured by a thermopile type radiometer. The radiometer was positioned so that it faced the experiment sample at a distance of $0.36 \mathrm{~m}$ from the center of the pan, at a height slightly above the top surface of the pan. Liquid temperatures were measured using a $0.3 \mathrm{~mm}$ diameter type $\mathrm{K}$ sheathed thermocouple positioned in the center of the pan. The tip of the thermocouple was submerged in the liquid at the start of the experiment, and located at $5 \mathrm{~mm}$ from the bottom of the pan.

After 30 seconds of baseline data were collected, a butane lighter flame was applied to the liquid surface until the fuel ignited. All crude oils ignited almost immediately after application of the flame, but it took several minutes of preheating to ignite the kerosene samples. All crude oil experiments were conducted in duplicate. The first experiment was terminated at $30 \mathrm{~min}$, and the second experiment was terminated at $20 \mathrm{~min}$. The kerosene was also experimented in duplicate, and both experiments were terminated at flameout.

\section{RESULTS AND DISCUSSION}

\section{Experimental Results}

Iranian Light crude oil is widely used in Japan. Iranian Light crude oil data are shown in Figure 2, as a typical example of the experimental results that were obtained. The shape of the curves is similar for the other crude oils that were experimented, but there are some significant quantitative differences. The results of the duplicate experiments were nearly identical for almost all the samples. The repeatability of experiments was very good.

\section{Data Analysis}

The burning rate of a liquid pool fire is controlled by the radiation heat transfer from the diffusion flame to the liquid fuel surface. The combustion regime corresponding to a $90 \mathrm{~mm}$ diameter fuel pan is not fully turbulent. Therefore, the conclusions drawn from this work may not be valid for large scale pool fires. However, it is expected that the results can at least be used to compare and rank the various crude oils.

Given a certain incident heat flux at the surface, the mass loss rate (and therefore heat release rate) of a liquid fuel is controlled by the ratio of the heat of combustion to the latent heat of 
vaporization [6]. In the present program, this characteristic ratio could not be determined, because the heat of vaporization could not be available. As an alternative, an attempt was made at correlating some of the measured burning characteristics against a physical or chemical property of the crude oil. The density was chosen as the independent variable since it is easily determined, and because it is directly related to the composition of the fuel. The resulting correlations are shown in Figure 3, and provide a reasonably accurate method to predict crude oil burning characteristics.

\section{Heat Release Rate}

The heat release rate (HRR) rapidly reaches a maximum value at approximately 50 seconds after ignition. Subsequently, the HRR decreases gradually and reaches a steady value. The HRR of some crude oils has the tendency to gradually rise again at approximately 1500 seconds after ignition. This is attributed to the boiling of a small amount of water trapped at the bottom of the fuel pan.

The average $H R R$ values $\left(H R R_{\text {avg }}\right)$ were calculated over a 1170 second period starting at ignition (30 seconds). HRR avg of Kafji is the lowest of all the crude oils experimented. HRR avg of Marib Light is the highest, and approximately 1.5 times the value for Kafji. The HRR of all crude oils varies within this range. A correlation was established between HRR and density, which shows that higher HRR correspond to lower densities. The maximum HRR values $\left(H_{R} R_{\max }\right)$ show the same trend as the $H_{R R}$ avg values. The ratio of $H R R_{\max }$ to $H R R_{\text {avg }}$ is approximately 1.5 .

It is interesting to compare the effective heat of combustion $\left(\Delta \mathrm{H}_{\text {c.eff }}\right)$ of different crude oils. $\Delta \mathrm{H}_{\mathrm{c}, \text { eff }}$ was calculated as the ratio of the total heat released during the first $20 \mathrm{~min}$ of a experiment to the total mass loss over the same period. $\Delta \mathrm{H}_{\mathrm{c}, \text { eff }}$ is nearly constant for the crude oils that were experimented, and appears to be independent of density. The combustion efficiency is defined as the ratio of $\Delta \mathrm{H}_{c, \text { eff }}$ to the net heat of combustion. The net heat of combustion of Umm Shaif, Murban and Kafji was known, and the resulting combustion efficiencies are $0.82,0.80$ and 0.83 respectively.

\section{Mass Loss Rate}

The average mass loss rate over a given period is equal to the ratio of mass loss over the period to the length of the period. The average mass loss rate in 60 seconds interval from ignition was calculated (see Figure 2). The mass loss rate rapidly reaches a maximum value. Subsequently, the mass loss rate decreases gradually and reaches a steady value. This can be explained by the fact that initially, due to the short freeboard height, almost the entire amount of heat transferred from the flame to the fuel pan contributes toward evaporation of fuel, while in the later stages part of the heat is lost to the edges of the pan. In addition, the lighter components of the fuel burn at a faster rate, and are consumed in the initial stages of the experiment. - The average mass loss rate (MLR) over the period between ignition and 1170 seconds was correlated against density. The correlations are similar to those between $\mathrm{HRR}_{\text {avg }}$ and density, although the density effect on the MLR appears to be slightly more pronounced (see Figure 3).

\section{Flame Radiation}

The heat flux from the flame to the radiometer quickly reaches a maximum value at approximately 60 seconds after ignition. Shortly thereafter, the heat flux drops to a lower steady value. The relative difference between the maximum and steady values is not as pronounced as for the HRR. The heat flux of some crude oils gradually increases toward the end of the experiment, concurrently with a rise of the HRR.

Average heat flux values were calculated over a 1170 second period starting at ignition (30 seconds). The average heat flux of Kafji is the lowest of all the crude oils experimented. The average heat flux of Marib Light is the highest, and approximately 1.3 times the value for Kafji. The heat flux of all crude oils varies within this range. The maximum heat fluxes show the same trend as the average fluxes. The ratio of maximum to average heat fluxes is approximately 1.3. Flame radiation is related to the heat of combustion and the mass loss rate and the radiative heat loss fraction [7]. The heat of combustion had relation to heat release rate. Consistent with the $\mathrm{HRR}_{\mathrm{avg}}$ correlations, the average heat flux decreases with increasing density. Since heat release 
rate was a function of crude oil density, it was no surprise to find a good correlation between heat flux and density.

It is instructive to examine whether and how the radiative heat loss fraction varies for the different crude oils that were experimented. In this paper, the radiative heat loss fraction is defined as the ratio of heat that is transferred from the flame to its surroundings in the form of radiation to the total heat released. A point source flame model was used to calculate the radiative heat loss fraction from the measured heat release rate and heat flux data:

$$
\chi_{r}=\frac{4 f \hat{\mathrm{I}} L^{2} \dot{q}_{f}{ }^{\prime \prime}}{\operatorname{HRR} \times A_{s}}
$$

where

$\chi_{\mathrm{r}}=$ radiative heat loss fraction (-)

$\mathrm{L}=$ distance from the center of the pan to the radiometer $(\mathrm{m})$

$q_{f}=$ heat flux from the flame measured with the radiometer $\left(\mathrm{kW} / \mathrm{m}^{2}\right)$

$\mathrm{A}_{\mathrm{s}} \quad=\quad$ exposed sample area $\left(0.0064 \mathrm{~m}^{2}\right)$

The radiative heat loss fraction is a useful variable when comparing the combustion characteristics of different fuels. $\chi_{\mathrm{r}}$ was found to be nearly independent of density. This follows from Equation (1), because both $q_{f}$ and HRR vary with density in a similar fashion.

Averaged $\chi_{r}$ ranges from 0.60 to 0.67 for the crude oils that were experimented. The actual heat release rate was used in the denominator of Equation (1). These values are higher than those defined by the theoretical amount of energy released for the whole because the actual heat release rate was lower than the theoretical heat release rate. Based on a combustion efficiency of 0.82 , the radiative heat loss fraction values based on the common definition ranged from 0.49 to 0.55 . Reference [8] gives a value for crude oil of $\chi_{\mathrm{r}}=0.57$, on the basis of heat release rate measured by the oxygen depletion measuring equipment. A value for crude oil of $\chi_{r}$ is regarded as 0.47 on the common definition in [8]. This could be explained by the fact the more smoke was made and covered radiation from the fire, since the value in [8] was based on measurements for 0.4 and 0.6 $\mathrm{m}$ diameter pans.

\section{Smoke Obscuration}

The smoke yield $\left(Y_{s}\right)$ was used to quantify smoke emissions in the crude oil experiments. $Y_{s}$ is equal to the ratio of the mass of soot particulates generated to the mass loss of the fuel. It can be calculated as follows:

$$
Y_{s}=\frac{\int_{t_{1}}^{t_{2}} \frac{k \dot{V}_{s}}{k_{m}} d t}{m\left(t_{1}\right)-m\left(t_{2}\right)} \approx \frac{\sum_{t_{1}}^{t_{2}} \frac{k \dot{V}_{s}}{k_{m}} \Delta t}{m\left(t_{1}\right)-m\left(t_{2}\right)}
$$

where $Y_{s}$ is the smoke yield (in $\mathrm{kg} / \mathrm{kg}$ ), $\mathrm{k}$ is the extinction coefficient (in $1 / \mathrm{m}$ ), $V_{\mathrm{s}}$ is the volumetric duct flow rate at the smoke meter (in $\mathrm{m}^{3} / \mathrm{s}$ ), $\mathrm{k}_{\mathrm{m}}$ is the ratio of the extinction coefficient to the mass concentration of soot $\left(7600 \mathrm{~m}^{2} / \mathrm{kg}\right.$ based on [3]), $\mathrm{m}\left(\mathrm{t}_{1}\right)$ is the sample mass at time $\mathrm{t}_{1}$ $(\mathrm{kg}), \mathrm{m}\left(\mathrm{t}_{2}\right)$ is the sample mass at time $\mathrm{t}_{2}(\mathrm{~kg}), \Delta \mathrm{t}$ is the scan interval (s). The extinction coefficient is calculated from:

$$
k=\frac{1}{l} \ln \left(\frac{I_{0}}{I}\right)
$$

where $l$ is the diameter of the duct (in $\mathrm{m}$ ), $\mathbb{I}_{0}$ is the light intensity of the laser light source, and I is the intensity of the beam that is transmitted through the smoke stream in the exhaust duct. The extinction coefficient is proportional to the concentration of soot particulates in the exhaust flow. To obtain the mass concentration of soot, $\mathrm{k}$ is divided by $\mathrm{k}_{\mathrm{m}}$.

A correlation was established between $Y_{s}$ and crude oil density. The smoke yield increases with 
density. This is due to the fact that the MLR decreases with increasing density, while $\mathrm{k}$ is nearly independent of density.

It was assumed that the amount of residual carbon after distillation of a crude oil affects the smoke yield. A correlation was established between residual carbon and smoke yield. It was found that higher density crude oils include more residual carbon and also have higher smoke yields.

\section{Burning Characteristics of Kerosene}

Kerosene was burned as a reference material. It took approximately four minutes to ignite kerosene with a small butane flame. Kerosene has a higher HRR avg $\left(632 \mathrm{~kW} / \mathrm{m}^{2}\right), \mathrm{MRL}(0.11$ $\mathrm{g} / \mathrm{s}), q_{f}\left(1.30 \mathrm{~kW} / \mathrm{m}^{2}\right)$, and $\mathrm{k}(2.58 \mathrm{l} / \mathrm{m})$ than any of the crude oils. However, the smoke yield (0.064) is lower. This can be explained by the fact that the MRL is approximately two times higher than for the crude oils, while the difference in $k$ values is much smaller.

\section{CONCLUSIONS}

Small-scale free-burning pool fire experiments were conducted to obtain the combustion characteristics of various crude oils. The main results are as follows.

(1) The effective heat of combustion, radiative heat loss fraction, and extinction efficient is almost constant for the range of crude oils experimented.

(2) Heat release rate, mass loss rate, flame radiation, and smoke yield appear to correlate well with crude oil density.

Additional intermediate or large scale tests are needed to extend the validity of these correlations to real size fires, so that they can be used to develop improved methods for fire protection of crude oil storage facilities and suppression of crude oil tank fires.

\section{REFERENCES}

1. Environment Canada, A Catalogue of Crude Oil and Oil Product Properties (1992 Edition), 1993.

2. Petty, S. E. "Combustion of Crude Oil on Water," Fire Safety Joumal, 5, p.123 (1983).

3. Mulholland, G., V. Henzel, and V. Babrauskas, "The Effect of Scale on Smoke Emission," Fire Safety Science, 2, p.347, 1989.

4. Huggett, C., "Estimation of Rate of Heat Release by Means of Oxygen Consumption Measurements," Fire and Materials, 4, p. 61, 1980.

5. Natsume, Y., H. Koseki, T. Hirano, and T. Takahashi, "Large Scale Crude Oil Fire Experiments - Outline and Procedure of the Experiments," 14th UJNR Panel Meeting on Fire Research and Safety, Tsukuba and Tokyo, June 1998.

6. Burgess, D. S., A. Strasser, and J. Grumer, "Diffusive Buming of Liquids in Open Trays," Fire Research Abstracts and Review, 3, p.177, 1961.

7. Modak, A.S., "The Burning of Large Pool Fires," Fire Safety Journal, 3, p.177, 1981.

8. McCaffrey, B.J., "Combustion Efficiency, Radiation, CO and Soot Yield from a Variety of Gaseous, Liquid, and Solid Fueled Buoyant Diffusion Flames," 22nd Symposium (International) on Combustion, the Combustion Institute, Pittsburgh, PA, p.1251, 1988. 


\title{
Improved Real-Scale Fire Measurements Having Meaningful Uncertainty Limits
}

\author{
William M. Pitts and George W. Mulholland \\ Building and Fire Research Laboratory \\ National Institute of Standards and Technology \\ Gaithersburg, MD 20899
}

\begin{abstract}
The National Institute of Standards and Technology has undertaken a long-term effort designed to improve our ability to make experimental measurements having quantifiable uncertainties in real-scale fire environments. The adopted approach has two components. The first focuses on quantifying the uncertainties associated with existing techniques commonly employed to characterize real-scale fire environments. Measurements considered thus far include gas temperature using thermocouples, smoke mass concentration using optical extinction, rate of heat release using the NIST furniture calorimeter, and radiative and total heat transfer using heat flux gauges. The measurement of smoke mass concentration is discussed in some detail as an example of how a measurement approach can be modified to provide improved information while at the same time providing reliable estimates of the uncertainty. The second component is centered on the development of new approaches for measurements in fire environments which offer both improved measurement capability and quantification of uncertainties. An effort to combine nearinfrared laser diode absorption spectroscopy with fiber optic coupling for local time-resolved measurements of carbon monoxide concentration in fire environments is discussed briefly.
\end{abstract}

\section{Introduction}

Man's existence on Earth is intimately tied to fire behavior both through the harnessing of combustion to perform useful functions and through the harmful effects of unwanted fire. To this day, unwanted fire continues to present severe challenges to modern societies. Death, injury, and personal property loss still occur with a distressingly high frequency, while property losses and the costs associated with fire prevention, fighting, and insurance represent significant fractions of developed countries' overall economies. Despite decades of sustained study and considerable progress, a complete understanding of the behavior of unwanted fires and an ability to predict their behaviors has remained elusive. One needs only to consider current capabilities for predicting the growth and effects of a fire in an arbitrary built environment to confirm this conclusion. This lack of understanding is due to the complexity of fire which involves interactions between physical/chemical processes which are difficult to quantify in the absence of any interactions. These processes include pyrolysis of solid fuels, radiative and convective heat transfer, combustion and soot formation, and mixing and reaction in turbulent flows.

The complicated nature of fire behavior has precluded developing an understanding based on first principles and has resulted in an emphasis on experimental characterization of fire behavior, which then serves as the basis for the development of the engineering correlations and fire models used for practical fire protection engineering. Thus experimental fire characterization, and particularly 
real-scale fire experiments, are central to the development of predictive models for fire growth and effects. The need for such models has become even more urgent with the shift in emphasis in many industrial countries from prescriptive codes (typically developed as responses to historical fire results) to performance-based codes which attempt to provide a specified level of safety through effective engineering based on understanding of fire behavior.

The experimental measurements required to characterize fire behavior are typically made in extremely harsh environments using instrumentation which is subject to errors of various kinds. Historically, the uncertainties associated with fire measurements have not been a focus of attention. Results have typically been reported with little or no discussion of uncertainty. This approach is inconsistent with modern experimental measurement practice which specifies that a quantitative result is incomplete unless it is accompanied by an estimate for its uncertainty and an account of how it was estimated. ${ }^{1}$ A specification of the uncertainty is required by anyone utilizing the results, whether it be for model development or some other purpose.

As a result of the above considerations, the Building and Fire Research Laboratory (BFRL) at the National Institute of Standards and Technology (NIST) has initiated a long-term research effort with the ultimate goal of providing quantitative estimates for the uncertainties associated with experimental measurements recorded during real-scale fire tests. The following summarizes our progress to date.

\section{Approach and Fire Diagnostics Considered}

The goal of this research effort is to improve the capabilities of BFRL and the general fire community for quantitatively characterizing fire behavior using experimental measurement techniques having reliable estimates of accuracy and precision. We have chosen to focus on measurements typically performed in the NIST large-scale fire test facility.

The project has two components. The first considers the uncertainties associated with existing measurement techniques employed during NIST real-scale fire tests. In addition to providing the means to estimate the uncertainty in a particular type of measurement, an additional focus is identifying easily implemented approaches for limiting the uncertainties associated with a measurement and extending the usefulness of the technique.

The actual fire diagnostics chosen for characterization have been selected based on interviews with NIST staff and outside fire researchers. Important criteria include the importance of the technique to fire research and the relative level of uncertainty associated with the measurement. The goal is to consider five such fire diagnostics during the course of the project. Currently, four diagnostics have received attention. These include thermocouple measurements of gas temperature, measurements of smoke mass concentration by optical attenuation in the furniture calorimeter, heat release rate measurements using the furniture calorimeter, and measurements of radiative and total heat transfer using heat-flux gauges.

The second component of the effort is the development of a new experimental technique for characterizing the environment in real-scale fire tests. Based on a need for an approach for time- 
and spatially-resolved in-situ measurements of gas composition, this component is focusing on the development of fiber optic coupled, near-infrared tunable diode laser absorption for concentration measurements. A number of fire species should be measurable using this approach

Analytical measurements based on the absorption of near-infrared tunable laser radiation have been undergoing rapid development during the past few years. ${ }^{2}$ A major driver has been the extensive development of these lasers by the communications industry. As a result, well characterized, reasonably priced tunable diode lasers are commercially available over extensive spectral ranges centered around $1.31 \mu \mathrm{m}$ and $1.55 \mu \mathrm{m}$. This is particularly true in the $1.55 \mu \mathrm{m}$ region where the implementation of wavelength division multiplexing, in which several different wavelengths are utilized simultaneously for communication purposes, has increased the availability of lasers over the $1.45 \mu \mathrm{m}$ to $1.65 \mu \mathrm{m}$ range. Lasers operating at other wavelengths are also available, but are not as well developed and tend to be more costly. Very efficient and reasonably priced fiber optics have also been developed for transmitting the communication wavelengths over large distances. Such fibers can be used for transporting a laser beam to and from an observation region within a fire environment. Absorption measurements are inherently line-of-sight, but by using a "throw and catch" configuration in which the laser beam is transmitted between fibers through a short open space, spatial resolution on the order of a few $\mathrm{cm}$ can be obtained. The ability to multiplex multiple lasers onto a single fiber opens the possibility of measuring concentrations for several species, and even temperature, simultaneously.

Absorption transitions in the near-infrared for most molecules are typically overtone and combination bands of the fundamental transitions which occur in the mid-infrared. As a result, the absorption coefficients tend to be small, and it becomes necessary to detect very small absorption signals when operating in the near-infrared. Techniques based on wavelength modulation and phase sensitive detection are often used to record the small absorption signals, but the signal-tonoise ratios of the measurements still generally limit minimum detectable concentrations. The current investigation is aimed at determining whether or not sufficient signal-to-noise ratios can be obtained in fire environments to allow meaningful concentration measurements of fire species. The initial target species is carbon monoxide. Laboratory investigations are being performed to assess our capability to measure carbon monoxide with sufficient spatial and temporal resolution to justify further development of the approach.

\section{Summary of Progress To Date}

A number of BFRL investigators have been involved in this effort. Table 1 lists their last names. In this section brief summaries are provided for each of the topic areas of the overall effort. The following section describes progress on the Smoke Meter study in more detail.

\subsection{Thermocouple Measurements}

Measurements were carried out in a $40 \%$-scale model of a standard room in order to investigate uncertainties associated with thermocouple measurements of gas temperatures in fire environments. Temperatures recorded by bare-bead thermocouples typical of those used in BFRL 
Table 1. BFRL Researchers Involved in the Fire Diagnostics Study

\begin{tabular}{|l|l||}
\hline \multicolumn{1}{|c|}{ TOPIC } & \multicolumn{1}{|c|}{ BFRL RESEARCHERS } \\
\hline Thermocouples & Pitts, Peacock, Blevins, Johnsson, Reneke, Braun, Fernandez \\
\hline Smoke Measurement & Mulholland, Putorti, Johnsson, Fernandez, Shear \\
\hline Furniture Calorimeter & Steckler, Johnsson, Pitts \\
\hline Heat Flux & Bryant, Womeldorf, Johnsson, Blevins, Ohlemiller, Pitts \\
\hline Near-IR Diode Laser & Blevins, Johnsson, Peterson, Fernandez \\
\hline
\end{tabular}

fire tests were compared with measurements recorded with aspirated thermocouples as well as with those for a group of closely spaced variable-diameter bare-bead thermocouples. The results of this investigations were summarized at the last UJNR meeting. ${ }^{3}$ Briefly, thermocouple gas temperature measurements were found to have significant errors due to radiative heat transfer. The largest relative errors for bare-bead thermocouples were for measurements of low temperature gases in which the thermocouple was subject to radiation from heated surroundings and gases. Temperature errors for thermocouples located in high temperature gases which could radiate to cooler surrounding were typically significant, but relatively smaller than for the former case. Aspirated thermocouples were shown to record temperatures which were less sensitive to the effects of radiation, but, contrary to ASTM recommendations, ${ }^{4}$ still had significant systematic errors. A model for the response of bare-bead, single-shield aspirated, and double-shield aspirated thermocouples predicted behaviors which were in qualitative agreement with the experimental findings. ${ }^{5}$ Attempts to correct for radiation effects by extrapolating measurements for a series of variable-diameter thermocouples to zero diameter were not successful. Measurements recorded with thermocouples much smaller than typically used for fire testing indicated that the limited time response of thermocouples routinely used in fire testing can lead to very large instantaneous errors in fire environments where temperature fluctuates rapidly.

\subsection{Smoke Meter Measurements}

The results of this part of the effort are summarized in somewhat greater detail in the following section as a demonstration of how existing fire diagnostics can be improved as well as how levels of uncertainty can be quantified for fire measurements.

\subsection{Rate of Heat Release Using the Furniture Calorimeter}

The NIST furniture calorimeter is a device based on oxygen depletion which is used to measure heat release rate for fires falling in the 50 to $500 \mathrm{~kW}$ range. ${ }^{6}$ It is similar to the more widely used cone calorimeter, but there is no source of radiative heating. The furniture calorimeter consists of a hood which captures combustion gases and an exhaust duct where the heat release rate measurements are made. The purpose of this investigation is to provide a quantitative analysis of the uncertainty in the heat release rate measurements. A similar analysis for the standard cone calorimeter has recently been published. ${ }^{7}$

A number of approaches having varying levels of sophistication are available to calculate heat release rate using oxygen depletion that depend on which species concentrations are measured in 
the effluent gases. For the furniture calorimeter, the stack gases are extracted and dried. Various instruments are then used to record oxygen, carbon monoxide, and carbon dioxide concentrations as functions of time. Other measurements which are required are the pressure drop associated with a bi-directional probe in the duct and the local gas temperature as determined by thermocouple. The latter two measurements are used to calculate the mass flow rate within the duct. Janssens has discussed the appropriate equations [see his Eq. (26) and associated Eqs. (5), (12), and (21)] to use when concentrations for these three gases are available. ${ }^{8}$

A detailed propagation of error analysis has been performed to identify how the uncertainties for the individual measurements influence the overall uncertainty associated with the heat release rate measurement. A series of tests using fires of various sizes has been performed to characterize the individual uncertainties of the various type of measurements required for the rate of heat release calculation. The results are currently being analyzed. They will be used along with the uncertainty propagation analysis to complete the uncertainty analysis for the furniture calorimeter heat release rate measurement.

\subsection{Heat Flux Measurements}

This part of the project was initiated during the current funding cycle. Initial efforts are focused on the identification of current applications of heat flux gauges within BFRL and the potential uncertainties for these measurements. Applications range from calibrations of heat flux levels in standard tests such as the cone calorimeter and LIFT, to measurements of heat flux at positions exposed to thermal radiation from a fire, to the measurement of total heat flux to a fuel surface during flame spread and burning. The latter environment is the most difficult in which to make heat flux measurements and to estimate the uncertainties associated with the measurement. At the same time, it is perhaps the most important since an understanding of fire spread is a prerequisite for predicting fire behavior. This particular scenario has been selected as a test case for developing the approaches necessary to estimate uncertainties in heat flux measurements.

\section{Smoke Meter Measurements}

The smoke (here meaning the particulate generated by a fire) yield, defined as the kilograms of smoke produced during the burning of a kilogram of fuel, is a crucial parameter for understanding fire behavior. Smoke plays a central role in fire dynamics because it is often the source of much of the thermal radiation generated by a fire which contributes to flame spread and ultimately flashover. Smoke also reduces visibility and irritates the eyes of people trying to escape a fire, contributing to death and injury. Smoke damage represents a major property loss mechanism in fires and is particularly harmful to modern solid-state electronic circuits.

Despite the importance of smoke yield in fires, it has traditionally not been measured during fire tests. Previous measurement approaches involved collecting samples on filters while monitoring the total flow rate of combustion gases and weighing the amount of particulate collected. This approach is tedious and expensive. Light extinction has been used as a qualitative measure of the tendency of a fuel to generate smoke. For instance, light extinction measurements are often

recorded during cone calorimeter tests. Until very recently, these measurements had provided 
primarily qualitative data since the specific extinction coefficient for smoke required to relate the observed light extinction to the smoke mass concentration had not been available.

Recently, Mulholland and Croarkin ${ }^{9}$ have demonstrated that values of the specific extinction coefficient for smoke, $\sigma_{s}$, are nearly constant for a wide range of fuels when burned under fully ventilated conditions. A statistical analysis based on a number of measurements performed in different laboratories yielded $\sigma_{s}=8.7 \mathrm{~m}^{2} / \mathrm{g}$ for a wavelength of $632.8 \mathrm{~nm}$ with an uncertainty interval of $\pm 1.1 \mathrm{~m}^{2} / \mathrm{g}$ at the $95 \%$ confidence level. This finding, in combination with Bouguer's Law, allows the ratio of the transmitted $(I)$ and incident intensities $\left(I_{o}\right)$ to be related to the mass concentration of smoke, $M_{s}$, the path length through the smoke, $L$, and $\sigma_{\mathrm{s}}$ via the expression

$$
\frac{I}{I_{0}}=\exp \left(-\sigma_{s} M_{s} L\right)
$$

When $\mathrm{L}$ is known, $M_{s}$ can now be determined from a light extinction measurement, and, when the volume flow rate within the duct, $\dot{V}$, is also measured, the mass generation rate of smoke can also be determined. If the mass burning rate for the fuel, $\dot{m}_{f}$, is measured independently, the smoke yield, $\epsilon$, over a period of time, $t$, can be calculated as

$$
\varepsilon=\frac{\int \dot{V} M_{s} d t}{\int \dot{m}_{f} d t} .
$$

This approach for measuring the smoke yield was implemented in the furniture calorimeter. A focus of the effort was to develop an optical system capable of accurate extinction measurements. The criteria required for accurate smoke extinction measurements were identified by Putort ${ }^{10}$ based on previous work at NIST and information available in the literature and included such parameters as the required sensitivity and noise levels. A system was then designed and built at NIST to meet these specifications.

Figure 1 shows a schematic for the optical system. The major components are a He-Ne laser with power stabilizer, a silicon photodiode detector and associated optics to minimize the effect of beam movement, purge tubes to prevent smoke deposition on the windows and to minimize forward scattered light reaching the detector, and both lateral and rotational positioning equipment for alignment of the laser beam and detector. Great care was taken to ensure that both the laser and silicon photodiode were sufficiently stable to allow a single-beam extinction measurement to be recorded over a twenty minute period. During the course of an experiment the temperature within the exhaust duct of the furniture calorimeter where the measurements are made increases, and the duct tends to expand somewhat. The expansion and contraction change the pathlength and, unless accounted for, can also result in misalignment of the optical system.

These and other effects were accounted for during the design and assembly of the smoke meter system. Commercial components were used, and the total cost for components and machining was less than $\$ 10,000$.

A number of experimental tests of the new system were performed in order to characterize its performance and to demonstrate its ability to record smoke mass concentrations, generation rates, 
and yields with quantified uncertainties. These tests included monitoring the laser intensity during burning of natural gas, a low smoke fuel, in order to test the thermal stability of the experimental system; simulating soot absorption by the addition of neutral density filters spanning the expected absorption range; and measurements of extinction for repeated $50 \mathrm{~kW}, 200 \mathrm{~kW}$, and 400 $\mathrm{kW}$ propane fires (a moderately smoky fuel) and more sooty pool fires burning on $50 \mathrm{~cm}$-diameter pans containing either heptane, a $50 \% / 50 \%$ mixture of heptane/toluene, or

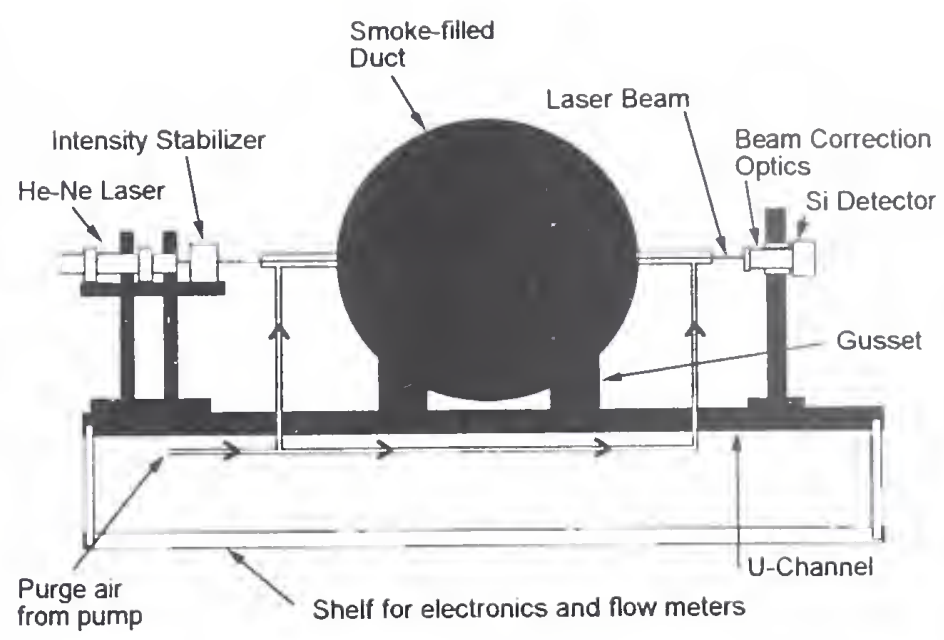
toluene. The smoke yield increases in

Figure 1. Overall schematic of smoke concentration meter.

the order heptane, $50 \% / 50 \%$ mixture of heptane/toluene, and toluene for the liquid fuels.

During a fire the mass burning rate of the fuel was monitored so that it was possible to calculate the smoke yield. Figure 2 compares the mass flow rate of smoke in the duct with the fuel burning rate for one of the heptane fires. During these measurements the smoke yield from the heptane fire was measured to be 0.0129 , which is within $7 \%$ of an earlier measurement for the same size fire using the smoke-collection method. ${ }^{11}$ The coefficient of variation, defined as the standard deviation normalized by the average value, for repeated measurements of smoke yield was determined for each fire type. Values ranged from 0.01 to 0.11 , with the highest values found for the smallest propane fires. The smoke yield was found to vary with propane fire size, decreasing from 0.0106 to 0.0052 over the range of heat release rates tested. The measured smoke yield for the toluene fires indicated that roughly $10 \%$ of the fuel mass appeared as smoke.

A detailed propagation of uncertainty analysis was performed for the smoke yield measurements. Such factors as the measured coefficient of variation and uncertainties in the specific extinction coefficient, fuel flow rates, smoke profile within the duct, and smoke deposition on the duct walls were considered in order to determine the overall uncertainty in the measurements. Including a coverage factor of 2 resulted in a relative uncertainty of 0.21 with a $95 \%$ confidence level.

To summarize, this work has significantly extended the usefulness of smoke extinction measurements in real-scale fire tests by developing an approach for quantifying the smoke mass concentration, and, when additional information is available, allowing calculation of the mass flow rate of smoke and smoke yield. A rigorous uncertainty analysis has provided a valid measure of the uncertainty associated with the measurements. The findings have been submitted for publication. $^{12}$ 


\section{Next Steps}

Much of the work summarized here is still in progress. Reports are being completed which describe the thermocouple results. An expert system will be developed to allow estimates for uncertainties in gas temperature measurements in real-scale fire tests. An operators manual for the new smoke meter is being prepared. The studies on heat-release rate and heat-flux measurements are continuing. Final reports will be prepared for each. One additional large-scale fire diagnostic in current use is to be selected for investigation during the project. A decision, based on written input, on whether or not near-infrared diode laser absorption offers a viable approach for measurement of molecular concentrations in fire environments will be available by summer. Based on this report, a decision will be made on whether or not to proceed with further development.

\section{References}

1. ISO, Guide to the Expression of Uncertainty in Measurement, International Organization for Standardization, Geneva, Switzerland, 1993.

2. M. G. Allen, Measurement Science and Technology 9, 545-562, 1998.

3. W. M. Pitts, E. Braun, R. D. Peacock, H. E. Mitler, E. L. Johnsson, P. A. Reneke, and L. G. Blevins, "Temperature Uncertainties for Bare-Bead and Aspirated Thermocouple Measurements in Fire Environments," Fourteenth Joint Panel Meeting of the UJNR Panel on Fire Research and Safety, Tsukuba and Tokyo, Japan, 1998.

4. ASTM Standard E 603-95a, 1996 Anmual Book of ASTM Standards, ASTM Publication Code 01-040796-10, ASTM, West Conshonocken, PA, 1995, p. 589.

5. L. G. Blevins and W. M. Pitts, Fire Safety Journal 33, 239-259, 1999.

6. T. J. Ohlemiller and J.R. Shields, Burning Behavior of Selected Automotive Parts from a Minivan, NISTIR 6143, National Institute of Standards and Technology, Gaithersburg, MD, 1998.

7. P. A. Enright and C. M. Fleischmann, Fire Technology 35, 153-169, 1999.

8. M. L. Janssens, Fire Technology 27, 234-239, 1991.

9. G. W. Mulholland and C. Croarkin, submitted for publication in Fire and Materials.

10. A. D. Putorti, Design Parameters for Stack-Mounted Light Extinction Measurement Devices, NISTIR 99-6215, National Institute of Standards and Technology, 1999.

11. G. W. Mulholland, V. Henzel, and V. Babrauskas in The Proceedings of the Second Fire Safety Science International Symposium, ed. By T. Wakamatsu, Y. Hasemi, A. Sekizawa, P. G. Seeger, P. J. Pagni, and C. E. Grant, pp. 347-357, Hemisphere, New York, N. Y., 1989.

12. G. W. Mulholland, E. L. Johnsson, M. G. Fernandez, and D. A. Shear, "Design and Testing of a New Smoke Concentration Meter," submitted to Fire and Materials. 


\section{SYMPOSIUM IN MEMORY OF PROFESSOR HOWARD EMMONS}




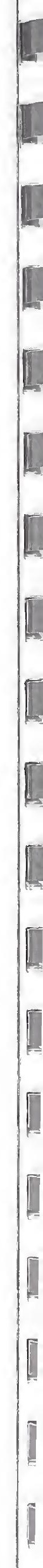




\section{Howard Wilson Emmons \\ $(1912$ - 1998)}

The fire research community in the United States lost its most influential leader on November 20, 1998 when Professor Howard W. Emmons died of cancer in Boston. He was 86 and an active investigator of fire-related scientific problems right up to the time of his death, e.g., he participated in the $14^{\text {th }}$ Meeting of the US-Japan Natural Resources Panel on Fire Research and Safety in Tokyo and Tsukuba, Japan in June, 1998.

Howard Wilson Emmons was born on August 30, 1912, in Morristown, New Jersey and was educated in the local public schools. He graduated as a Mechanical Engineer from Stevens Institute of Technology with a BS in 1993 and an MS in 1935. He was awarded a ScD degree from Harvard University in 1938 with a dissertation on condensation phenomena. He studied steam turbine systems at Westinghouse for two years followed by one year at the University of Pennsylvania. He was then invited to join Harvard University where he continued his technical career for 58 years. His positions at Harvard included: Assistant Professor - 1940, Associate Professor - 1944, Gordon McKay Professor of Mechanical Engineering - 1949, Abbot and James Lawrence Professor of Engineering - 1966 and Professor Emeritus - 1983.

He was honored by membership in the US National Academy of Science (1966), the National Academny of Engineering (1965) and the American Academy of Arts and Sciences (1946). He was an active member of several professional societies including: the American Physical Society, which awarded him the Office of Naval Research Prize in 1982; the American Society of Mechanical Engineers, which gave him the Timoshenko Medal in 1971; and the Combustion Institute, from which he received the prestigious Egerton Gold Medal in 1968. Stevens Institute of Technology bestowed an honorary ScD (1963), its $100^{\text {th }}$ Anniversary Medal (1970) and the Stevens Honor Award Medallion (1977). He was named Fire Protection Man of the Year by the Society of Fire Protection Engineers in 1982. Worcester Polytechnic Institute awarded him an honorary doctorate in 1983.

Professor Emmons' teaching was always accompanied by research and consulting. During World War II, he carried out gas turbine research for Pratt and Whitney and advised Aberdeen Proving Ground on the design and construction of its first supersonic wind tunnel.. He served on numerous government panels and committees beginning with the Naval Technical Mission to Europe in 1945. From 1958 until 1970, he was a member of the Space Science and Technology panel of the Presidential Scientific Advisory Council. In the fire research area, he was a founding member of the Committee on Fire Research in the National Research Council of the National Academy of Sciences from 1956 to 1976, serving as Chairman from 1967 to 1970. He also chaired the National Bureau of Standards Panel 490 which had oversight responsibility for the Center for Fire Research from 1971 to 1976. He played a critical role in the establishment of the Factory Mutual Research Corporation in 1964 and helped guide its development into a foremost industrial fire research laboratory. He was a member of the Products Research Committee from 1974 to 1979. He also advised his home state of Massachusetts on Fire Science 
and on Science and Technology. He served as a member of the Lincoln-Sudbury from 1969 to 1972.

We are fortunate he chose to direct his talents to Fire Research nearly 50 years ago under the urging of Professor Hoyt Hottel. In 1956, Emmons published a landmark paper on boundary layer burning which has become know as the "Emmons Problem". Shortly thereafter, he prepared the booklet "A Fire Research Program for the United States" which serves as a blueprint for the next 30 years' effort. He contributed to Fire Research Abstracts and Reviews and to the seminal conference proceedings, "The Use of Models in Fire Research". In 1962, he chaired the National Academy of Science sponsored Summer Study on Fire Research at Woods Hole, which recommended a federal program in fire research as the only practical way tao enlarge the then weak scientific base for fire safety design.

The formal development of the fire research program at Harvard had its beginning in his worldwide survey of fire laboratories in 1966-1967 and his observation of the disparity among the then nationally accepted flammability standards. As Chairman of the Committee on Fire Research, he spearheaded the effort of the scientific community to identify fire research as a national priority. He argued before Congress for a Fire Research and Safety Act, which was adopted in 1968. This act gave the National Bureau of Standards (now the National Institute of Standards and Technology) responsibility for the technical aspects of the fire problem and led to the establishment of the Center for Fire Research (now the building and Fire Research Laboratory). The act also empowered the Presidential Commission that published "America Burning" in 1972.

The National Science Foundation under its Research Applied to National Needs program initiated funding of the "Home Fire Project" at Harvard University - Factory Mutual Research Corporation in 1972. The success of that project, under the direction of Howard Emmons along with Raymond Friedman, is well documented in its 1982 final report. One of its accomplishments was the Harvard Compartment Fire Code, or Fire Simulation Technique (FIRST), which predicts the growth of fire in buildings and remains a useful tool today.

Howard Emmons had major renown as both an inspiring teacher and an innovative researcher. He set the tone for the unusually scholarly community in the Division of Applied Sciences at Harvard University. His 50 doctoral students include many distinguished scientists. His research associates were attracted to fire safety science through Professor Emmons' boundless enthusiasm. It is their consensus that the time spent with Howard is the highlight of their careers. He had the uncommon ability to ignore error and develop what was correct so that it seemed as if it were all your idea in the first place. His over one hundred research papers are hallmarks of clarity and understanding. A skillful experimentalist, as well as a theorist of unusual mathematical competence, he saw the essential concepts in complex problems and addressed them with energetic single-mindedness until he produced solutions bursting with insight and elegance.

Many of his ideas reached fruition in the laboratory and computer facility he constructed in his home. He is survived by three children and three grandchildren. His wife, Dorothy, died in 1991. His daughter, Beverly, is a theatrical lighting designer and Artistic Director of the Lincoln Center Institute in New York. His son, Dr. Scott Emmons of Brooklyn, is Siegfried Ullmann 
Professor of Molecular Genetics at Albert Einstein College of Medicine. His son, Keith Emmons, serves as a fund-raiser for non-profit organizations in Los Gatos, CA. The grandchildren are Annie Simon of Brooklyn and Alexandra and Andrew Emmons of Los Gatos.

It is not possible to properly summarize the magnitude of Professor Emmons' unique contributions to the establishment of fire safety science as a discipline, other than to call him "Mr. Fire Research". We gratefully acknowledge our debt to Professor Emmons for his insistence on technical quality, his excellent leadership, his extraordinary gift for inspiring colleagues and his many warm friendships. He will be dearly missed.

\section{Patrick J. Pagni}

Mechanical Engineering Department

University of California at Berkeley

Berkeley, CA 94720-1740, USA 


\title{
EXPERIMENTS ESTABLISHING THE SIMILARITY OF WALL FIRE COMBUSTION
}

John L. de Ris

\author{
Factory Mutual Research \\ Norwood, MA 02062
}

\begin{abstract}
A recent study' shows that fuel to air ratio of the flames, $\Psi$, controls the buoyant turbulent boundary layer combustion problem. The similarity of the fluid mechanics and the combustion at fixed $\Psi$, allows one to correlate and develop expressions for the flame thickness, $\delta_{s}$, and flame radiance, $N_{r}$, in addition to correlating the temperature and velocity profiles. It also results in a soot volume fraction, $f_{v}$, and effective flame radiation temperature, $T_{f}$, independent of height and mass transfer rate for propylene flames.
\end{abstract}

\section{INTRODUCTION}

The overall objective is the development of models predicting the total heat transfer from the flames to the wall in both the pyrolysis and forward heat transfer zones of a spreading fire. The present study focuses on the pyrolysis zone supplying fuel to the fire. Figure 1 shows the burner used to study two-dimensional burning of a single wall. This is the simplest wall geometry for studying buoyant boundary layer mixing and combustion. A goal is to identify a fundamental similarity parameter that controls the buoyant turbulent combustion, but is insensitive to fuel chemistry. Having found such a parameter, one can then focus on the fuel type without being distracted by the fluid mechanics. Fuel is supplied uniformly through the individual water-cooled sinteredmetal burners. Each burner measures $380 \mathrm{~mm}$ wide and $132 \mathrm{~mm}$ high; so that the overall height of the ten burners is $1320 \mathrm{~mm}$. This is certainly large enough to achieve

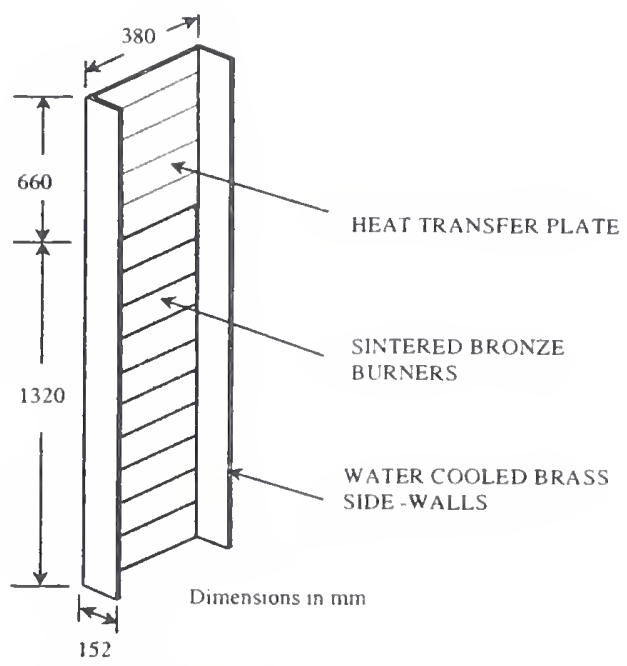

Figure 1 Gas Burner Apparatus fully turbulent flames.

\section{SOOT DEPTH}

Our first task is to characterize the thickness of the luminous turbulent flames. The soot depth, $\boldsymbol{\delta}_{\mathrm{s}}$, is measured by simply inserting arrays of $5 \mathrm{~mm}$ diameter glass rods into the flame perpendicular to the wall surface and rapidly withdrawing them after a two second exposure. Soot is deposited by action of thermophoresis. See Figure 2, below. The propylene $\left(\mathrm{C}_{3} \mathrm{H}_{6}\right)$ flames were quite sooty. The rate of soot deposition (1) is driven by the temperature difference between the flame and glass rod, (2) is proportional to the soot volume fraction and (3) is independent of the soot particle size. Two arrays, each containing five rods, were inserted one at 


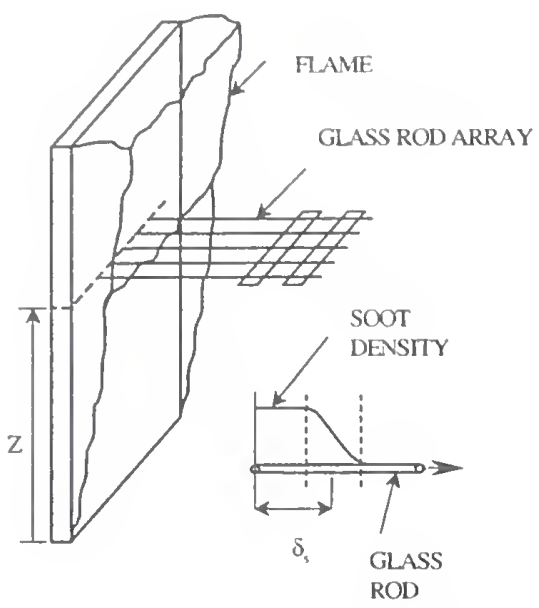

Figure 2 Sketch and detail of soot depth measurement

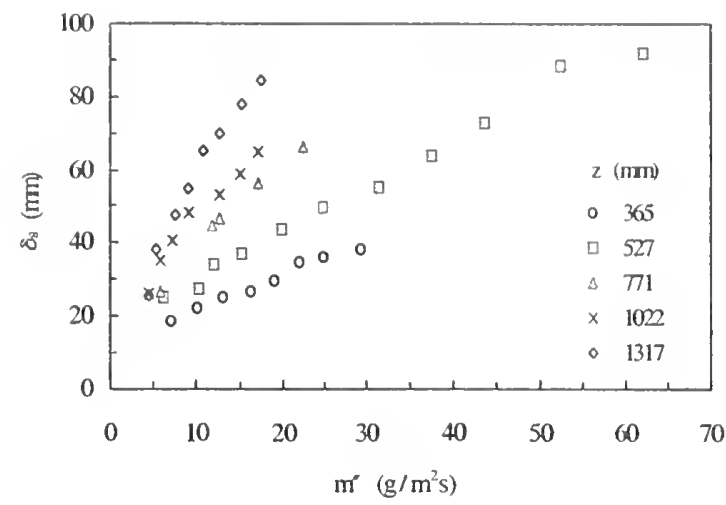

Figure 3 Measured soot depth, $\delta_{\mathrm{s}}$, vs. fuel mass transfer, $\dot{m}^{\prime \prime}$, at several heights, $\mathrm{z}$

a time for each measurement at heights of 365, 527, 771, 1022 and $1317 \mathrm{~mm}$. The lowest height of $365 \mathrm{~mm}$ insures readings well within the turbulent region. As shown in the figure detail, the soot deposition was uniform to the left of the first dotted line and then decreased gradually to zero over a distance about equal to the uniform deposition distance on the left. The soot depth, $\delta_{\mathrm{s}}$, is defined as the distance where the soot deposit is visually judged to have decreased to $50 \%$ of the maximum deposit on that rod. Figure 3 shows the variation of soot depth with mass transfer at different heights. Figure 4 shows the correlation of normalized soot depth by the fuel to air ratio of the flames, $\Psi$.

The fuel to air ratio, $\Psi$, is proportional to the total fuel supplied up to a given height divided by the accumulated entrainment of air up to the same height. As shown in Figure 10, below, the maximum mean upward velocity is insensitive to the fuel mass transfer and correlates according to

$u_{\max }=0.95 \sqrt{2 g z}$.

According to Taylor's entrainment concept ${ }^{2}$, the local air entrainment, $\dot{m}_{\text {air }}^{\prime \prime}$ into the flames is proportional to this upward velocity

$\dot{m}_{\text {air }}^{\prime \prime} \propto \rho_{A} \sqrt{2 g z}$

where $\rho_{A}$ is the density of ambient air. ${ }^{1}$ The integral of the entrainment into the flame boundary layer up to height $\mathrm{z}$ is proportional to $\rho_{A} z \sqrt{2 g z}$. This is to be

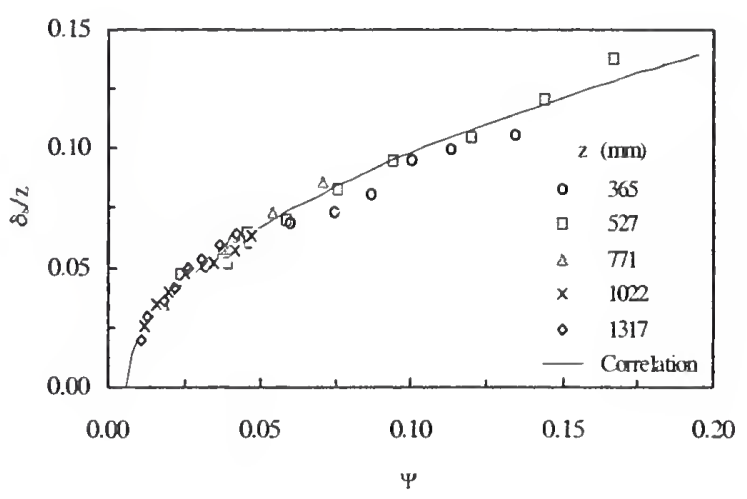

Figure 4 Correlation (solid line) of measured (symbols) normalized soot depth, $\delta_{s} / z$ vs. relative fuel richness, $\Psi$, at different heights, $z$.

\footnotetext{
${ }^{1}$ Strictly speaking, the entrainment is slightly dependent on the boundary layer width, which in turn depends on $\Psi$.
} 
compared to the stoichiometric air requirement, s, of all the fuel supplied up to $\mathrm{z}$; so that the relative richness is proportional to

$$
\Psi \equiv \frac{s \int_{0}^{z} \dot{m}_{F}^{\prime \prime} d z}{\rho_{A} z \sqrt{2 g z}}
$$

The correlation gives the empirical formula (solid line) for the flame thickness, $\delta_{s}$,

$$
\frac{\delta_{s}}{z}=0.32\left(\Psi-\Psi_{0}\right)^{1 / 2} \text { with } \quad \Psi_{0}=0.006
$$

This formula says that the soot depth disappears as $\Psi \rightarrow \Psi_{0}$. Indeed, the flames turn blue in this limit. The above formula applies to the turbulent region. One can use theoretical arguments to extend the soot depth formula to the laminar region, yielding

$$
\frac{\delta_{s}}{z}=\left[1+\left(\frac{z_{t}}{z}\right)^{9}\right]^{1 / 12}\left[0.32\left(\Psi-\Psi_{0}\right)^{1 / 2}\right]
$$

where $z_{t}=110 \mathrm{~mm}$ is a nominal laminar to turbulent transition height.

It is interesting to note that the condition $\Psi=\Psi_{0}$ also gives the overall turbulent flame height, $\mathrm{z}_{f}$ in meters, for a line fire against a wall

$$
z_{f}=\left[\frac{s \dot{M}_{f}^{\prime}}{\Psi_{0} \rho_{A} \sqrt{2 g}}\right]^{2 / 3}=\left[\frac{s \dot{Q}^{\prime}}{\Psi_{0} \Delta H_{c} \rho_{A} \sqrt{2 g}}\right]^{2 / 3}=0.047\left[\dot{Q}^{\prime}\right]^{2 / 3}
$$

for typical fuels releasing $\Delta H_{c} / s=13.2 \mathrm{~kJ} / \mathrm{g}$ of $\mathrm{O}_{2}$ consumed with heat release rates per unit width, $\dot{Q}^{\prime}$ in $\mathrm{kW} / \mathrm{m}$, and the constant 0.047 in units of $\mathrm{m}(\mathrm{kW} / \mathrm{m})^{-2 / 3}$. This expression compares favorably with Ahmed's empirical correlation ${ }^{3} z_{f}=0.052\left[\dot{Q}^{\prime}\right]^{2 / 3}$ of visible flame heights against a wall.

\section{TEMPERATURE}

The temperature profile across the flame boundary layer was measured by a thermocouple rake. The measured temperatures were first time-averaged and then corrected for the radiant heat loss from the thermocouples as well as the radiant heat received from the flame. Our detailed knowledge of the radiation field produced by these propylene flames made it possible to accurately calculate these

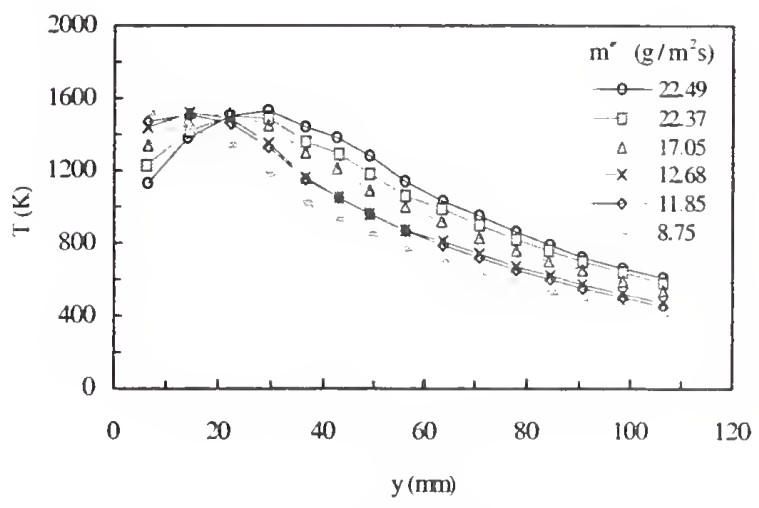

Figure 5 Corrected temperature, T, vs. distance, $y$, for various propylene mass transfer rates, $\dot{m}^{\prime \prime}$, at $\mathrm{z}=771 \mathrm{~mm}$ from leading edge. 
radiation corrections. It gives considerable confidence to these corrected temperatures. Figure 5 shows the corrected temperature profiles at a height of $771 \mathrm{~mm}$ for various mass transfer rates. Figure 6 shows the same temperatures plotted instead against $\mathrm{y} / \delta_{\mathrm{s}}$. One sees that the temperatures are well-correlated inside the flame envelope. That is, the temperature profile inside the flame is independent of the fuel to air ratio, $\Psi$. In particular, the temperature at the flame boundary at $\mathrm{y}=\delta_{\mathrm{s}}$ remains around $1000 \mathrm{~K}$ for all values of relative richness, $\Psi$. The similarity correlation is not so good outside the flame. For leaner flames, having lower values of $\Psi$ the temperature extends out to larger values of $y / \delta_{s}$. It is shown later that this same lack of perfect similarity also occurs for the velcity profiles.

\section{RADIANCE}

Measurements of the local outward

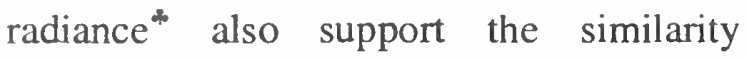
concept. Radiation comes only from the flames (i.e. the water-cooled sintered-metal burner emits negligible radiation.) Figure 7 shows the outward radiance from the flames vs. mass transfer at four different heights.

The radiation comes almost entirely from soot in the case of propylene. More specifically, the radiance depends on the effective flame radiation temperature, $T_{f}$, the soot volume fraction, $f_{v}$, and the soot depth, $\delta_{s}$. The effective flame radiation temperature is determined by first measuring the radiant emission from the flames at both 0.9 and $1.0 \mu \mathrm{m}$ wavelengths. The emission is then compared to measurements of the absorption of externally imposed radiation at the same wavelengths. The inferred effective flame radiation temperature is $1375 \mathrm{~K}$. The inferred temperature turned out to be independent of wavelength, heights and mass

\footnotetext{
* Here the outward radiance is defined as the radiant flux per unit solid angle in the outward normal direction.
} 
transfer rate. ${ }^{1}$ This invariance is, indeed, welcome. It simplifies the interpretation of data and development of models.

Making the usual assumption that the soot absorption coefficient of, $\alpha_{\lambda}=k f_{v} / \lambda$, varies inversely with wavelength, $\lambda$, it is shown ${ }^{4}$ that the radiance, $N_{r}$, from a homogeneous cloud of soot having volume fraction $f_{v}$ and depth, $\delta_{s}$, is given by

$$
N_{r}\left(T_{f}, f_{v}, \delta_{s}\right)=\frac{\sigma T_{f}^{4}}{\pi}\left[1-\frac{15}{\pi} \psi^{(3)}\left(1+\frac{k f_{v} \delta_{s} T_{f}}{C_{2}}\right)\right]
$$

where $\sigma$ is the Stefan-Boltzmann constant, $C_{2}$ is Plank's second constant, $k=8.6$ is the soot extinction constant ${ }^{5}$ and $\psi^{(3)}(1+x)$ is the Pentagamma function ${ }^{4}$. The expression,

$\frac{15}{\pi^{4}} \psi^{(3)}(1+x)$, can be conveniently approximated ${ }^{6}$ by $\exp (-3.6 x)$, to yield

$$
N_{r}\left(T_{f}, f_{v}, \delta_{s}\right)=\frac{\sigma T_{f}^{4}}{\pi}\left[1-\exp \left(-\frac{3.6 k f_{v} \delta_{s} T_{f}}{C_{2}}\right)\right]
$$

Finally, upon rearranging Equation (2), $\frac{3.6 k f_{v} \delta_{s} T_{f}}{z C_{2}}=-\frac{1}{z} \ln \left(1-\frac{\pi N_{r}}{\sigma T_{f}^{4}}\right)$ and substituting for $\delta_{s}$ from Equation (1), one has

$$
\begin{aligned}
Y & =\frac{-\ln \left(1-\frac{\pi N_{r}}{\sigma T_{f}^{4}}\right)}{\left[1+\left(\frac{z_{t}}{z}\right)^{9}\right]^{1 / 12}}= \\
& =\frac{3.6 k f_{v}\left[0.32\left(\Psi-\Psi_{0}\right)^{1 / 2}\right] T_{f}}{C_{2}}
\end{aligned}
$$

The radiance data of Figure 7 is plotted in Figure 8 using the left-hand side of Equation (3) above, as ordinate and $\Psi$ as abscissa. The correlation is excellent. It implies that the soot volume fraction $f_{v}$ for these propylene flames is independent of height and mass transfer rates.

\section{VELOCITY}

Most, Sztal and Delichatsios ${ }^{7}$ measured the velocity and temperature profiles of vertical turbulent ethane wall fires. The measurements were performed at Factory Mutual Research Corporation during the summer of 1982. The measurements were not correlated at the time. Now, with the present approach, both the velocity and temperature profiles are successfully correlated. 


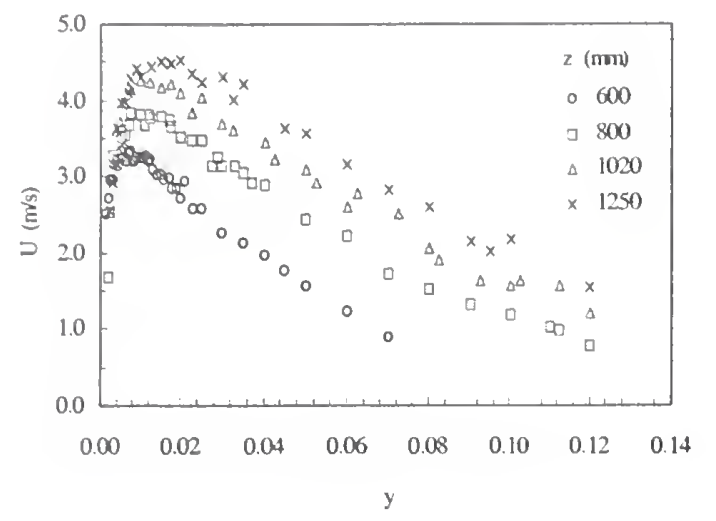

Figure 9 LDV measured velocity, U, vs. distance, $y$, for different heights, $z$, at mass transfer rate, $\dot{m}^{\prime \prime}=5.4 \mathrm{~g} / \mathrm{m}^{2} s$

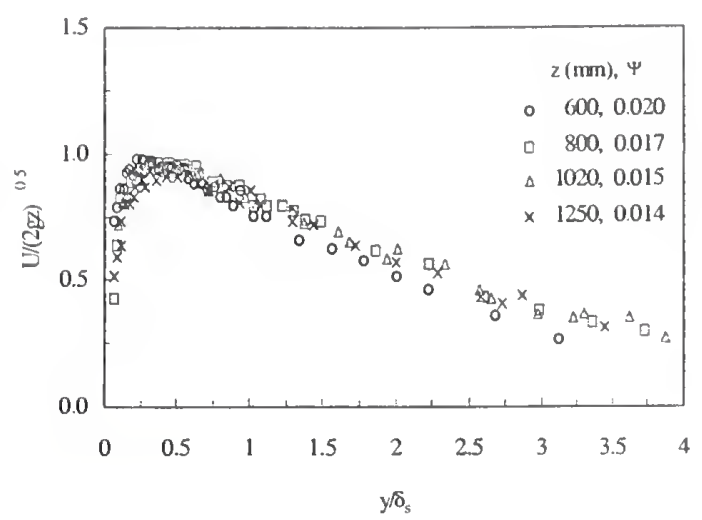

Figure 10 Correlation of $U /(2 g z)^{1 / 2} \mathrm{vs}$. normalized distance, $y / \delta_{s}$ for different heights, $\mathrm{z}$, at $\dot{m}^{\prime \prime}=5.4 \mathrm{~g} / \mathrm{m}^{2} s$.

Their ethane flame temperature measurements are almost identical to those of Figures 5 and 6. Figure 9 shows their LDV velocity measurements, U, vs. distance, y, for different heights, $\mathrm{z}$, for an ethane mass flow rate of $\dot{m}^{\prime \prime}=5.4 \mathrm{~g} / \mathrm{m}^{2} \mathrm{~s}$. Figure 10 shows the same data correlated as $U /(2 g z)^{1 / 2}$ vs. $y / \delta_{s}$.

\section{CONCLUSION}

The similarity presented here has greatly simplified the development of flame heat transfer models for wall fires in the pyrolysis zone. Indeed reference [1] presents an algebraic model for the flame heat transfer in the pyrolysis zone for an arbitrary fuel having a given smoke point. The semi-empirical model is based on extensive measurements of methane, ethane, ethylene and propylene wall fires.

\section{REFERENCES}

${ }^{1}$ de Ris, J. L., Markstein, G. H., Orloff, L. and Beaulieu, P. A., Flame Heat Transfer Part I: Pyrolysis Zone, Factory Mutual Research Tech. Report J. I. OD0J9.MT, September 1999.

${ }^{2}$ Morton, B. R., Taylor, G. I. and Turner, J. S., "Turbulent Gravitational Convection from Maintained and Instantaneous Sources," Proc. Roy. Soc. A 234, 1 (1956).

${ }^{3}$ Ahmed, T., "Investigation of the Combustion Region of Fire-Induced Plumes Along Upright Surfaces," PhD. Thesis, Pennsylvania State University, (1978).

${ }^{4}$ Siegel, R. and Howell, J. R., Thermal Radiation Heat Transfer, $3{ }^{r d}$ Ed., Hemisphere Publishing Co. (1992).

${ }^{5}$ Choi, M. Y., Mulholland, G. W., Hamins, A. and Kashiwagi, T., "Comparisons of the Soot Volume Fraction Using Gravimetric and Light Extinction Techniques," Combustion and Flame, 102, 161-169 (1995).

${ }^{6}$ Yuen, W. W. and Tien, C. L., "A Simple Calculation Scheme for the Luminous Flame Emissivity," Sixteenth Symposium (International) on Combustion. The Combustion Institute, Pittsburgh, pp. 1481-1487, 1977.

${ }^{7}$ Most, J. M., Sztal, B. and Delichatsios, M. A., "Turbulent Wall Fires - LVD and Temperature Measurements and Implications," Presented at the Second International Symposium on Applications of Laser Anemometry to Fluid Mechanics, Lisbon, Portugal, July 2-4, 1984, (Also Factory Mutual Report Number, RC84-PT-11.) 
NECESSITY OF DESIGN METHODOLOGY IN THE FRAMEWORK OF A PERFORMANCE BASED FIRE SAFETY DESIGN SYSTEM

\author{
Takeyoshi TANAKA \\ DPRI, Kyoto University \\ Gokasho, Uji, Kyoto 611-0011 NIHON
}

\title{
INTRODUCTION
}

Sometimes research people tend to esteem 'science' more than 'engineering'. The difference between the two may not matter for most fire researchers but may subconsciously affect the preference of their research targets. The primary goal of 'science' may be defined as to 'discover' the facts, truths or rules in the objects which exist in this world from the beginning. On the other hand, the main role of 'engineering', the word said to be derived from 'engine', has been considered to 'invent' something which 'benefits' our society. Hence, it follows that engineering creates something beneficial which does not exist in this world.

Moving to the subject fire modeling, the author consider that fire models belong more to engineering than to science and that they should find the area of developments more in that direction. In this paper, the author therefore would like to discuss how fire safety engineering tools in general, including computer fire models, can benefit our society, particularly building related community. A particular focus is placed on two layer zone fire models because of the authors expertise, although notable progress was of course made in other type of models, such as field models and detector response models.

\section{PROGRESS IN FIRE MODELING}

The notable fire models developed until 1993 are summarized in TABLE 1 according to type and year of publication. Although many more fire models have been developed to date, a thorough coverage is, needless to say, next to impossible here. The models shown in TABLE 1 are basically those cited in one of Refs.[1] - [8], which are papers for reviews or surveys of the state of arts of the fire models at those days. In other words, they are the models which, more or less, drew somebody else's attention.

(1) Dawn of Fire Models

Noticeably, a well mixed type (one layer) compartment fire model was published as early as in the late 1950s by Kawagoe and Sekine, BRI, Japan. It may be said that the means to predict the mass burning rate and the opening flow rates in compartment fires were established by this model. Despite that computers, or even hand calculators, are not available at that time, boundary wall temperatures were predicted using Shmit's method. This model was used until very recently with virtually no modification in the area of structural fire resistance in Japan perhaps because it was an excellent model. Only drawback of this model may be that so-called 'complete combustion ratio' $(=0.6)$ was used probably to adjust the temperature predictions to experience. The universal validity of this parameter is questionable and this can be replaced with the fact that heat release rate in a ventilation limited fire is controlled by the air supply rate into the compartment. However, this must be a too harsh criticism. Considering the general conditions about fire research at that time, this model can be said an outstanding accomplishment. 
Another important model appeared in this period is the one published in 1963 by Thomas et al. in conjunction with the investigations into roof smoke venting. The concept of a smoke layer and a fire plume were introduced in this model. It is suspected that this model gave a basic idea to the two layer zone models which thrived in later years.

\section{(2) Smoke Movement Models}

The next stage of fire modeling started with the onset of the computer era. The smoke movement model by Wakamatsu, BRI, Japan appeared as early as in 1968, before long when the use of computers began in some of the scientific area. This model was extensively used in the analyses of smoke movement in building fire accidents, such as Sennichimae Department Fire, and efficiency of smoke control systems, such as the stair pressurizations in the two office towers in Shinjuku, Tokyo. It may be said that this model convinced the fire research community in Japan the opening of a new epoch for fire research. In Canada, a similar model was developed by Tamura, NRC, Canada at nearly the same time. As the author believes, his model became the basis of ASCOS developed by Klote, NBS. USA,

\section{(3) Two Layer Zone Models}

A building fire involves a number of physical and chemical processes in coupling manners and its behavior is awfully affected by building environment. In conventional studies, only limited aspects of fires could be investigated in some simplified configurations because of the limitations of analytical methodologies, which must be a major reason for that fire researches had been somewhat slow for a significant time period. On the other hand, rapid progress of computers made it practicable to analyze complex fire behaviors as they are without neglecting many aspects.

It is the Home Fire Project in the USA that envisioned a promising progress in fire research area on the basis of the extensive computer capability and vigorously promoted the development of fire models. This project was conducted under the strong leadership of Professor Emmons, Harvard University. In his future scope there was such a model that is capable of predicting the transient fire environment of any kind, including burning, at any space in a building after an item has ignited in a room. He considered that a field type model was too heavy in terms of computing time despite of the enormous capability of the computers at that time, so that two layer zone models would be appropriate for such a purpose. It is suspected to be under the influence of his thoughts that many models were published almost simultaneously in the USA, by Rockett, Quintiere, NBS and Harvard University etc. In this sense, it can be said that Professor Emmons was the foster father of two layer zone models.

Ever since, the computer capability has been tremendously enhanced beyond our imagination. Still, Professor Emmons' decision seems to retain appropriateness. To borrow the words of Kokkala, VTT, it is the oxygen consumption calorimetry and the two layer zone models are the two major inventions that dramatically changed the way of fire research in this decade. The author has the same feeling, although wish to add the performance-based fire safety design method in near future. Thus, it turns out that Professor Emmons also triggered the rapid progress of fire research in recent years worldwide.

In Japan, Fire simulation workshop was initiated responding to the invitation of Professor Akita, University of Tokyo, about the same time as the Home Fire Project. Around ten or more members participated voluntarily from University of Tokyo, BRI, FRI etc. This small workshop had no particular mission nor financial support. Youth was the only asset, in fact most of the members were in their 20s, accustomed to lack of fund, incidentally. The members exchanged the ideas of each other's models with curiosity. Looking back, the author feel that this workshop, which continued 
several years, played a valuable role in the early stage growth of fire modeling research in Japanese scene.

It is about such a time that UJNR Panel on Fire Research and Safety was initiated and active exchange of the fire research started between the USA and Japan. Since then, fire modeling has always been a central topic in the US - Japan joint meetings. Many two layer zone fire models were developed during this period in both countries, such as FIRST, CFAST, HARVARD III - VI, ASET in the USA, BRI2 etc. in Japan. UJNR Fire Panel affected on many of the model, directly or indirectly. It is well known that two layer zone models, of which the UJNR Fire Panel took the lead, have now propagated to many countries, stimulated their fire research and are being used for a number of practical applications such as to fire safety design of real buildings.

\section{FUTURE DIRECTION OF FIRE MODELING}

The progress of the two layer zone models was remarkable for a good while since they first appeared in the mid-1970s. They increased their predicting capabilities by incorporating new ideas and new findings. Coming to this point of time, however, it seems that the progress has somewhat slowed down. The author's impression is that this stagnation implies that the fire modeling has reached at the stage to have to think about what the objectives of prediction of fire behavior are.

(1) What Should Predict?

What a model should predict depends on the objective of the prediction. In the development of BRI2, including its preceding models, the consistent thinking was that it should be an engineering tool for fire safety designs of buildings rather than a scientific tool. Because of this, it did not deal with prediction of burning and tried to minimize the burden of data input. Modeling of burning behavior itself is difficult enough, but moreover it will require much detailed input data. This might be all right for scientific purposes but will be too much for most of design practices.

How detail and accurate a model should predict will also depend on the purpose. As long as usual building design practices are concerned, what the designer of a building would like to know based on the prediction will be such as whether or not exit width is enough for evacuating people within the available egress time, how much smoke extraction and air supply rates are required to clear the egress routes, whether or not the danger of breaking of the glass roof of the atrium exists and the sort of things. Since such assessments are normally made under a certain assumptions of the size, the location etc. of the fire source, a prediction in detail gives little reality so will not be paid for the extra work for detailed data inputting etc.

(2) Fire Models in the Framework of Performance-based Fire Safety Design

There is an impression that the priority area of fire research has shifted from fire modeling to performance-based fire safety design system. In fact, such a design system is considered to be vital to fire research as well as to building design practices. Many fire models will be able to find their objectives in this system.

What a fire model is to a performance-based design system looks like what a car is to a street system. However high ability a car may have, we will have no choice but cherish it in a garage unless the streets are smoothly paved. Likewise, however capable a fire model may be, we cannot but admire it for a while in a paper and forget before long if building designs have to comply to the existing prescriptive provisions. 
Currently, several ideas exist on what the structure of the performance-based fire safety design system should be. One of them is 'Objective-based' type design system, which is most rational as long as the author believes. According to this system, a number of fire safety engineering tools, are needed for the verifications of compliance to the fire safety objectives. They are not necessarily computer fire models although indispensable, It follows that computer fire models hold a seat among these engineering tools. In a sense, this is natural since the purpose of a performance-based design system is not to use computer fire models but to provide a means for rational and effective fire safety designs, which is just like not only cars but also pedestrians, bicycles, motorcycles, street cars etc. use streets depending on the convenience.

\section{PERFORMANCE-BASED FIRE SAFETY DESIGN METHODOLGY}

\section{(1) Problems in Using Fire Safety Engineering}

Clearly, fire safety engineering tools, including computer fire models, and performance-based fire safety design methods are great contributions from the fire research community to the world of practice. But are they sufficient?

The current state of design practice is that building designers have established their own design methodologies to effectively plan buildings, harmonizing the requirements from building owners and the prescriptive safety provisions. However, a performance-based design system is such a drastic transition for nearly all of them that they currently have very little idea on how they can effectively design buildings based on the new framework. Without such design methodologies, performance-based design systems and fire safety engineering tools will be virtually useless.

Fire researchers may claim that such is the matter of education or training. However, fire researcher may be able to act as teachers of engineering tools but there is no teacher of design methodologies. The author noticed in one of the case study papers presented to an international symposium for performance-based fire safety design method such a sentence which says ' mechanical extraction at the rate of some $200 \mathrm{~kg} / \mathrm{s}$ is sufficient to attain some $20 \mathrm{~m}$ smoke clear height'. This is of course an extreme case, but in general fire researchers need to know that there are a lot of things which are practically impossible or too difficult albeit theoretically possible. In this regard, it may be said that the technical research center of the construction companies in Japan are doing good jobs, but even in such exceptionally lucky cases as to be able to have such a research center, the sizes of the staff are often too small for extensive and in-depth studies on the design methodologies. Evidently, fire researchers and practitioners need to have good contact with each other and jointly work for new methodologies. Such endeavors will not end up with mere well-fare services from the side of researchers. They will in return be paid off with a number of attractive research topics.

\section{(2) Sprouts of Performance-based Fire Safety Design Methodologies}

It may be said that, since the 5 year project 1981 - 1986, by BRI, MOC, a considering number of exercises for performance-based fire safety designs have been made through Article 38 of Building Standards Law. Thus, step by step, some engineers have got accustomed to the use of several fire safety engineering tools and accumulated some know-how to harmonize the requirements both from fire safety and building economy, that is design methodologies, for several cases of frequent appearance, such as atria smoke venting, lobby pressurization smoke control, unprotected car park steel structure. However, most of such methodologies still remain to be in-company know-how so their universal validity have not yet been proved.

Pressurization Smoke Control Workshop of Kinki branch of Architectural Institute of Japan attempted to work out a widely usable hand calculation methods for air supply rate in lobby 
pressurization smoke control systems [9]. Another attempt was made by General Building Research Corporation to develop a smoke control design methodology for department stores with virtually no windows. However, perhaps, many more important issues are still untouched by fire research community.

\section{CONCLUDING REMARKS}

It is true that in the development of the fire models, some of the scientific knowledge on fire which existed at that time was used. But this does not mean that fire models depend only on the scientific knowledge, which was often insufficient to build a fire model. Some engineering dealings had to be invented in many cases and fire modeling practices identified the needed area of fire science.

Similar saying will be also true in the relationship between fire safety engineering tools and performance based design systems. The progress of fire models motivated the development of performance-based design systems, but in return the design system will draw demands for various engineering tools, and further on fire science.

It will be important and beneficial for fire researchers to more positively get involved in fire safety design methodologies to run smoothly performance-based design system, just like it is important to master how to drive a car in the streets.

\section{REFERENCES}

[1] Benjamin, I. A., Fung, F. and Roth, L.: Control of Smoke Movement in Buildings - A Review, NBSIR 77-1209, 1977.

[2] Quintiere, J. G.: Growth of Fire in Building Compartments, ASTM STP 614, 1977.

[3] Emmons, H. W.: Scientific Pogress on Fire, Ann. Rev. Fluid Mech., 1980.

[4] Friedman, R.: Status of Mathematical Modeling of Fires, FMRC 81-BT-5, 1981.

[5] Jones, W. W.: A Review of Compartment Fire Models, NBSIR 83-2684.

[6] Quintiere, J. G.: A Perspective on Compartment Fire Growth, Comb. Sci. and Tech., 1984.

[7] Friedman, R.: Survey od Computer Models for Fire and Smoke (Second Edition), Preparation for FORUM, 1991.

[8] Tanaka, T.: History of Development and Future Direction of Fire Models, Kasai Vol.43, No.5, Japan Association for Fire Science and Engineering, 1993 (in Japanese)

[9] Kujime, M., Matsushita, T. and Tanaka, T.: Hand Calculation Method foe Air Supply Rates in Vestibule Pressurization Smoke Control System, Int. J. on Engineering Performance-Based Fire Codes, Vol. 1, No. 1, p27-40, 1999. 


\title{
Use of Fire Simulation in Fire Safety Engineering and Fire Investigation
}

\author{
David D. Evans \\ Fire Safety Engineering Division \\ Building and Fire Research Laboratory \\ National Institute of Standards and Technology \\ Gaithersburg, Maryland 20899-8640
}

\begin{abstract}
A discussion is presented of recent applications of the Fire Dynamics Simulator software developed at NIST for modeling fires using large eddy simulation technology. Applications and impacts of the model include: prediction of wind-blown smoke plume trajectory and particulate concentration predictions, the interaction of sprinklers, draft curtains and roof vents in warehouse facilities, and fire fighter fatality investigations.
\end{abstract}

\section{BACKGROUND}

One way that the understanding of fire phenomena can be demonstrated is through consistent ability to predict the consequences of fires. The careful study of controlled laboratory experiments provides the foundation for our understanding of fire phenomena. Empirically based predictive methods have formed the basis for the development of many of the tools used in fire safety engineering today. Two of the most frequently used engineering predictive methods for life safety in buildings are ASET-B [1] and DETACT [2]. ASET-B provides time estimates for the onset of hazardous conditions based on smoke layer filling of an enclosure. DETACT provides a time to automatic fire detection by ceiling level devices. ASET-B is based on the experimental correlation of plume entrainment developed by Zukowski [3]. DETACT is based on the experimental correlations of ceiling jet temperature and velocity developed by Alpert [4].

More advanced than the direct applications of experimental-correlation based engineering methods are the often used single-enclosure two-zone fire models. These are capable of representing fire conditions in multiple room geometries of residential and commercial buildings. One of the first of these generalized fire models was the groundbreaking Harvard Computer Fire Code [5], developed under the leadership of Professor Howard Emmons at Harvard University. Today a widely used two-zone fire model is CFAST [6] developed at the National Institute of Standards and Technology (NIST). These models have for a generation served as vehicles for bringing together the best knowledge of fire phenomenon in a form that could be used for engineering purposes. Working from the basic two-cell per room structure of the zone model, many of the sub-grid fire phenomena such as detector actuation and second item ignition have been included as features of the model prediction. Although CFAST at the time of its introduction in 1984 as part of the HAZARD I software package [7], stretched the capabilities of the emerging personal computer resources, this is no longer the case. The core technology of the two- 
zone fire models is now employed to generate faster-than-real-time fire emergency condition predictions for buildings as a potential part of future technology for fire loss reduction and fire fighter safety. With the onset of faster and cheaper computing, it is now practical at about the same computational time as engineers experienced with the original two-zone fire models to perform simulations containing a million cells. With the capability for high spatial and temporal resolution fire models, comes the possibility of generating technology for visual simulation of fire events. The ability to create accurate visual representations of fire events, whether for product and test method development, fire investigation, training, or simply gaining insight into fire phenomena at scales impractical to test, will forever change the fire safety paradigm. In addition, there will be a need for better fire measurements for model validation and a need for test methods to supply the input for these models. These new fire tests will require measurement of the general fire properties of materials and will move away from relative measurements that are not useful in the physically based models. A new generation of separate empirically based sub-grid fire-phenomena models will be needed that are consistent with the high resolution of the new fire modeling technology and the phenomena that it is capable of predicting.

\section{APPLICATIONS}

In 1980 NIST started a competence building project to investigate the application of the large eddy simulation technique to enclosure fire modeling. In 1983 using the CRAY XMP supercomputer at NIST, a 64,000 cell simulation of a fire driven flow in an enclosure was produced, Figure 1 [8]. The large eddy simulation captured the major features of the large-scale turbulence in the fire driven flow, although much larger numbers of cells would be needed for accuracy. Today, with a fine grid of nominally one million cells, flow features over two orders of magnitude in length scale can be captured in enclosure fires.

\section{Wind Blown Smoke Plumes}

The first major application of this new technology by NIST was in the area of smoke plume dispersal from large fires. The oil spill response community needed to develop the technology that would allow safe use of in-situ burning of spills as a response method. One of the immediate concerns was the trajectory and ground area impacted significantly by the smoke plume produced by the burning. To be successful, the computational domain had to be moved from the room-scale of meters to the scale of kilometers. Fortunately the scale of the important mixing phenomena also increased with the size of the fire source now representative of a major fuel spill, so that an approximate large eddy simulation technology was practical with an equivalent 500,000 cell simulation. Figure 2 shows an early 1990's simulation where the transition from the existing simulation of the fire in an enclosure to the wind blown smoke plume simulation is demonstrated [9].

The new calculations that considered the dynamics of a strong fire source in a crosswind flow provided predictions that were great improvements over the existing Gaussian 
models for dispersion of pollutants. Calculations for the State of Alaska [10], showed that under even severe conditions, the downwind area effected by high concentrations of smoke particulate extended only a few kilometers from the fire. As a result of the calculations, guidelines were established under which spill burning could be approved for areas beyond $5 \mathrm{~km}$ distance from populated areas with site specific analysis. With suitable computations for specific incidents, this distance might be reduced to $1 \mathrm{~km}$.

To facilitate the use of this technology in spill and other hazardous fire conditions, a portable computer version of the model was developed by NIST for free distribution. This software works with information that would readily be available visually to responders to produce the needed input for the simulation. Of course, measured information, if available, may be entered to improve the accuracy of the predictions for a specific incident. This software A Large Outdoor Fire plume Trajectory model - Flat Terrain (ALOFT-FT) [11] is available for downloading from the web site http://fire.nist.gov. In 1999, the visual simulations of smoke plume trajectories performed by NIST in Gaithersburg using this software provided the information needed for Oregon authorities to approve the intentional burning of fuel aboard the grounded freighter New Carissa, Figure 3. Burning before the break-up of the ship significantly reduced the pollution from the incident. This software has also been used in the planning of large-scale oil pool fire experiments conduced by the Japan National Oil Company at Tomakomai.

\section{Warehouse fires}

Fire driven flows dominate the spread of fires in box arrays typical of industrial storage facilities. Options for the protection of these facilities include fire sprinklers, heat and smoke vents, and draft curtains that are barriers to horizontal spread of smoke under ceilings in large area facilities. Even though these three systems are often installed together, the interactions during a fire have not been fully quantified. With suitable development of sub-grid phenomena models for fire growth, fire suppression with water sprays, and the response of heat activated devices, such as sprinklers and roof vents, it was felt that the large eddy simulation modeling could provide valuable insight into the performance of these systems. The use of modeling as both a planning and analysis tool was likely to yield an understanding of the interactions of sprinklers, vents and draft curtains that had not been gained from many years of limited large-scale testing.

Warehouse-size fire tests are expensive. They are also complex and variable. Figure 4 shows the geometry of the fire test used to evaluate the interactions of fire sprinklers, roof vents and draft curtains at Underwriters Laboratories in Northbrook, Illinois. In order to make a meaningful prediction, both the fire growth and the suppression of the array of boxed plastic commodity must be predicted from modeling with a cell size of $15 \mathrm{~cm}$ length. The ability to predict burning rates and suppression is the fundamental advancing step in fire modeling that needs to be addressed before simulations of fire are possible that would provide benefit comparable to large-scale testing. In this first effort considerable small-scale testing with the fuel packages and parts of the array were 
performed so that the initial behavior of the fire growth in the array and the suppression with water could be duplicated with the large eddy simulation model. This allowed the larger issues of the interactions between the fire protection systems and their effects on the overall fire to be studied and compared to large-scale tests. Reliable predictions of large-scale tests provided a basis for exploring conditions that were not directly tested. This enhancement of the experimental results through the use of modeling both increased the value of the modeling to the study and also increased confidence in the results. Figure 5 shows predicted near-ceiling temperatures and the predicted results for sprinkler actuation for one of the fire tests [12]. The results show that major features of the test, such as the number and locations of sprinklers activated, are predicted well. Even with the large amount of effort expended in this study, the details of time of activation of each sprinkler is not dependably predicted particularly near the edge of the area of activation. In order to do better, there must be improvements in both the predictions and the measurements of the heat sensitive hardware devices like sprinklers. With the normal variations that occur in large-scale testing, it may be beneficial to understand the uncertainties of the tests themselves to properly gauge the accuracy of the models.

Applications of this model are limited. We cannot easily change the fuel or the suppressant in the simulation. A simple change in the box container material, the sprinkler, or the spacing in the array would introduce changes that at this time could not be handled without input from extensive experimentation to generate sub-grid models.

The high temporal and spatial resolution of the large eddy simulation technology provide a basis for visual simulation of fire scenarios that can be adapted to real-time animations for viewing on a computer monitor or for recording on video tape. Of course these animations are visualizations of the quantitative information from the fire models. The animations provide the easiest way to transmit information about the fire performance for use of decision makers who may not be technically trained in fire engineering. These animations will also be useful for training purposes. Figure 4 shows one image from an animation of the sprinkler-draft curtain-vent test. Colors for the flame surface and smoke particulate are based on imaging parameters set to visually represent the scalar temperature and composition properties of the predicted flows.

\section{Fire Fighter Fatality Investigations}

In the United States about a hundred line-of-duty deaths of fire fighters occur annually. Many of these occur when fire fighters are caught in situations where the behavior of the fire is unexpected. The emerging ability to simulate the dynamics of fire in buildings with the large eddy simulation technology and display the computed results using a visual animation with quantifiable features is providing new insight to the dynamics events leading to fire fighter deaths and injuries. This technology can provide a basis for training future fire fighters to avoid the mistakes of the past.

NIST has provided advice on several fire fighter fatality incidents based on its use of large eddy simulation to recreate as closely as possible fire events that have been 
recorded from witnesses. As information on the fuels involved and on the initial time line is generally unavailable, greater uncertainty is associated with these predictions than those of controlled laboratory tests. We have succeeded in demonstrating the major fire phenomena that played a role in the tragedies. For example, in New York City in 1998, three fire fighters died in the hallway outside of a tenth floor apartment. In that case, calculations with the large eddy simulation model showed that gusting winds outside of the building provided puffs of fresh air at high velocity into the room of fire origin. The high velocity fresh air flow allowed increased burning of the accumulated combustion products. Hot combustion products were forced continually into the hallway and out of the building through the open windows of an apartment on the downwind side. The hot gases moving at high velocities in the corridor subjected the fire fighters to conditions that exceeded the capacity of their protective garments to protect them, see Figure 6.

Many fire fighters who have viewed the animations of the high-rise apartment fire incident were unaware of the fire dynamic hazard generated by gusting wind loads on buildings when the fire can vent through openings on both the upwind and downwind sides of the building. Lessons learned though this analysis may help to save lives of fire fighters in the future.

Personal computer versions of the large eddy simulation fire model named Fire Dynamics Simulator (FDS) and the companion software SMOKEVIEW for visualization of results are available for downloading free of charge from the web site, http://fire.nist.gov.

\section{CONCLUDING REMARKS}

Fire simulation provides an opportunity for the benefits of fire science research to be showcased in engineering applications that allow fire events to be understood more readily by the diverse audience of professionals involved in fire safety. Each one of the applications presented provided new insight for the users into the fire phenomena and fire effects that are important to their needs. This technology is only beginning to be practical for application to engineering problems. A great amount of research remains to be done to support the continued development of the underlying sub-grid models and the verification of predictions in a variety of applications. High quality fire modeling combined with effective visualization of results will provide the foundation for fire safety decisions of the future.

\section{ACKNOWLEDGMENT}

This paper is presented as part of a symposium to honor Professor Howard Emmons as part of the UJNR Technical meeting. The author had the opportunity during his formal engineering education to be a student of Professor Howard Emmons. During those years of the Home Fire Project at Harvard, full-scale bedroom fire experiments were conducted to measure and observe fire phenomena from ignition to extinction. The metric for success then and now is the ability to accurately predict building fire phenomena. We 
continue to build on the foundations established for us by the fire research pioneered by Howard Emmons. The more work that I do to help advance fire safety, the more I appreciate the magnitude of his accomplishments.

\section{REFERENCES}

[1] Walton, W.D., "ASET-B: A Room Fire Program for Personal Computers," Fire Technology, Vol. 21, No. 4, 293-309, (1985).

[2] Evans, D. D., "Calculating Sprinkler Actuation Time in Compartments", Fire Safety Journal, Vol. 9, No. 2, pp. 147-155, (1985).

[3] Zukoski, E.E., "Development of a Stratified ceiling layer in the early stages of a closed-room fire", Fire and Materials, Vol 2, p 54 - 62, (1978).

[4] Alpert, R.L., Calculated Response Time of Ceiling-mounted Fire Detectors, Fire Technology, Vol 8, pp. 181 - 195, (1972)

[5] Mitler, H. E., Emmons, H. W., Documentation for CFC V: The Fifth Harvard Computer Fire Code, National Bureau of Standards, Gaithersburg, MD NBS GCR 81-344, (1981).

[6] Peacock, R. D., Forney, G. P., Reneke, P. A., Portier, R. W., Jones, W. W., CFAST, The Consolidated Model of Fire Growth and Smoke Transport. National Institute of Standards and Technology, Gaithersburg, MD NIST TN 1299, (1993).

[7] Peacock, R. D., Jones, W. W., Bukowski, R. W., Forney, C. L., Software User's Guide for the HAZARD I Fire Hazard Assessment Method. Version 1.1. Volume 1. National Institute of Standards and Technology, Gaithersburg, MD, NIST Handbook 146/I, (1991).

[8] Baum, H.R., Rehm, R.G., "Calculations of Three Dimensional Buoyant Plumes in Enclosures," Combustion Science and Technology, Vol. 40, pp.55-77, (1984).

[9] Evans, D.D., Walton, W.D., Baum, W.R., Notarianni, K.A., Tennyson, E.J., Tebeau, P.A., "Mesoscale Experiments Help to Evaluate in-situ Burning of Oil Spills," Proceedings of the 1993 International Oil Spill Conference, March 29-April 1, 1993, Tampa, Florida, American Petroleum Institute, Washington, DC 20005, pp.755-760, (1993).

[10] McGrattan, K. B., Putorti, A. D., Jr., Twilley, W. H., Evans, D. D., Smoke Plume Trajectory From In Situ Burning of Crude Oil in Alaska. National Institute of Standards and Technology, Gaithersburg, MD, NISTIR 5273, (1993).

[11] Walton, W. D., McGrattan, K. B., ALOFT-FT TM A Large Outdoor Fire plume Trajectory model - Flat Terrain Version 3.04. National Institute of Standards and Technology, Gaithersburg, MD, NIST SP 924, (1998).

[12] McGrattan, K.B., Hamins, A., Stroup, D., Sprinkler, Smoke \& Heat Vent, Drat Curtain Interaction - Large Scale Experiments and Model Development, National Institute of Standards and Technology, Gaithersburg, MD, NISTIR 6196-1, (1998). 


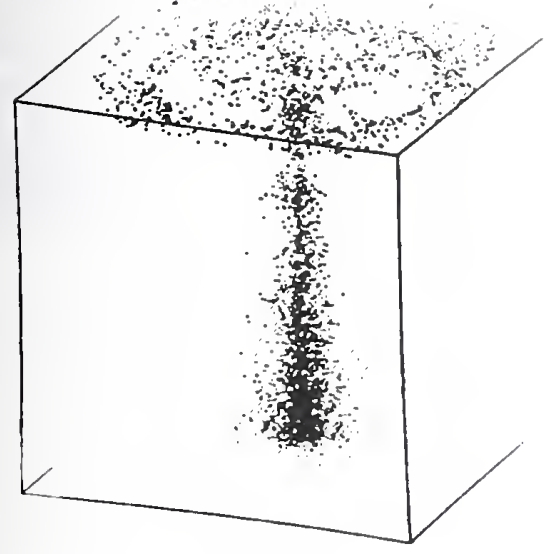

Figure $1 \quad 64,000$ cell simulation of an enclosure fire, 1983 [8]
Jeight

$1.6 \mathrm{~km}$

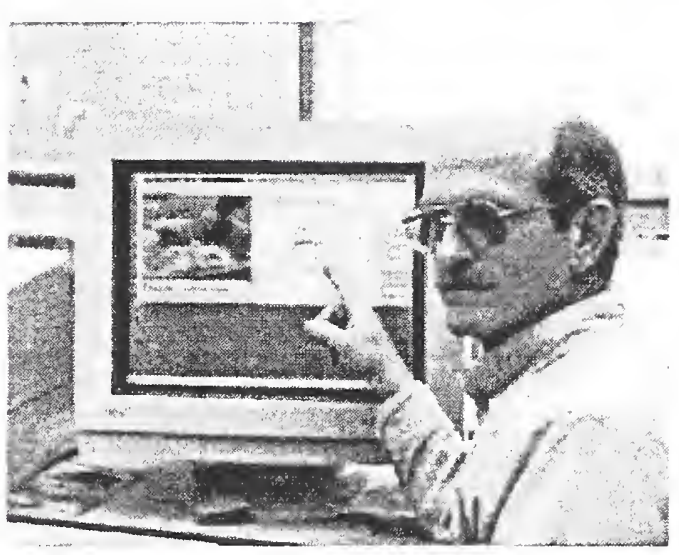

Figure 3 ALOFT-FT aids oil spill response, 1999
Figure 2 Simulation of wind blown smoke plume, 1993 [9]

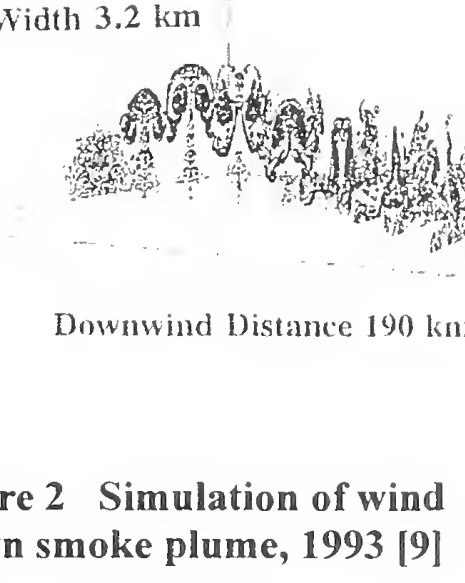



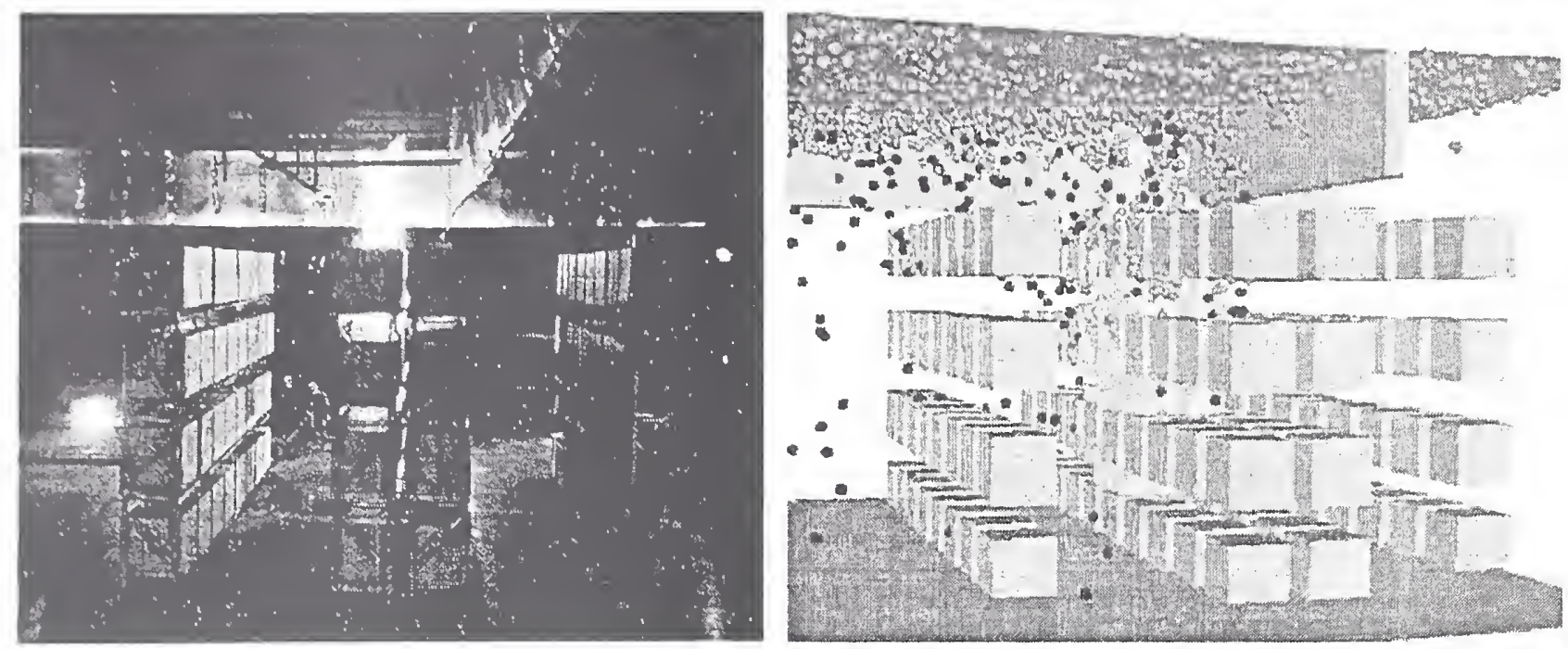

Figure 4 Geometry for sprinkler, roof vent and draft curtain experiments and simulation

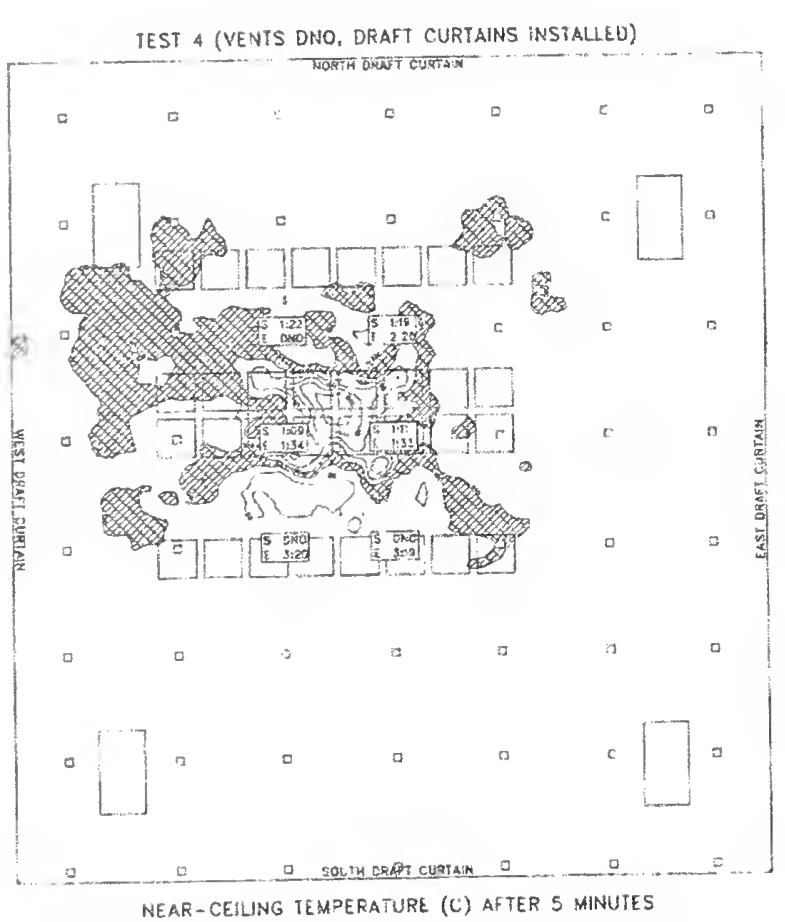

Figure 5 Fire Dymamics Simulator predictions of sprinkler response

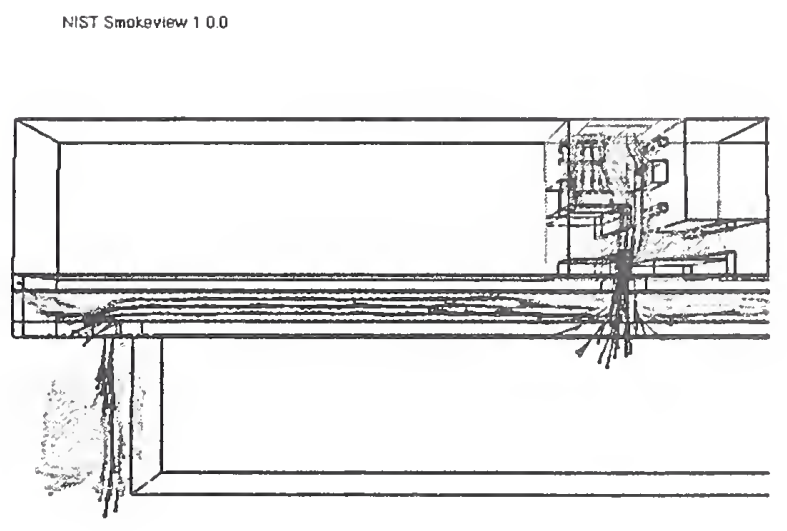

Figure 6 Apartment building fire simulation 


\title{
A CONVECTIVE HEAT TRANSFER MODEL FOR LARGE EDDY FIRE SIMULATIONS
}

\author{
Howard R. Baum \\ National Institute of Standards and Technology \\ Building and Fire Research Laboratory \\ Gaithersburg, MD 20899
}

\begin{abstract}
A model for the calculation of convective heat transfer to surfaces is presented. The model is designed to be used in conjunction with the large eddy simulation fire dynamics model developed at The National Institute of Standards and Technology. It is based on the approximate solution of the three-dimensional time dependent laminar boundary layer equations together with self-consistent boundary conditions. The approach involves the use of a suitable coordinate transformation to account for variable property effects in the boundary layer. A brief derivation of the required transformation is included as it does not seem to be in the standard heat transfer and combustion texts.
\end{abstract}

\section{INTRODUCTION}

The purpose of this work is the development of a model of convective heat transfer to approximately plane surfaces that can be used in conjunction with the large eddy simulation (LES) models of fire dynamics currently in use at The National Institute of Standards and Technology (NIST) [1]. At present, the convective heat transfer is either ignored or is represented by an empirical heat transfer coefficient. In either case, the LES code predicts an effective "surface" temperature $T_{e}(x, z, t)$ on a surface defined locally by a value of a "normal" coordinate $y=0$. Similarly, the code predicts a surface velocity vector $\left(u_{e}, w_{e}\right)$ that accounts for the transport between the last interior point in the computational domain and the physical boundary. This information represents the best estimate the LES model can give of the state of motion outside the boundary layer adjacent to any surface.

The approach taken here is to use this information together with an approximate solution to the three dimensional time dependent boundary layer equations to obtain the local heat transfer to each surface. The crucial simplification that makes the solution possible lies in the assumption that the components of the velocity field in the boundary layer parallel to each surface can be represented by a constant fraction $c\left(u_{e}, w_{e}\right)$ of the external velocity field. The heat transfer problem then reduces to the solution of the coupled mass and energy conservation equations. The temperature $T_{e}(x, z, t)$ is interpreted as the temperature "at infinity" with respect to the local boundary layer normal coordinate $y$. The actual wall temperature as predicted by a conjugate heat transfer analysis is denoted by $T_{w}(x, z, t)$.

The approximate boundary layer model retains the same overall mathematical structure as the full boundary layer equations. In particular, the velocity component normal to the surface is determined by conservation of mass, rather than a normal component of the momentum equation. The 
transverse components of the velocity still come from transverse momentum equations, but here the result of the LES calculation are used rather than local boundary layer equations. Approximations of this type have a long history in laminar heat transfer and combustion problems. Indeed, the approach taken here is motivated by a well-known heat transfer formula originally derived by Lighthill [2]. Thus, to the extent that the wall region of the thermal boundary layer can be considered laminar, the present model should give reasonable solutions if the LES predictions of the near-wall velocity components parallel to the surface are reliable.

The use of the Howarth Transformation removes the effects of variable transport properties, reducing the equations to an equivalent constant density heat transfer problem. This reduced system is further transformed into an equivalent heat conduction problem in a suitably defined Lagrangian coordinate system. The relative simplicity of the final system of equations permits the convective heat transfer to a complex array of surfaces to be calculated. Little more computation is required than that needed for the heat conduction to the interior of the solid boundaries that define the surfaces.

The remainder of the paper is organized as follows. The next section presents a derivation of the three-dimensional time-dependent Howarth transformation, applied to the boundary layer equations. This is rather difficult to find in textbooks, and is crucial for the analysis to follow. The third section analyzes the Howarth Transformed model equations and shows their equivalence to the heat conduction equation in a suitably chosen coordinate system. The final section contains a discussion of alternative methods of solving the equation and extracting the wall heat transfer from the results.

\section{THE HOWARTH TRANSFORMATION}

The starting point is the three-dimensional time dependent form of the low Mach number boundary layer equations. These take a slightly different form depending upon the orientation of the surface with respect to gravity. Since we are ultimately concerned with the energy and mass conservation equations, and these differences arise only in the momentum equations, they will be omitted from the present analysis. Let $y$ be the coordinate normal to the surface pointing into the gas, with $v$ the corresponding velocity. The geometry is shown schematically in Figure 1. Then, if $(x, z)$ are local cartesian coordinates in the surface layer, with $(u, w)$ the corresponding velocity components and $\rho$ the density, the conservation of mass takes the form:

$$
\frac{\partial \rho}{\partial t}+\frac{\partial(\rho u)}{\partial x}+\frac{\partial(\rho v)}{\partial y}+\frac{\partial(\rho w)}{\partial z}=0
$$

In what follows, much use is made of the fact that the convective derivative of any physical quantity is unchanged by the Howarth Transformation. In the present notation it takes the form:

$$
\frac{D}{D t}=\frac{\partial}{\partial t}+u \frac{\partial}{\partial x}+v \frac{\partial}{\partial y}+w \frac{\partial}{\partial z}
$$

Using this construct, the energy conservation equation for a non-reacting radiatively transparent 


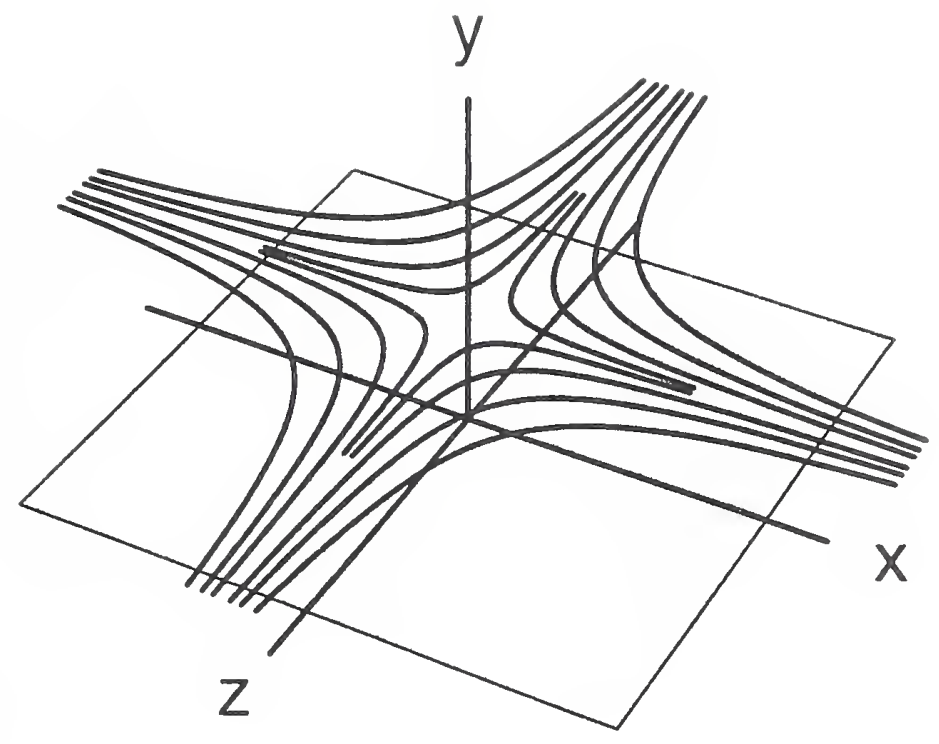

FIGURE 1: Schematic showing streamlines from LES simulation at outer edge of boundary layer. The actual surface is shaded with the coordinate $y$ pointing into the gas.

ceiling layer is:

$$
\rho C_{p} \frac{D T}{D t}=\frac{\partial}{\partial y}\left(k \frac{\partial T}{\partial y}\right)
$$

The specific heat is denoted by $C_{p}$, the thermal conductivity by $k$, and the temperature in the ceiling layer is $T$. These equations are supplemented by the low Mach number version of the equation of state:

$$
\rho T=\rho_{w} T_{w}=\rho_{e} T_{e}
$$

The essence of the transformation is the choice of a normal coordinate $\eta$ and a fictitious normal velocity component $V$ that preserves the convective derivative operator defined by equation (2) and allows the energy and mass conservation equations to take an incompressible form. To this end we introduce $\eta$ as:

$$
\eta=\int_{0}^{y} \frac{\rho}{\rho_{o}} d y
$$

Here, the subscript " $O$ " denotes a reference state that can be taken as the initial density before any heating takes place. We seek to recast the equations in terms of the independent variables $x=X$, $z=Z, \eta$, and $t$. The transformation rules are:

$$
\left.\frac{\partial}{\partial t}\right|_{x, z, y}=\left.\frac{\partial}{\partial t}\right|_{X, Z, \eta}+\left.\frac{\partial \eta}{\partial t}\right|_{x, z, y} \frac{\partial}{\partial \eta}
$$




$$
\begin{gathered}
\frac{\partial}{\partial x}=\frac{\partial}{\partial X}+\left.\frac{\partial \eta}{\partial x}\right|_{y, z, t} \frac{\partial}{\partial \eta} \\
\frac{\partial}{\partial z}=\frac{\partial}{\partial Z}+\left.\frac{\partial \eta}{\partial z}\right|_{y, x, t} \frac{\partial}{\partial \eta} \\
\frac{\partial}{\partial y}=\frac{\rho}{\rho_{o}} \frac{\partial}{\partial \eta}
\end{gathered}
$$

The normal velocity $V$ is now defined so that the convective derivative transforms into itself.

$$
V=\frac{\partial \eta}{\partial t}+u \frac{\partial \eta}{\partial x}+w \frac{\partial \eta}{\partial z}+\frac{\rho}{\rho_{o}} v
$$

Using the transformation rules it is readily seen that the convective operator given by equation (2) is preserved as:

$$
\frac{D}{D t}=\frac{\partial}{\partial t}+u \frac{\partial}{\partial X}+V \frac{\partial}{\partial \eta}+w \frac{\partial}{\partial Z} \equiv \frac{\tilde{D}}{\tilde{D} t}
$$

Next, the temperature dependence of the viscosity $\mu$, thermal conductivity $k$, and specific heat $C_{p}$ are specified by assuming that $C_{p}$, the Prandtl number $\operatorname{Pr}=\left(\mu C_{p}\right) / k$, and the product $\rho \mu$ are constant. Away from the firebed, the primary gases will be either undiluted air or nitrogen. For these constituents, the above approximations are accurate to within ten percent up to $1000^{\circ} \mathrm{K}$. Applying these relationships and the transformation rules to the energy conservation equation yields:

$$
\frac{\tilde{D} T}{\tilde{D} t}=\frac{\nu_{o}}{\operatorname{Pr}} \frac{\partial^{2} T}{\partial \eta^{2}}
$$

The quantity $\nu_{o}$ is the kinematic viscosity evaluated at the reference state.

The last step is the demonstration that the conservation of mass takes the incompressible form. To see this we again use the definition of $\eta$ to rewrite equation (1) in the form:

$$
\frac{\partial(\rho u)}{\partial x}+\frac{\partial(\rho w)}{\partial z}+\frac{\partial}{\partial y}\left(\rho v+\rho_{o} \frac{\partial \eta}{\partial t}\right)=0
$$

The last term in equation (13) can be rewritten as:

$$
\rho_{o} \frac{\partial V}{\partial y}-\left(u \frac{\partial \rho}{\partial x}+w \frac{\partial \rho}{\partial z}\right)-\rho_{o}\left(\frac{\partial u}{\partial y} \frac{\partial \eta}{\partial x}+\frac{\partial w}{\partial y} \frac{\partial \eta}{\partial z}\right)
$$

Using this expression together with equation (9), equation (13) becomes:

$$
\rho\left(\frac{\partial u}{\partial x}-\frac{\partial \eta}{\partial x} \frac{\partial u}{\partial \eta}\right)+\rho_{o} \frac{\partial V}{\partial y}+\rho\left(\frac{\partial w}{\partial z}-\frac{\partial \eta}{\partial z} \frac{\partial w}{\partial \eta}\right)=0
$$


Finally, using the transformation rules one more time, equation (15) takes the desired form:

$$
\frac{\partial u}{\partial X}+\frac{\partial V}{\partial \eta}+\frac{\partial w}{\partial Z}=0
$$

The final transformed set then consists of equations (16) and (12). They are respectively the "incompressible" form of the mass and energy conservation laws in the boundary layer.

\section{MODEL EQUATIONS}

Up to this point, only the boundary layer approximation has been made. The assumptions regarding both the thinness of the layer where the molecular viscosity and thermal conductivity are important and the dependence of these quantities on temperature are well founded. The solution of these equations however, requires considerable computational effort unless some further approximations are made. As noted in the Introduction, the crucial step consists of replacing the in-plane components of the velocity vector that appear in the convective derivative by $c\left(u_{e}, w_{e}\right)$. Then using equation (16) to obtain a consistent approximation for $V$, the convective derivative takes the form:

$$
\frac{\tilde{D}}{\tilde{D} t} \approx \frac{\partial}{\partial t}+c\left[u_{e} \frac{\partial}{\partial X}+w_{e} \frac{\partial}{\partial Z}-\eta\left(\frac{\partial u_{e}}{\partial x}+\frac{\partial w_{e}}{\partial z}\right) \frac{\partial}{\partial \eta}\right] \equiv \frac{\hat{D}}{\hat{D} t}
$$

The conservation equations can now be transformed without further approximation into the heat conduction equation. The starting point is the observation that since $u_{e}$ and $w_{e}$ are independent of $\eta$, the introduction of surface Lagrangian coordinates $\left(x_{0}, z_{0}\right)$ removes the corresponding convective terms from equation (12). We now introduce the dimensionless temperature $\Theta$ as:

$$
\begin{aligned}
\Theta & \equiv \frac{T}{T_{e}}=\Theta\left(t, \eta, x_{o}, z_{o}\right) & \\
\frac{d X}{d t}\left(t, x_{o}, z_{o}\right) & =c u_{e}(X, Z, t), & Y\left(t_{o}\right)=x_{o} \\
\frac{d Z}{d t}\left(t, x_{o}, z_{o}\right) & =c w_{e}(X, Z, t), & Z\left(t_{o}\right)=z_{o}
\end{aligned}
$$

Using the fact that $T_{e}$ must be approximately constant in this system of coordinates if the LES represents an essentially inviscid mixing process, equation (12) now takes the form:

$$
\begin{gathered}
\frac{\partial \Theta}{\partial t}-a(t) \eta \frac{\partial \Theta}{\partial \eta}=\frac{\nu_{o}}{\operatorname{Pr}} \frac{\partial^{2} \Theta}{\partial \eta^{2}} \\
\alpha(t) \equiv c\left(\frac{\partial u_{e}}{\partial x}(\mathrm{X}(t), Z(t), t)+\frac{\partial w_{e}}{\partial z}(X(t), Z(t), t)\right)
\end{gathered}
$$

The quantity $\alpha(t)$ is the surface strain rate evaluated in the moving surface Lagrangian coordinate system. It plays an important role in the remaining transformations, and hence in the final formulae 
for wall shear and heat transfer. The final step is the introduction of a stretched normal coordinate $\lambda$ and time $\tau$ as follows:

$$
\begin{gathered}
\lambda=\eta f(t) \\
\tau=\int_{t_{\mathrm{o}}}^{t} f^{2}\left(t^{\prime}\right) d t^{\prime} \\
f(t)=\exp \left(\int_{t_{\mathrm{o}}}^{t} \alpha\left(t^{\prime}\right) d t^{\prime}\right)
\end{gathered}
$$

Note that the surface strain rate appears exponentially in the definition of both the time and length scales. Thus, the results are extremely sensitive to variations in $\alpha$. It is this sensitivity which gives rise to the enormous enhancement of the wall shear and heat transfer in flows with strong mixing.

With these transformations, the energy equation takes its final form:

$$
\frac{\partial \Theta}{\partial \tau}=\frac{\nu_{o}}{\operatorname{Pr}} \frac{\partial^{2} \Theta}{\partial \lambda^{2}}
$$

The heat flux to the wall $q_{w}$ can be written explicitly as a function of $\Theta$ as follows:

$$
q_{w}(X(t), Z(t), t)=k_{w} T_{e}\left(\frac{\rho_{w}}{\rho_{o}}\right) \exp \left(\int_{t_{o}}^{t} \alpha\left(t^{\prime}, x_{o}, z_{o}\right) d t^{\prime}\right) \frac{\partial \Theta}{\partial \lambda}\left(0, \tau\left(t, x_{o}, z_{o}\right)\right)
$$

Equation (27) shows how three factors contribute to the wall heat transfer. The convection of the heated gas is accounted for by the Lagrangian coodinates $\left(x_{o}, z_{o}\right)$, the effect of the strain rate history by the presence of the integral over $\alpha$ along the Lagrangian trajectory, and the molecular diffusion of heat by the normal derivative of $\Theta$ at the surface.

\section{SOLUTION OF MODEL EQUATIONS}

The solution of the boundary layer equations in the present formulation breaks up naturally into three parts. First, the Lagrangian coordinates and the transformation connecting the $(t, y)$ and $(\tau, \lambda)$ coordinate systems must be advanced in time. Second, the solution to the diffusion equations expressing the transformed conservation laws must be solved for the time interval of interest. Finally, the results must be inserted back into the rectangular grid employed by the LES code and the condensed phase analysis so that these can be updated. As part of this last step, new Lagrangian elements must be added or deleted as needed.

The procedure to be followed must be considered in the context of the solution of the LES equations. Thus, although the general solution of the heat conduction equation (26) can be written down in the form of a convolution integral, it is unlikely that such a result would be employed in practice. Instead, consider the advancement of the boundary layer solution following the completion of a time step in the LES code. The new values of the wall velocities $u_{e}$ and $w_{e}$ together with the wall temperatures $T_{w}$ and external temperature $T_{e}$ are available. 
The first step is to update the Lagrangian coordinates $\mathrm{X}(t)$ and $Z(t)$ of each of a large number of fluid elements. The techniques needed to accomplish this are already employed to track the thermal elements used to represent the combustion generated energy release in the LES code. The value of the strain rate $\alpha$ on each trajectory can now be updated, along with the increment in the timelike coordinate $\tau(t)$. Next, the solution to the heat conduction equation for each fluid element is updated the required increment in time. Again, this represents no more work than is already required to advance the wall temperatures in the LES code by solving the solid phase heat conduction equation for each wall cell. The last step requires an interpolation procedure to estimate the convective heat flux to each wall cell in the rectangular grid employed in the LES code. With this information, the external temperature $T_{e}$ needed at the next time step by the LES code can be found. The required value of $T_{e}$ is the one which yields the same wall heat flux when the LES code is used to estimate the wall heat transfer. The LES code uses the eddy viscosity and a constant Prandtl number to estimate the heat transfer to the wall. The temperature gradient calculated at the wall by that code will depend on the choice of $T_{e}$. Inevitably, the LES temperature gradient will be much smaller and the "eddy conductivity" much higher than that predicted by the boundary layer equations. Requiring both predictions of the heat flux to be identical at all wall cells then closes the system of equations. At this point, the number of elements in each wall cell can be determined. New elements are introduced into cells that are no longer occupied and those elements that have left the region of interest can be removed from the list of those under consideration.

The numerical values of the heat transfer predicted by the model are affected by the choice of the convective constant $c$. However, it is not difficult to decide and test a plausible range of values for this parameter. Since the velocity will increase monotonically to its external value in the laminar sublayer described by this model, a plausible choice should be near $c=1 / 2$. This choice can be optimized by comparing it with known exact solutions like the flat plate and stagnation point heat transfer formulae [3]. The corresponding solutions can be determined analytically from the present model. The results for the wall heat flux $q$ (assuming constant properties) are:

$$
\begin{array}{cc}
q=k\left(T_{e}-T_{w}\right) \sqrt{\frac{2 c P r}{\nu \pi}\left(\frac{d u_{e}}{d x}\right)} & \text { stagnation point } \\
q=k\left(T_{e}-T_{w}\right) \sqrt{\frac{c u_{e}}{\nu x}\left(\frac{P r}{\pi}\right)} & \text { flat plate }
\end{array}
$$

A choice of $c=0.45$ yields a 9.5 percent underprediction for the stagnation point and an 8.2 percent overprediction for the flat plate using a value of 0.7 for the Prandtl number $\mathrm{Pr}$. Time dependent effects should act to reduce the relative errors since the corresponding term in the energy equation is not approximated.

\section{CONCLUDING REMARKS}

A convective heat transfer model is presented based on the idea that a three-dimensional time dependent laminar sublayer connects solid boundaries with a turbulent fire induced flow field. The 
boundary layer equations governing the energy and mass transport in this layer are reduced to an approximate form which requires little more than the solution to the heat conduction equation to obtain the heat flux to a planar boundary. In its present state, it does not account for mass transfer from walls, although that extension is relatively straightforward. Hopefully, this represents the beginning of a systematic effort to put the prediction of heat, mass, and momentum transport near solid boundaries at a level of sophistication currently available in the interior of enclosure fire domains. Ultimately, any such undertaking will involve consideration of many other phenomena which can be relevant in fire scenarios. However, one has to begin any such effort somewhere, and this seems to be a useful place to start.

\section{ACKNOWLEDGEMENT}

Since this paper is offered as a contribution to the Symposium in honor of Prof. Howard Emmons, a personal remark may be forgiven. I was guided from my graduate school days as his teaching fellow , thru a junior faculty position at Harvard University, an industrial consulting job, and finally my present tenure at NIST, by his kindness, patience, and wisdom. It will be a long time before we see his equal again.

\section{References}

[1] McGrattan, K.B., Baum, H.R., and Rehm, R.G., "Large Eddy Simulations of Smoke Movement", Fire Safety J., Vol. 30, pp. 161-178, (1998).

[2] Lighthill, M.J., "Contributions to the theory of heat transfer through a laminar boundary layer", Proc. Roy. Soc. London A, Vol. 202, pp. 359-377, (1950).

[3] Schlichting, H., Boundary Layer Theory, McGraw-Hill, New York, pp. 263-272, (1955). 


\title{
Mathematical Model for Fire Phenomenon
}

\author{
Masahiro Morita \\ Department of Applied Mathematics \\ Science University of Tokyo \\ 1-3 Kagurazaka, Shinjuku-ku, Tokyo 162-8601
}

\begin{abstract}
The constitutional and the verification methods for the mathematical modeling are briefly made the propositions. The introductory equations are formed the connection with zone model and field model. We had compared the results of calculation of the field model with the zone model.
\end{abstract}

\section{Introduction}

The mathematical models for the compartment fires in the buildings were various developed in the response of the purpose of utilizations. Figure 1 shows the modeling of the fire in the relationship from the real fire to the building designs for the fire safety engineering and/or the improvement of the fire regulations.

In this paper, we proposed the transformational equations from the results of calculations of field model to the zone model, and we inquired

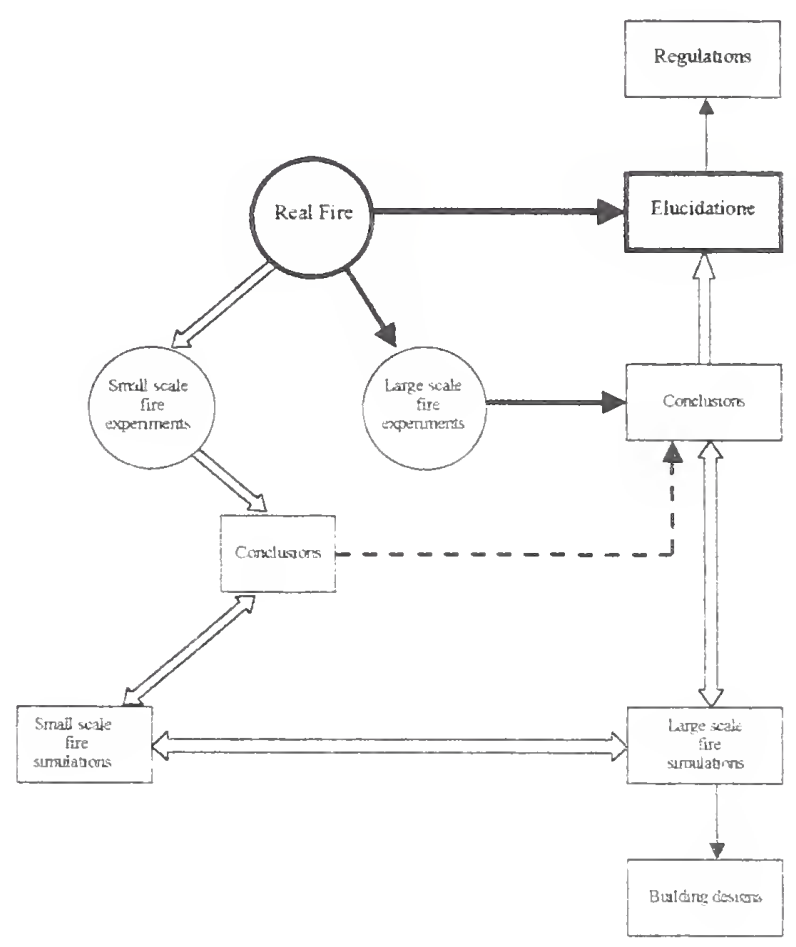
the adequacy for the zone model from the point of view in the field model.

Figure 1. Fire and mathematical fire modeling. 


\section{Fire Modeling}

When we shall make a mathematical modeling for the fire, we have to take the procedure into consideration in shown Fig 2. We have to make a "Physical Model" for the fire from abstraction of the "Real Fire Phenomenon" as the taking of experimental procedures over and over again. We can directly and qualitatively comprehend the fire phenomenon by the "Physical Model". In order to have the quantitative results for the fire, we have to make the "Mathematical Model" which is abstracted and approximated the "Physical Model" again. The formulations of the most of "Mathematical Model" are introduced the nonlinear equations. We have hard the explicit solutions of these nonlinear formulae. The "Numerical Model" is needed to have the quantitative results of the "Mathematical Model" by using the numerical analysis and techniques and the computational performances. The "Simulation Model" is called another name of the "Numerical Model". The "Simulation Code" is coded by the computer language and gives directly the quantitative results of the "Numerical Model".

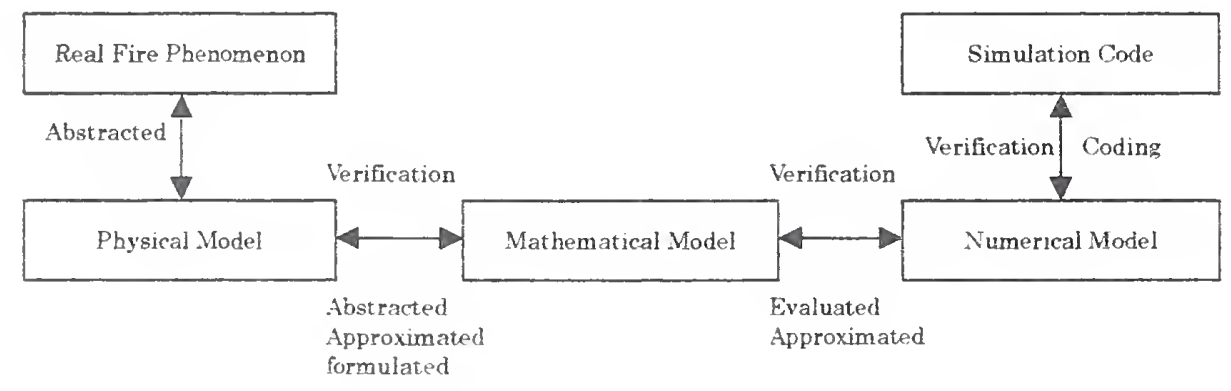

Figure 2. Modeling

When the calculational results from the simulation model are almost agreed with the measurements by the experiment, we are under the hallucination to be guaranteed the adequacy of the mathematical model. Unfortunately since we have simulated various case of fire by using this mathematical model, we have the erroneous results from this model. Moreover the results from this model are not a little applied to design and to evaluate the fire safety for the buildings, because of both the double abstractions and the double approximations from the real fire phenomenon to the mathematical model. Therefore we have to check the mathematical model from the physical model, and also physical model is checked the real fire phenomenon. It is not difficult to check the mathematical model to the numerical model by using the theoretical and numerical analysis of the nonlinear partial differential equations. 


\section{Fire simulation models}

It is not difficult to convert the results of field model to the values of zone model on the average. The Navier-Stokes' type equations of the field model which are derived the law of mass, the momentum balance, and the energy balance, are indicated the time dependent nonlinear partial differential equation. On the other hand, the equations of the zone model which are derived the mass balance and energy balance without the momentum balance, are indicated the time dependent nonlinear ordinal differential equation by produced Harvard Code and Tanaka Code etc.

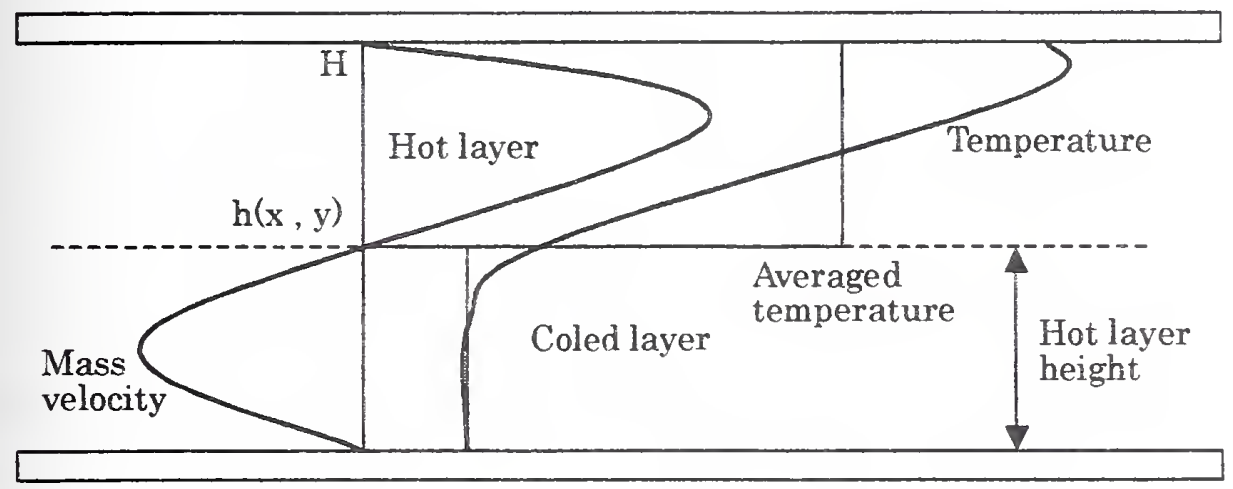

Figure 3. Outline of field and zone models

Following formula are the conversion forms with reference to Fig. 3.

(1) Temperature

$$
\left\{\begin{array}{l}
\text { Hot layer } \overline{\theta_{u}}=\frac{1}{L_{x} L_{y}} \int_{0}^{L_{z}} \int_{0}^{L_{y}} \frac{1}{H-h(x, y)} \int_{h(x, y)}^{H} \theta(x, y, z) d z d y d x \\
\text { Cold layer } \bar{\theta}_{i}=\frac{1}{L_{x} L_{y}} \int_{0}^{L_{x}} \int_{0}^{L_{y}} \frac{1}{h(x, y)} \int_{0}^{h(x, y)} \theta(x, y, z) d z d y d x
\end{array}\right.
$$

(2) Layer height without plume zone.

$$
\rho w(x, y, h(x, y))=0
$$

(3) Mass velocity at vents (. $x$-direction at $x_{L}$ location)

$$
\left\{\begin{array}{l}
\text { Hot layer } \overline{\rho w_{u}}=\frac{1}{L_{y}} \int_{0}^{L_{y}} \frac{1}{H-h\left(x_{L}, y\right)} \int_{h\left(x_{L}, y\right)}^{H} \rho w\left(x_{L}, y, z\right) d z d y \\
\text { Cold layer } \overline{\rho w_{\ell}}=\frac{1}{L y} \int_{0}^{L y} \frac{1}{h\left(x_{L}, y\right)} \int_{0}^{h\left(x_{L}, y\right)} \rho w\left(x_{L}, y, z\right) d z d y
\end{array}\right.
$$




\section{Computational Results and Discussions}

In this study, the field model and zone model are adopted for the mathematical models. We have calculated the Sutfire Simulation Code[1] for the field model and the Harvard VI Fire Simulation Code[2] for the zone model. The room sizees are both $4.22 \times 3.35 \times 2.44 \mathrm{~m}$ and the door sizes are both $1.07 \times 2.03 \mathrm{~m}$.

Figure 4 shows the calculational results of the distributions of the stream line and the temperature distributions by using Sutfire field model simulation code, and the mean values of the hot layer height and mass velocities at the vents.
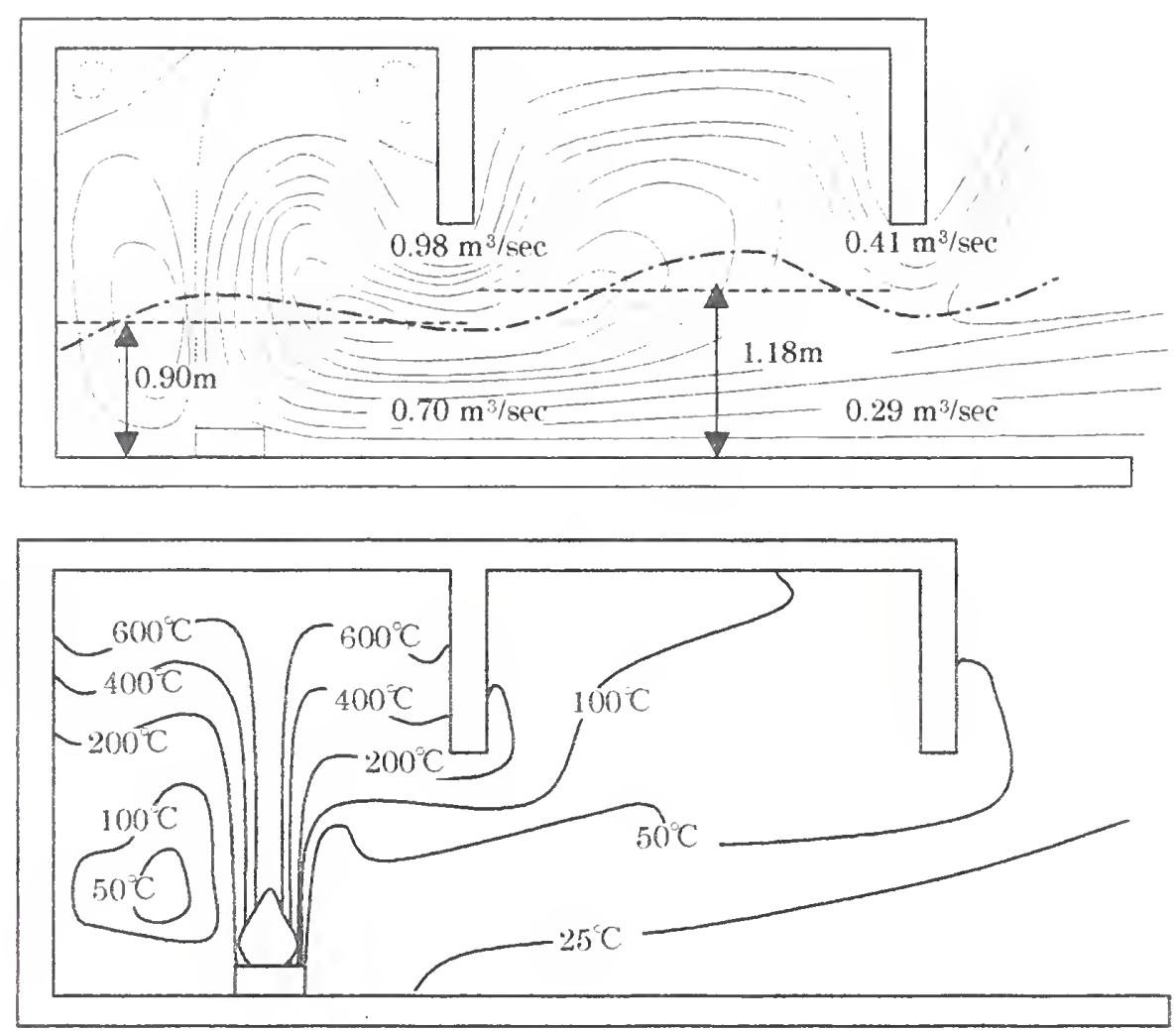

Figure 4. Calculation results for the field model

The mean values of the neutral zone from the field model are about $0.90 \mathrm{~m}$ in the fire room and $1.19 \mathrm{~m}$ in neighbor room. The mass velocities at the vent are about $0.98 \mathrm{~m}^{3} / \mathrm{sec}$ outflow and about $0.71 \mathrm{~m}^{3} / \mathrm{sec}$ outflow at the door in the fire room, and about $0.70 \mathrm{~m}^{3} / \mathrm{sec}$ outflow and about $0.29 \mathrm{~m}^{3} / \mathrm{sec}$ outflow at the outside door in the neighbor room. The mean values of room temperature are about $432 \mathrm{C}$ at the upper layer and about $41 \mathrm{C}$ at the lower layer in the fire room 
Figure 5 shows the calculational results by using Harvard VI zone model fire simulation code

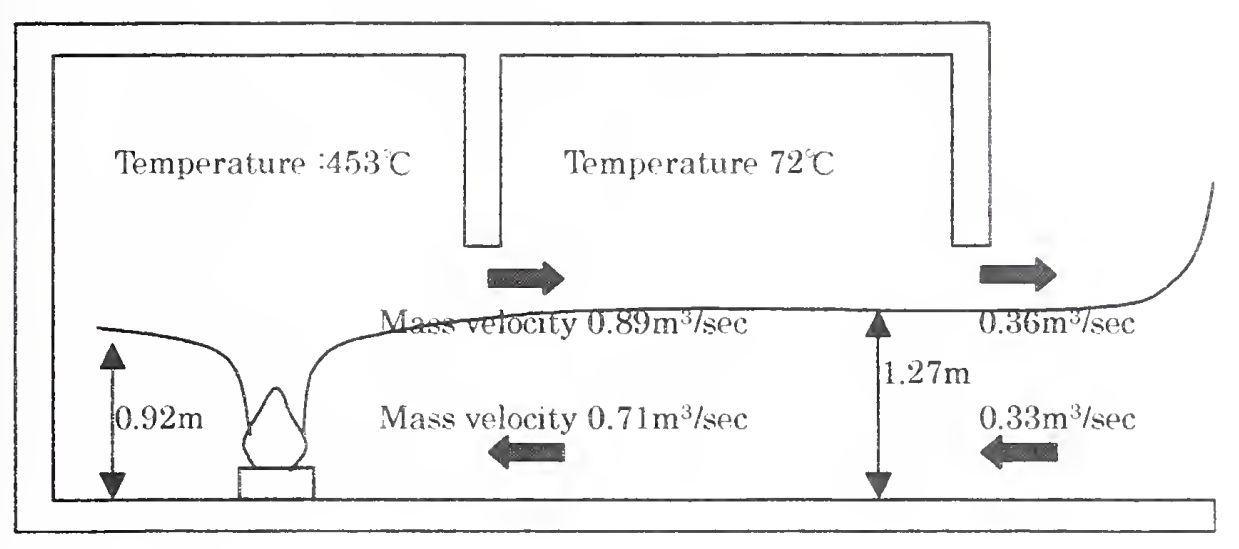

Figure 5. Calculation results for the zone model

We have a good agreement between the results of the zoon model and of the field model because of above figures.

\section{References}

[1] Masahiro Morita et al, Feasibility of Numerical Computational Methods of Heat Flow in Fire Compartment, Fire Science and Technology, Vol.5, No.2, 159-164(1986)

[2] John A. Rockett and Masahiro Morita, The NBS/Harvard Mark VI Multi-Room Fire Simulation, NBSIR 85-3281, 1986 


\title{
MODELING FIRE GROWTH IN ROOM/CORNER CONFIGURATIONS
}

\author{
Craig Beyler, Ph.D. \\ Technical Director \\ Hughes Associates, Inc. \\ 3610 Commerce Drive, Suite 817 \\ Baltimore MD 21227
}

\begin{abstract}
The results of this project show that it is possible to learn a great deal about the expected performance of materials in the ISO 9705 Test from bench-scale tests like the Cone Calorimeter and the LIFT Apparatus. Both the simple correlation using the Flammability Parameter deduced from the Cone Calorimeter and the mathematical model using Cone Calorimeter and LIFT data provided clear insights into the burning behavior of materials in the ISO 9705 Test.
\end{abstract}

The Flammability Parameter deduced from the Cone Calorimeter was able to correlate the heat release rate (peak and average) and time to flashover in the ISO 9705 Test. The Flammability Parameter is based solely on Cone Calorimeter Tests performed at $50 \mathrm{~kW} / \mathrm{m}^{2}$ incident heat flux. This provides the opportunity to obtain significant information concerning expected ISO 9705 performance from a few tests of $10 \mathrm{~cm}$ by $10 \mathrm{~cm}$ samples. As such, the Flammability Parameter is a powerful material development tool. It is significant that LIFT results are not required to allow correlation of the material performance.

The mathematical model performed well in predicting the heat release rate and time to flashover in the ISO 9705 Test. This more sophisticated method provides additional confidence in the ability of bench-scale tests to be used to predict the performance of materials in the ISO 9705 Test. Further, the model has the potential to allow prediction of realistic scenarios, which differ, from the ISO 9705 Test. Different initiating sources, different ceiling heights, different room sizes and ventilation rates are among the significant variables that are included in the model that significantly impact fire performance. Blind tests of the model under a wider range of experimental conditions are required to realize this potential.

Neither the correlation from the Cone Calorimeter nor the mathematical model adequately predict the smoke generation rates in the ISO 9705 Test. The inability to predict smoke generation is particular significant for materials that pass the heat release rate criteria in ISO 9705 Test. There are indications in this work that smoke generated by materials which are pyrolyzing but are not ignited during the test contribute significantly to smoke production. This is not considered in the existing methods and the Cone Calorimeter Tests needed to support modeling of this effect are not currently performed. Cone Calorimeter Tests at heat fluxes where ignition is not expected are not currently conducted to study thermal degradation of materials and the associated smoke production. Significant additional work is needed in this area. 


\section{INTRODUCTION}

As the father of computer fire modeling, Howard Emmons always understood that the prediction of the development of the fire needed to be an integral part of compartment fire modeling. From the beginning of the Harvard Fire Code, simple models of fire growth were included. The prediction of fire growth was an active research area in Professor Emmons' laboratory throughout the period during which the Harvard Code was conceived and developed.

While his vision was clear, our progress in realizing the objective of modeling fire growth for situations of practical interest has been slow. Modeling fire growth involving interior finish materials has been an active area of research in recent years. This work has been motivated by the recognition that the varied international methods for assessing interior finish fire performance are both widely divergent and poorly related to the actual hazards of interior finish materials. This recognition has its roots in Emmons survey of national fire test methods in use around the world in which he recognized and documented the lack of consistency among the nationally used reaction to fire tests.

The room/corner fire scenario has been recognized to be a challenging configuration and tests like ISO 9705 are recognized as real scale fire tests, which reasonably represent the hazards of interior, finish materials. While the room/corner fire test is recognized to be realistic, it is not useful for material development due to its high cost and large material requirements. Further, the results from ISO 9705 tests cannot be used to predict the material's performance in other fire scenarios of importance. As a result, there is an ongoing interest in relating bench scale fire tests to more real scale fire tests like the ISO 9705 test, and in the use of results of bench scale tests in models that can predict material performance over a wide range of fire scenarios of importance. The most highly developed bench scale fire tests, which have potential to relate to actual fire performance, are the Cone Calorimeter and the LIFT tests.

Two means of relating Cone Calorimeter data to full scale performance will be evaluated; correlations and mathematical models of corner fire flame spread. The correlational method and the mathematical model were developed by HAI in prior work for the U.S Navy (Beyler, Iqbal, and Williams (1995), Lattimer et al., 1999). In this work, the correlation and model will be used to predict the results of ISO 9705 tests performed by Janssens et al., (1998) for the U.S. Coast Guard. Model inputs were deduced from Cone Calorimeter test results also performed by Janssens et al., (1998). The work described in this extended abstract is detailed in Beyler et al., (1999).

\section{CORRELATION OF ROOM/CORNER FIRE BEHAVIOR}

The correlational method used here was that previously developed by Beyler, Iqbal, and Williams (1995). The method is a modification of the correlational method of Mowrer and Williamson (1991) and is based upon the linearized upward flame spread model of Quintiere, Harkleroad, and Hasemi (1986). The correlating parameter is the parameter in the linearized upward flame spread model, which determines if the flame spread accelerates or decays. The parameter, which has been called the Flammability Parameter, FP, is given by 


$$
F P=k_{f} \dot{E}^{\prime \prime}-t_{f} / t_{b}
$$

If FP is greater than one, the linearized model results in acceleratory spread.

Mowrer and Williamson (1991) used this parameter to correlate corner fire tests involving textile interior finish materials. They used the time to ignition in the Cone Calorimeter as $t_{f}$ and the time to the peak heat release in the Cone Calorimeter as $t_{b}$, and used the peak heat release rate as E". They found that the correlation was most satisfactory if cone data at 50 $\mathrm{kW} / \mathrm{m}^{2}$ was used. Beyler, Iqbal, and Williamson (1995) attempted to use this method to correlate additional data from U.S. Navy room/comer tests and found that the two data sets did not follow the same correlation. On examination, it became clear that by redefining the means of deducing $t_{b}$ and E", a single correlation for the two data sets could be accomplished. Beyler et al., defined $t_{b}$ to be the duration of burning of the sample and E' to be the average heat release rate over this period. Using these definitions the peak heat release rate in the room/comer tests could be correlated for the two data sets together.

The reasons for the improved performance of the new correlation lie in both the theoretical and practical realms. First, the duration of burning is more relevant to the ability to sustain flame spread than is the time to peak heat release rate. Both thick and thin materials can have the same time to peak burning but have very different burning durations. This significant difference was not captured in the original correlational method. Secondly, the ability to measure times to peak heat release rate and the magnitude of the peak heat release rate is not satisfactorily resolved in the cone calorimeter for thin materials. Thus, there will be difficulty in achieving adequate correlations when relying upon these Cone Calorimeter results. The modified method uses the duration of burning which is ideally evaluated visually, but can be deduced from heat release rate histories. The modified method uses this time and the integrated total energy release from the Cone Calorimeter to deduce $\mathrm{E}^{\prime}$.

The modified correlational method was applied to a wide range of available data for materials which have been tested in the cone calorimeter and in room/corner tests (USCG: Janssens et al., (1998), U.S. Navy PFP: Beyler et al., (1995), Textile Wall Coverings: Mowrer and Williamson (1991) \& Harkleroad (1989), Swedish Materials: Sundstrom, B. (1986) \& Tsantaridis, L., and Ostman, B., (1989), EUREFIC: Soderbom, J., (1991) \& Thureson, P., (1991), and LSF: Dillon et al., (1998)). The peak heat release rate results are shown in Figure 1. The correlation of the actual heat release values for the materials above $400 \mathrm{~kW}$ has no meaning as some of these tests flashed over and the tests were terminated at flashover. The key in the performance of the correlation is the transition in behavior around $\mathrm{FP}=1$. Figure 2 shows the time to flashover as a function of the flammability parameter. The time $1100 \mathrm{~s}$ indicates no flashover.

IMO (1995) defines performance requirements for use with ISO 9705. The peak heat release rate must be less than $500 \mathrm{~kW}$ and the test average heat release rate must be less than 100 $\mathrm{kW}$. Based on all the testing, all materials with $\mathrm{FP}<0$ passed the IMO heat release rate criteria 
and none of the materials caused flashover. The results are mixed in the range $0>\mathrm{FP}>0.5$ transition range, with some materials in this range passing while others fail. Materials with FP > 0.5 overwhelmingly fail the IMO criteria, though there are several materials (Swedish and LSF) with FP $>0.5$ which pass one or both of the IMO heat release rate criteria. Based on the available information, the reasons for the failure of the correlation for these materials is unclear. Nonetheless, the value of the flammability parameter as a screening tool is well established by this work, and the potential for the use of the cone calorimeter and the Flammability Parameter as a regulatory tool at some time in the future is promising.

The ability of correlations based on the Flammability Parameter and the smoke data from the cone calorimeter to predict smoke production results in the ISO 9705 was explored, but the results were unsatisfactory. This issue will be addressed in the modeling section.

\section{ROOM/CORNER FIRE GROWTH MODELING}

The HAI/Navy Corner Fire Model was originally developed as a wall fire spread model (Beyler et al., 1997), but was always intended to be generalized to the comer configuration. The gridding of the corner configuration is two-dimensional, so that the prediction of heating of the material surface is more spatially refined than the other models. Heat flux mapping experiments were performed to develop heat flux maps for use in the model. Heat of gasification methods are used in this model to determine burning rates. The room gas temperature is predicted using the $\mathrm{MQH}$ correlation and the predicted burning rate.

The current version of the flame spread model is an expanded and improved version of the earlier vertical wall flame spread model [Williams et al., 1997, Beyler et al., 1997]. Additional features include two dimensional flame spread, area source fire exposures, corner/ceiling configurations, and hot layer effects. The model retains the ability to calculate flame spread on vertical walls that are not influenced by a corner or ceiling. All new features incorporated into the current flame spread model are summarized in this report. A model verification section is also included. The model results when used to predict the USCG ISO 9705 full-scale room fire tests are presented and compared with the test data. The ISO 9705 room fire tests were performed on a variety of composite materials for the U. S. Coast Guard. A complete description of the model is included in Beyler et al., (1999) and the bases for the model is more fully described in Lattimer et al., (1999).

The flame spread model retains the element and node concept and the surface-heating algorithm that was part of the original version. A node has a specific coordinate relative to the base of the corner and an element is a region bounded by four nodes, one at each corner. This version of the flame spread model divides the corner-ceiling configuration into uniformly spaced horizontal and vertical nodes. Symmetry requires that the ceiling be square and that it be discretized in the same way as the horizontal wall dimension. The flame spread model calculates the temperature and burning condition at each element.

This study was motivated by the need to evaluate the performance of composite materials. A means of predicting the heat release rate and the flame spread potential of materials 
with known properties was sought. A computer flame spread model seemed ideally suited for this goal, offering the ability to calculate conditions on an elemental basis where simple hand calculations fall short. The corner version of the flame-spread model was developed for the U. S. Navy to predict the performance of composite materials in an open corner test configuration [Lattimer et al., 1999]. When this code was adapted for use with the U. S. Coast Guard ISO 9705 tests, it was apparent that the effect of the hot layer had to be included. Hence, an expanded version of the corner flame spread model was developed to include room gas temperature predictions using the $\mathrm{MQH}$ correlation. The compartment temperature effects on fire development were included in the model.

Table 1 shows a summary of the comparison of the HAI/Navy model with the USCG test data. The model correctly predicts which materials will cause flashover and predicts the time of flashover to within 2 minutes in all tests. For those materials that do not cause flashover, the tendency is to underpredict the average and peak heat release rates. The comparisons of peak heat release rate for materials that flashover the compartment are not meaningful, since these tests were terminated artificially. The average heat release rates in these tests is the average up to the time of flashover, so this comparison is meaningful. Overall the performance of the model in predicting flashover and heat release is quite good.

Predictions of smoke generation make use of the heat release rate predictions and the specific extinction area measured in the cone calorimeter. The predictions are generally very low, especially among the materials where flashover did not occur. It is hypothesized that this is the result of smoke production from material, which did not burn during the test. The model includes smoke generated during burning and does not include smoke generated by simple pyrolysis of material beyond the flame front. Since the standard cone calorimeter testing does not evaluate smoke generation from material, which is not burning, there is no means to include this contribution. Additional work is needed in this important area. At this time, the model does not adequately predict smoke generation in the ISO 9705 test.

\section{REFERENCES}

Beyler, C., Hunt, S., Lattimer, B., Iqbal, N., Lautenberger, C., Dembsey, N., Barnett, J., Janssens, M., Dillon, S., Greiner, A. (1999), "Prediction of ISO 9705 Room/Corner Test Results," U.S. Coast Guard Research and Development Center, Report No R \& DC-21599.

Beyler, C. L., Iqbal, N., and Williams, F. W. (1995), "Flame Spread Evaluation for the U.S. Navy Passive Fire Protection (PFP) Test Materials," NRL Ltr Rpt Ser 6180/0216.2, U.S. Navy Technology Center for Safety and Survivability, Washington, DC, April 1995.

Beyler, C.L., Hunt, S.P., Iqbal, N., and Williams, F.W., "A Computer Model of Upward Flame Spread on Vertical Surfaces," Fire Safety Science-Proceedings of the Fifth International Symposium, International Association of Fire Safety Science (IAFSS), Hasemi and Taukuba, Editors, Australia, March 307, 1997, pp. 297-308. 
Dillon, S.E., Kim, W. H., and Quintiere, J, G., (1998), "Determination of Properties and Prediction of the Energy Release Rate of Materials in the ISO 9705 Room-Corner Test," Interim Report, NIST-GCR-98-753, U.S. Department of Commerce, National Institute of Standards and Technology (NIST) Building and Fire Research Laboratory (BFRL), Gaithersburg, Maryland July 1998.

IMO Resolution MSC.40 (62), "Standard for Qualifying Marine Materials for High Speed Craft as Fire Restricting Materials," International Maritime Organization (IMO), London, 1994.

ISO DIS 9705-1: 1993, "Fire Tests - Full-Scale Room Test for Surface Products," International Organization for Standardization, Geneva, Switzerland, 1993.

Janssens, M. L., Garabedian, A., and Gray, W., (1998), "Establishment of International Standards Organization (ISO) 5660 Acceptance Criteria for Fire Restricting Materials Used on High Speed Craft," Final Report, CG-D-22-98, U.S. Department of Transportation, U.S. Coast Guard, September, 1998.

Lattimer, B.Y., Hunt, S.P., Sorathia, U., Blum, M., Graciek, T., MacFarland, M., Lee, A., and Long, G. (1999), "Development of a Model for Predicting Fire Growth in a Combustible Corner," NSWCCD-64-TR-1999/XX, U.S. Navy, Naval Surface Warfare Center-Carderock Division, West Bethesda, MD, September 1999.

Mowrer, F. W., and Williamson R. B., (1991), "Flame Spread Evaluation for Thin Interior Finish Materials, "Fire Safety Science-Proceedings of the Third International Symposium, International Association of Fire Safety Science (IAFSS), Scotland, U.K., Cox and Langford, Editors, Elsevier Applied Science London and New York, July 8-12, 1991, pp. 689-698.

Quintiere, J. G., Harkleroad, M. F., and Hasemi, Y., (1986), "Wall Flames and Implications for Upward Flame Spread," Combustion Science and Technology, Volume 48, No. 3\&4, 1986, pp. 191-222.

Soderbom, J., (1991), “EUREFIC-Large-scale Tests According to ISO DIS 9705,” SP Report 1991:27, SP Swedish National Testing and Research Institute, Boras, Sweden, 1991.

Sundstrom, B., (1986), "Full-Scale Fire Testing of Surface Materials," Technical Report SPRAPP 1986-45, Swedish National testing and Research Institute, Boras, Sweden, 1986.

Thureson, P., (1991), "EUREFIC - Cone Calorimeter Test Results," SP Report 1991:24, SP Swedish National Testing and Research Institute, Boras, Sweden, 1991. 


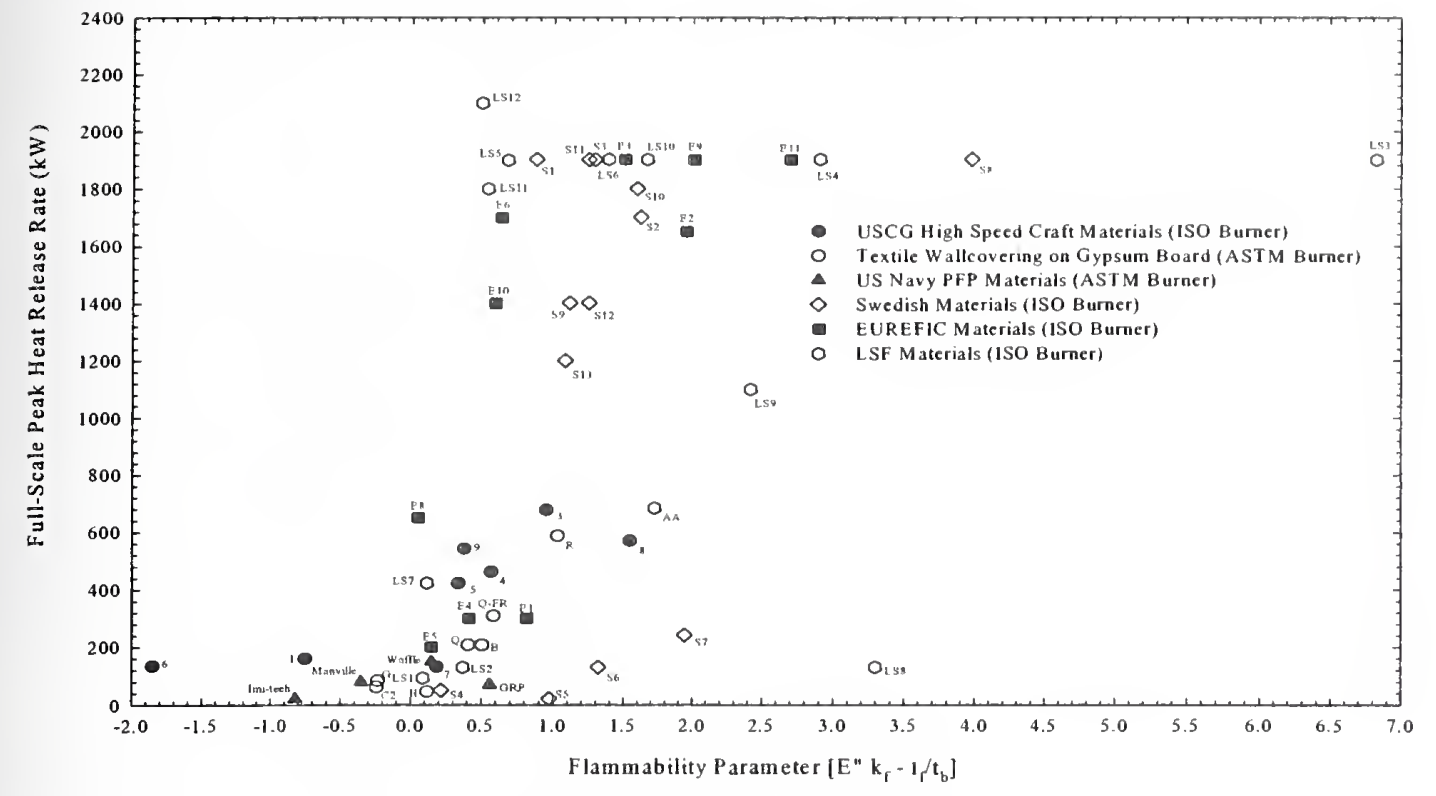

Figure 1 - Comparison of USCG High Speed Craft Materials Results With PFP Navy, Textile Wall Covering On Gypsum Board, Swedish, EUREFIC, and LSF Materials Results

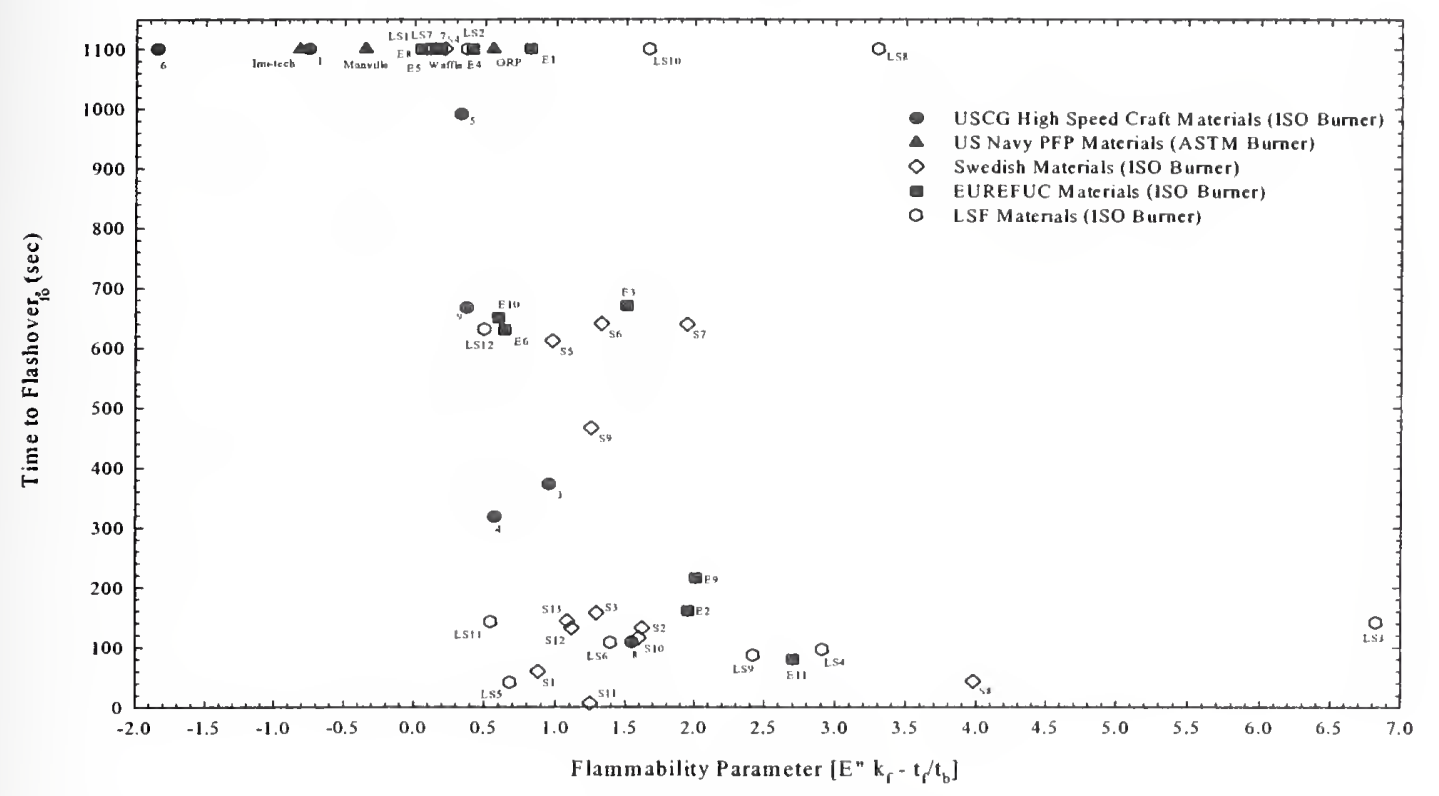

Figure 2 - Comparison of USCG High Speed Craft Materials Results With PFP Navy, Swedish, EUREFIC, and LSF Materials Results. 


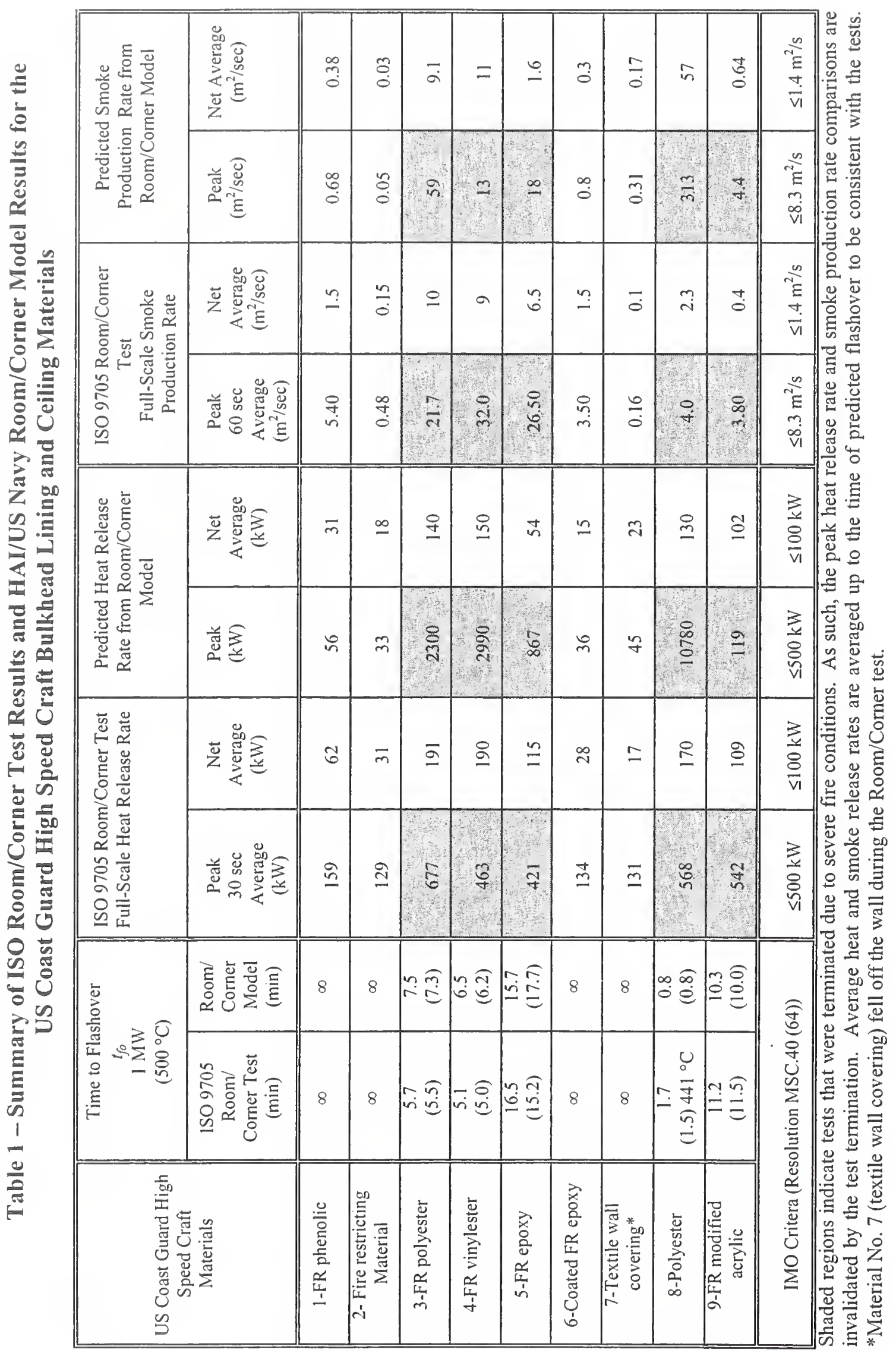




\title{
Simultaneous Measurements of Drop Size and Velocity in Large-Scale Sprinkler Flows Using Laser-Induced Fluorescence
}

\author{
David Everest and Arvind Atreya \\ Department of Mechanical Engineering and Applied Mechanics \\ University of Michigan, Ann Arbor, MI 48109-2125
}

\begin{abstract}
This paper reports an experimental technique that is developed for instantaneous planar measurements of droplet size and velocity for dilute sprays in general and sprinkler sprays in particular. This particle tracking technique relies on photographic measurements of fluorescence and Mie scattering from water droplets to determine their size and velocity. Measurements were made in a plane that passes through the vertical axis of symmetry of a specially designed axis-symmetric sprinkler. Drop sizes down to $0.2 \mathrm{~mm}$, within the $250 \mathrm{~mm} \times 350 \mathrm{~mm}$ viewing area, were measured from the digitized photographs. Drop velocities were determined from the same double-exposed photographs and the directional ambiguity was resolved by color differentiation of fluorescence vs. scattering. Dye selection and its concentration was determined by testing the fluorescence output of water tracer dyes. Collection optics and laser power was varied to optimize the color differentiation and maximize the resolution for drop size measurements.
\end{abstract}

\section{INTRODUCTION}

Water spray sprinklers are the most commonly used automatic fire protection systems in buildings ranging from small offices to large warehouses. For effective fire suppression, the sprinkler water must reach the burning surface. An optimum sprinkler system, for a given application, is one that provides the maximum fraction of water delivered by the sprinkler (or sprinklers in a large warehouse) to the burning surfaces and suppresses the fire in the shortest time after its initiation. The design of such a sprinkler system depends on the geometrical relationship between the sprinkler(s) and the fire source and its heat release rate, the geometry of the room and its ventilation conditions and the sprinkler spray characteristics. Given the complexity of the problem, the optimization, as well as the evaluation, of various sprinkler systems is most cost-effectively accomplished via computer models that can calculate the fire and sprinkler induced flows for different geometries. Such models have been developed at BFRL (NIST) by McGrattan, Baum and Rehm [see Ref. 1 \& references therein]. For experimental validation of these models, instantaneous field measurements are needed on drop size distribution, drop velocity, sprinkler induced flows, and the actual delivered density. This paper develops a laser-based technique to provide the data on drop size distribution and drop velocities.

A number of standard techniques and instruments are available for measuring drop size distributions in sprays such as Phase-Doppler Anemometer (PDA) [2] and Particle Measuring System (PMS) [3]. These techniques are suitable for measuring a single point or an array of points, but do not provide the instantaneous spatial drop distribution in the spray. Consequently, a large number of measurements must be taken at different points to determine the drop-size distributions and the spray must be considered time invariant. To overcome this difficulty, an axis-symmetric sprinkler was designed and instantaneous planar measurements were made along the vertical axis of the sprinkler spray. Different techniques of simultaneous planar measurement of droplet size and velocity have recently appeared in the literature. Kadambi et al. [4] have identified the errors associated with particle size measurements from Particle Image Velocimetry (PIV) images. Herpfer and Jeng [5] have introduced streak PIV for planar measurements of droplet sizes and velocities. Cao et al. [6] have used planar laser-induced fluorescence for measurements of droplet size and Particle Tracking Velocimetry (PTV) for measuring drop velocities. The PTV technique is similar to the PIV technique and is useful when the density of seed particles is low. In this paper, we present a Particle Tracking Velocimetry and Imaging (PTVI) technique, similar to Cao et al. [6], that relies on taking instantaneous double-exposed color photographs of the spray and using them to obtain both velocities and particle sizes. Since the double-exposed photographs are created by laser shots of two different wavelengths, the color differentiation also helps resolve the flow direction. 


\section{EXPERIMENTAL TECHNIQUE}

\section{Droplet Sizing Considerations}

Sizing and tracking a particle in a large field of view (FOV) requires simultaneously satisfying disparate requirements of low magnification and high spatial resolution. For proper sizing, the spatial resolution of the optical, film and digital components must result in a fully resolvable drop, indicating as large a magnification as possible. Meeting the spatial requirements for drop sizing results in limiting the FOV and a subsequent loss in the dynamic velocity resolution and the dynamic spatial resolution, as defined by Adrian [6]. Greater than optimal magnification required to meet the sizing requirements reduces the spatial and velocity spectrums over which the velocity measurements can be made.

Kadambi et al. [4] identify the effects that must be considered in properly resolving the drop size. In their experiments, scattering from solid particles suspended in a liquid was measured. They identified effects of spatial resolution, light sheet intensity distribution, and depth of field (DOF) on particle size measurements. It was observed that the particle image should be greater than 3 pixels in diameter to accurately determine its size. In quantifying the light sheet intensity distribution effect and the DOF effect, they used a $200 \mu m$ particle, a DOF of $200 \mu \mathrm{m}$ and a beam sheet thickness of $1600 \mu \mathrm{m}$. By moving the focused particle through the light sheet, they observed a decrease in the measured diameter of approximately $9 \%$ and a roughly $50 \%$ decrease in scattered light intensity at the edges of the light sheet relative to the center. In another experiment, they traversed the imaging camera while holding the particle and laser sheet fixed to determine the effect of DOF. It was observed that the particle diameter increased by approximately $9 \%$, while the intensity level again decreased by roughly $50 \%$. Thus, when a particle is not centered in the light sheet and the focal plane, DOF and beam sheet intensity effects approximately cancel each other out resulting in a constant particle diameter. Their reported particle diameters had a standard deviation of $7 \%$.

While Kadambi et al. [4] and Adrian's [6] results were very helpful, scattering measurements did not yield a reliable droplet size in the present work perhaps due to a greater disparity in the index of refraction between air and water. Thus, planar fluorescence imaging along with scattering was used to make drop size and velocity measurements in a large FOV with low-density sprinkler spray. The fluorescence emission signal ' $F$ ' for droplets is given by the equation:

$$
F \sim \phi I_{O} v(m /(m+1) / f \#)^{2} V c R
$$

Here, ' $F$ ' is proportional to the fluorescence yield ' $\phi$ ', intensity of light incident on the droplet ' $I_{O}$ ', frequency of emitted light ' $v$ ' and the volume of the illuminated droplet ' $V$ '. The signal is nonlinearly related to the magnification ' $m$ ', $f \#$, the dye concentration ' $c$ ' and the film response function ' $R$ '. The scattering signal for large water drops in a low-density spray is given by:

$$
S \sim I_{0} v(m /(m+1) / f \#)^{2} A \tau R
$$

The signal ' $S$ ' is linearly related to ' $I_{0}$ ' - the incident intensity, $v$ - the frequency of scattered light and ' $A$ ' - the area of the illuminated drop. It is nonlinearly related to the magnification ' $m$ ', $\mathrm{fH}$, the angle of incidence of a light ray on the drop ' $\tau$ ', and the film response function ' $R$ '. For both cases, the signal quality is improved by using higher magnifications and smaller $f \# s$. However, to meet the FOV requirements the magnification is fixed at 0.1 , and only $f \#$ can be reduced.

The response function ' $R$ ' of the film is dependent on the spectral and exposure response characteristics of the film emulsions. Characteristic sensitivity curves for Kodak Pro film were used to define the film spectral response function. These curves indicate that the film is 30 times more sensitive for $588 \mathrm{~nm}$ (fluorescence) and $532 \mathrm{~nm}$ (scattering) than for $355 \mathrm{~nm}$ UV scattered light. The increased energy in the shorter UV wavelength improves the signal but lower $355 \mathrm{~nm}$ laser power offsets that gain. As a result, $355 \mathrm{~nm}$ scattering was observed only in a few images.

Tests were conducted to identify the effect of fluorescent dye concentration, resolution of the imaging system, effect of variation in laser sheet intensity and effect of laser sheet power. The results of these tests are used to 
quantify the ability of the measuring system to accurately characterize the spray velocities and particle size while maximizing FOV.

\section{Experimental Setup}

Fig. 1 schematically shows the experimental layout for the droplet velocity and size distribution measurements. Water exits through a $8 \mathrm{~mm}$ diameter nozzle at 5 gallons/min and impinges on a conical strike plate creating the sprinkler spray. A fluorescent tracer dye is injected into the water far upstream of the nozzle. A dual-pulse ND:YAG laser provides two laser beams that are formed into light sheets by a single $\mathrm{f} 6.35 \mathrm{~mm}$ diverging cylindrical lens. The leading beam sheet, formed by the third harmonic $(355 \mathrm{~nm})$ occurs 1 millisecond prior to the lagging beam sheet, which results from the second harmonic $(532 \mathrm{~nm})$ of the second ND:YAG laser. Fluorescence and Mie scattered light from the two laser pulses is captured by a $35 \mathrm{~mm}$ color film camera using a $50 \mathrm{~mm} \mathrm{fl} .2$ lens with 800 ASA Fujicolor film. Since the framing rate of the film camera is too low to obtain images on separate frames, the photographs were double exposed. Time discrimination was obtained by the fluorescent dye that created different color droplet images for the two laser pulses firing at two different wavelengths. To control the scattering signal at $532 \mathrm{~nm}$, Quantaray R2 red filter or Schotts OG530 was used to allow only the fluorescence signal and some portion of the scattered signal to reach the film. Images of water droplets in a region $250 \mathrm{~mm} x$ $350 \mathrm{~mm}$ and $300 \mathrm{~mm}$ downstream of the strike plate were taken at a magnification of 0.1 to characterize the droplet size and velocity. The negatives were digitized with a $4000 \mathrm{dpi}$ Polaroid film scanner that resulted in a digital resolution of $71 \mu \mathrm{m}$ in the droplet plane/pixel (based on scattering from two fibers at a known distance apart). The optical spatial resolution of the imaging system was also measured by using a standard USAF resolution chart. Images were obtained at a magnification of 0.1 for various f\#s. The best resolution obtained was for an $f \#$ of 2.8 at $3.17 \mathrm{lp} / \mathrm{mm}$ i.e. a line $158 \mu \mathrm{m}$ thick can be resolved in the droplet plane. This corresponds to roughly 2 pixels in the image. Assuming that $3 \times 3$ pixels are needed to measure the drop size with reasonable accuracy, we obtain the minimum measurable droplet diameter of about $0.2 \mathrm{~mm}$.

The digitized images were processed using the TSI Insight and SCION Image software for determining the droplet velocities and droplet size respectively. These images had sufficient spatial resolution for sizing $0.2 m m$ diameter droplets, as well as, color differentiation for resolving the directional ambiguity in velocity measurements. For a laser pulse separation of $1 \mathrm{~ms}$, velocities in the range of $0.2 \mathrm{~m} / \mathrm{s}$ (for small drops) to $10 \mathrm{~m} / \mathrm{s}$ (for large drops) could be measured.

\section{Determination of Fluorescent dye Concentrations}

Proper choice of the fluorescent dye and its concentration must be made to obtain the best signal. Two types of water tracing dyes with high fluorescence yield, red rhodamine and yellow/green fluoroscein, can be injected into the water stream 1.5 meters upstream of the nozzle exit (to ensure mixing) as shown in Figure 1. Different concentrations of these dyes were tested by passing a beam through a glass tube filled with the mixture. The

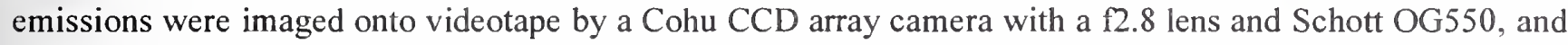
analyzed using a Data Translation frame-grabber board and Image-Pro software. The relative emission curves of the rhodamine and fluoroscein dye are shown in Figure 2. Emissions from the excitation due to the UV, $355 \mathrm{~nm}$, laser and the visible, $532 \mathrm{~nm}$, laser are indicated. The laser power was intentionally low at $5 \mathrm{~mJ} / \mathrm{shot}$ to simulate the laser fluence that exists in the sprinkler experiment.

A number of striking observations can be made from Figure 2. At low concentrations, the rhodamine dye is much better at fluorescing than the fluoroscein dye for both excitation wavelengths. The $355 \mathrm{~nm}$ excitation is more effective than excitation at $532 \mathrm{~nm}$ for low fluoroscein dye concentrations. The rhodamine dye reaches a maximum fluorescence signal at approximately $0.005 \mathrm{~g} / \mathrm{l}$, and this maximum is reached earlier at $532 \mathrm{~nm}$. The fluoroscein dye reaches a maximum near a concentration of $0.05 \mathrm{~g} / \mathrm{l}$, and again the stronger excitation wavelength, $355 \mathrm{~nm}$, reaches the maximum first. Absorption was also qualitatively measured and observations indicated that the rhodamine dye is the more effective dye for absorbing both excitation wavelengths. The $532 \mathrm{~nm}$ excitation was more effectively absorbed than the $355 \mathrm{~nm}$ excitation. Beyond $0.1 \mathrm{~g} / \mathrm{l}$, both dyes have a high absorption that reduces the emissions. 
In a different set of experiments, a Schotts OG530 filter replaced the OG550 filter in front of the CCD camera, allowing some $532 \mathrm{~nm}$ scattering to be imaged. $532 \mathrm{~nm}$ scattering from air bubbles was observed to have a signal that is equal to $75 \%$ of the net fluorescence signal at a concentration of $0.0066 \mathrm{~g} / \mathrm{l}$. Since the scattering of a water drop in air is expected to be 10 times greater than an air bubble in water, clearly scattering will be dominant in the sprinkler flow when fluoroscein dye is used. When rhodamine dye is used, test results indicate that scattering and fluorescence will be of the same order of magnitude with the OG530 filter.

For imaging droplets, rhodamine dye was used at a concentration of $3.3 \mathrm{mg} / \mathrm{l}$. If used at higher concentrations, Figure 2 indicates that the signal would not increase due to absorption of the laser beam. If used at lower concentrations, the UV fluorescence signal becomes too weak. As shown below, scattering appears to dominate the drop signal except when it is fully in the laser sheet, where the scattering vs. fluorescence signal depends on the scattering angle.

\section{Identification of Minimum Signal Levels}

It is instructive to understand how the fluorescence signal varies as the drop size changes and the f\# of the optics is varied. This was investigated by imaging fluorescence from a $2.8 m m \pm 5 \%$ diameter drop that was centered in the $355 \mathrm{~nm}$ laser light sheet and centered in the depth of field of the camera. A long-pass $550 \mathrm{~nm}$ filter was used to collect fluorescence at $588 \mathrm{~nm}$ that results from $355 \mathrm{~nm}$ excitation. Images were taken at a magnification ' $m$ ' of 0.09 for $f \# s$ of $1.2,2.8,4.0$ and 5.6. The laser intensity was 2.2 times higher than that in the spray experiments. The measured droplet diameters were $2.7 \mathrm{~mm} \pm 10 \%$.

The change in the relative maximum intensity with $f \#$ is shown in Fig.3 for $f \# s$ of 1.2, 2.8, 4.0 and 5.6. The average background signal of 34 was subtracted from the data in Figure 3. From Equ. (1) the signal is proportional to volume/f\#? Thus, the intensity is plotted against $1 / \mathrm{fH}^{2}$, which should result in a linearly increasing function, but it is clearly not linear across the entire range. The two highest f\#s $(4.0 \& 5.6)$ were used to fit a line through the origin. This line defines the expected intensity level for the $2.8 \mathrm{~mm}$ drop. However, at $\mathrm{f \#}$ of 1.2 , the intensity is significantly lower than the expected level.

A reason for this drop in the signal level can be found in the depth of field $(\delta z)$, calculated according to [6]: $\delta z=4\left(1+m^{-1}\right)^{2} f \#^{2} \lambda$. For a given magnification and wavelength, the depth of field becomes $3 \mathrm{~mm}$ for $f \#$ greater than 2.8. However for $f \#$ of 1.2 , the depth of field is only $0.5 \mathrm{~mm}$, much smaller than the drop diameter. As discussed below, the $355 \mathrm{~nm}$ beam sheet FWHM was $3.5 \mathrm{~mm}$, much larger than the depth of field and slightly larger than the drop. The drop is therefore fully illuminated, however the fluorescence outside the depth of field is not in focus and therefore does not increase the signal as anticipated. Hence, the depth of field serves to limit the fluorescence volume used in Eq. (1) for drops that are larger than the depth of field. The fluorescence volume is proportional to $\delta z \times(d r o p-d i a .)^{2}$. Since, $\delta z$ is also proportional to $\#^{2}$, it would appear that for drops larger than the depth of field, the intensity should not depend on the f\#. However, there is some increase as indicated by the dotted line in figure 3 ; the reason is that the portion out of the depth of field still makes some contribution to the signal.

For small drops that are less than a pixel wide, the fluorescence intensity (Equ.(1)) is proportional to the volume of the drop. For diameters greater than the pixel size, the maximum fluorescence volume is proportional to the pixel area $x$ drop diameter until the depth of field limit is reached. Thus, the question arises: What is the minimum diameter at which fluorescence signal can be determined above the noise? The answer to this question can be estimated from Figure 3 if the background noise level is known. From the drop images it was determined that noise in the background signal level is $10 \%$ of 34 , indicating that intensity levels below 7 will have a signal to noise ratio (SNR) less than 2. The linear curve fit in Figure 3 represents Eq. 1 for the lim it where the fluorescence measurement volume is proportional to the pixel area $x$ drop diameter, and can be used to find the expected signal at a smaller drop diameter. For $f \# 2.8$, particles less than $104 \mu m$ diameter will give a fluorescence signal below

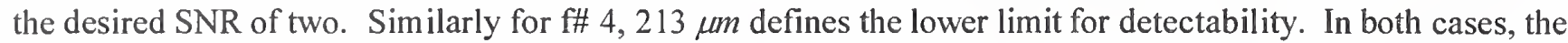
limiting fluorescence diameter is greater than the pixel dimension as required. Equ. (1) can be used to estimate the lower identifiable limits in the spray experiments where the beam sheet intensity was 2.2 times less and the 
magnification was 0.1 . The lower limit under those conditions for an $f \#$ of 2.8 is $189 \mu \mathrm{m}$ and $387 \mu \mathrm{m}$ for an $f \#$ of 4.

The f\# experiment was repeated for scattering of the $532 \mathrm{~nm}$ beam. The experimental parameters were the same as above except both fluorescence and scattering from the drop contributed to the signal. The drop size estimated from the images was $3.3 \mathrm{~mm} \pm 13 \%$, slightly larger than the expected $2.8 \mathrm{~mm}$ diameter. Scattering was observed from the portion of the drop on which the laser beam was incident. The size of this region changed with $f \#$, but the maximum scattering intensity was insensitive to the increase in $f \#$, due to saturation of the film. The scattering from the drops at $532 \mathrm{~nm}$ excitation is very useful in identifying the location of drops, by not so in identifying the size.

To determine if the $355 \mathrm{~nm}$ excitation and $532 \mathrm{~nm}$ excitation would result in the same drop size, a series of images were taken with long pass filters used to cutoff the short wavelengths. With no filter primarily scattering from $532 \mathrm{~nm}$ is observed. The $550 \mathrm{~nm}$ filter adequately blocks the scattering and shows a round drop (eccentricity $=$ $1.04), 3.0 \mathrm{~mm} \pm 10 \%$ in diameter for $532 \mathrm{~nm}$ excitation and a slightly smaller drop (eccentricity $=1.05$ ), $2.7 \mathrm{~mm}$ $\pm 10 \%$ in diameter for $355 \mathrm{~nm}$ excitation. The maximum fluorescent signal for $532 \mathrm{~nm}$ excitation is about $16 \%$ larger than the corresponding $355 \mathrm{~nm}$ excitation.

\section{Effect of Beam Sheet/Drop Size Variation}

The laser beam incident intensity, the illuminated drop volume, and the incidence angle of the ray on the drop are important for determining the intensity of the signal collected from the drop. The incident intensity is a function of the location of the drop in the light sheet, both vertically and in the depth of the sheet. The beam sheet thickness for the $355 \mathrm{~nm}$ excitation and various powers of the $532 \mathrm{~nm}$ excitation are shown in Figure 4, normalized by the full width at half maximum (FWHM) of $4.4 \mathrm{~mm}$ for the $532 \mathrm{~nm}$ beam at $220 \mathrm{~mJ} / \mathrm{pulse}$. For high laser power, the visible excitation beam sheet is thicker than the $355 \mathrm{~nm}$ sheet. Thus, visible scattering is seen more often than fluorescence.

The results for the higher laser power $(220 \mathrm{~mJ} / \mathrm{pulse}$ for $532 \mathrm{~nm}$ beam sheet and $130 \mathrm{~mJ} / \mathrm{pulse}$ for the $355 \mathrm{~nm}$ beam sheet) are shown in Figure 5. Here the pulse separation between the two beams is $4 \mathrm{~ms}$. A $2.8 \mathrm{~mm}$ drop is traversed in $1 \mathrm{~mm}$ increments from behind through the light sheets. These drops were ejected from a 22 gauge hypodermic needle at a rate of $6 \mathrm{drops} / \mathrm{s}$ and images were taken apart with a resolution of $71 \mu \mathrm{m} / \mathrm{pixel}$ at a downstream location of about $160 \mathrm{~mm}$. The highest velocity of the drops, accelerated by gravity, is around $1.8 \mathrm{~m} / \mathrm{s}$. Fluorescence at $588 \mathrm{~nm}$ from $355 \mathrm{~nm}$ excitation is observed in the upper drop in each frame, while scattering and fluorescence from $532 \mathrm{~nm}$ beam is observed in the lower drop. Filters were not used to taking these images. The scattering of the $532 \mathrm{~nm}$ laser beam by the forward edge of the drop is the first and last signals observed in the sequence. The largest source of this light is reflected light although signals from the rear and top of the drop indicate the effect of internal reflection. Fluorescence from $532 \mathrm{~nm}$ appears before the fluorescence from $355 \mathrm{~nm}$ due to both a wider beam and the increased response of the dye to $532 \mathrm{~nm}$ excitation. The $532 \mathrm{~nm}$ drop measurement indicated elongated drops with an average eccentricity of 1.14 , while the $355 \mathrm{~nm}$ measurements were more round with an eccentricity of 1.07 .

An important consideration in defining the beam sheet thickness is the size of the particle that is to be measured. If the sheet is very thin relative to the particle, the probability of measuring the true diameter is small. The measured mean drop diameter is related to the beam sheet thickness by the following formula:

$$
D_{m}=\left((2 / 3)^{1 / 2} D_{a}^{2}+D_{a} b\right) /\left(D_{a}+b\right)
$$

Where $D_{m}$ is the measured mean drop diameter, $D_{a}$ is the actual drop diameter and $b$ is the beam sheet thickness. If the beam sheet is infinitesimal, the measured diameter is $81.6 \%$ of the actual diameter. This means that if all the drops where uniformly the same diameter, the images would show a variety of sizes with a mean diameter that is $81.6 \%$ of the actual diameter. If the beam sheet is equal to the drop diameter, the measured particle will be $90.8 \%$ of the actual particle, while if 10 times the diameter of the drop, the measured drop will be $98.3 \%$ of the true diameter. When a variety of drop sizes are to be measured instantaneously, it is important that the measured diameter be as nearly equal 
to the true diameter as possible. This would indicate that a wider beam sheet is better than a thin one. In the spray experiments, the $532 \mathrm{~nm}$ beam sheet thickness was maintained at the FWHM of $4.4 \mathrm{~mm}$.

Another reason for a thicker beam sheet is related to the size of the sampling region. Given a number of drops randomly distributed in a volume such that the mean distance between drop denoted is ' $s$ ', then there is a lower limit to the smallest volume that can be sampled and still return the correct number density, which iss ${ }^{3}$. Sampling with a beam sheet dimension less than the mean distance between drops may result in underestimating the total number of drops and over-sampling the large drops. In the sprinkler experiment, the laser beam was expanded in only one direction, leaving the sheet thickness equal to the initial beam diameter of $5 \mathrm{~mm}$. The water flow rate was calculated from the measured drop diameters and the mean axial velocity of the drops. The calculated water flow rate matched the rotameter flow rate to within the measurement error.

\section{MEASUREMENTS IN SPRINIKLER SPRAYS}

Images of fluorescence and Mie scattering from sprinkler sprays are shown in Figures 6 and 7 . The images are 84mm by $118 \mathrm{~mm}$ sections of the overall imaged area of $25 \mathrm{~cm}$ by $35 \mathrm{~cm}$. The camera f\# was 2.8 and the magnification was 0.1 . The $355 \mathrm{~nm}$ excitation consistently gives a much redder drop than the $532 \mathrm{~nm}$ excitation, due to the scattered light. The $355 \mathrm{~mm}$ beam precedes the visible by $1 \mathrm{~ms}$, which was verified using an oscilloscope triggered by a photodiode. The $532 \mathrm{~nm}$ laser power in Figure 6 is $10 \mathrm{~mJ} / \mathrm{pulse}$ while the power in Figure 7 is $200 \mathrm{~mJ} / \mathrm{pulse}$. The $355 \mathrm{~nm}$ power of $120 \mathrm{~mJ} / \mathrm{pulse}$ and the dye concentration are held constant.

At low $532 \mathrm{~nm}$ laser power, there are clear particle pairs throughout the image. The drops illuminated by the green laser are only slightly more yellow than the red drops, making distinction in colors difficult. Only due to the direction of gravity can the drop sequence be known and the velocity determined. The velocity of the large drops can be easily measured, but almost no small drops are visible. Increasing the $532 \mathrm{~nm}$ laser power to $200 \mathrm{~mJ} / \mathrm{pulse}$ improves the color differentiation between the two drops. More particle pairs are indicated but unpaired green drops appear as a result of the higher intensity of scattering. The drop size at low $532 \mathrm{~nm}$ power was the same for both laser beams, while at higher laser powers all $355 \mathrm{~nm}$ drops are smaller than the corresponding $532 \mathrm{~nm}$ drops. Drops illuminated by $532 \mathrm{~nm}$ tend to have three types of images. In the first type, drops are solid or faint green with no fluorescence, indicating that they are at the edges of the beam or caused by secondary scattering of the laser sheet. The second type has a halo of green scattering completely or partially surrounding a fluorescent core. These are most likely small drops inside the light sheet. Finally, large drops have bright green scattering on the incident side of the laser beam while the rest of the drop image is dominated by a yellowish fluorescence that delineates the drop perimeter.

Figure 8 is an enlargement of Figure 7. In this image, two drops appear to coalesce as they fall. The initial UV beam indicates two fluorescence centers that are disconnected while the second visible laser indicates two bright centers with a single surrounding drop that is oblong. The upper most UV illum inated drop measures $1.47 \mathrm{~mm}$ or 21 pixels across. The velocity of the drops is easily measured from drop center to drop center. The radial component is $3.3 \mathrm{~m} / \mathrm{s}$ outward and the axial component is $5.74 \mathrm{~m} / \mathrm{s}$ downward, resulting in a speed of $6.6 \mathrm{~m} / \mathrm{s}$.

\section{Size and Velocity Distributions}

Using the technique described above, images of sprinkler sprays from a $8 \mathrm{~mm}$ nozzle at three combinations of flow rates and strike plate cone angles were analyzed. Fluorescence data was obtained using a Quantaray red filter to remove scattering. Thus, directional ambiguity was resolved only by the direction of gravity. Af\# of 1.2 was used and the magnification was 0.1. As discussed earlier, the minimum fluorescence signal depends on thef\# of the lens and the magnification. Based on Equ. (1) and Fig. 3, the minimum detectable fluorescence results from a drop of approximately $35 \mu \mathrm{m}$. The image resolution was dominated by the film resolution resulting in an expected minimum measurable diameter of $158 \mu \mathrm{m}$. Based on Kadambi's [4] criterion of 3 pixels per particle, the actual minimum measurable diameter is $210 \mu \mathrm{m}$. Although drops of smaller diameters can be detected, their diameters can not be accurately determined.

Particle trajectories are indicated by the instantaneous drop locations in Figure 9 for the three cone angles. The sprays originated at the 0,0 point and were directed downward and outward at an angle determined by the cone angle of the 
nozzle. Measurements are made with $5 \mathrm{gpm}$ and a cone angle of $90^{\circ}, 4 \mathrm{gpm}$ and $120^{\circ}$ and $3 \mathrm{gpm}$ and $140^{\circ}$. The corresponding velocities of particle pairs are shown in Figure 10. Very few images are required to determine the flow trajectories, velocities, and statistics of the spray distribution. For example, in this case two images were used.

Figures 11, 12, and 13 describe the spray statistics. In each of these images, the drop sizes below $150 \mu m$ have been binned together at $100 \mu \mathrm{m}$. The lowest resolvable drop size is $200 \mu \mathrm{m}$, which is the second bin in the graphs. Figure 11 is the drop size distribution function. The peaks have been normalized to indicate the spread. The $5 \mathrm{gpm}$ and $4 \mathrm{gpm}$ drop distributions are similar, while $3 \mathrm{gpm}$ indicates larger diameter drops that account for a higher percentage of flow. It should be noted again that although the drops cannot be accurately sized, they are observable and therefore the large size bin into which there are placed indicates the possible error in size estimation.

Figure 12 is the cumulative number distribution, where 0.5 represents half of the total particles in the flow. The statistics indicate that over half of the observed particles in the flow are below the accurately measurable limit of the imaging systems. However, the cumulative volume fraction in Figure 13 indicates that these particles carry about $0.2 \%$ of the water flow rate. The cumulative number distribution also indicates that the lower flow rates have a higher fraction of larger drops, which is indicated in the cumulative volume fraction graph for $3 \mathrm{gpm}$.

\section{CONCLUSIONS}

In measuring large fields of view, delectability of drop diameters down to $35 \mathrm{\mu m}$ is possible but size measurement is limited by fluorescence intensity and collection optics parameters. Fluorescence curves indicate that the proper concentrations of dye for maximum fluorescence imaging are around $0.0033 \mathrm{~g} / \mathrm{l}$ for rhodam ine. In order to detect small drops, a low $\mathrm{f}$ is desired, however there is limit to the $\mathrm{f}$ \# beyond which the ability to accurately measure size is impeded. Accurate measurements of drop sizes greater than $210 \mu \mathrm{m}$ were obtained in this work in a field of view of $25 \mathrm{~cm} \times 35 \mathrm{~cm}$ by using fluorescence. This measurements is limited only by the film resolution and the standard digital resolution requirement of three pixels per particle. Scattering images did not prove to adequately represent the particle size. The effect of variation of intensity across the beam sheet, depth of focus, and volumetric response of the fluorescence signal combine to give varying drop sizes. These sizes varied by $8 \%$ and were observed to give an estimated drop size $7 \%$ lower than physical measurements.

Using the technique developed, particle tracking velocimetry and size measurements of water droplets in large-scale sprinkler flows were conducted. Spray patterns, drop velocities and drop sizes were measured to provide data on instantaneous and time averaged water delivery density for three separate spray conditions. Drop sizes were detected down to $35 \mu \mathrm{m}$ and were accurately measurable down to $210 \mu \mathrm{m}$. Spray number distributions indicate that many of the drops are below the measurable size, but volume measurements indicate that $99.8 \%$ of the flow is carried by drops of measureable size.

\section{REFERENCES}

1. McGrattan, K.B. Hamins, A. and Forney, G.P., 1999, "Modeling of Sprinkler, Vent and Draft Curtain Interaction," Sixth (International) Symposium on Fire Safety Science, France.

2. W.D. Bachalo. Experimental Methods in Multiphase Flows. Int. J. Multiphase Flow. Vol. 20, Suppl. pp261-295. 1994.

3. C.R. Tuck, M.C. Butler Ellis, and P.C.H. Miller. Techniques for the measurement of droplet size and velocity distributions in agriculture sprays. Crop Protection. Vol. 16 No. 7. pp619-628. 1997.

4. J.R. Kadambi, W.T. Martin, S. Amirthaganesh, and M.P. Wernet. Particle sizing using Particle Imaging Velocimetry for two-phase flows. Powder Technology Vol. 100. pp251-259. 1998.

5. D.C. Herpfer, S. Jeng. Planar Measurements of Droplet Velocities and Sizes Within a Simplex Atomizer. AIAA Journal, Vol. 35 No. 1. January. pp 127-132. 1997.

6. Z.Cao, K. Nishino, and K. Torii. Measurement of Size and Velocity of Water Spray Particle Uising Laser-Induced Fluorescence Method. Proceedings of the $2^{\text {nd }}$ Pacific Symposium on Flow Visualization. Honolulu, Hi. May 1619, 1999. 


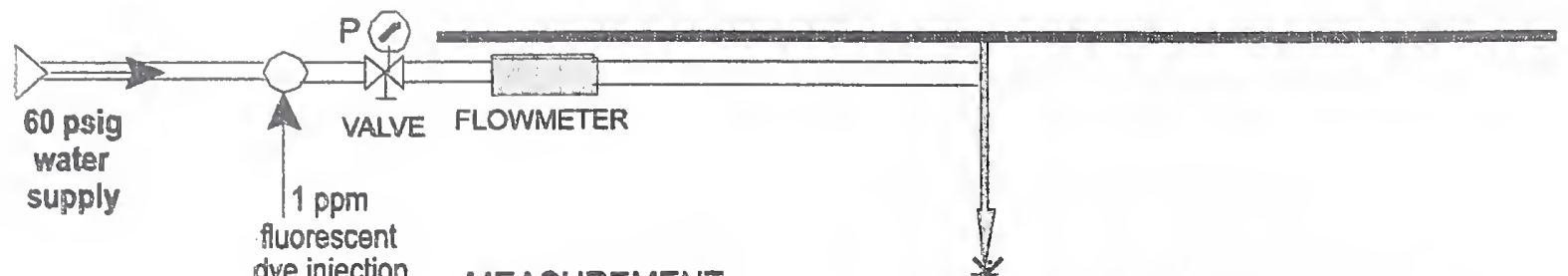

Dual Pulse Nd:Yag P V Laser

$532 \mathrm{~nm}, 200 \mathrm{~mJ} / \mathrm{pulse}$

$355 \mathrm{~nm}, 130 \mathrm{~m} /$ pulse

1 mspulse separation

LASER PULSE \&

CAMERA SHUTTER

SYNCHRONIZER

TO: $35 \mathrm{~mm}$ FILM CAMERA

$50 \mathrm{~mm}$ f 1.2 LENS Oriented $\perp$

to the measurement plane

Figure 1. Experimental arrangement for spray measurements.

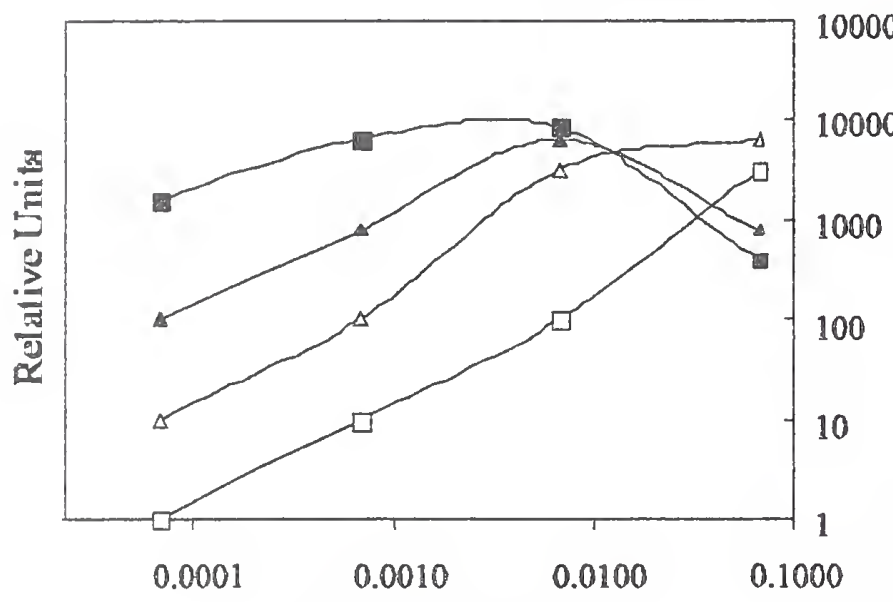

5-6 mm thick light sheet: 5 ns duration
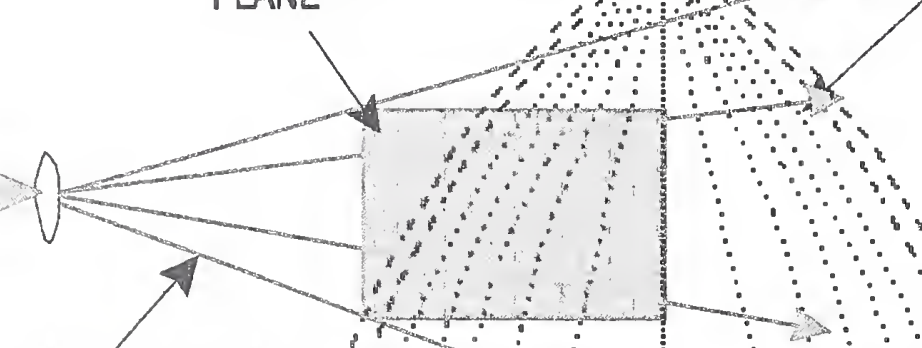
SPDINKLER SPRAY

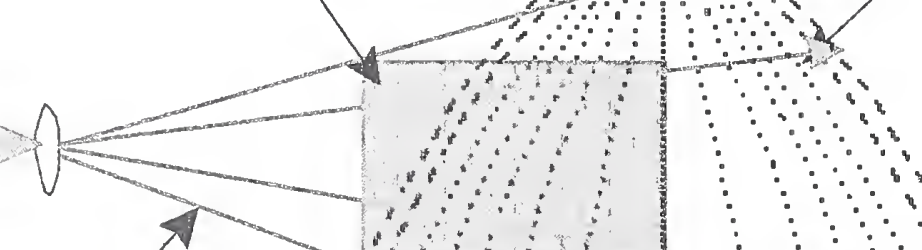



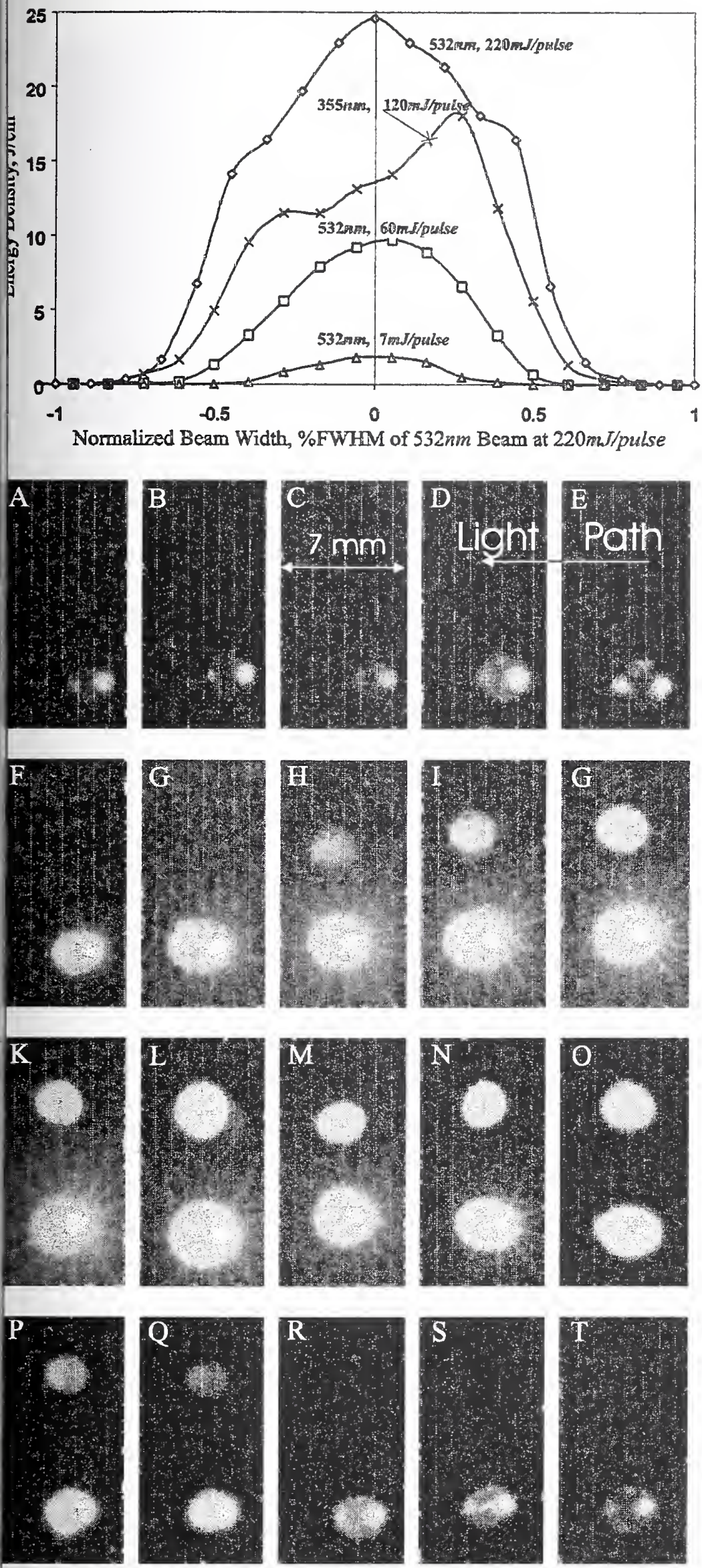

Fig. 4: Relative beam sheet thickness for $355 \mathrm{rm}$ laser beam at bigh laser fluence and for 3 different laser fluences of the $532 \mathrm{~nm}$ beam.

Fig. 5: The 2.8mm drop is moved forward from behind the laser sheet in $1 \mathrm{~mm}$ increments. The $532 \mathrm{~nm}$ laser sheet has a FWHM of $4.4 \mathrm{~mm}$ and the $355 \mathrm{~nm}$ laser sheet has a FWHM of $3.6 \mathrm{~mm}$. Laser power for the $532 \mathrm{~nm}$ beam is $220 \mathrm{~mJ} / \mathrm{pulse}$ and for the $355 \mathrm{~nm}$ beam is $130 \mathrm{~mJ} / \mathrm{pulse}$. Fluorescence at $588 \mathrm{~nm}$ from $355 \mathrm{~nm}$ excitation is observed from the upper drop in each frame, while scattering and fluorescence from $532 \mathrm{~nm}$ beam is observed from the lower drop. Filters were not used to taking these images. When the drop is centered in the beam sheets, the drop size as measured by fluorescence from $355 \mathrm{~nm}$ excitation is $2.7 \mathrm{~mm}$, while the drop size as measured from $532 \mathrm{~nm}$ excitation and scattering is $3.3 \mathrm{rm}$. When centered in the $355 \mathrm{~nm}$ laser sheet, some scattering from $355 \mathrm{~nm}$ was detected by the film. 


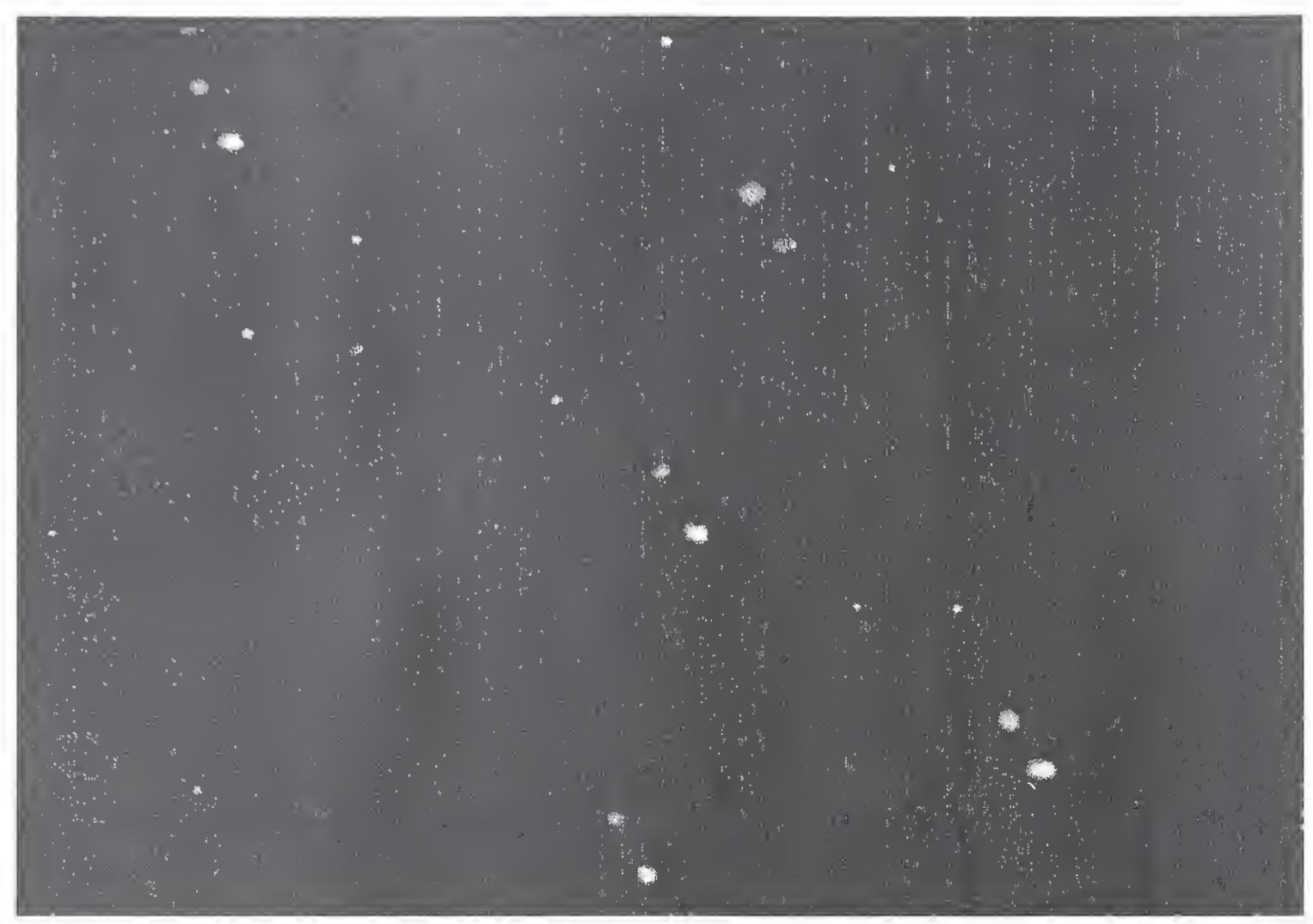

Fig. 6: Low Laser Power at $532 \mathrm{~nm}$ (10 mJ/shot). High Laser Power at $355 \mathrm{~nm}(120 \mathrm{~mJ} / \mathrm{shot})$. Imaged area: $84 \mathrm{mmX} 118 \mathrm{~mm}$.

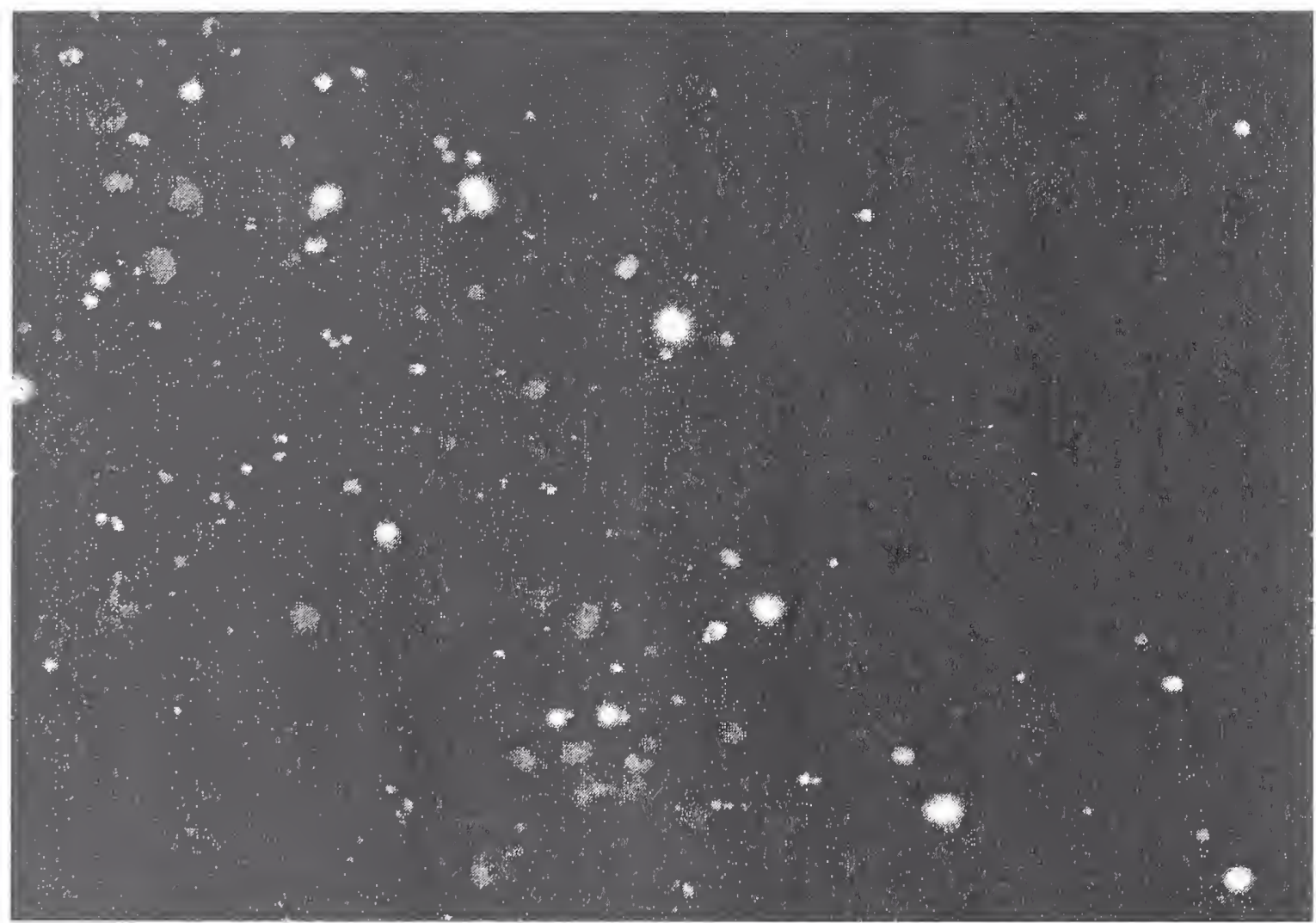

Fig. 7: High Laser Power at $532 \mathrm{~nm}(200 \mathrm{~mJ} / \mathrm{shot})$. High Laser Power at $355 \mathrm{~nm}(120 \mathrm{~mJ} / \mathrm{shot})$. Imaged area: $84 \mathrm{mmX} 118 \mathrm{~mm}$. 


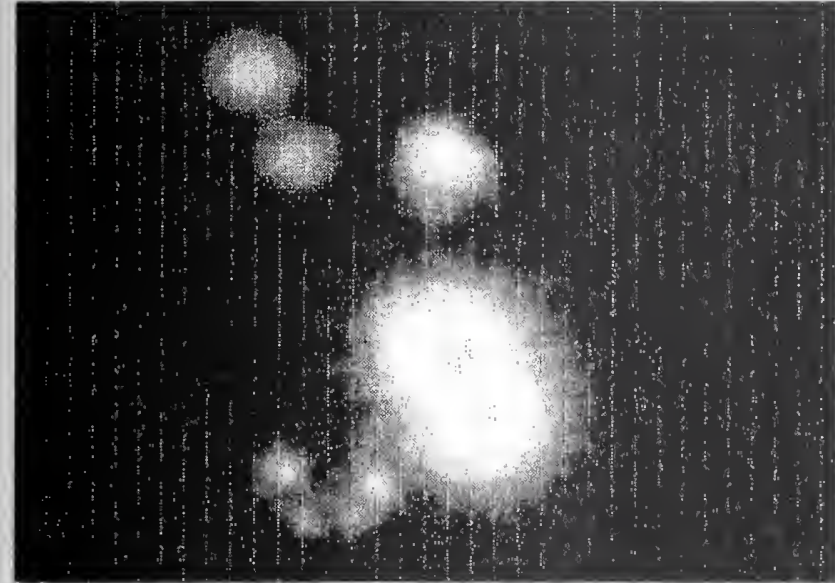

Fig. 8: Enlarged view of a small region of Fig.7. The upper red drop is caused by UV excitation. Its diameter is $1.47 \mathrm{~mm}$ or 21pixels. The bright yellow drops are caused by visible radiation. A green corona appears due to scattering at the front edge of the drop.

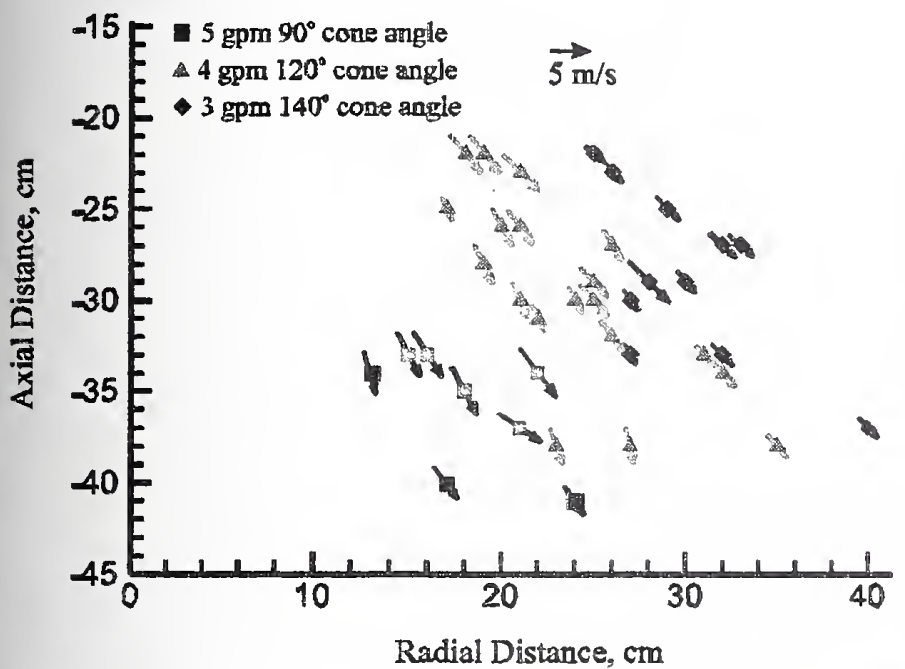

Fig. 10: Drop yelocities for a nozzle with an orifice diameter of $8 \mathrm{~mm}$.

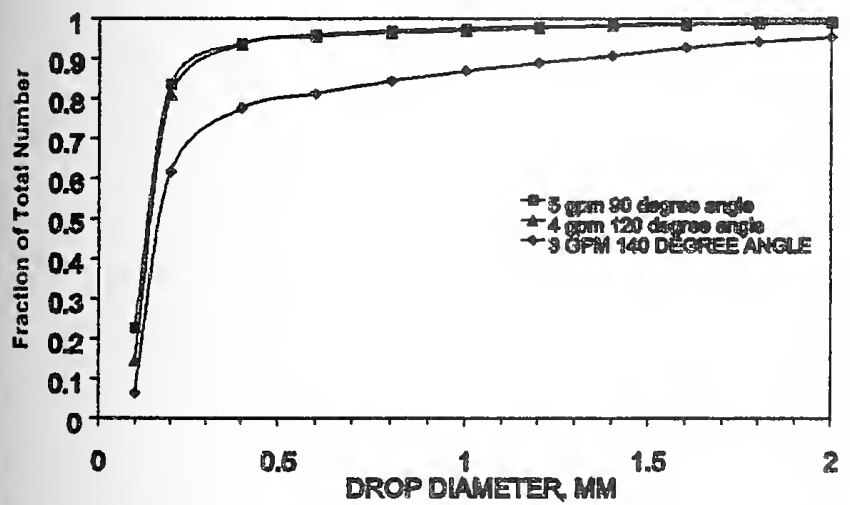

Fig. 12: Cumulative number density distribution for the $8 \mathrm{~mm}$ dia. nozzle. Thus, comparatively fewer number of drops are larger than $0.5 \mathrm{~mm}$.

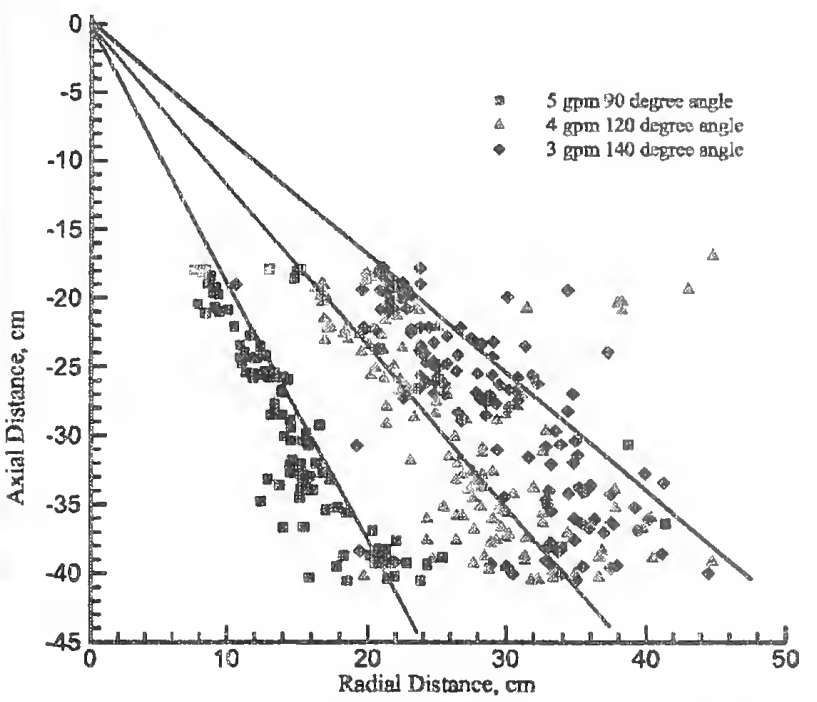

Fig. 9: Drop trajectories for e nozzle with an orifice diameter of $8 \mathrm{~mm}$. These trajectories are indicated by 3 lines corresponding to different cone angles of the strike plate that control the spray pattern.

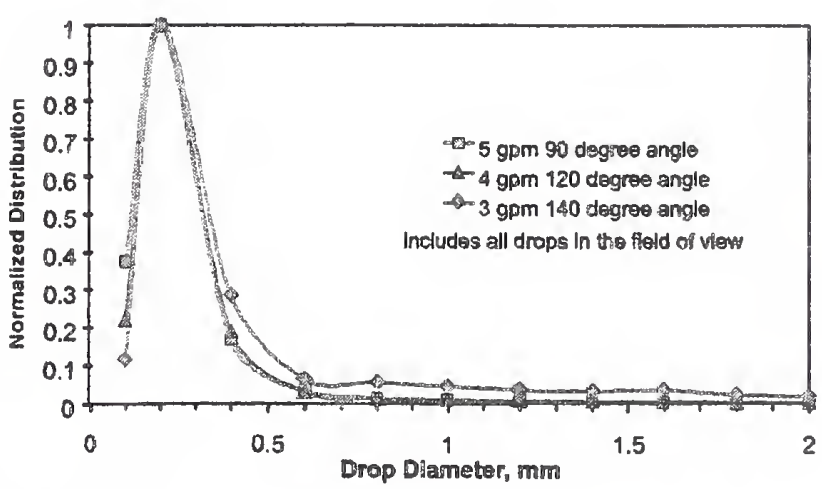

Fig. 11: Drop size distribution for a nozzle of 8 mant dia orifice. Normalized by the maximum number density.

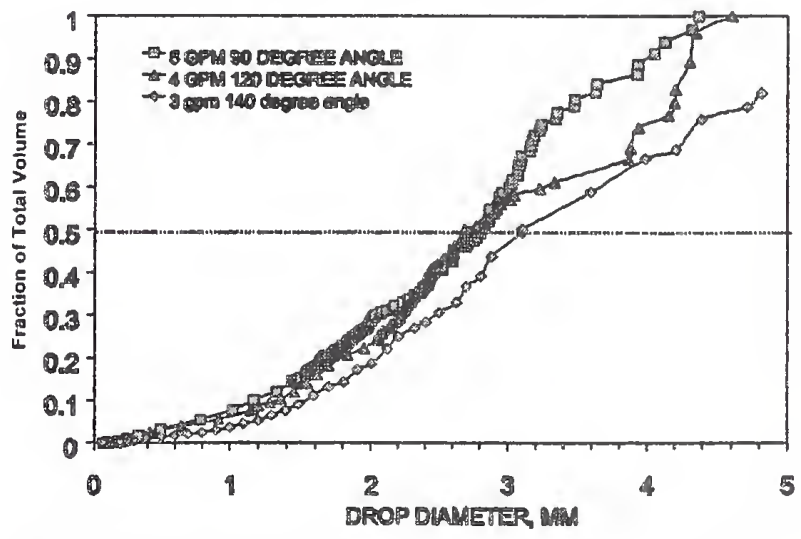

Fig. 13: Cumulative volume fraction distribution for the $8 \mathrm{~mm}$ dia. nozzle. The drop diameter at 0.5 is about $2.8 \mathrm{~mm}$, indicating that half the volume of water is carried by larger drops. 


\title{
FLAME LENGTH AND FLAME HEAT TRANSFER CORRELATIONS IN CEILING FIRES
}

\author{
Yuji Hasemi*1, Masashi Yoshida*2, and Ryosuke Takaike*3 \\ * 1 School of Science and Engineering, Waseda University \\ *2 Building Research Institute, Ministry of Construction \\ *3 Nishimatsu Construction Co., formerly Science University of Tokyo
}

\begin{abstract}
Flame length and flame heat transfer correlations are obtained for circular flames developing radially beneath an unconfined inert ceiling, and are compared against the correlations for one-dimensional flames in a downward channel. The both correlations resulted in the proportionality of the area covered by a ceiling flame to heat release rate and the sole dependence of flame heat transfer on the distance from the source normalized by the flame length. Heat release rate per unit flame area is found to be smaller with circular flames than with one-dimensional flames, which seems to mean a weaker entrainment of ambient air in circular flames than in one-dimensional flames. The weak heat flux from a ceiling flame suggests the importance of the preheating of combustible ceiling by hot gas layer for the fast fire spread generally observed in real and experimental room fires. Flame spread tests with Midium Density Fiberboard ceiling showed very weak flame spread and support this conclusion.
\end{abstract}

Keywords: ceiling fire, flame length, heat flux, heat release rate.

\section{INTRODUCTION}

Flame development beneath a ceiling is very of ten the direct trigger for the occurrence of flashover. In spite of the importance of ceiling fires for fire safety, there are few laboratory measurements on this phenomenon. In a previous study by the authors[1], experimental correlations for flame length and flame heat transfer were reported on a downward channel simulating one-dimensional ceiling fires as a first step for the quantitative understanding of ceiling fires. That study revealed a proportionality of the length of a ceiling flame to heat release rate and single dependence of the flame heat flux on the relative distance from the injection normalized by flame length. The proportionality of the flame length to heat release rate suggested a uniform entrainment of air to the flame all over the flame, and is consistent with the assumptions for so-called "linearized flame approximation". Indeed, analysis on flame spread tests using Midium Density Fiberboard(MDF) showed a good agreement between the test results and the flame spread behavior predicted using the linearized flame approximation. Another important result of the previous study is that the heat flux from a onedimensional ceiling fire is considerably weaker than in wall fires and flame spread beneath a one-dimensional MDF ceiling is much weaker than that along a vertical surface of the same material as long as the combustible surface is not exposed to any external heat source.

This observation was however hardly consistent with experience with real fires and large scale burn tests which have generally demonstrated development of ceiling fires more dramatic than wall fires. This discrepancy was attributed to the preheating of the whole ceiling surface by a smoke layer in a large scale room fire. However, since ceiling fires in real buildings is more complicated than one-dimensional fires, it was felt necessary to run experiments on other ceiling configurations for leading further understanding of the significance of ceiling fires. In this study, measurements of flame size and flame heat transfer have been made on radially flowing steady flames beneath an inert ceiling. The results are 
compared with those on one dimensional ceiling fires to quantify the controlling mechanism of ceiling fires. Flame spread tests are also carried out using MDF.

\section{EXPERIMENTAL ARRANGEMENT AND MEASUREMINTS-Circular Ceiling Fires}

Figure 1 shows the experimental arrangement. The $1.82 \mathrm{~m} \times 1.82 \mathrm{~m}$ unconfined noncombustible ceiling was composed of two layers of $12 \mathrm{~mm}$ thick fiber-reinforced cement boards(Perlite).

During the flame radius and flame heat transfer measurements, $90 \mathrm{~mm}$ and $160 \mathrm{~mm}$ diameter porous round bumers were installed downward flush to the ceiling surface. Propane was used as the fuel. Measurements were made on the heat flux to the ceiling, fuel supply rate and the radius of the flames. Heat flux was monitored with Schmidt-Boelter heat flux gages with their surfaces flush to the ceiling. Flame geometry was recorded with digital video cameras; reported flame radius will be the time average of the location of flame tips from the center of the burner measured with eyes for at least 3 minutes with the interval of one second on video tape. Fuel supply rate to the burner was in the range of $3.31 / \mathrm{min}$ to $33 \mathrm{1} / \mathrm{min}$. The whole apparatus was located beneath a hood connected to an exhaust duct and a fan. Gas analysis was made in the exhaust duct to measure effective heat release rate by the oxygen consumption method. The measured effective heat release rate was generally considerably lower than the heat release rate assuming the complete combustion. This suggests a lower combustion efficiency in a ceiling fire than in a wall fire.

Observation of the flame spread beneath a combustible ceiling was made with a $12 \mathrm{~mm}$ thick MDF applied to the surface of the inert ceiling and the $0.16 \mathrm{~m}$ diameter burner as the fire source with its injection surface rearranged flush to the combustible surface. No external heating source was used for the flame spread tests. Surface temperature of the Midium Density Fiberboard was monitored with $0.1 \mathrm{~mm}$ Chromel-Alumel thermocouples.
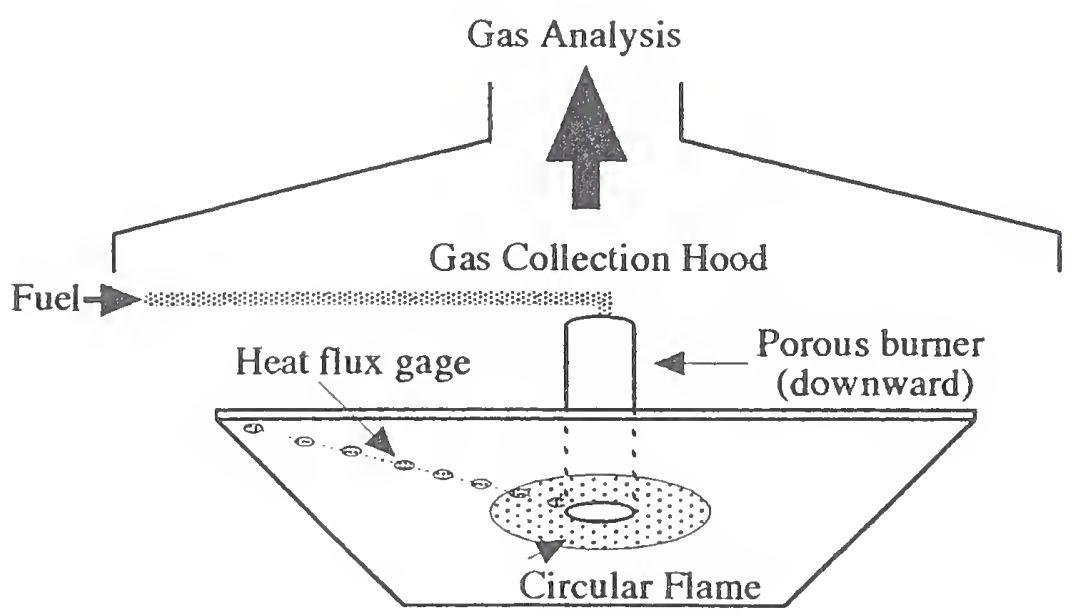

Figure 1 Experimental Arrangement, Circular Ceiling Flames 


\section{EXPERIMENTAL RESULTS}

\section{Flame Radius and Flame Area}

Figure 2 summarizes the correlation between the radius of the area covered by the visible flame and heat release rate measured by Oxygen Consumption Method. Solid and intermittent flames were much less distinguishable than in one-dimensional ceiling fires and wall fires. According to Figure 2, flame radius is nearly proportional to the square root of the heat release rate. While the flame radius is slightly smaller for the $0.16 \mathrm{~m}$ diameter burner than for the $0.09 \mathrm{~m}$ diameter burner, the difference seems to diminish with increase of heat release rate. With a circular ceiling flame enough larger than the injection source, it is believed that the flame radius become independent of the source size. The power dependence of the flame radius suggests a proportionality of the flame area to heat release rate, which has already been reported for one-dimensional ceiling fires.

Figure 3 is a summary of the relation between the area covered by the flame and heat release rate for the present experiments and the one-dimensional flames obtained from the previous experiment. Flame area is nearly proportional to the heat release rate whether for onedimensional ceiling fires or for circular ceiling fires, but flame area for a circular ceiling flame is close to three times that for a one-dimensional ceiling flame of a given heat release rate. This suggests a notably weaker entrainment of ambient air into the flame per unit area in radially flame spread than in one-dimensional flame spread.

Figure 2

Flame radius and heat release rate
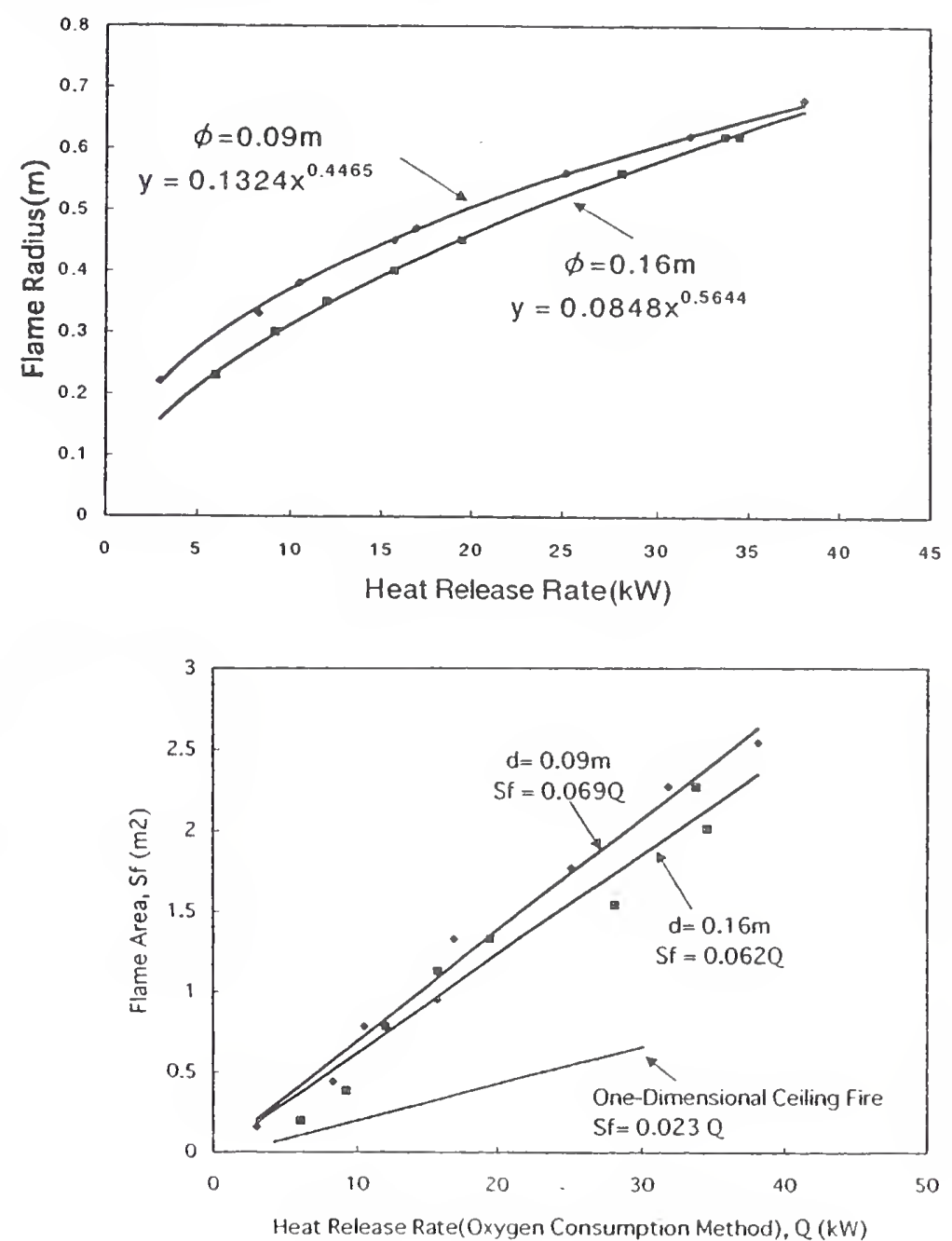

Heat Release Rate(Oxygen Consumption Method), Q (kW)
Figure 3

Flame area and heat release rate 


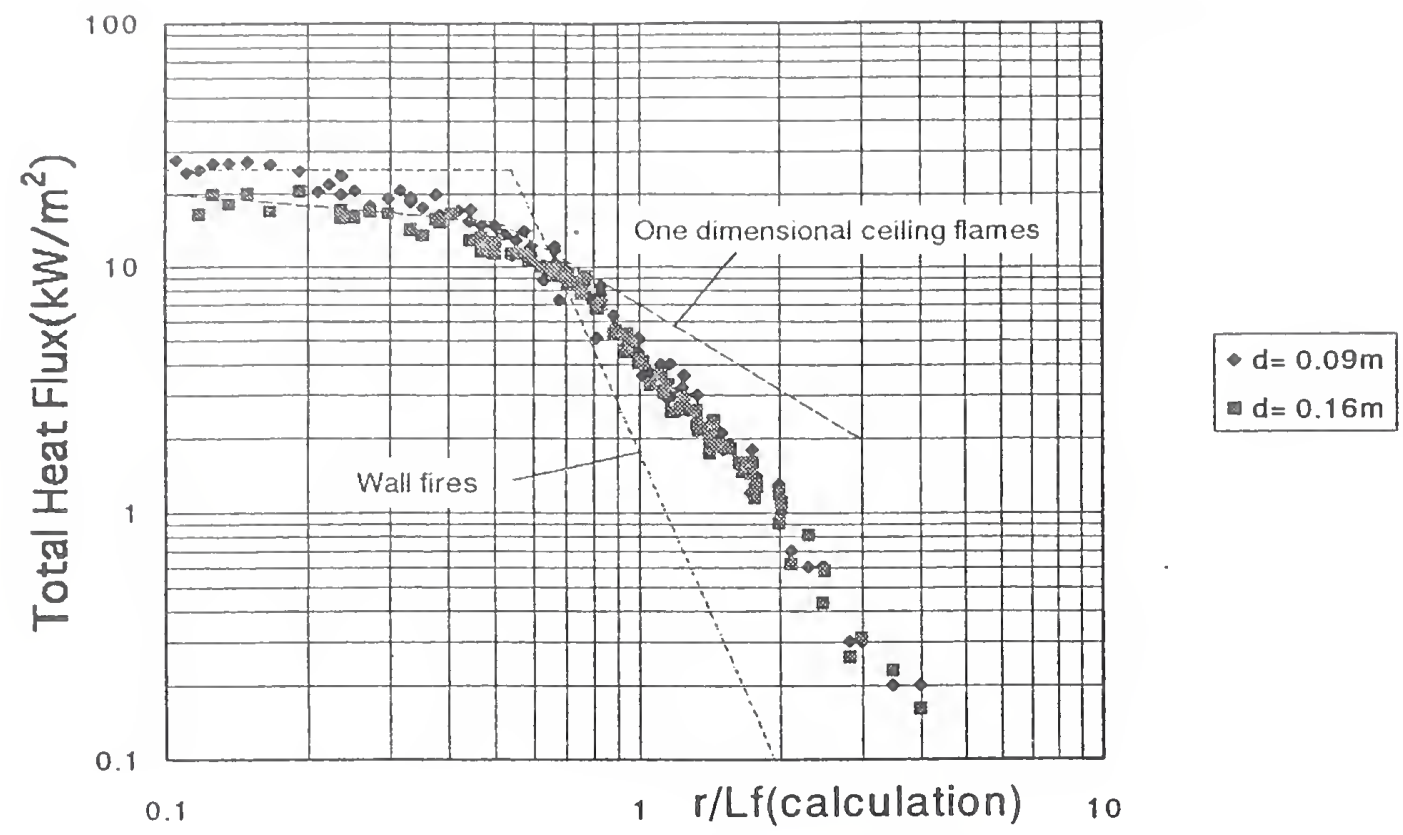

Figure 4 Flame heat flux vs. radius normalized by calculated flame radius

\section{Flame Heat Transfer}

Results of the flame heat transfer measurements are summarized against the distance between heat flux gage and the center of the injection source, $r$, mormalized by the flame radius, $L f$, in Figure 4. The flame radius used for this correlation was calculated from heat release rate using the regressive formula in Figure 2. Figure 4 also shows the flame heat flux distribution for wall fires and one-dimensional ceiling flames. The results of the present tests are found to be highly concentrated along one single curve, whilst heat flux near the injection source is slightly larger with the $0.09 \mathrm{~m}$ diameter source than with the $0.16 \mathrm{~m}$ diameter source. The heat flux is nearly uniform for r/Lf below 0.40 and then starts to decay gradually with increasing distance. The plateau heat flux, within the range of $20-30 \mathrm{~kW} / \mathrm{m}^{2}$, is close to that for onedimensional ceiling fires and is weaker than that for wall fires. The slope representing the decay is notably steeper than for the one-dimensional ceiling fires, and is less steeper than for wall fires. The steeper decay of flame heat flux for radial ceiling fires than for one-dimensinal ones is probably because of the faster decay of convective heat transfer due to the faster decrease of velocity in radial convection than in one-dimensional convection.

The comparison between the two modes of turbulent flames beneath a ceiling seems to suggest weaker contribution of flame heat transfer to concurrent flame spread in radial flame spread than in one-dimensional ones. Also, it is believed that the high plateau heat flux is delivered generally only to the pyrolyzing surface, and the unburnt surface beyond the pyrolysis front is exposed to only weak heat flux, which may not be enough to ignite wood based materials in a reasonable period for "smooth" spread of a flame. This suggests that the accelerated flame spread along a combustible ceiling commonly observed in room fires is caused by the uniform heating by the hot gas layer rather than the progressive heating by the ceiling flame. Provided that the temperature rise in the hot gas layer reaches $200 \mathrm{~K}$, gross total heat flux from the hot gas layer should reach several $\mathrm{kW} / \mathrm{m}^{2}$, which is already comparative or even larger than the heat flux beyond the flame front of a ceiling fire. 


\section{Flame Spread beneath a MDF Ceiling}

Figures 5,6 and 7 are a summary of the time-history of the location of the flame front and estimated pyrolysis front, and heat release rate for different intensity of the fire source. Fire source intensity is excluded from the reported heat release rate. The location of the pyrolysis front was estimated by the surface temperature arriving the ignition temperature of $\mathrm{MDF}, 380$ C. Although flame front reached relatively long, surface burning did not develop beyond the extent of the flame from the fire source. The ultimate burn pattern was roughly consistent with the maximum estimated pyrolysis front. The extremely weak flame spread without external heating seems to endorse the weak heating of unburnt surface by a ceiling flame. This result also support the insignificant role of the flame heat transfer for the development of fires beneath a combustible ceiling.

\section{CONCLUDING REMARKS}

Measurements of flame heat transfer and flame spread beneath a ceiling have been conducted using an unconfined inert and combustible ceilings. Following conclusions can be drawn on flames and flame spread beneath a combustible ceiling.

(1) Area covered by a ceiling flame is nearly proportional to heat release rate.

(2) Area covered by a ceiling flame per unit heat release rate depends on the mode of flame spread, and is larger with circular flames than with one-dimensional flames.

(3) Flame heat flux distribution is represented as a function of the location relative to the flame length for each mode of ceiling fires. Heat flux is nearly constant for $\mathrm{r} / \mathrm{Lf}$ less than around 0.4 and is within the range of $20 \sim 30 \mathrm{~kW} / \mathrm{m}^{2}$. Flame heat flux beyond the flame front is weaker for circular ceiling flames than for one-dimensional fires.

(4) Flame heat transfer in a ceiling fire does not seem to be enough to maintain and accelerate flame spread. The significant spread of ceiling flames generally seen in real and experimental room fires is attributed to the uniform heating of combustible ceiling by the hot gas layer.

\section{TERMINOLOGY}

$\mathrm{d}$ : bumer diameter

Lf: flame length, flame radius

Q: heat release rate

Qo: heat source intensity

Sf: horizontal area covered by a ceiling flame

r. radius

\section{REFERENCE}

[1]Hasemi,Y., Yoshida,M., Yokobayashi,Y., and Wakamatsu,Takao: Flame Heat Transfer and Concurrent Flame Spread in a Ceiling Fire, Proceedings of the Fifth International Symposium on Fire Safety Science, Melboume, 1997. 
Figure 5 Flame spread on MDF $\mathrm{Qo}=9.7 \mathrm{~kW}$

solid line: heat release rate

$\mathrm{O}$ : estimated pyrolysis front $\left(380^{\circ} \mathrm{C}\right)$

: location of flame tips

Figure 6 Flame spread on MDF $\mathrm{Qo}=16.2 \mathrm{~kW}$

solid line: heat release rate

$\mathrm{O}$ : estimated pyrolysis front $\left(380^{\circ} \mathrm{C}\right)$

: location of flame tips

Figure 7 Flame spread on MDF

$\mathrm{Qo}=22.6 \mathrm{~kW}$

solid line: heat release rate

$\bigcirc$ : estimated pyrolysis front $\left(380^{\circ} \mathrm{C}\right)$

? location of flame tips
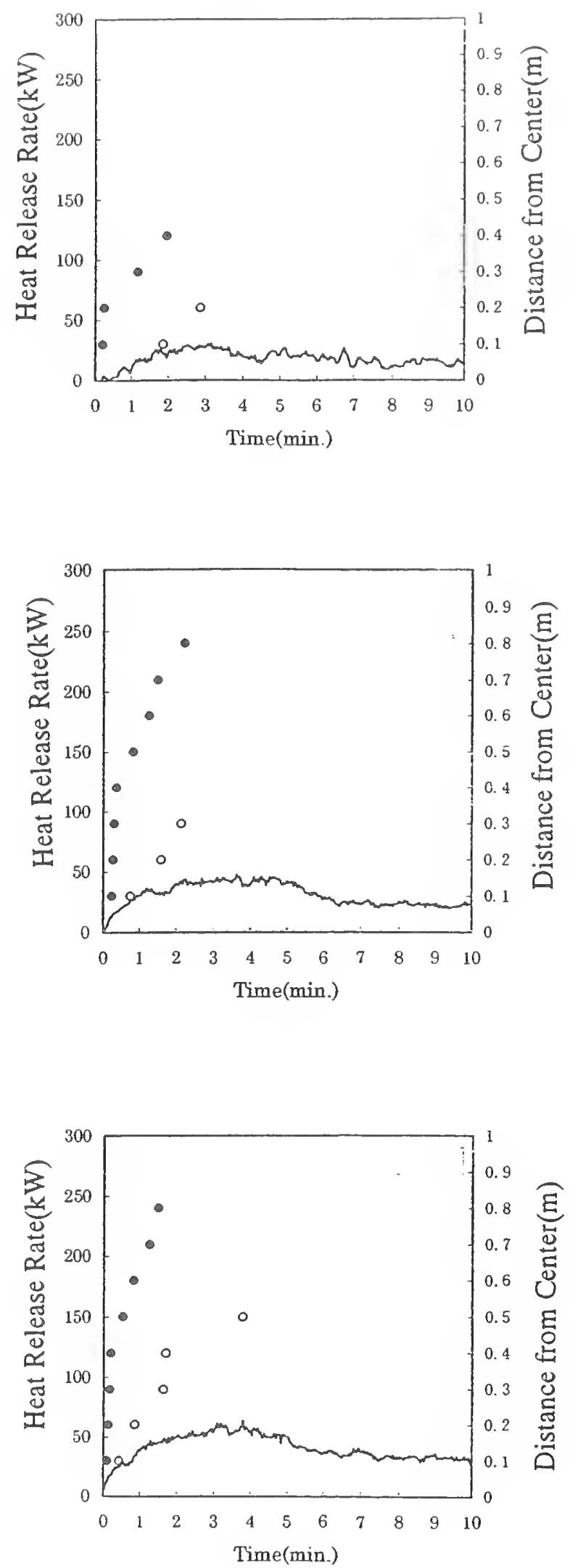


\title{
Behavior of Flame/Plume Flow in and near Corner Fire -Entrainment Coefficient For Corner Fire -
}

\author{
Osami Sugawa* and Muneharu Tobari** \\ ${ }^{*}$ Center for Fire Science and Technology, Science University of Tokyo \\ ** Data Communication System Co., Ltd. (Graduated Student of the SUT)
}

\begin{abstract}
Experimental study on the flow behavior in and near corner fire was carried out using a model fire source changing the distance from the corner and heat release rate. Temperature, upward velocity, and $\mathrm{CO}_{2}$ gas concentration were measured systematically in flame region and in lower part of the plume. Flame length and the height where the peripheral part of the flame touched to the wall were also observed. Based on the horizontal distributions of temperature, $\mathrm{CO}_{2}$ gas concentration, and upward velocity, mass fluxes were estimated at several measuring heights. Then increased mass fluxes between the measuring heights were calculated and air entrainment coefficients were estimated as a function of separation distance. The air entrainment coefficient is smaller than that in the free boundary condition in case of a fire locates within the dimensionless separation, S/D, of 3 .
\end{abstract}

Key Words: corner fire, air entrainment, mass flux

1. Introduction

Flame height in a free boundary condition is well correlated with dimensionless heat release rate $\mathrm{Q}^{*}$ Many researchers have proposed the models on this correlations [1], and in these correlations the efficiency of burning reaction is included as the coefficient between dimensionless flame height and $\mathrm{Q}^{*}$. As air entrainment into a flame and plume is restricted by walls, so that flame and plume properties must be perturved resulting in flame extension. Many items, such as furniture, trash can, bed, etc., are set near and in corner for real life. In this situation, considering real fire scenario for better fire safety, it is necessary to consider the flame and plume behavior from a fire which locates in a corner. The near and in a comer fire gives the flame extension and leaning to corner and/or walls resulting rapid fire propagation to ceiling and then which gives rapid flashover in a compartment. The flow behavior in and near corner showed different manner [2] from that from a fire in a free boundary. However, there is not enough knowledge on this flow behavior. In this paper, we deal with the flow behavior from a fire set in and near corner. We would like to make clear the air entrainment coefficient quantitatively.

\section{Experimental Procedures}

Three types of square propane gas burner of $10 \mathrm{~cm} \times 10 \mathrm{~cm}, 25 \mathrm{~cm} \times 25 \mathrm{~cm}$, or $50 \mathrm{~cm} \times 50 \mathrm{~cm}$ were used respectively as model fire source giving $4.5 \mathrm{~kW}$ to $200 \mathrm{~kW}$. Main series of the experiments, presented in this paper, were carried out using $4.5 \mathrm{~kW}, 7.5 \mathrm{~kW}$ and
$15 \mathrm{~kW}$ fire from a $10 \mathrm{~cm} \times 10 \mathrm{~cm}$ square burner. The square burner, which gives a turbulent diffusion gas flame, locates on the 45 degree line from a right angle (90 deg.) corner taking the dimensionless separation, $S / D$, of $0,0.5$, 1.0 and 2.0. Where $S$ is separation from wall to a burner and $D$ is length of a burner. Figure 1

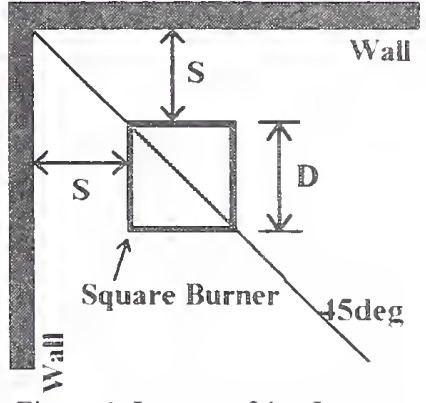

Figure 1 Layout of the fire source in and near comer. shows the schematic plan view of an arrangement of a burner and wall.

Two walls were composed by several ceramic boards of $25 \mathrm{~mm}$ thick with $1.7 \mathrm{~m}$ wide and $3 \mathrm{~m}$ high and no ceiling was attached them.

Flame height and its leaning behavior was observed and recorded by a video system. Temperatures and upward velocities in several horizontal planes were measured systematically and which were recorded every $5 \mathrm{sec}$. Their time-averaged data were estimated and which were used to calculate the upward mass fluxes at several horizontal planes

\section{Results and Discussion}

\section{3-1. Cross section of the Flame and Plume Area}

Figure 2 shows the representative cross sections of the excess temperature maps including the regions 


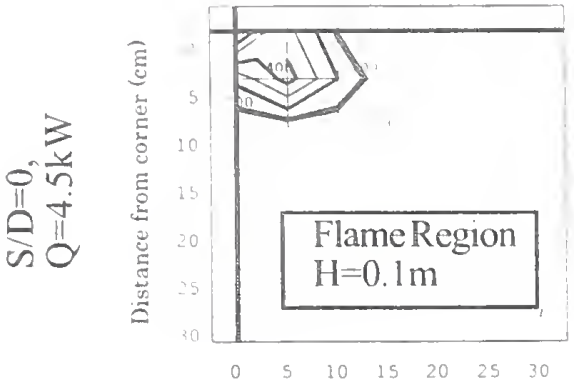

Distance from corner $(\mathrm{cm})$

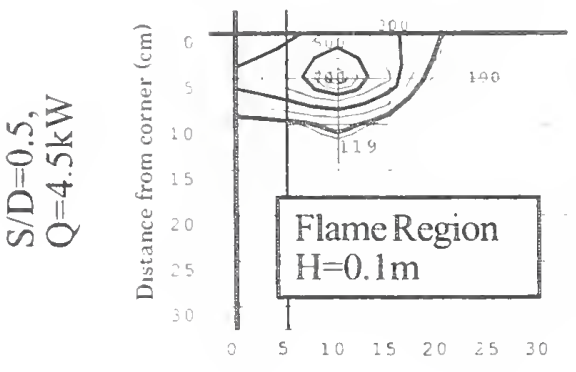

Distance from corner $(\mathrm{cm})$

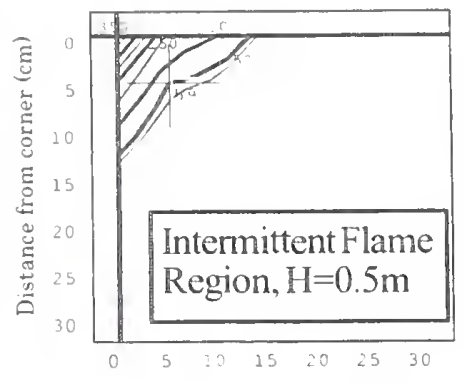

Distance from corner $(\mathrm{cm})$

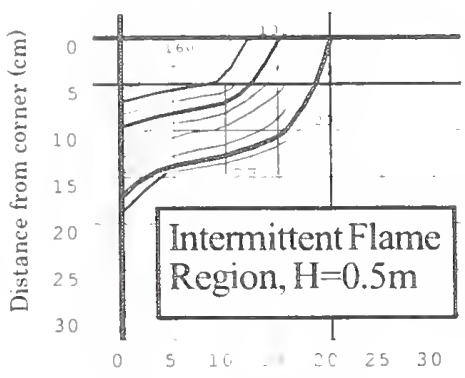

Distance from corner $(\mathrm{cm})$

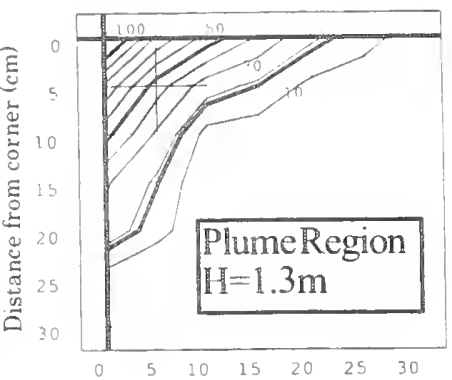

Distance from corner (cm)

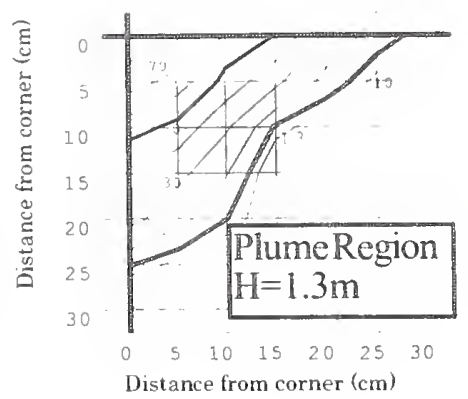

Figure 2 Representative cross section of the flow in and near comer using a $4.5 \mathrm{~kW}$ square model fire source.

of flame, intermittent flame, and plume where the mass fluxes were estimated taking the peripherals boundary of $15 \%(\mathrm{~N}=15 \%)$ of the maximum value in the each cross section. The square shadow is location of the fire source. It is clearly observed that the cross sections changed from circular to triangular shape with the increase of the measuring height. These shapes indicate the ambient air entrainment was induced mostly along the $45 \mathrm{deg}$ line to the corner and poor entrainment was induced along the walls' surface. The mass flux in these cross sections along the height were evaluated by the summations of mass fluxes of small cells by

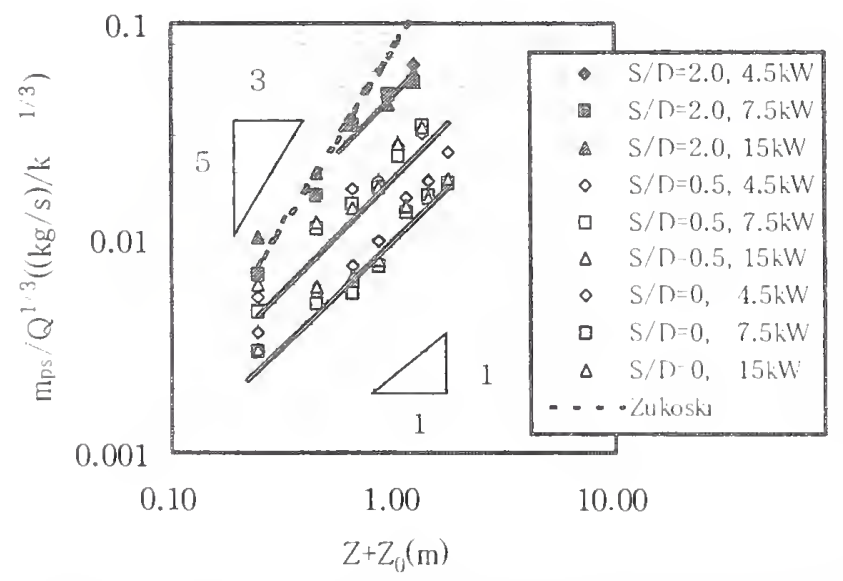

Figure 3 Upward mass flux at the several measuring planes are plotted against the height from the virtua! point source. Mass fluxes are normalized $\mathrm{Q}^{1 / 3}$.

$$
\min _{p s}=\sum \rho v d A
$$

Where in is mass flux, $\rho$ is gas density, $v$ is upward velocity, and $d A$ is cell area of the measuring cross section taking $d A$ of $5 \mathrm{~cm} \times 5 \mathrm{~cm}$ in our experiments.

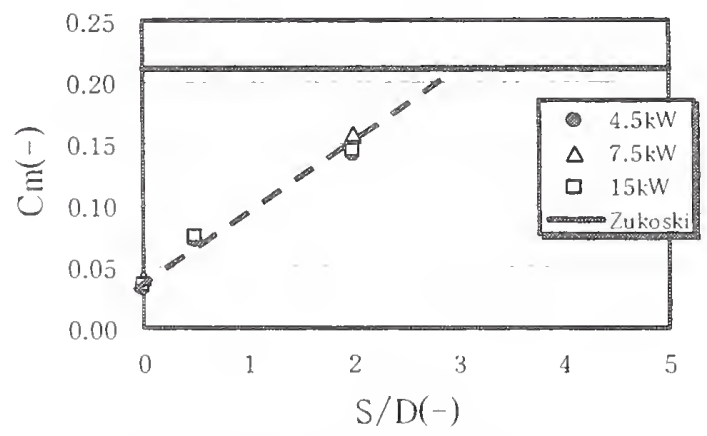

Figure 4 Entrainment coefficient as a function of dimensionless separation distance.

\subsection{Mass Flux along the Trajectory}

Figure 3 shows the correlation of mass fluxes normalized by heat release rate of $1 / 3$ powered, $m_{\rho s}$ ' $\mathrm{Q}^{1 / 3}$, with height from the virtual source point of $Z+Z o$. Where Zo is evaluated as $1.5 \sqrt{A_{f}}$ after Thomas [3] taking $\mathcal{A}_{\text {f }}$ as area of the fire source. When the fire source locates far from the corner, in the case of $\mathrm{S} /$ $D=2.0$ in our experiments, the correlation between mass flux and height in the lower part of the flame showed the similar correlation that obtained in the free boundary condition. Based on the Figure 3, the 
mass flux along the height can be modeled and described by $\dot{\mathbf{m}}_{\mathrm{ps}}=\mathrm{k} \dot{\mathrm{Q}}^{1 / 3}\left(\mathrm{Z}+\mathrm{Z}_{0}\right)^{5 / 3}$ taking the coefficient $k$ of 0.21 [1]. However, the correlation in the intermittent and plume regions of the flow, and the

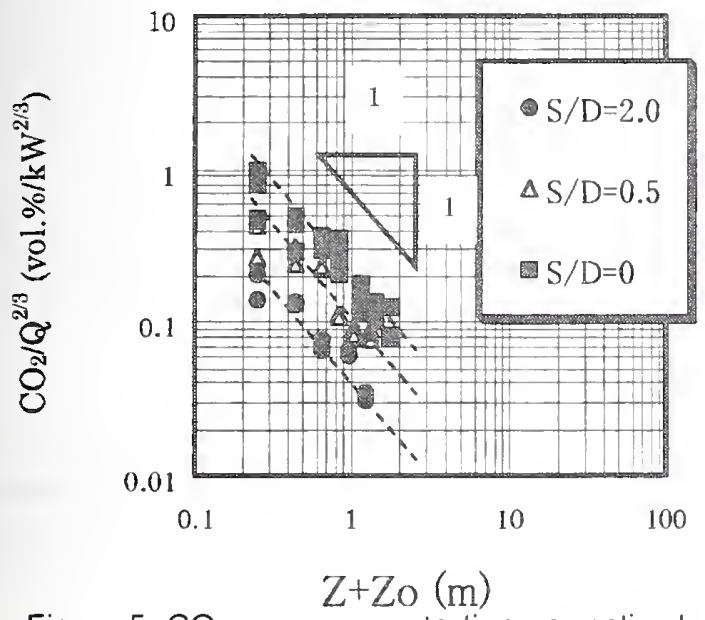

Figure $5 \mathrm{CO}_{2}$ gas concenetration normalized by $2 / 3$ power of heat release rate as a function of height from the virtual point source.

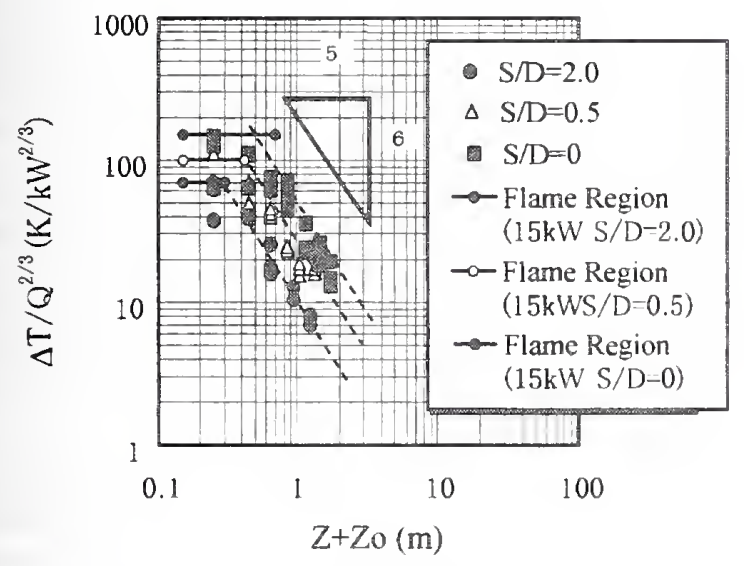

Figure 6 Excess temperature normalized by $2 /$ 3 power of heat release rate as a function of height from the virtual point source.

flow from a fire source locates in and near corner, the gradient between normalized mass flux and height, $Z+Z_{0}$, along the trajectory changed from $5 / 3$ to $1 / 1$ as shown in Figure 3. These show that the ambient air entrainment into the flow is strongly restricted by walls The height where the gradient changed from $5 / 3$ to $1 / 1$ corresponded to the height where the peripheral zone of the flame touched to the walls. The upward flow from a fire source which locates near corner leans to the corner of walls. Lower part of the flow, which is sur- rounded by ambient air, which showed the same manner of air entrainment. In cases of the fire source located in or near to a corner, $S / D=0$ and $S / D=0.5$ in our experiments, increasing rate of the upward mass flux showed smaller value than that obtained in a free boundary. The correlation for the flow in and near corner fire, we obtained the simple model of

$$
\dot{m}_{p s}=k^{*} \cdot \dot{Q}^{1 / 3} \cdot(Z+Z 0)^{1 / 1} .
$$

It is clearly identified that two kinds of increasing modes exit in the correlation between upward mass flux for far "corner fire" and "in and near corner fire" and which suggested that the amount of air entrainment was governed by the space between the flame and walls. in order to evaluate the air entrainment behavior into flame in and near comer, entrainment coefficients, $\mathrm{Cm}$, were evaluated based on the mass flux and are as plotted a function of separation distance as is shown in Figure 4. This figure shows that entrainment coefficient, $\mathrm{Cm}$, approaches to the value of 0.21 as dimensionless separation, $S / D$, increases up to about 3 which corresponds to the value obtained in the free boundary condition as was reported by Zukoski [1].

\section{3-3. Averaged $\mathrm{CO}_{2}$ Gas Concentration and Averaged} Excess Temperature along the Trajectory

In the previous section, we evaluated the quantitative air entrainment into the flame and plume. Entrained air dilute the combustion products and which resulted in the decrease of flame temperature and $\mathrm{CO} 2$ gas concentration along the trajectory. Figure 5 and 6 show the $\mathrm{CO}_{2}$ gas concentration and excess temperature decreasing modes respectively for height along the trajectory. Both physical values were normalized by the $Q^{2 / 3}$ changing the dimensionless separation distance $\mathrm{S} / \mathrm{D}$. Gradient of $\mathrm{CO}_{2}$ gas concentration for height was evaluated as $-1 / 1$ and which is similar to the gradient obtained for the decreasing mode of excess temperature from a line fire source. As similar to this gradient, excess temperature along the corner space, showed the almost the same gradient as shown in Figure 6. In our case of experimental results, however, the gradient for excess temperature showed slightly greater gradient of $-6 / 5$ than that of $\mathrm{CO}_{2}$. This discrepancies may be caused by the heat loss to walls

The upward velocity was also measured and which showed gradient of 0 for height along the trajectory in flame and lower part of the plume suggesting the same 
behavior as observed from the line fire source.

The decreasing modes obtained along the trajectory for $\mathrm{CO}_{2}$ gas concentration, excess temperature,

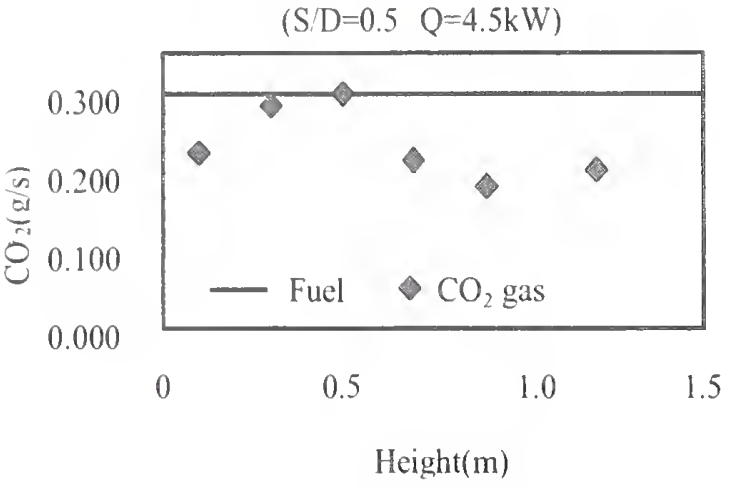

Figure $7 \mathrm{CO}_{2}$ mass flux along the flow.

and upward velocity implied that the hot flow from in and near a corner fire is quite similar to those from a line fire source.

As representatively shown in Figure 2, we estimated the periphery based on the $\mathrm{N} \%$ method to evaluate the mass flux by integrating the upward velocity and gas density. This method liable to bring about under estimation by cutting off the peripheral part of the flow. In order to check asbout the $\mathrm{N} \%$ ( $N=15 \%$ ) method, we also evaluate $\mathrm{CO}_{2}$ mass flux taking the same $\mathrm{N} \%$ method and compare the carbon mass balanace between fuel and $\mathrm{CO}_{2}$ gas mass flux at measuring heights. Figure 7 shows the $\mathrm{CO}_{2}$ mass balance between fuel and gas in flame. We assumed that carbon in the fuel reacts with $\mathrm{O}_{2}$ stoichiometrically. In the upper part of the flame and plume, it is very difficult to measure diluted $\mathrm{CO}_{2}$ gas concentration. This difficulty brought about the shortage in $\mathrm{CO}_{2}$ mass balance, as shown in Figure 7, however, this figure revealed $\mathrm{N} \%$ method taking ( $N=15 \%$ ) is acceptable to estimate the mass flux.

\subsection{Flame Height in and near Corner}

Sugawa et al. [4] reported the flame extention behavior in and near corner and presented the model.

$$
\frac{\mathbb{L}}{\mathbb{L} 0}=\left\{\frac{S^{2}+\mathbb{D}^{2}}{4 \mathbb{D}^{2}+\mathbb{D}^{2}}\right\}^{\mathbb{1} / 2}
$$

where Lo is the flame height in case of the fire locates in a corner, $\mathbb{L}$ is flame height with separation $\mathbf{S}, \mathbb{D}$ is side length of a square fire source. This model is appli-

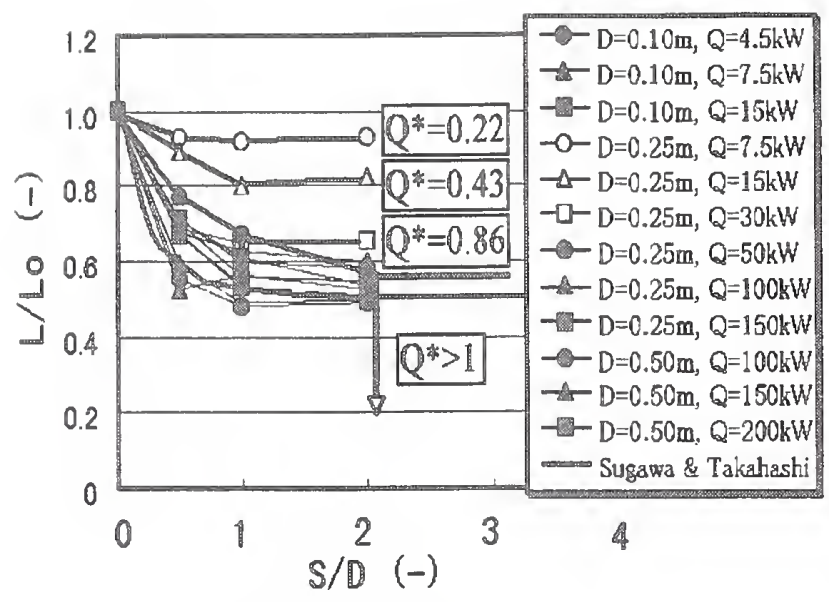

Figure 8 Dimensionless flame height against the dimensionless separation distance from wall with changing the dimensionless heat release rate $Q^{*}$.

dimesnionless flame height, L/LO, as a function of dimensionless separation distance, S/D, changing the dimensionless heat release rate of $Q^{*}$. It is noted that the flames from fires of having $Q^{*}<1$ indicated scarce extension behavior as if they were set in a free boundary condition. No apparent obstacle or shortage of air entrainment into flame was observed for fires having of $Q^{*}<1$. Flames from greater $Q^{*}$ fires $\left(Q^{*}>1\right)$ showed pronounced flame extension when they approached to walls (or into corner) due to wall effects. It is necessary to establsih the model on flame extension behavior considering the chemical reaction for $Q^{*}<1$ fires.

4. Conclusion

Air entrainment coefficient for in and near a corner fire was obatained as a function of dimensionless separation distance from a corner based on the measurements of excess temperature, $\mathrm{CO}_{2}$ gas concentration, and upwawrad velocity. This coefficient changes from 0.03 for a corner fire and 0.21 for a fire which locates more than three times far from a corner. This result indicated that wall-effect, as a obstacle effect on air entrainment into flame, reach to about three times separation distance of a fire source's side length. Flame extension is apparently observed for a corner fire as its dimensionless heat release rate, $Q^{*}$, is greater than 1 . For $\mathrm{Q}^{*}<1$ fires locate in and near corner, there is little effect on the flame extension.

\section{Reference}

1) Zukoski, Z., Kubota, T., Cetegen, "Entrainment in 
(1980/1981)

2)Takahashi, W., Sugawa, O., Tanaka, K., and Ohtake, M., "Flame and Plume Behavior in and near a Corner of Walls", Proceeding of 5th IAFSS Symposium, pp 261-271, (1997)

3) Thomas, P. H., Hinkley, P.H., Theobald, C.R., and Simms, D.L., "Investigations into the Flow of Hot Gases in Roof Venting", Fire Research Technical Paper, No.7, HMSO, (1963)

4) Sugawa, O., and Takahashi, W., "Flame Height Behavior from Multi-fire Sources", Fire and Material, vol.17, pp.111-117, (1993) 


\section{RESOLUTIONS}


March 7, 2000

\section{RESOLUTIONS}

The members of the United States-Japan Conference on Development of Natural Resources? Panel on Fire Research and Safety are pleased with the results of the $15^{\text {th }}$ Joint Panel Meeting, held in San Antonio, Texas on March 1-7, 2000. We wish to thank the staff of the Department of Fire Technology of the Southwest Research Institute for their hospitality and the National Fire Protection Association, Underwriters Laboratories, Factory Mutual Research, and Omega Point Laboratories for their support.

This Panel continues to facilitate the exchange of important research ideas between two of the world's leading fire research communities. We are pleased to have been able to gather at this meeting some of the best minds in fire research and safety from both the United States and Japan.

The following resolutions summarize the consensus for the future:

It is hereby resolved that:

1. The objectives of the meetings of this Panel are to:

a. Exchange particularly interesting technical information regarding our latest research, and

b. Promote cooperative research on focused areas within fire safety science.

2. Because of the emergence of such meetings as the International Symposia on Fire Safety Science, IAFSS sectional meetings, and Interflam, the future focus of the UJNR Panel will be on small, specialist meetings on topics of strong mutual interest. Possible topics could include: quantitative test methods for fire safety design, performance-based fire codes and design, fires after earthquakes, fire detection, fire suppression, wind effects on fire, fire modeling, fire physics, fire chemistry, fire measurements, burning behavior of furnishings or interior finish, large-scale tests, behavior of people in fires, firefighter safety technologies, and risk and hazard analysis.

The specific subject matter and timing of these UJNR workshops will be selected in two ways:

a. Technical experts from the two countries may arrange such workshops among themselves.

b. The leaders of the fire research programs at NIST, BRI and NRIFD will meet annually to identify topics of mutual interest. 
The University of Kyoto has offered to host the first of these workshops in the fall of 2001. Candidate topics, each with a statement of purpose and draft list of participants, should be distributed in both countries by October 1, 2000 .

3. To facilitate communications between meetings, NIST, BRI and NRIFD will increase their efforts to share publications in a timely manner. This will include posting publications on our respective web sites, sending publications to the other country by e-mail or post, and updating "UJNR Fire Research and Safety News."

4. Due to financial and organizational circumstances, there has been less United States-Japan joint research in recent years. The Panel encourages resumption of such highly productive interactions. We particularly recommend extended visits by young researchers to each others' laboratories. Topics and collaborators for such projects will be presented to the leaders of the fire research programs at NIST, BRI and NRIFD by October 1, 2000. 
INDEX 


\section{AUTHOR INDEX}

\section{VOLUMES 1 and 2}

B

Baum, H., 449

Beyler, C., 175, 463

Bukowski, R., 210

Bushby, S., 349

D

de Ris, J., 429

E

Ebihara, M., 121

Evans, D., 441

Everest, D., 471

F

Fahy, R., 153

G

Gann, R., 127, 230

Grand, A., 105

Grosshandler, W., 357

H

Hagiwara, I., 161

Hall, J., 113

Hamins, A., 250

Harada, K., 381

Hasemi, Y., 51, 483

Hayasaka, H., 365

Hayashi, K., 51

Himoto, K., 309

Hurley, M., 335

I

Iwata, Y., 407

J

Janssens, M., 43
K

Kagiya, K., 329

Kashiwagi, T., 9, 71

Kung, H., 289

$\mathbb{L}$

Lyon, R., 97

M

Matsuyama, K., 321

Morita, M., 273

N

Nakaya, I., 3

Naruse, T., 399

Noguchi, S., 300

o

Ogawa, Y., 267

Ohlemiller, T., 81

Ohimya, Y., 189

$\mathbb{P}$

Pagni, P., 373, 425

Phan, L., 389

Pitts, W., 242, 413

Q

Quintiere, J., 63

S

Saito, N., 236

Sekizawa, A., 145

Sheppard, D., 281

Sugawa, O., 341, 489

T

Takeichi, N., 222

Tanaka, T., 196, 435
Tsujimoto, M., 169

Tsuruda, T., 258

Y

Yamada, T., 89

Yashiro, Y., 135

Yoshida, M., 15

Yusa, S., 181 



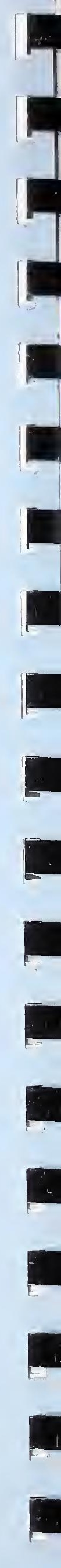

